$$
\text { FGol-c10 DOE/CE/21.007--T }
$$

DE93 007017

\title{
Looking Past the First Year: Do the Savings Last?
}

\section{A Study of the Persistence of Energy Savings in Low-Income Wisconsin Residences}

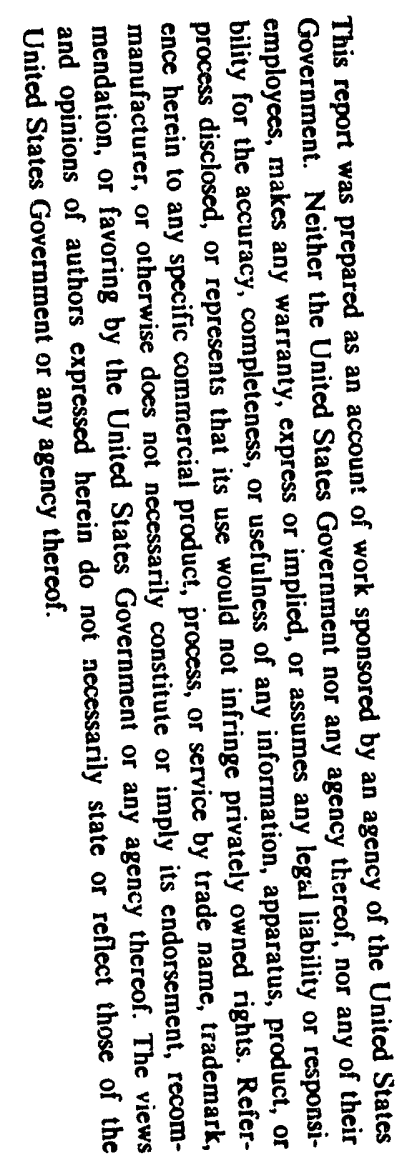

\section{Final Report}

September 1992

$\frac{8}{3}$

Prepared for:

U.S. Department of Energy

Existing Buildings Efficiency Program

Prepared by:

David Narum

Scott Pigg

Jeff Schlegel

Wisconsin Energy Conservation Corporation

2158 Atwood Avenue

Madison, WI 53704

Tel: 608-249-9322

FAX: 608-249-0339 
This report was prepared as an account of work sponsored by an agency of the United States Government. Neither the United States Government nor any agency thereof, nor any of their employees, makes any warranty, express or implied, or assumes any legal ability or responsibility for the accuracy, completeness, or usefulness of any information, apparatus, product or process disclosed or represents that its use would not infringe privately owned rights. Reference herein to any specific commercial product, process, or service by trade name, trademark, manufacturer, or otherwise, does not necessarily constitute or imply its endorsement, recommendation, or favoring by the United States Government or any agency thereof. The views and opinions of the authors expressed herein do not necessarily state or reflect those of the United States Government or any agency thereof. 


\section{Acknowledgments}

WECC would like to thank the Department of Energy for the funding to conduct the study. In particular, WECC thanks the following individuals for their assistance with the methodology and careful review of the study drafts:

Ernest Freeman, U.S. Department of Energy

Bill Mixon and Mark Ternes, Oak Ridge National Laboratory

WECC would like to thank the four Wisconsin utilities that provided the program and consumption information for the study. In particular, WECC thanks the following individuals:

John Nelson, Wisconsin Gas Company

Lynn Hobbie, Madison Gas \& Electric Company

Jack Betzig and Richard Koepnick, Wisconsin Southern Gas Company

Robert Frohlich and Randy Chase, Wisconsin Natural Gas Company

WECC thanks the following individuals for their review of and valuable comments regarding the study:

Mimi Goldberg, XENERGY (formerly of the Energy Information Administration, U.S. Department of Energy)

Michael Blasnik, Grass Roots Alliance for a Solar Pennsylvania

David Sumi, HBRS, Inc.

Mariiyn Brown, Oak Ridge National Laboratory

Kathleen Greely, Virginia Center for Coal and Energy Research

David Carroll, Response Analysis

Ken Keating and Pamela Brandis, BPA

Norman Draper, Statistics Department, University of Wisconsin-Madison

WECC thanks the following individuals with their assistance in obtaining information for the study:

Ralph Prahl and Oscar Block, Wisconsin Public Service Commission Robert Korb, Wisconsin Department of Health and Social Services 


\section{CONTENTS}

EXECUTIVE SUMMARY

INTRODUCTION

Objectives $\quad 12$

Program Description $\quad 13$

Defining Persistence 14

Cost-Effectiveness $\quad 15$

Previous Studies of Persistence $\quad 15$

Selection of Analysis Methodology 16

METHOD 18

Modification of Proposed Plan 18

Data Collection $\quad 18$

Structure of Consumption Information $\quad 21$

Unit of Analysis $\quad 23$

Sample Attrition $\quad 26$

Analysis 28

Weather-Normalization $\quad 28$

Energy Consumption and Savings $\quad 29$

Persistence Analysis $\quad 30$

Modelling Process $\quad 36$

Composite Savings Estimates $\quad 41$

Determining the Baseline 46

$\begin{array}{ll}\text { Resampling } & 47\end{array}$

RESULTS 48

Wisconsin Gas Company 48

Overview of Gas Consumption and Savings Trends 48

Summary Consumption and Savings Statistics $\quad 52$

Results of the Model Runs $\quad 53$

Stability of the Model Results $\quad 58$

Cost-Effectiveness Analysis $\quad 59$

Subgroup Analysis $\quad 62$

Madison Gas \& Electric Company $\quad 65$

Summary Consumption and Savings Statistics $\quad 68$

Gross and Net Energy Savings $\quad 70$

Stability of the Model Results $\quad 72$

Cost-Effectiveness Analysis $\quad 73$

Subgroup Analysis $\quad 75$

Snapshot Analysis $\quad 76$

The Increase in Consumption $\quad 78$

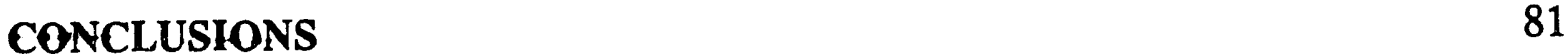




\section{APPENDICES}

A: Representativeness Analysis

B: Bootstrap Resampling

C: Normalization Statistics

D: ECM and Demographic Data

E: Median Polish Statistics

F: Summary NAC and NAC Change Graphs 


\section{TABLES}

1. Structure of Consumption Information, Wisconsin Gas Company 22

2. Structure of Consumption Information, Madison Gas \& Electric Company

3. Buildings and Dwelling Units in the Study Groups 25

4. Summary of Sample Attrition 28

5. Example of a Two-Way Table 32

6. Structure of Two-Way Tablc for Wisconsin Gas Company 37

7. Example of Median Polish Results 38

8. Consumption and Savings Estimates, 1987-90 Wisconsin Gas Company Participants

9. Total Median Polish and Trimmed ANOVA Results, Wisconsin Gas Company

10. Net Savings, Total Group Median Polish, 6-Year Group Median Polish, and Trimmed Group ANOVA

11. Net Savings Probabilities, Wisconsin Gas Company 56

12. Ner Energy Savings by Measure Type, Total Program and
6-Year Data, Wisconsin Gas Company

13. Cost-Effectiveness Analysis, First and First through Eighth Year Comparisons, Wisconsin Gas Company

60

14. Cost-Effectiveness Analysis, Total Program and Measure Comparisons, Wisconsin Gas Company

61

15. Comparison of Consumption and Savings, 1988-90 Madison Gas \& Electric Company Participants

16. Total Median Polish and Total Trimmed ANOVA Results, Madison Gas \& Electric Company

17. Net Energy Savings, Median Polish and Trimmed ANOVA, Madison Gas \& Electric Company

18. Net Energy Savings by Measure Group, Madison Gas \& Electric Company

19. Cost-Effectiveness Analysis, First and First through Eighth Year Comparisons, Madison Gas \& Electric Company

20. Cost-Effectiveness Analysis, Total Program and Measure Comparisons, Madison Gas \& Electric Company 


\section{FIGURES}

1. Box Plot of 1987 NAC for 1990 Wisconsin Gas Company Participants

2. Box Plot of $1987-88$ Change in NAC for 1990 Wisconsin Gas Company Participants

3. How Gross and Net Changes in Consumption are Derived from the Model Coefficients

4. Contribution of Participation Cohorts and ECM Groups in Determining Model Effects

5. Wisconsin Gas Company, Median NAC and Change in NAC Relative to Calendar Year

6. Wisconsin Gas Company, Median NAC and Change in NAC Relative to Participation Year

7. Gross Change in Energy Use, Wisconsin Gas Company 54

8. Gross Change in Energy Use, 6-Year Data, Wisconsin Gas 54

9. Net Energy Savings, Wisconsin Gas Company 55

10. Net Energy Savings, 6-Year Data, Wisconsin Gas Company 55

11. Net Energy Savings, with Measures, Wisconsin Gas Company 57

12. Net Energy Savings, 6-Year Data, with Measures, Wisconsin Gas Company

13. Net Energy Savings, Total and Trimmed ANOVA with Total Median Polish, Wisconsin Gas Company

14.-20. Subgroup Analyses, Wisconsin Gas Company

21. Madison Gas \& Electric Company, Median NAC and Change in NAC Relative to Calendar Year

22. Madison Gas \& Electric Company, Median NAC and Change in NAC Relative to Participation Year 67

23. Gross Change in Energy Use, Madison Gas \& Electric Company 70

24. Net Energy Savings, Madison Gas \& Electric Company 70

25. Net Energy Savings, Total and Trimmed ANOVA and Median Polish, Madison Gas \& Electric Company 72

26. Net Energy Savings with Measures, Madison Gas \& Electric 72

27-8. Subgroup Analyses, Madison Gas \& Electric Company 75

29. Energy Use, 1984 and 1991, Wisconsin Natural Gas Company 76

30. Energy Use, 1984 and 1991, Wisconsin Southern Gas Company 76

31. Change in Energy Use from 1984 to 1991, Wisconsin Natural Gas Company and Wisconsin Southern Gas Company 77

32. Wisconsin Statewide Natural Gas Use Per Customer, 1970-90 79

33. Wisconsin Residential Natural Gas Prices, $1970-90 \quad 80$ 


\section{EXECUTIVE SUMMARY}

Wisconsin Energy Conservation Corporation (WECC) conducted a Study of the Persistence of Energy Savings in Low-Income Wisconsin Residences for the Department of Energy's (DOE) Existing Buildings Efficiency Program. The study assessed the persistence of energy savings resulting from participation in the Wisconsin Utility Weatherization Assistance Program (UWAP). Unlike the majority of past energy conservation program evaluations, which focus on energy savings one year after weatherization, the study assessed the impact of weatherization up to eight years after the installation of energy conservation measures (ECMs) in low-income, gas-heated residences, the majority of which are 1- and 2-unit buildings.

Primary data for the study came from two utilities, Wisconsin Gas Company and Madison Gas \& Electric Company. Both vtilities provided WECC with their weatherization program databases, which contained participant information back to 1982 . WECC also obtained fuel consumption information for the program participants from each utility. The consumption histories spanned a 6-year period from March 1985 through May 1991 for Wisconsin Gas Company participants, and a 5-year period from October 1986 through August 1991 for Madison Gas \& Electric Company participants. After attrition, the study included 5,129 customers from the Wisconsin Gas Company program and 1,553 customers from the Madison Gas \& Electric Company program.

\section{PROGRAM DESCRIPTION}

The Wisconsin Gas Company program installs shell measures (caulking, weatherstripping, wall and attic insulation) and heating system measures (replacements and retrofits), either individually or in combination with other measures. The Madison 
Gas \& Electric Company program installs shell measures and mechanical measures (heating system, water heating system, and clock thermostats). The median per-unit cost for the Wisconsin Gas Company Program was \$1,591. For Madison Gas \& Electric Company, the median per-unit cost was $\$ 1,222$. The figures for both utilities include an estimated $\$ 300$ per building for program administration costs.

Most participants in the Wisconsin Gas Company program live in the Milwaukee metropolitan area. Participants in the Madison Gas \& Electric Company program live in Madison or in nearby communities and rural areas. Consequently, the housing stock for the two utilities is different. Pre-weatherization median annual consumption for the Wisconsin Gas Company program participants is 1,801 therms, and for Madison Gas \& Electric Company program participants, median annual consumption is 1,088 therms.

\section{OBJECTIVES}

There are two main ways in which persistence can be defined, and, in turn, evaluated: 1) at the measure-specific level (measure retention, measure lifetimes, and measure performance considerations); and 2) at the program level (total and net impacts). ${ }^{1}$ This study looks at the persistence of energy savings in large groups of customers. Where possible, persistence of energy savings is assessed for broad program subgroups, such a measure type or participant demographic category. It does not explore issues such as measure retention or the longevity of individual measures, nor does it examine persistence at the individual building level through site visits. While these are valuable approaches, they were beyond the scope of this study.

\footnotetext{
${ }^{1}$ For a more detailed discussion of the issues surrounding the persistence of energy savings, see Ed Vine's, "Persistence of Energy Savings: What Do We Know and How Can it Be Ensured?" ACEEE Summer Study on Energy Efficiency in Buildings, vol. 7, pp. 257-266.
} 
The main objective of this study was to assess the persistence of energy savings at a broad, program-wide level. WECC approached the study with the following questions in mind:

- How persistent were program level energy savings?

- How persistent were energy savings for different demographic and building subgroups (e.g., tenants vs. owners, 1- and multi-unit buildings) and for different ECM groups?

- How does persistence or erosion of energy savings affect program costeffectiveness?

\section{DETERMINING THE BASELINE}

A question of vital importance to any study of the persistence of energy savings is: "Persistence relative to what?" That is, relative to what baseline are we assessing persistence? The baseline represents what the participants' energy usage would have been in the absence of the program, and hence any conclusions made about net savings and their persistence cepends heavily on the validity of the estimated baseline. For this study, the energy usage of treated buildings is compared in relation to the energy usage of a similar group of untreated buildings (composed of later participants), with the assumption that the untreated buildings' energy usage patterns is a reasonable representation of what the treated buildings would have done had they not participated in the program. Comparison of pre-weatherization energy use for early and later participants indicates that this is a valid assumption.

\section{METHOD}

The general approach used was a two-way model that separates year-to-year changes in gas consumption into two types of effects: 1) year-to-year changes in gas consumption that affect all weatherized and unweatherized buildings (year effects); and 2) changes in gas consumption that occurred in periods before, during, and after weatherization (weatherization effects). WECC employed two main modelling approaches: 1) the classical analysis of variance (ANOVA) technique; and 2) a robust analogue of the 
ANOVA, the median polish. ${ }^{2}$ Because the datasets contained extreme values, and because the median polish is more resistant to data with extreme values than is ANOVA, the primary method chosen for the analysis was the median polish.

The results of these analyses were used to produce composite estimates of energy savings over 8 years for both treated and untreated buildings. The estimates for the untreated buildings are the comparison group for the treated buildings. To produce an estimate of net savings, untreated group savings were subtracted from the treated group savings.

\section{MAJOR FINDINGS}

The major findings of the median polish runs and composite savings calculations are:

- $\quad$ First-year energy savings were 19 percent (343 therms) of preweatherization energy consumption for the Wisconsin Gas Company program, and 13 percent (142 therms) for the Madison Gas \& Electric Company program.

- Overall, program savings did not erode over time. In fact, net savings increased over the time period studied.

- There were differences in both the level and persistence of savings among subgroups within the programs.

- Cost-effectiveness analyses based only on first-year savings underestimated cost-effectiveness by about 15 percent.

These major findings are discussed in greater detail below.

First-year energy savings were 19 percent of pre-weatherization energy consumption for the Wisconsin Gas Company program, and 13 percent for the Madison Gas \& Electric

Company program. Weatherization resulted in a clear decrease in gas consumption between the years immediately before and after weatherization. For Wisconsin Gas Company participants, the estimate of net first year energy savings was $343 \pm 25$ therms per gas account (at 90 percent confidence), which represents a decrease in consumption

\footnotetext{
${ }^{2}$ The ANOVA relies on means, the median polish relies on medians.
} 
of $19 \%$ when compared to the overall median gas consumption in the year before weatherization (1,801 therms). The Wisconsin Gas Company gas accounts studied largely represent single family homes and single dwelling units in 2-unit buildings.

For Madison Gas \& Electric Company participants, the model-derived estimate of net first-year energ savings was $142 \pm 30$ therms per gas account (at 90 percent confidence), or $13 \%$ of the median pre-weatherization gas consumption (1,088 therms). The first-year energy savings estimates for Madison Gas \& Electric Company are lower than estimates based on a pre-post analysis of a subgroup of participants. For these buildings, first-year energy savings was approximately 175 therms, which is at the high end of the confidence interval for the estimates derived from the median polish model. The Madison Gas \& Electric Company gas accounts mainly represented single family homes and individual dwelling units in 2- to 4-unit buildings.

Overall, program savings did not erode over time. In fact. net savings increased over the time period studied. Gas consumption increased over the period of analysis for both treated and untreated buildings in both of the utility programs. While gross consumption of treated buildings increased over the eight-year period, the consumption of untreated buildings for both utilities increased during this time at a greater rate. As a result, net savings increased. Figures E-1 through E-4 depict the Wisconsin Gas Company results for both the total group of participants, and for a group of participants who had continuous consumption information for the period 1986-91. ${ }^{3}$ Figures E-5 and E-6 depict the Madison Gas \& Electric Company results.

\footnotetext{
${ }^{3}$ Complete 6-year consumption histories could not be reconstructed for many Wisconsin Gas Company participants. Thirty-three percent of the total potential account-years of data were missing. Analysis of 1,214 buildings with complete consumption histories showed somewhat lower savings, but a comparable trend in persistence of savings.
} 


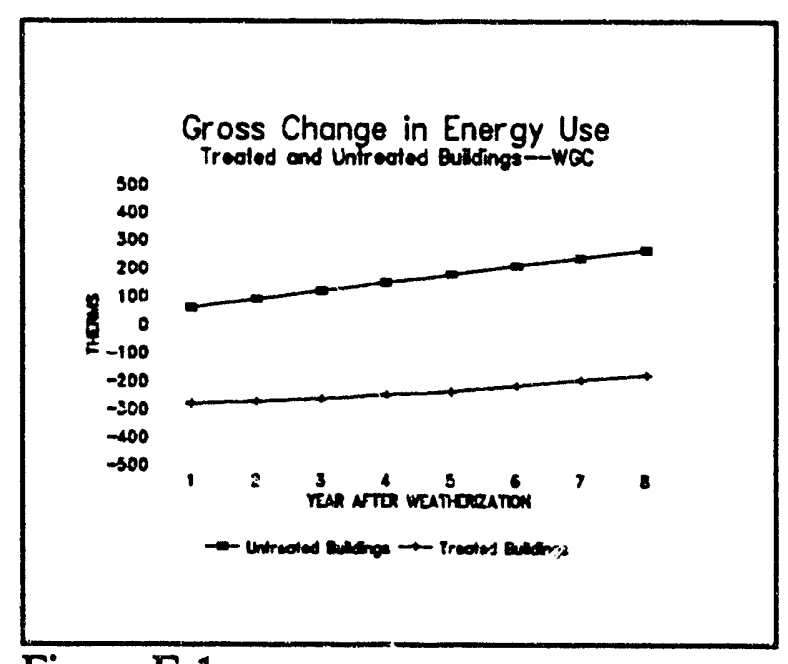

Figure E-1

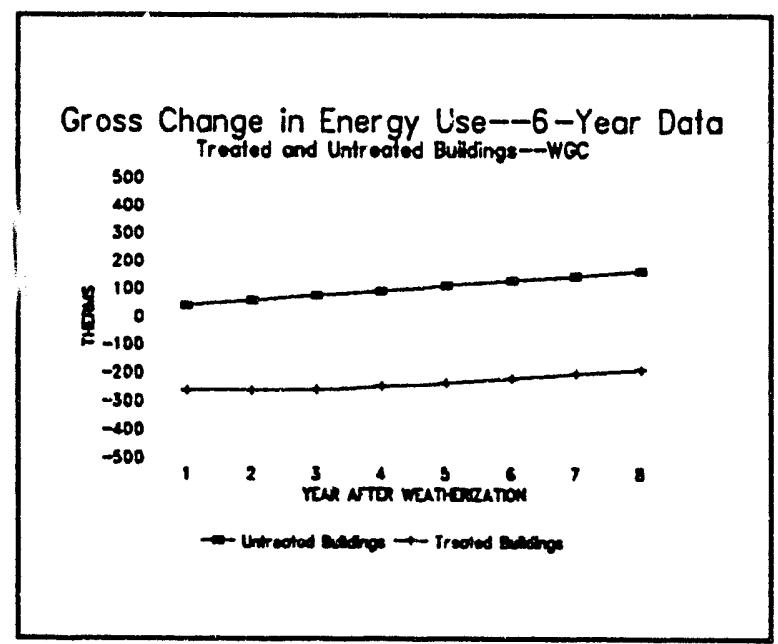

Figure E-3

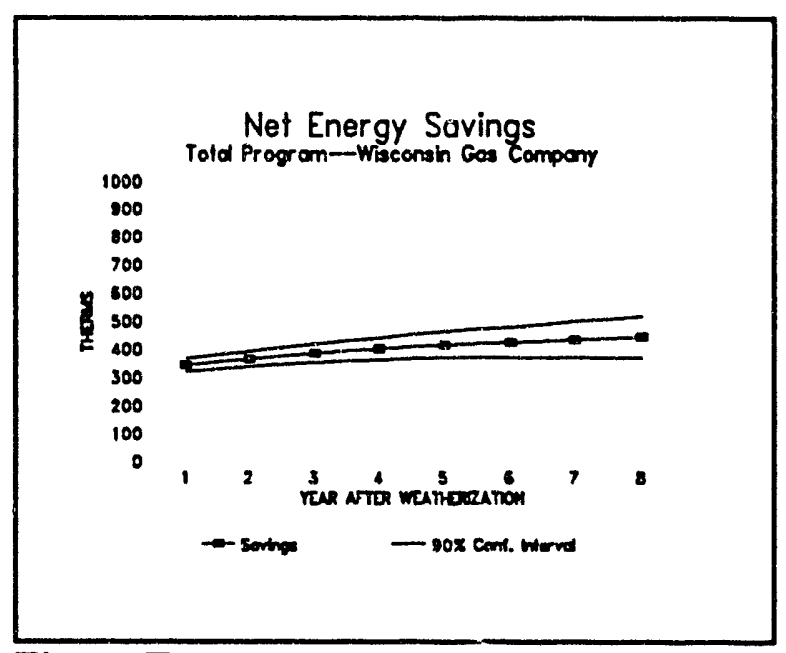

Figure E-2

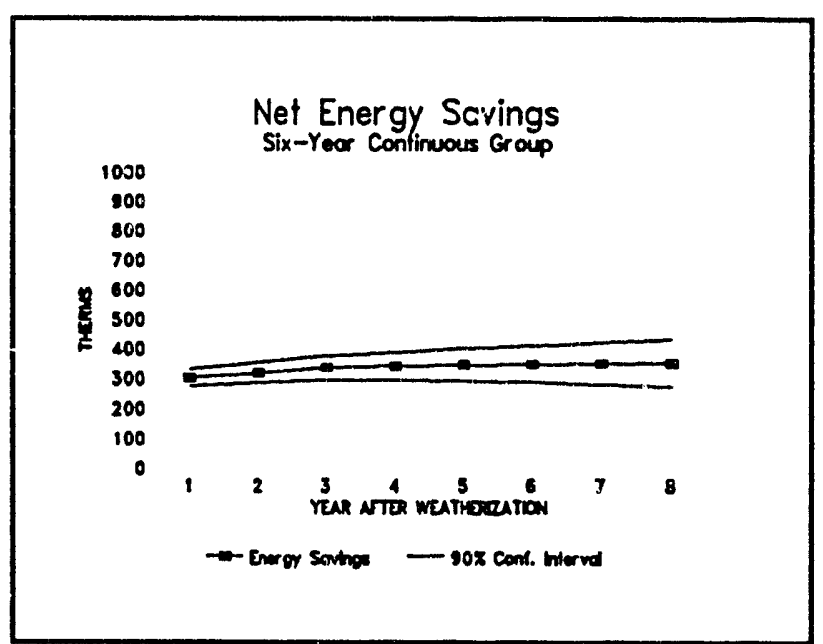

Figure E-4

Note that these graphs represent a composite picture of net savings over time. Early post-weatherization savings trends are largely determined by later program participants (for whom we have more pre-weatherization information), while savings in later years are determined primarily by early participants (for whom we have more postweatberization information). Because both programs changed over time, the results may 
be influenced by changes in type of participants or measures installed over the years (see caveats below).

The results for the Wisconsin Gas Company indicate that net savings persist over time. For the total group, net savings increase from 343 therms in Year 1 to 443 therms in Year 8 (the 6-year continuous data group increases from 301 to 351 therms from Year 1 to 8). Statistical analysis indicates a 99 percent confidence that 5 th and 8 th year net savings are greater than savings in the year immediately following weatherization, subject to the assumptions and caveats expressed below.

Analysis of subgroups within the Wisconsin Gas Company study group-and consideration of changes in the program over time-suggest that there is more uncertainty in the magnitude of the increase in net savings than the statistics indicate. Regardless, there is little indication that net program savings are eroding over time. Almost all subgroups for the Wisconsin Gas Company program showed net energy savings that either remained stable or increased over the years.

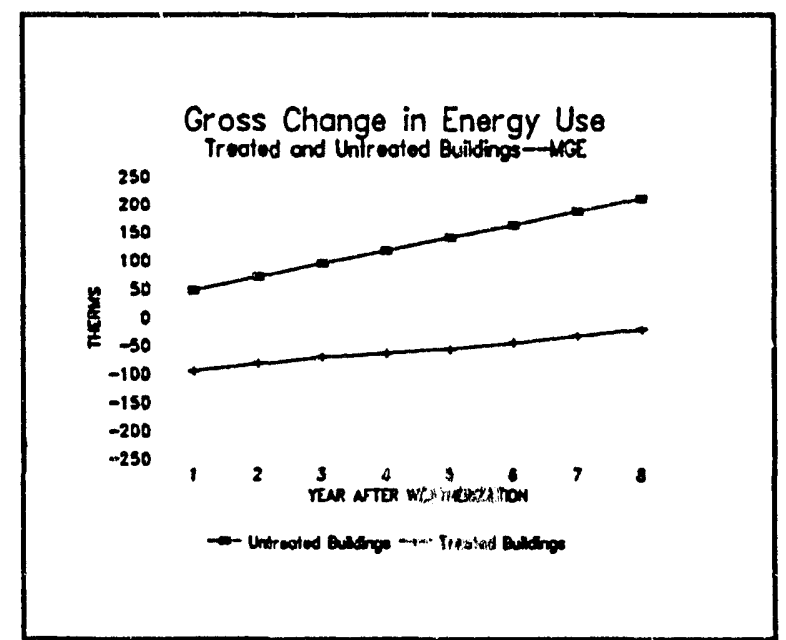

Figure E-5

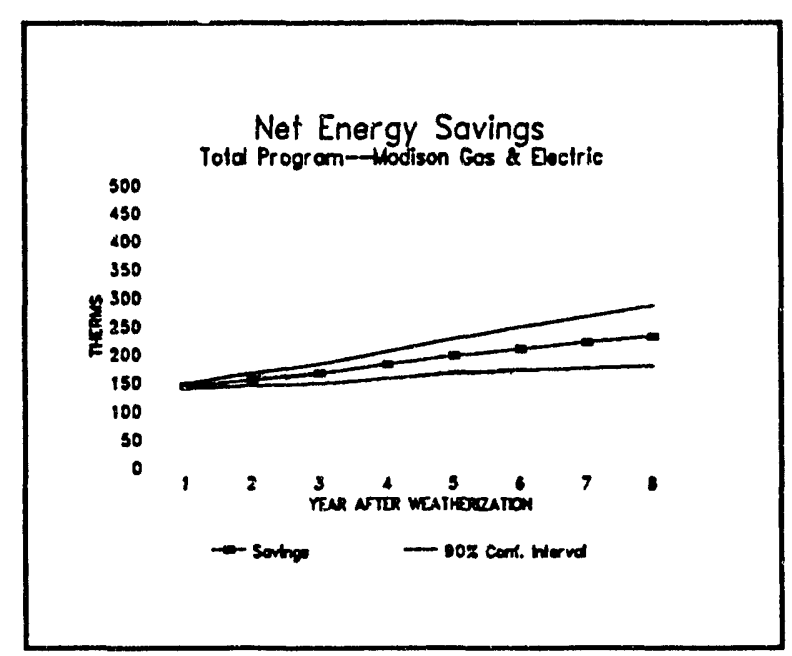

Figure E-6 
Madison Gas \& Electric Company's overall program results indicate that net energy savings persist over time, increasing from Year 1 net savings of 142 therms to Year 8 net savings of 230 therms. Statistical analysis indicates a 98 percent confidence that net savings in the 5th and 8th year after weatherization are greater than first year savings.

The estimates of statistical precision for the Madison Gas \& Electric and Wisconsin Gas Company results do not account for biases caused by sample attrition or by changes in the program over time. That both utilities showed an across-the-board increase in gas consumption and in net savings over time, however, does add weight to these findings.

There were differences in both the level and persistence of savings among subgroups within the programs. Analysis of subgroups of participants revealed some substantial differences in the level and persistence of energy savings. For Wisconsin Gas Company participants:

- Buildings with higher pre-weatherization gas consumption had higher savings that tended to increase over time, while buildings with lower preweatherization gas consumption had lower savings that tended to erode over time.

- Gas accounts from multi-unit buildings had higher savings than those from single-family buildings.

- Combinations of shell and heating measures provided greater savings than either measure alone, and higher expenditures in buildings were associated with greater savings. None of the ECM subgroups indicated a significant erosion of energy savings over time. In fact, most showed an increase in net savings.

Subgroup analysis of Madison Gas \& Electric Company participants indicated that:

- Unlike the results for Wisconsin Gas Company, there were no differences between the savings and persistence of savings for gas accounts from multiunit buildings versus those from single-family homes.

- Shell measures installed alone produced much lower savings than either mechanical measures alone or a combination of shell and mechanical measures. 
- Buildings where the owners pay the heat tended to show greater energy savings than buildings with tenant heat payers.

These subgroup analyses represent exploratory results; in most cases the analyses did not attempt to analyze more than one variable at a time.

Cost-effectiveness analyses based only on first-year savings underestimated costeffectiveness by about 15-25 percent. A cost-effectiveness analysis of the utilities' programs indicates that analyses based solely on first-year post-weatherization savings estimates undervalue the program effects when net savings increase over time. For Wisconsin Gas Company, the cost of conserved energy (CCE) based on only the first year of net energy savings was $\$ 4.5 / \mathrm{MMBtu}$, where the CCE estimate using eight years of savings estimates was \$3.9/MMBtu. For Madison Gas \& Electric Company, CCE based on first-year energy savings was $\$ 8.5 / \mathrm{MMBtu}$, and the estimates using eight years of savings was $\$ 6.4 / \mathrm{MMBtu}$.

\section{Snapshot Analysis of Participants from Two Additional Utilities}

In addition to the persistence analysis, a "snapshot" analysis was conducted on limited gas consumption data for participants in low-income weatherization programs for two additional Wisconsin utilities: Wisconsin Natural Gas Company $(n=38)$ and Wisconsin Southern Gas Company $(\mathrm{n}=50)$. This analysis compared energy use of weatherized buildings in 1984 (the first year after weatherization) to energy use in 1991 (the eighth year after weatherization). For both utilities, average energy use in 1991 was less than energy use in 1984. This result is different than the rise in post weatherization gas consumption seen for the Wisconsin Gas Company and Madison Gas \& Electric Company participants.

\section{STUDY LIMITATIONS AND CAVEATS}

1. The net savings results of the study are based on pre-weatherization consumption informatir - for later participants and post-weatherization consumption information for early participants. The validity of these results depends on an assumption that 
pre-weatherization gas usage for later participants can serve as a proxy for changes in gas usage that would have occurred for early participants had they not participated in the program. Although there were differences between early and later participants, the differences do not appear to be large enough to invalidate this assumption. ${ }^{4}$

2. As the results of the study are a composite of early post-weatherization consumption trends for later participants and later post-weatherization trends for earlier program participants, to some degree the results for early postweatherization periods are based on different ECMs, buildings, and participants than results for later post-weatherization periods. The most important of these changes are covered below. This limitation is the unavoidable result of having gas consumption histories for a limited window of time for participants that are staggered across the years.

3. The mix of conservation measures employed by both utilities changed over time. Heating system replacements became more common in the Wisconsin Gas Company program after 1986, and the frequency of shell-only jobs decreased over the years. The Madison Gas \& Electric Company program has evolved to address both heating systems and shell measures more frequently than either measure alone in treated buildings. Subgroup analysis indicates that shell measures and heating measures differ more in the level of savings than in the trend of savings persistence or erosion, which suggests that the persistence trend (as opposed to level) over time will not be greatly affected.

4. A change in program emphasis in 1988 to target high arrearage customers meant that later Wisconsin Gas Company participants were more likely to be paymenttroubled than in previous years. While gas consumption for the payment-troubled customers was (on average) higher than other participants, the entire pool of 1988 through 199i participants had levels of pre-weatherization gas usage that were similar to early participants.

5. The study was based on gas accounts in single-family and 2-4 unit buildings. Most of the multi-unit gas accounts represent a single dwelling unit in a multi-unit building. This means that dwelling units in multi-unit buildings are underrepresented in the study groups. This does not appear to affect the Madison Gas \& Electric Company program results, but probably causes the magnitude of the Wisconsin Gas Company program results to be understated somewhat to the extent that all of the savings attributable to multi-unit buildings are not captured.

\footnotetext{
4A comparison of pre-weatherization energy usage for 1987 through 1991 participants indicated no statistically significant differences.
} 
6. Participants in the Wisconsin Gas Company Program in 1983 and 1984 had higher gas consumption than other post-weatherization cohorts. Though the level of gas consumption is higher for these early participants, changes in gas consumption over time appear to be in line with later participants. Nevertheless, these early participants who largely determine the savings trend 5-8 years after weatherization may be different from later participants in other unmeasured ways.

The overall ffect of these limitations is difficult to assess definitively, but together they do not appear to invalidate the basic conclusion that savings due to weatherization have not eroded over time. Some of the identified biases tend to overstate the increase in net savings; others act to understate this trend. While the magnitude of the increase in net savings is therefore more uncertain than the confidence bands indicate, it is unlikely that overall savings are eroding. 


\section{INTRODUCTION}

This document is a report of Wisconsin Energy Conservation Corporation's (WECC) Study of the Persistence of Energy Savings in Low-Income Wisconsin Residences. The U.S. Department of Energy (DOE) contracted with WECC to conduct the study. WECC examined the persistence of energy savings up to eight years after weatherization from the installation of energy conservation measures (ECMs) in low-income, gas-heated, Wisconsin residences (the majority of which are 1- and 2-unit buildings). The ECMs were installed as part of the Utility Weatherization Assistance Program (UWAP) over the period 1983-91.

Primary data for the study came from two utilities, Wisconsin Gas Company and Madison Gas \& Electric Company. Both utilities provided WECC with their weatherization program databases, which contained participant information back to 1982 . WECC also obtained fuel consumption information for the program participants from each utility. The final sample size for the Wisconsin Gas Company Program is 5,129; the final sample size for the Madison Gas \& Electric Company Program is 1,553.

\section{OBJECTIVES}

There are two main ways in which persistence can be defined, and, in turn, evaluated: 1) at the measure-specific level (measure retention, measure lifetimes, and measure performance considerations); and 2) at the program level (total and net impacts). ${ }^{5}$ This

\footnotetext{
${ }^{5}$ For a more detailed discussion of the issues surrounding the persistence of energy savings, see Ed Vine's, "Persistence of Energy Savings: What Do We Know and How Can it Be Ensured?" ACEEE Summer Study on Energy Efficiency in Buildings, vol. 7, pp. 257-266.
} 
study looks at the persistence of energy savings in large groups of customers. Where possible, persistence of energy savings is assessed for broad program subgroups, such a measure type or participant demographic category. It does not explore issues such as measure retention or the longevity of individual measures, nor does it examine persistence at the individual building level through site visits. While these are valuable approaches, they were beyond the scope of this study.

The main objective of this study was to assess the persistence of energy savings at a broad, program-wide level. WECC approached the study with the following questions in mind:

- How persistent were program level energy savings?

- How does persistence or erosion of energy savings affect program costeffectiveness?

- How persistent were energy savings for different ECMs and ECM mixes, and for different demographic subgroups (e.g., tenants vs. owners, 1- and 2-unit buildings)?

The study examined: 1) the relationship between various ECM categories (shell measures, heating or mechanical measures, and combinations of measures) and the persistence of energy savings; 2 ) the relationship between building type (1- or $2+$ units) and persistence; and 3) the relationship between persistence and various customer demographic groupings (for example, landlord heatpayers versus tenant heatpayers).

\section{PROGRAM DESCRIPTION}

The Wisconsin Gas Company program installed shell measures (caulking, weatherstripping, attic and wall insulation) and heating system measures (replacements and retrofits), either individually or in combinations of measures. The Madison Gas \& Electric Company program installed shell measures and mechanical measures (heating system, water heater measures, clock thermostats), either individually or in combination with other measures. To be eligible for participation in UWAP, a household must be at or below 150 percent of federal poverty guidelines. 


\section{DEFINING PERSISTENCE}

There are two main ways in which persistence can be defined, and, in turn, evaluated: 1) at the measure-specific level (measure lifetimes, measure retention, and operation and performance considerations); and 2) at the program level (total and net impacts). ${ }^{6}$ This study looks at the persistence of energy savings in large groups of customers. Where possible, persistence of energy savings is assessed for broad program subgroups, such a measure type or participant demographic category. It does not explore issues such as measure retention or the longevity of individual measures. The study also does not examine persistence at the individual building level of detail through site visits. While these are valuable approaches, they were beyond the scope of this study.

For the purposes of this study, "persistence" is defined as the degree to which energy savings stay the same following weatherization. Gross persistence occurs when consumption in the years following weatherization is stable or falling; net persistence occurs when comparison-adjusted post-weatherization consumption is stable or falling.

A question of vital importance to any study of the persistence of energy savings is: "Persistence relative to what?" That is, relative to what baseline are we assessing persistence? The baseline represents what the participants' energy usage would have been in the absence of the program, and hence any conclusions made about net savings and their persistence depends heavily on the validity of the estimated baseline. For this study, the energy usage of treated buildings is compared to the energy usage of a similar group of untreated buildings (composed of later participants), with the assumption that the untreated buildings' energy usage patterns is a reasonable representation of what the treated buildings would have done had they not participated in the program.

\footnotetext{
${ }^{6}$ For a more detailed discussion of the issues surrounding the persistence of energy savings, see Ed Vine's, "Persistence of Energy Savings: What Do We Know and How Can it Be Ensured?" Proceedings of the 1992 ACEEE Summer Study on Energy Efficiency in Buildings, vol. 7, pp. 257-266.
} 
Comparison of pre-weatherization energy use for early and later participants indicates that this is a valid assumption.

\section{Cost-Effectiveness}

Evaluations of energy conservation programs are often limited by the availability of data to assessing only first-year energy savings. Similarly, analyses of the cost-effectiveness of these programs are also restricted to estimates based on only one year of energy savings. If savings in the years following the first year differ (in any direction) from the first year, then cost-effectiveness analyses based on first-year figures alone will be inaccurate. This study allowed WECC to compare cost-effectiveness analyses using first-year savings estimates, and analyses using eight-year savings estimates. Because our analysis indicated net savings that increased over time, it also provided estimates of costeffectiveness that increased over time (as opposed to estimales based on only one year of savings).

\section{Previous Studies of Persistence of Energy Savings}

Other studies of the persistence of energy savings have used a variety of analytical approaches, including: 1) calculations of energy savings from raw or weather-normalized consumption figures; 2) multivariate regression models; 3) pre-post analyses with comparison groups; and 4) the SAS time-series/cross-section regression procedure (TSCSREG).

Gregory ${ }^{7}$ studied up to three years of post-weatherization gas consumption information of buildings that participated in the Ohio Home Weatherization Assistance Program, and found that savings tended to decrease slightly (about $1 \%$ per year) in comparison to pre-

\footnotetext{
7Judith Gregory, "Durability of Fuel Savings for Single-Family Households: Ohio Home Weatherization Assistance Program (HWAP) Program Years 1985 and 1986," 1989 Energy Program Evaluation Conference, Chicago, pp. 67-71.
} 
weatherization energy usage. Brandis and Haeri ${ }^{8}$ studied three years of postweatherization electricity consumption information for buildings in conservation programs offered by Bonneville Power Administration (BPA), and found either some decay in savings or little change. ${ }^{9}$ Ecker et al. ${ }^{10}$ studied six years of postweatherization information of buildings in BPA's Interim Residential Weatherization Program (electric measures), and found energy savings to be relatively stable over the period. Sumi and Coates ${ }^{11}$ studied six years of post-weatherization electricity consumption information of buildings that in Seattle City Light's Home Energy Loan Program, and found that energy savings eroded at approximately 5.9 percent per year (27 percent overall from 1982-87).

\section{Selection of Analysis Methodology}

The method of analysis for the study needed to differentiate program-induced changes in energy use from other factors that affect energy use, such as weather and general economic and/or social conditions. Traditionally, this is achieved through comparing weather-normalized energy use before (pre) and after (post) participation to produce an estimate of gross energy savings. A matched comparison group is then used to adjust for other exogenous factors (such as economir and social conditions) to produce an estimate of net energy savings. While this method is useful when the period of interest is one

\footnotetext{
${ }^{8}$ Pamela Brandis and M. Hossein Haeri, The Persistence of Energy Savings Over Time: Two and Three Years After Participation in a Retrofit Program," 1989 Energy Program Evaluation Conference, Chicago, pp. 317-320.

'Analyzing more up-to-date information on the same weatherization program, Brown and White found an average 10 percent annual decline in energy savings when comparing first-, second- and third-year savings across three program years between 1981 and 1986. See Dennis White and Marilyn Brown, "Electricity Savings Among Participants Three Years After Weatherization in Bonneville's 1986 Residential Weatherization Assistance Program," Oak Ridge National Laboratory, 1991.

${ }^{10}$ Linda Ecker, Philipp Degens and Jean Sullens, "Evaluation of the Long-Term Impacts of Bonneville's Interim Residential Weatherization Program on Household Energy Savings," 1991 Energy Program Evaluation Conference, Chicago, pp. 512-517.

${ }^{11}$ David Sumi and Brian Coates, "Longitudinal Evaluation of Energy Savings from Seattle City Light's Home Energy Loan Program," Seattle City Light, 1988.
} 
year after weatherization, it becomes more problematic when the period of interest extends past this period. ${ }^{12}$

The general approach used in this study was a two-way model that separates changes in gas consumption into two types of effects: 1) changes in gas consumption in specific calendar years that affect all buildings (weatherized and unweatherized); and 2) changes in gas consumption are a result of weatherization. WECC employed two different twoway modelling approaches: 1 ) the classical analysis of variance (ANOVA) technique; and 2) an exploratory analogue of the ANOVA, the median polish. Both methods distinguish changes in energy consumption from weatherization from more global changes in consumption. Because the datasets contained extreme values, and because the median polish is more resistant to data with extreme values than is ANOVA, the primary method chosen for the analysis was the median polish.

The results of these analyses were used to produce composite estimates of energy savings over 8 years for both treated and untreated buildings. Net savings were then calculated as the treated group savings minus the untreated group savings.

\footnotetext{
${ }^{12}$ It is problematic largely because the approach (comparing pre-participation energy use to postparticipation energy use) becomes less valid the further away you get from the pre-participation year. That is, energy use in the year immediately after participation is more closely related to energy use in the year immmediately preceding participation than is energy use eight years after participation.
} 


\section{MODIFICATION OF PROPOSED PLAN}

In the original proposal to DOE, WECC outlined a study based on datasets from two earlier evaluations of the Utility Weatherization Assistance Program (UWAP). ${ }^{13}$ The proposed approach was to obtain the fuel consumption histories for the buildings evaluated in the studies, and assess the persistence of energy savings for the buildings using the results from the earlier evaluations and from our updated analyses. An inability to reconstruct the original evaluation databases, however, necessitated a change in procedure. WECC was able to obtain the complete weatherization databases from two Wisconsin utilities: Wisconsin Gas Company and Madison Gas \& Electric Company. WECC used these databases to construct entirely new samples for the analysis. Additional data for Wisconsin Natural Gas Company and Wisconsin Southern Gas Company were used to create "snapshot" comparisons of consumption in 1984 (which was the first year after weatherization) and 1991.

\section{DATA COLLECTION}

\section{Obtaining UWAP Databases}

WECC requested and obtained the computerized UWAP databases from Wisconsin Gas Company and Madison Gas \& Electric Company. The database for Wisconsin Gas Company contained records for 9,956 participants. The Madison Gas \& Electric Company database contained records for 2,969 participants. Both databases contained participants back to 1983. WECC used the databases as the initial samples for the study.

\footnotetext{
${ }^{13}$ See Banerjee, Asit K. and Miriam Goldberg, "Evaluation of Utility Weatherization Programs in Wisconsin," Statistical Laboratory, University of Wisconsin-Madison, September 1985; see also Horowitz, Marvin J. and Philipp Degens, "Evaluation of the Utility Weatherization Assistance Programs," International Energy Associates Limited, November 1987.
} 


\section{Identifying Program Subgroups}

The procedures for identifying program and demographic subgroupings are discussed below.

\section{Determination of Participation Year--Wisconsin Gas Company}

In determining the year of participation, it was necessary to define a beginning and an ending weatherization date. Because of the structure of the Wisconsin Gas weatherization database, it was not always possible to determine the exact date when ECMs were installed and/or began operation. To ensure that the date of installation was included in the participation year defined for each building, WECC used the "award" and "pass" dates indicated for each ECM installation as the beginning and ending dates for the ECM installation. The award date refers to the vendor award date for the particular building installation, and the pass date refers to the date when the ECM installation passed inspection.

The records were then grouped into participant years, using the pass date as the reference. We defined the participant year as September through August so as not to split the heating seasons. For example, all buildings with pass dates falling in the period September 1, 1986, to August 31, 1987, were slassified as 1987 participants. Those buildings with beginning and ending dates exceeding a one-year period were classified as participants in a given year if their beginning dates did not fall in typical heating months. For example, if the beginning and ending date for weatherization spans two heating seasons, and it is not clear when the building was weatherized during that period (it could have been weatherized before or after the first heating season), then the building was excluded from the analysis. This was a minor problem, resulting in the loss of only 23 buildings.

\section{Determination of Participation Year--Madison Gas \& Electric Company}

For the Madison Gas \& Electric Company group, the process used to determine the year 
of participation was the same as the process used for Wisconsin Gas Company, except the definition of participation year was slightly different: October through September (as opposed to September through August for Wisconsin Gas Company). The reason for this difference is that fuel consumption for Madison Gas \& Electric Company was obtained for the period from October 1986 through October 1991.

\section{Organization of Program and Demograpiric Variables--Wisconsin Gas Company} The Wisconsin Gas Company database organized ECM information under two general topics, shell measures (e.g., weatherstripping and caulking, attic and wall insulation) and heating measures. Eack building was grouped into one of three ECM categories: 1) shell measures; 2 ) heating system measures; and 3 ) both measures. These three main areas were further refined on the basis of cost. For example, the heating category displayed costs that ranged from $\$ 22$ to $\$ 10,891$, suggesting that some of the measures were heating system tune-ups and retrofits, and others heating system replacements. The heating measures were split to form two groups: expenditures less than or equal to $\$ 1,000$, and expenditures greater than $\$ 1,000$ (as a proxy for distinguishing between retrofits and replacements). This split was chosen because the distribution of costs indicated a sharp change at approximately $\$ 1,000$. The shell measure category was split at two levels: expenditures less than or equal to $\$ 1,600$, and expenditures greater than $\$ 1,600$. This split is at the middle of the expenditure range for shell measures.

In addition to ECMs, subgroups were created based on building type (1- or 2-units) and occupant characteristics (rental tenant heatpayer or owner occupant heatpayer). A complete table of the program and demographic subgroups for the Wisconsin Gas Company group is found in the appendices.

\section{Organization of Program and Demographic Variables--Madison Gas \& Electric Company} The Madison Gas \& Electric Company database organized the ECM information into a number of different ECMs, most of which fell into the following general ECM 
categories: 1) shell measures (weatherstripping and caulking, insulation, storm windows); 2) mechanical measures (heating system and water heater measures, clock thermostats); and 3) both shell and mechanical measures. Subgroups were also created for building type (1- and > 1-units) and occupant characteristics (tenant or owner). Because the performance of the model in part depends on a sufficiently large sample, further disaggregation of the subgroup categories was not possible. A complete table of the program and demographic variables for the Madison Gas \& Electric Company group is found in the appendices.

\section{Structure of Consumption Information}

The consumption histories for Wisconsin Gas Company span the 6-year period 1986-91. The consumption histories for Madison Gas \& Electric span the 5-year period 1987-91. Data on program participants are available back to 1983. Tables 1 and 2 set out the structure of the datasets for Wisconsin Gas Company and Madison Gas \& Electric Company. 
Table 1, Structure of Consumption Information, Wisconsin Gas Company

\begin{tabular}{||c||c|c|c|c|c|c||}
\hline \multirow{2}{*}{$\begin{array}{c}\text { Participant } \\
\text { Year }\end{array}$} & 1986 & 1987 & 1988 & 1989 & 1990 & 1991 \\
\cline { 2 - 7 } & post 3 & post 4 & post 5 & post 6 & post 7 & post 8 \\
\hline 1983 & post 2 & post 3 & post 4 & post 5 & post 6 & post 7 \\
\hline 1984 & post 1 & post 2 & post 3 & post 4 & post 5 & post 6 \\
\hline 1985 & W & post 1 & post 2 & post 3 & post 4 & post 5 \\
\hline 1986 & pre 1 & W & post 1 & post 2 & post 3 & post 4 \\
\hline 1987 & pre 2 & pre 1 & W & post 1 & post 2 & post 3 \\
\hline 1988 & pre 3 & pre 2 & pre 1 & W & post 1 & post 2 \\
\hline 1989 & pre 4 & pre 3 & pre 2 & pre 1 & W & post 1 \\
\hline 1990 & pre 5 & pre 4 & pre 3 & pre 2 & pre 1 & W \\
\hline 1991 & & & & &
\end{tabular}

Table 2, Structure of Consumption Information, Madison Gas \& Electric Company

\begin{tabular}{|c|c|c|c|c|c|}
\hline \multirow{2}{*}{$\begin{array}{l}\text { Participant } \\
\text { Year }\end{array}$} & \multicolumn{5}{|c|}{ Calendar Year } \\
\hline & 1987 & 1988 & 1989 & 1990 & 1991 \\
\hline 1983 & post 4 & post 5 & post 6 & post 7 & post 8 \\
\hline 1984 & post 3 & post 4 & post 5 & post 6 & post 7 \\
\hline 1985 & post 2 & post 3 & post 4 & post 5 & post 6 \\
\hline 1986 & post 1 & post 2 & post 3 & post 4 & post 5 \\
\hline 1987 & $\mathbf{w}$ & post 1 & post 2 & post 3 & post 4 \\
\hline 1988 & pre 1 & $\mathbf{w}$ & post 1 & post 2 & post 3 \\
\hline 1989 & pre 2 & pre 1 & $\mathbf{w}$ & post 1 & post 2 \\
\hline 1990 & pre 3 & pre 2 & pre 1 & $\mathbf{w}$ & post 1 \\
\hline 1991 & pre 4 & pre 3 & pre 2 & pre 1 & $\mathbf{w}$ \\
\hline
\end{tabular}




\section{Unit of Analysis}

There are several possible ways of organizing data for a study such as this. The three choices are:

- by building;

- by dwelling unit; or,

- by customer gas account.

Both weatherization databases are organized in terms of buildings. A building can have a single dwelling unit or multiple dwelling units. Multi-unit buildings can have a single or multiple gas accounts associated with it. Some multi-unit buildings have a single gas account for the entire building (master-metered buildings), others have a separate gas account for each dwelling unit (individually-metered buildings), and some have more complicated arrangements, such as individual metering for space heating and mastermetering for water heating.

Since the consumption histories are naturally organized in terms of customer accounts, a decision was made to use only a single account from each weatherized building. The procedure for selecting the account to use was slightly different for the two utilities. The Wisconsin Gas Company weatherization database contained a primary account number for each building (which usually represents the account number for the tenant who applied for the program), plus up to four secondary account numbers for additional gas accounts in the building. For this study, consumption histories were only requested for the primary account number. For Madison Gas \& Electric Company, consumption histories were requested for all gas accounts that matched the building's service address (as recorded in the weatherization database). Where multiple gas accounts were received for a single building, the account with the most complete consumption history was chosen. This occurred for only 180 buildings out of the 1,553 in the study. 
The main advantage of using a single gas account for each weatherized building is that it avoids the considerable problem of how to represent building gas consumption over time from multiple accounts that often have periods of service interruption. On the other hand, the main disadvantage of the approach is that it muddies the distinction between whether dwelling units or buildings are being studied. If a multi-unit building is mastermetered, the selected account represents consumption for the entire building. If the building is individually metered, though, the selected account will represent only one dwelling unit in the building.

Analysis of the secondary account numbers in Wisconsin Gas Company's weatherization database shows that $25 \%$ of the multi-unit buildings have only one customer account listed. Since multi-unit buildings make up 57\% of the final study group, this means that only about $14 \%$ of the accounts in the study group represent master-metered multi-unit buildings. The figure may well be lower than $14 \%$, since secondary account numbers may exist but may not have been entered into the weatherization database. Wisconsin Gas Company personnel estimated that less than $10 \%$ of multi-unit buildings in the program are master-metered.

The situation is somewhat different for the Madison Gas \& Electric study group. There are fewer multi-unit buildings in the study group (29\%), but more of these (55\%) had only one gas account associated with the building's service address. Overall, though, again about $14 \%$ of the accounts in the study group are multi-unit master-metered buildings. This figure may also be high, however, since accounts were identified using the building service address. Multi-unit buildings with different house numbers for each dwelling unit will yield only a single gas account, though there may be other gas accounts in the building that do not quite match the service address that was entered into the weatherization database.

Overall, it appears that the gas accounts studied mainly represent individual dwelling 
units. For Wisconsin Gas Company, about half of these dwelling units are single-family homes, and most of the others represent one unit of a two-unit building. For Madison Gas \& Electric, about $70 \%$ of the accounts represent single family homes, and the remaining $30 \%$ represent one dwelling unit in a multi-unit building (mostly 2 -unit and 4unit buildings).

If the gas accounts selected for the study mainly represent individual dwelling units, then multi-unit dwelling units are under-represented in the study, since only one of two or more dwelling units was selected from each multi-unit building. As Table 3 shows, multi-unit buildings comprise about $57 \%$ of the gas accounts in the Wisconsin Gas Company study group, but make up $73 \%$ of the dwelling units. For Madison Gas \& Electric buildings, multi-unit buildings comprise $29 \%$ of the buildings and $52 \%$ of the dwelling units.

Table 3, Buildings and Dwelling Units in the Study Groups

\begin{tabular}{|c|c|c|c|c|c|c|c|c|}
\hline \multirow{3}{*}{$\begin{array}{l}\text { Building } \\
\text { Type }\end{array}$} & \multicolumn{4}{|c|}{$\begin{array}{l}\text { WISCONSIN GAS } \\
\text { COMPANY }\end{array}$} & \multicolumn{4}{|c|}{$\begin{array}{l}\text { MADISON GAS \& ELECTRIC } \\
\text { COMPANY }\end{array}$} \\
\hline & \multicolumn{2}{|c|}{ Buildings } & \multicolumn{2}{|c|}{ Dwelling Units } & \multicolumn{2}{|c|}{ Buildings } & \multicolumn{2}{|c|}{ Dwelling Units } \\
\hline & $\#$ & $\%$ & \# & $\%$ & \# & $\%$ & $\#$ & $\%$ \\
\hline 1-Unit & 2222 & 43 & 2222 & 27 & 1103 & 71 & 1103 & 48 \\
\hline $\begin{array}{l}\text { Multi- } \\
\text { Unit }\end{array}$ & 2902 & 57 & 6189 & 73 & 450 & 29 & 1184 & 52 \\
\hline Unknown & 5 & $<1$ & & & 0 & 0 & 0 & 0 \\
\hline Total & 5129 & 100 & 8411 & 100 & 1553 & 100 & 2287 & 100 \\
\hline
\end{tabular}




\section{SAMPLE ATTRITION}

Both raw data and statistical screens were used, resulting in sample attrition. Below is a description of the four sources of sample attrition.

Billing Ledger. After receiving the UWAP databases from each utility, WECC requested the consumption histories for the buildings in the database. To do this, it was necessary to match each building in the database with its consumption history contained in the utility's mainframe billing ledger. For Wisconsin Gas Company, this match was obtained using the premise portion of the building's account number; for Madison Gas \& Electric Company, the match was obtained by using the building address.

The consumption draws were not able to match all buildings from the UWAP database with their consumption histories. For Wisconsin Gas Company, of 9,956 buildings in the UWAP database, the match produced consumption data for 7,259 buildings (73\%). For Madison Gas \& Electric Company, the match produced consumption data for 2,270 buildings out of an original population of $2,969(76 \%)$.

Normalization, The weather-normalization model requires the input data to be within certain parameters for proper estimation of normalized annual consumption (NAC). Data was omitted that did not meet the format requirements of the normalization model. If the output of the normalization model for a particular building was based on fewer than four consumption periods in a year (after aggregating consumption to periods between actual meter reads), or if less than 240 days in a year were represented in the consumption periods, it was removed from the study. An R-squared screen was not used.

Because there is potentially more than one NAC for each building (6 for Wisconsin Gas Company, 5 for Madison Gas \& Electric Company), it is possible for a building to be 
retained even if bad consumption data results in the loss of one or more years of consumption. The final consumption array for Wisconsin Gas Company contained 67 percent of the possible building NACs. The final consumption array for Madison Gas \& Electric Company contained 92 percent of the possible building NACs.

Twice Treated, If a building was treated in another weatherization program, or was treated twice under UWAP, it was removed from the study group. The State of Wisconsin offers a low-income weatherization program that operates in the same service territory as UWAP. WECC obtained the state weatherization program's Milwaukee area database to cross-reference with the UWAP database. The lack of electronically stored data for the state program in Madison made cross-referencing infeasible, so a twicetreated screen was not completed for the Madison Gas \& Electric dataset.

Database. Aggregating the buildings into participant cohorts, ECM groups, and demographic groups resulted in sample attrition owing to insufficient or anomalous database information. For example, if the award and pass dates for an ECM installation were missing, there was no way to assign that building to a particular participant group or to be sure the work was completed. For Madison Gas \& Electric, the database was also screened of multifamily buildings that had more than 4 units. Occupancy changes were not screened so as not to bias the results (on the assumption that such changes occur randomly over the period of the analysis).

\section{Summary of Sample Attrition}

The total sample that remained for Wisconsin Gas Company program was 5,129 buildings, or 71 percent of the buildings for which consumption information was obtained $(7,259)$. The total sample that remained for Madison Gas \& Electric Company program was 1,553 buildings, or 68 percent of the buildings for which consumption information was obtained $(2,270)$. Table 4 presents an overall summary of the sample attrition: 
Table 4, Summary of Sample Attrition

\begin{tabular}{|c|c|c|c|c|}
\hline \multirow[b]{2}{*}{$\begin{array}{l}\text { TYPE OF } \\
\text { ATTRITION } \\
\text { SCREEN }\end{array}$} & \multicolumn{2}{|c|}{$\begin{array}{l}\text { WISCONSIN GAS COMPANY } \\
\text { total } \mathrm{n}=9956\end{array}$} & \multicolumn{2}{|c|}{$\begin{array}{c}\text { MADISON GAS \& ELECTRIC } \\
\text { total } \mathrm{n}=2969^{*}\end{array}$} \\
\hline & $\begin{array}{l}\text { NUMBER } \\
\text { ATTRITED } \\
\text { (and \% of } \\
\text { original } \\
\text { population) }\end{array}$ & $\begin{array}{c}\text { NUMBER } \\
\text { REMAINING }\end{array}$ & $\begin{array}{l}\text { NUMBER } \\
\text { ATTRITED } \\
\text { (and \% of } \\
\text { original } \\
\text { population) }\end{array}$ & $\begin{array}{c}\text { NUMBER } \\
\text { REMAINING }\end{array}$ \\
\hline Billing Ledger & 2697 (27.1) & 7259 & $699(23.5)$ & 2270 \\
\hline Normalization & $293(2.9)$ & 6966 & $37(1.2)$ & 2233 \\
\hline Twice Treated & $246(2.4)$ & 6720 & & \\
\hline Database & $1591(16.0)$ & 5129 & $680(22.9)$ & 1553 \\
\hline Total & $4827(48.5)$ & 5129 & $1416(47.7)$ & 1553 \\
\hline
\end{tabular}

This figure includes larger multifamily buildings ( $>4$ units) that were not a part of the study.

The effects of sample attrition on the representativeness of the study samples is examined in Appendix A. While sample attrition did not result in samples that could be considered random, the overall differences between the samples and their respective populations are small, as is the impact of the difference on the results of the study.

\section{ANALYSIS}

\section{Weather-Normalization}

Before analyzing the consumption histories for persistence, WECC used a weathernormalization model to control for the yearly variability in energy consumption attributable to variations in heating degree days. The model uses the same variable degree-day model of gas consumption employed in the Princeton Scorekeeping Method 
(PRISM) software. ${ }^{14,15}$ The model predicts gas consumption as a function of heating degree days, where the reference temperature for calculating heating degree days is individually estimated for each account:

$$
\mathrm{C}=\alpha+\beta * \mathrm{H}(\tau)
$$

where:

$\mathrm{C}$ is gas consumption (therms/day)

$\alpha$ is base use (therms/day)

$\beta$ is the heating slope (therms/HDD)

$\mathrm{H}(\tau)$ is heating degree days per day (HDD/day) as a function of reference temperature, $r$.

Normalized Annual Consumption (NAC) is calculated as:

$$
\mathrm{NAC}=365.25\left(\alpha+\beta * \mathrm{H}_{0}(\tau)\right)
$$

where:

$\mathrm{H}_{0}(\tau)$ is the long-term normal heating degree days at reference temperature, $\tau$.

The weather-normalization model was programmed to produce NAC estimates based on the years of participation (for example, September-August for Wisconsin Gas Company), not on calendar years; this procedure also meant that heating seasons would not be split. To the extent possible, NACs were produced for each building (or each unit, as the case may be) in the study for every year. Summary results of the weather-normalization are presented in Appendix C.

\section{Energy Consumption and Energy Savings Analysis:}

To gain insight into the general magnitude and trends in energy use and energy savings, the mean and median NAC for each participant cohort was calculated. Absolute and percentage energy savings were calculated for those buildings with pre- and post-

\footnotetext{
${ }^{14}$ See M. Fels, "PRISM: An Introduction," Energy and Buildings, vol. 9, nos. 1,2, pp. 5-18, 1986.

${ }^{15}$ We used our own implementation of these algorithms rather than the PRISM software.
} 
weatherization consumption information (1987-90 participants for Wisconsin Gas Company, and 1988-90 participants for Madison Gas \& Electric Company). This analysis offers insight both into comparative magnitude of energy use of the buildings in each utility program, and into the general effectiveness of each program in achieving energy savings.

\section{Persistence Analysis}

The method of analysis for the study needed to differentiate program-induced changes in energy use from other factors that affect energy use, such as weather and general economic and/or social conditions. Traditionally, this is achieved through comparing weather-normalized energy use before (pre) and after (post) participation to produce an estimate of gross energy savings. A matched comparison group is then used to adjust for other exogenous factors (such as economic and social conditions) to produce an estimate of net energy savings.

While this method is useful when the period of interest is one year after weatherization, it becemes more problematic when the period of interest extends past this period. This is because comparing pre-participation energy use to post-participation energy use becomes less valid the further away you get from the pre-participation year. That is, energy use in the year immediately after participation is more closely related to energy use in the year immediately preceding parcicipation than is energy use eight years after participation.

To assess the persistence of energy savings over time, WECC examined the year-to-year change in weather-normalized gas consumption. Unlike a "pre-post" analysis, which compares post-weatherization annual energy use to the year before participation, this approach compares post-weatherization annual energy use to energy use in the year immediately preceding it. Changes in energy use from year to year are assessed rather than from the pre-year to a given post-year. 
As shown in Tables $1 \& 2$, participation in the program is staggered across the years for the buildings in the study. Some buildings were weatherized in 1983, some in 1984, and so on. This suggests a model structure in which time is measured relative to the year of weatherization, rather than according to the actual year ${ }^{16}$ in which it occurred. For example, for studying the first year after weatherization, one would take 1986 consumption for the 1985 participants, and 1990 consumption for the 1989 participants.

Such a structure must also take into account the possibility that other changes in gas consumption occur in a given year across all participants, regardless of when they were weatherized. For example, if gas consumption in 1988 increased by 100 therms for all buildings, this increase affects program participants at different points relative to weatherization: for 1983 participants, the change occurs in the fifth year after weatherization; for 1985 participants it occurs three years after weatherization; for 1988 participants it occurs in the year of weatherization. If this across-the-board 1988 effect is not separately accounted for, it will be shuffled into a number of different years relative to weatherization, and could confound the analysis.

Any model attempting to explain gas consumption or changes in gas consumption must handle these separate effects:

1) changes that occur relative to weatherization, which are the main object of interest in the study, and;

2) changes that occur in a given actual year or across a number of actual years that must be handled so that the estimates for (1) will not be confounded.

\footnotetext{
${ }^{16}$ Actual year" means the defined year of weather normalization: September through August for the WGC study group, and October through September for the MG\&E study group.
} 


\section{Two-Way Modelling}

After considering several ways

of framing a model that

estimates these effects, ${ }^{17} \mathrm{a}$

two-way additive model of the

year-to-year change in NAC

was selected. A two-way model

separates data arrayed in rows

and columns into different

factors. Table 5 is a simplified

example of a two-way table.
Table 5, Example of Two-Way Table

\begin{tabular}{|c|c|c|c|}
\hline FACTORS & & $\begin{array}{c}\text { First } \\
\text { Year-to-Year } \\
\text { Change }\end{array}$ & $\begin{array}{c}\text { Second } \\
\text { Year-to-Year } \\
\text { Change }\end{array}$ \\
\hline & \multirow{3}{*}{$\overrightarrow{+}$} & 1 & 1 \\
\hline weatherization & & RESPONSE & RESPONSE \\
\hline $\begin{array}{c}\text { Year } 2 \text { after } \\
\text { weatherization }\end{array}$ & & RESPONSE & RESPONSE \\
\hline
\end{tabular}

The response cells are combinations of both a year-to-year change (the columns) and a change relative to when weatherization occurred (the rows). In addition, all cells have a common factor that affects all cells equally, and each individual cell has a residual factor (what is left after the other three factors have been determined).

Change in gas usage from year to year for program participants is a combination of what years are involved, how much time has elapsed since weatherization (or has yet to elapse before weatherization), common factors, and residuals. Our primary interest is the relationship between the length of time from weatherization and changes in energy usage. If we estimate a model that separates out the year-to-year changes and common

\footnotetext{
${ }^{17}$ These included: 1) fitting straight lines for NAC trends across actual years separately for weatherized and unweatherized buildings (discarded because it presumes a linear trend in consumption, and because it does not distinguish early and late post-weatherization effects); 2) measuring the change in NAC relative to the year before (or after) weatherization (discarded because the ability to discern actual year effects is lost, and because early participants did not have consumption data for the years immediately before and after participation); 3) measuring the change in NAC relative to a given actual year, such as 1986 or 1991 (discarded because it is the reverse of (2), in that it does a good job of measuring the actual year effects, but cannot properly measure effects relative to weatherization); 4) a two-way analysis of NAC, separating actual year, and weatherization year effects (discarded because by itself this model can be confounded by differences in NAC level between participation groups----and, if a third dimension is added to account for these differences, the model becomes partially collinear given the structure of the data).
} 
factors, we can focus more closely on the relationship between weatherization and energy use.

As noted above, the model actually separates the year-to-year change in NAC for each building into four parts:

1) a Grand Effect -

2) Weatherization Effects -

3) Year Effects -

4) Residual - represents a change in NAC that is common to all buildings in all years;

represent changes common across buildings that occur at given points relative to weatherization (before, during, and after);

represent changes common across buildings that occur in given actual years; and,

what is left for each building after the previous three effects (estimates of what is common to all buildings) have been taken out.

Year-to-year change in energy use is estimated as:

$$
\begin{aligned}
& N_{A C}+1+N A C_{t}=\text { Grand Effect }+ \text { Weatherization Effect }+ \text { Year Effect }_{(t \text { to } t+1)} \\
& + \text { Residual }
\end{aligned}
$$

The first three effects above estimate how NAC changes on average among the thousands of buildings in the study. If, on average, ${ }^{18} \mathrm{NAC}$ tends to rise by 10 therms a year across all buildings in all years, then this value is taken out as the grand effect, and all other effects are measured relative to this 10 therm/year rise in consumption. Similarly, if consumption tends to drop on average by 100 therms immediately after weatherization, or consumption in 1988 tended to rise by 50 therms, then these effects will be captured as part of the weatherization and year effects. By adding together the

\footnotetext{
${ }^{18}$ What is meant by "on average" depends on how the model is estimated, as will be explained shortly.
} 
first three effects, an estimate is obtained of how NAC tends to change for buildings that are in a given point relative to weatherization and in a given year. For example, the change in NAC fo: a building that has just undergone weatherization might be estimated as $10+(-100)+50=-40$ therms (grand effect + weatherization effect + year effect).

The residual is what is left of the actual change in consumption for any particular building after the estimates of what is common across many buildings is taken out. For example, the model might predict an average change in NAC of -40 therms, but this just represents what happens on average for buildings in this situation. A particular building might have had an actual change in NAC of -50 therms. The residual for this building is then $-50-(-40)=-10$ therms. The residual thus captures how a particular bvilding differs from what is estimated to be the average effect across all buildirys. It represents changes in NAC that are not explained by the model.

The goal of fitting this model is to properly separate out the first three common effects, and leave residuals (unexplained changes) that average out to be zero and have as little variation as possible. Once the model is fitted, the weatherization effects can bs examined to see whether, on average, significant changes in consumption havs occurred after weatherization. A standard procedure for fitting such a model is analysis of variance (ANOVA). This approach extracts mean effects from the data, leaving residuals that have an average of zero and have minimum variation.

A less well-known but more robust fitting procedure is the median polish. ${ }^{19}$ The median polish works analogously to ANOVA, except that it extracts median effects rather than mean effects. The robustness of the median polish comes from the fact that the median is less influenced by extreme data than the mean. The presence of a single

\footnotetext{
${ }^{19}$ For a detailed explanation of the median polish procedure, see David C. Hoaglin, Frederick Mosteller, and John W. Tukey, Understanding Robust and Exploratory Data Analysis, New York: John Wiley and Sons, 1983, pp. 166-210. See also Paul F. Velleman and David C. Hoaglin, Applications, Basics and Computine of Exploratery Data Analysis, Boston: Durbury, 1981, pp. 219-253.
} 
extreme data point can change a mean considerably, but will have little or no effect on the median. Because the data for the analysis included extreme data, the median polish was chosen as the primary method of analysis upon which all major findings are based, with ANOVA serving as a secondary method. Figures 1 is a box $\operatorname{plot}^{20}$ of the 1987 NAC for the 1990 participants, and Figure 2 is a box plot of the 1987-88 change in NAC for the 1990 participants. Both figures are representative of the data in the study, and both show ranges that include extreme values.

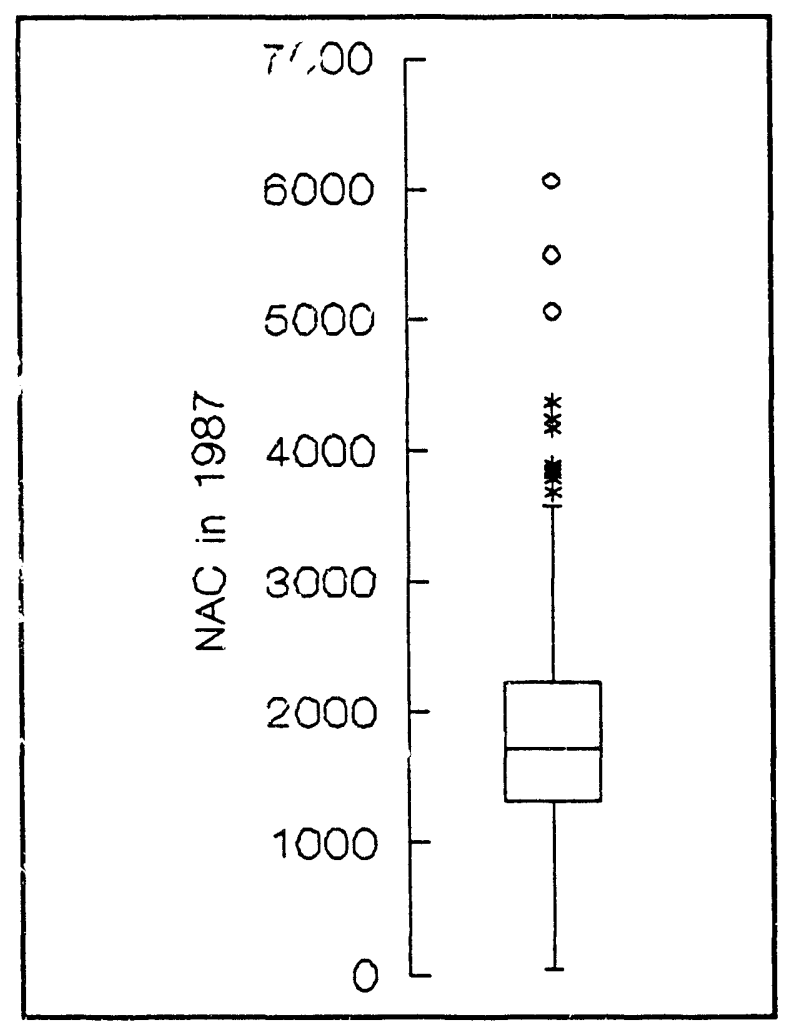

Figure 1

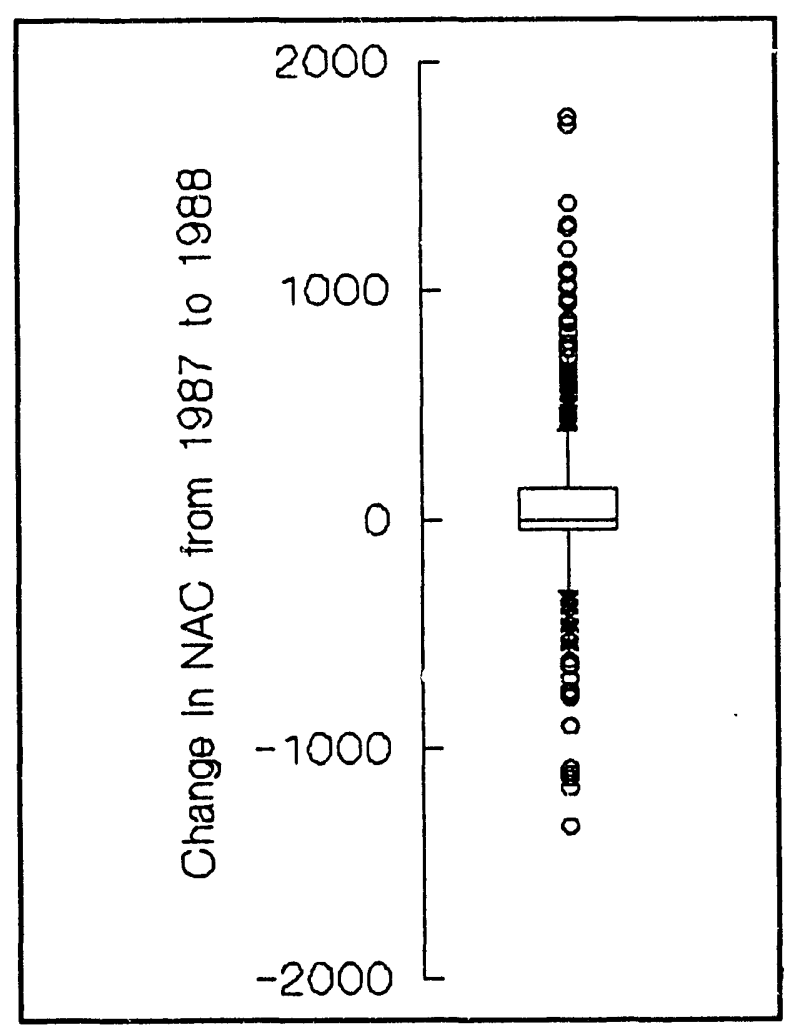

Figure 2

\footnotetext{
${ }^{20} \mathrm{~A}$ box plot is typically interpreted as representing the median, first and third quartiles, approximate 95 percent range, and the outliers in a given sample of observations. In the box plots here, the median is the middle line in the box, with the first and third quartiles represented by the ends of the box. Typically, 95 percent of the data is contained within the straight line "whiskers" that extend beyond the boxes. The asterisks represent "near" outliers, and the circles represent "far" outliers.
} 


\section{Modelling Process}

Because of the nature of calculating medians, the median polish must be performed iteratively on the data. That is, the model sweeps out medians for year effects, then sweeps out medians for weatherization effects, and so forth, until all effects have been extracted. ${ }^{21}$ By definition, the residuals that are left after sweeping out the various effects have a median of zero. In addition, the year effects have a median of zero, as do the weatherization effects.

The model used in the study comprised five separate year effects (the Madison Gas \& Electric Company dataset had only four year effects), and five weatherization effects. Each year effect accounted for an across-the-board change in consumption between two years in the consumption histories. Thus a year effect was estimated for the change in NAC from 1986 to 1987, a separate year effect was estimated for the change in NAC from 1987 to 1988, and so on. The weatherization effects were defined as follows:

1) a pre-weatherization effect, which captured changes in NAC that occurred among unweatherized buildings;

2) a weatherization effect, which captured the change in NAC going into and coming out of the year of weatherization; and,

3) three post-weatherization effects, which captured changes in NAC that occurred at various points after weatherization. These effects were defined as:

Post 1 - changes in NAC between the first and third years after weatherization;

Post 2 - changes in NAC between the third and fifth years after weatherization; and,

Post 3 - changes in NAC between the fifth and eighth years after weatherization.

\footnotetext{
${ }^{21}$ For this study, 6 complete sweeps of year and weatherization effects were used. The model estimates were generally stable to within 0.1 therms after this many sweeps.
} 
Table 6 shows how the model was laid out. In the table, year effects are represented by columns, and weatherization effects are represented by rows. Performing a median polish on the data is simply a process of sweeping out medians across rows and columns. Year effects are estimated by sweeping medians down the columns (across all weatherization effects), and weatherization effects are estimated by sweeping medians across the rows (across all years). The grand effect is formed by sweeping medians out of the year and weatherization effects themselves. ANOVA works similarly, except that means are extracted rather than medians.

Table 6, Structure of Two-Way Table for Wisconsin Gas Company

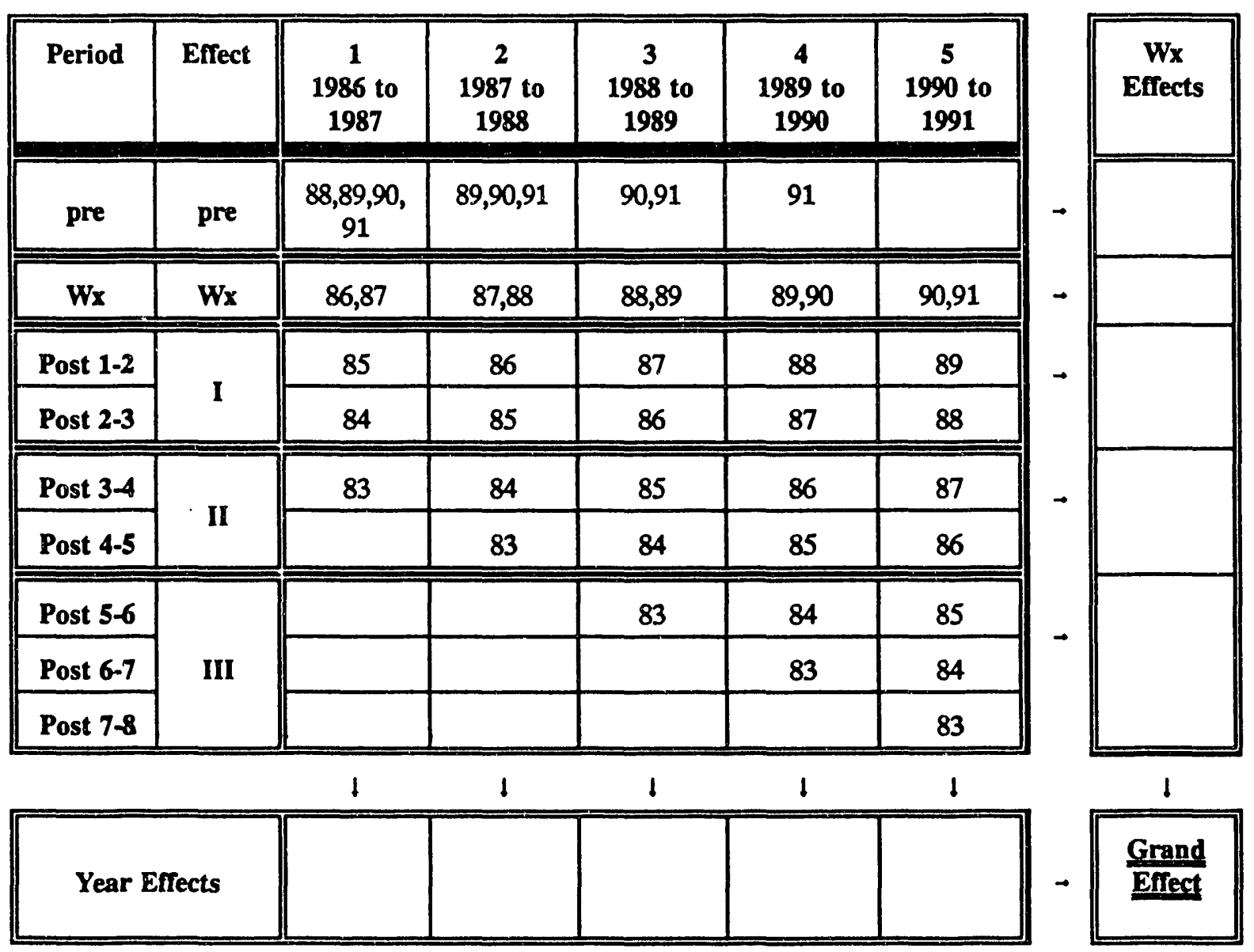


Table 7 shows an example of the model results (in therms, without residuals). Several points about the interpretation of the weatherization effects bear additional explanation.

Table 7, Example of Median Polish

Results

First, it should be noted that what is being estimated is changes in gas consumption. Thus, any gas savings due to weatherization will show up as a negative effect in the model estimates.

Second, the pre-weatherization effect provides a baseline estimate of how gas consumption changed for unweatherized buildings during the time period for which consumption data is available. This is the comparison group for this study. It is estimated from later participants $(1988,1989$, 1990 and 1991). If the estimates of postweatherization effects show up as positive numbers, it means that consumption was

\begin{tabular}{|c|c|}
\hline $\begin{array}{c}\text { Weatherization } \\
\text { Effects }\end{array}$ & $\begin{array}{c}\text { Median Polish } \\
\text { Results }\end{array}$ \\
\hline Pre & 10 \\
\hline Weatherization & -150 \\
\hline Post I & -5 \\
\hline Post II & 0 \\
\hline Post III & 5 \\
\hline \hline Year Effects & \\
\hline $1986-87$ & 0 \\
\hline $1987-88$ & 10 \\
\hline $1988-89$ & -25 \\
\hline $1989-90$ & 20 \\
\hline $1990-91$ & 5 \\
\hline Grand Effect & 15 \\
\hline
\end{tabular}
increasing after weatherization (and hence that gross savings were eroding). But if the pre-weatherization effect is an even larger positive number, one would not necessarily conclude that net savings were eroding, since unweatherized buildings showed a larger increase in consumption during the same time period. For example, the numbers in Table 7 indicate a weatherization Period III effect of 5 therms, which would imply that gross savings are eroding. But because the pre-weatherization effect is 10 therms, the implication is that there is still a net effect of -5 therms in Period III.

Third, the weatherization effect does not estimate the immediate impact of 
weatherization on gas consumption between the year before weatherization and the year after weatherization, but rather creates an estimate of savings based on two change years. ${ }^{22}$ For example, buildings that were weatherized early in the 1987 participation year (September through August for Wisconsin Gas Company), will show savings in the first heating season (approximately October 1986 through March 1987). But if a building is treated after the 1986-87 heating season, the effects will not show up until the 1987-88 heating season. The rest of the buildings will be somewhere between these extremes. The model homogenizes these differences, and comes up with an estimate of one-half the total effect of weatherization. To estimate the change in gas consumption between the year before weatherization and the year after weatherization, it is necessary to double the model estimate of the weatherization effect.

This situation is an artifact of the decision to model year-to-year changes in gas consumption, when in this case one is interested in an effect that occurs across two years. The model estimates could be thrown off if the distribution of the number of buildings weatherized is not relatively uniform throughout the year. For Wisconsin Gas Company, analysis of the program data, and direct comparison of the model coefficients with the average year-before to year-after change in NAC indicates that the immediate weatherization effect is reasonably estimated in this way.

For Madison Gas \& Electric Company, this comparison indicates an underestimation by the model of first year savings in the range of $15-20$ percent. The underestimation is a result of calculating first-year savings as the composite of two change years--the year going into weatherization, and the year coming out of weatherization. A standard prepost analysis (using medians) would calculate the change in energy use from the first year before weatherization to the first year after weatherization as the median of all the changes for all buildings with pre- and post-weatherization consumption information.

\footnotetext{
${ }^{2}$ For example, a "change year" is the change in energy use from 1987 to 1988.
} 
The procedure in this study calculates the median change as a combination of the median pre- to weatherization-year change and the median weatherization- to post-year

change. The underestimation will thus affect the overall magnitude of savings, even though the savings trend itself is unaffected. ${ }^{23}$

Alternatively, it is possible to eliminate the weatherization periods from the analysis, since the main object of interest is how gas consumption changes after weatherization. This would eliminate an estimate of the magnitude of the first-year savings due to weatherization, however, thereby robbing the subsequent persistence analysis of much of its context.

Finally, note that the post-weatherization effects are defined as groups of postweatherization years. This means, for example, that the Post 3 effect is a combined estimate of how NAC changes on average between the fifth and sixth, the sixth and seventh, and the seventh and eighth years after weatherization. Alternatively, one could have specified a model that estimates a separate effect for each post-weatherization year, or, at the other extreme, a model that only estimates a single effect for all postweatherization years.

The model was specified in groups of years for two reasons: 1) estimating the change in gas consumption for each of eight years after weatherization is not really necessary for the purposes of this study---a few trends over the span of available post-weatherization data is sufficient to assess persistence; and, 2) for a year-to-year post-weatherization analysis, the data become very unbalanced in later post-weatherization years. For example, there is only one participation cohort available that contains data on how NAC

\footnotetext{
${ }^{2}$ The problem of adding two median changes to produce a complete pre- to post-weatherization change does not occur with ANOVA, as the two half-steps add to the same number as a full step (because means are additive).
} 
changed between the seventh and eighth years after weatherization (the 1983 cohort). But if instead a single "late" period is defined that comprises the fifth through the eighth year after weatherization, the 1983,1984 and 1985 cohorts all contribute to its determination. As defined, the model used in this study represents a compromise between an over-specified model that tries to estimate year-to-year changes, and an unilluminating model that averages all post-weatherization effects into a single estimate.

\section{Composite Savings Estimates}

While the direction and magnitude of the model estimates of weatherization effects can provide indications as to whether important changes in gas consumption occur in the years after weatherization, they do not by themselves provide a complete picture of what the savings history of a typical building might be over a 1- to 8-year period after weatherization.

To provide a picture of how savings vary over the years, a secondary calculation was performed using the estimated effects from the median polish model. This calculation estimated energy savings 1 to 8 years after weatherization relative to the year before weatherization by simply adding effects from the model. For example, the total change in gas consumption from the year before weatherization to three years after weatherization is found as the sum of the year-to-year changes from the year before weatherization to the third year after weatherization. Each of these year-to-year changes is represented in the model by the sum of the grand effect plus a weatherization effect. Thus if Year 0 is the year in which weatherization occurs, Gross Total Change $e_{\text {year }-1}$ to year $3=$

$$
\begin{aligned}
& \text { change }_{\text {year }-1 \text { to year } 0}+\text { change }_{\text {year } 0 \text { to year } 1}+\text { change }_{\text {year } 1 \text { to year } 2}+\text { change }_{\text {year } 2 \text { to year } 3} \\
&=\quad(\text { grand }+ \text { Wx effect })+(\text { grand }+ \text { Wx effect })+(\text { grand }+ \text { Post } 1 \text { effect })+ \\
&(\text { grand }+ \text { Post } 1 \text { effect }) \\
&= 4^{*} \text { grand effect }+2 * \text { Wx effect }+2 * \text { Post } 1 \text { effect }
\end{aligned}
$$


This gives an estimate of how gross savings from weatherization vary from year to year. ro express savings in net terms, the background changes in gas consumption that occurred among unweatherized buildings must be subtracted. Over a single year, this change is represented as the sum of the grand effect plus the pre-weatherization effect. When considering the total change over $\boldsymbol{n}$ years, $\boldsymbol{n}$ times the sum of the grand effect and the pre-weatherization effect should be subtracted from the gross change calculated above. Note that this has the effect of canceling the grand effect from the calculation. Continuing the above example, net savings between the year before weatherization and three years after weatherization would be calculated as:

Net Total Change $e_{\text {year }-1 \text { to year } 3}=$

$4 *$ grand effect $+2 *$ Wx effect $+2 *$ Post 1 effect -

4 * (grand effect + pre Wx effect)

$=2 * \mathrm{Wx}$ effect $+2 *$ Post 1 effect $-4 *$ Pre Wx effect

Figure 3 is a graphic representation of how net changes in usage are estimated. A similar process can be followed to estimate net savings for each of the 8 postweatherization years available.

There is an important point to be raised about these calculations: the gross and net savings estimates represent a composite picture based on early post-weatherization consumption for some participants, and later consumption for other participants. Because only a six-year window of gas consumption data was available (5 years for Madison Gas \& Electric Company), and because participation was staggered from 1983 to 1991, there are no buildings with continuous consumption data from the year before 
How Gross and Net Changes in Consumption are Derived from the Model Coefficients

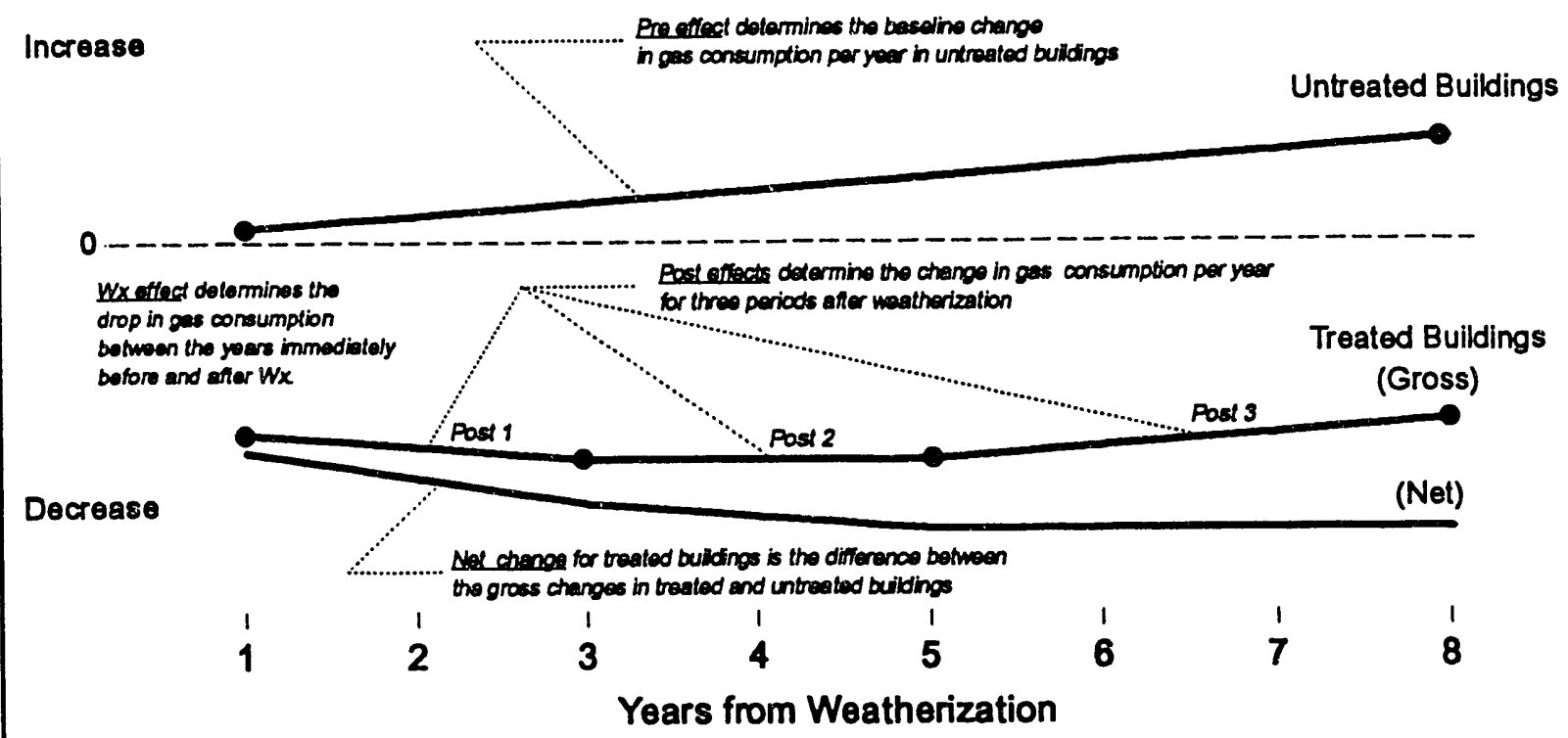

(Note: All changes also include the Grand effoct.)

Figure 3

Wisconsin Energy Conservation Corporation 
weatherization to eight years after weatherization. Instead, the model uses data from later participants to estimate pre-weatherization and early post-weatherization changes, and data from early participants to estimate later post-weatherization effects. The net savings calculation described above then combines these estimates into a single composite picture.

To the extent that early participants differ from later participants in the type of housing, the occupants, or the conservation measures employed, the results will reflect these differences. In particular, Figure 4 shows how the ECM mix changes between the weatherization effects. For Wisconsin Gas Company there is a steady increase in the proportion of the effect determined by buildings that received shell measures as one moves away from the year of weatherization. In other words, early post-weatherization savings are determined by fewer buildings that received shell measures alone than are later post-weatherization savings. For Madison Gas \& Electric Company, the proportion of buildings receiving both measures is greater in the early participants, with more even distribution of measures in the later participants. As a result, estimates of third period (years 5-8) energy savings are affected more by combinations of measures than by shell or mechanical measures alone. 


\section{Contribution of Participation Cohorts and ECM Groups in Determining Model Effects}

\section{Participation Cohorts}

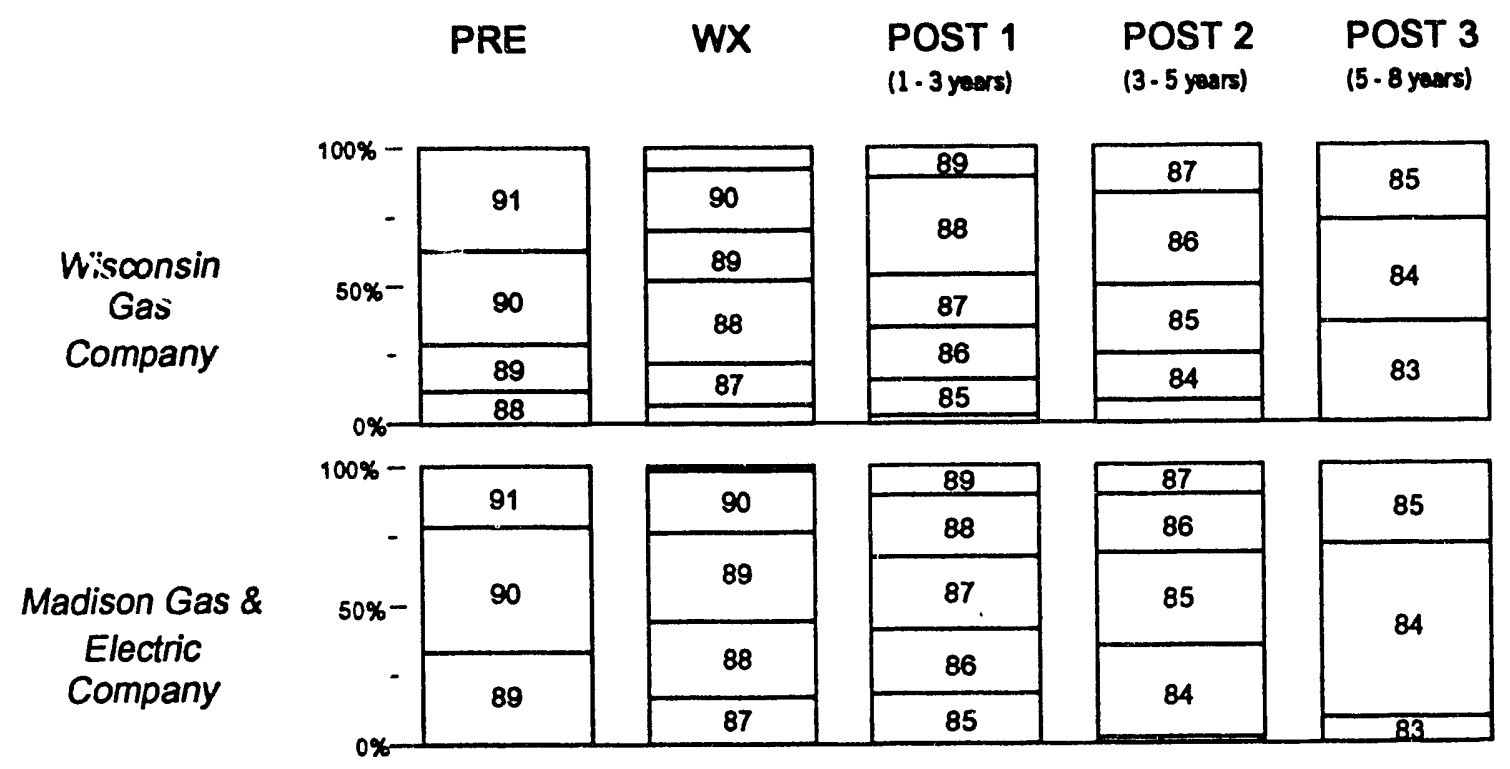

ECM Groups

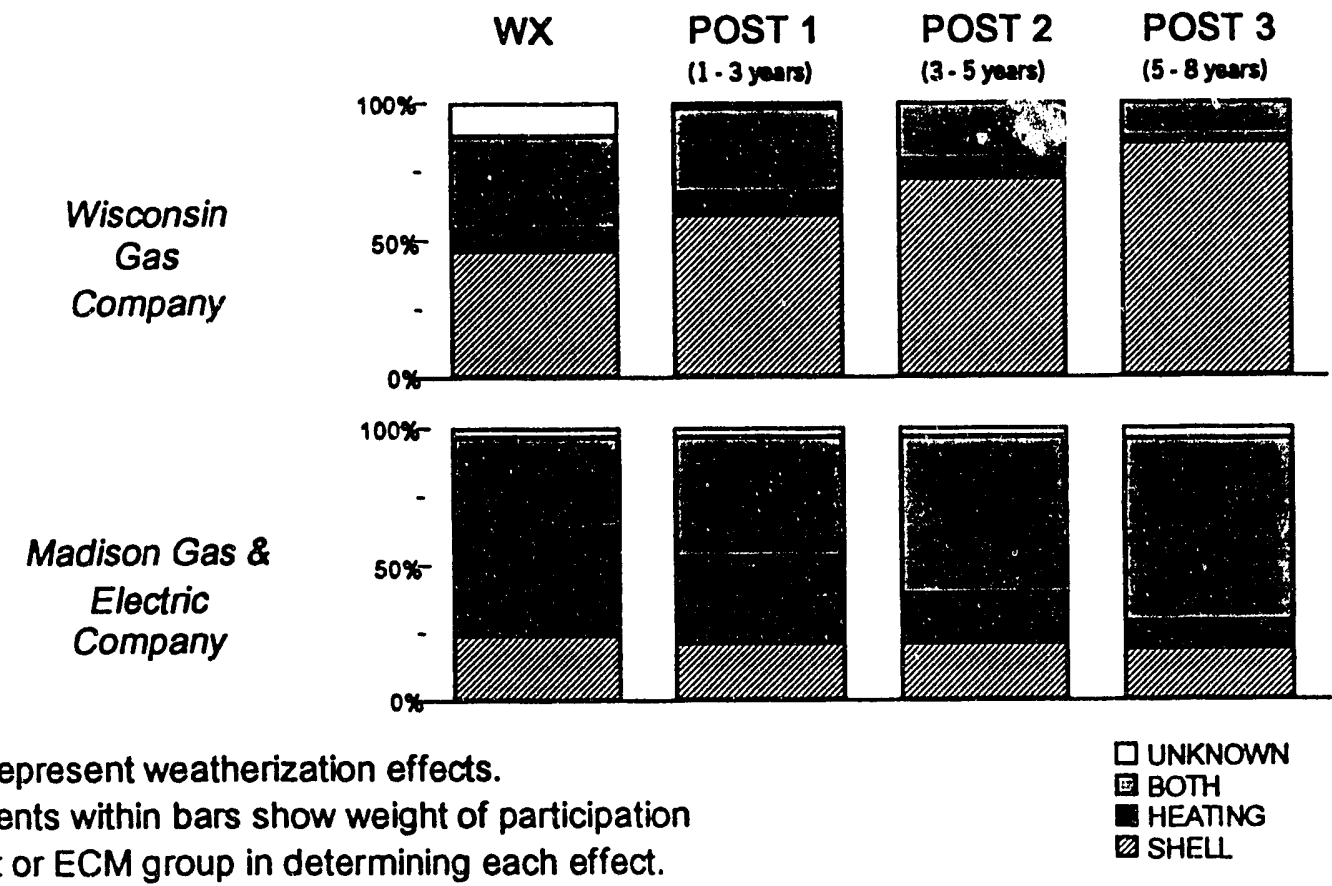

Figure 4

Wisconsin Energy Conservation Corporation 


\section{Determining the Baseline}

A question of vital importance to any study of the persistence of energy savings is: "Persistence relative to what?" That is, relative to what baseline are we assessing persistence? If we are interested in comparing participant's actual post-weatherization energy use to what energy use might have been had they not participated, then the baseline represents what the participants' energy usage would have been in the absence of the program. Any conclusions made about net savings and their persistence would thus depend on the validity of the estimated baseline.

For this study, the baseline is constructed from a group of participants who have yet to be weatherized. In Table 6 these participants are included in the "pre" row. A key assumption is whether the pre-participation energy usage patterns of these participants adequately represents what the participants would have done had they not participated. As indicated in Table 6, the pre-participation participants are primarily composed of later participants $(1988,1989,1990$, and 1991). The extent to which these participants are similar to or differ from earlier participants determines the validity of using them as a baseline.

A change in program emphasis in 1988 meant that later Wisconsin Gas Company participants were more likely to be payment-troubled. While this might imply that these customers would be higher consumers, and thus lead to an overstatement of net savings over time, analysis of energy use in the year before participation for 1987 through 1991 participants does not indicate a significant difference in consumption. Comparison of ECM and demographic information of the participant groups also does not indicate a significant shift in program focus or targeting after 1988 (see Appendix D). 
The baseline group will never perfectly match the treated group in any study, but the conclusion that savings do not erode--and that net savings increase over time--cannot be invalidated because of the identified dissimilarities between the two groups.

\section{Resampling}

The median polish, unlike the ANOVA, is not normally used to make inferences or hypothesis tests about the model estimates. To produce estimates of the sampling error of the median polish composite savings estimates, a bootstrap resampling procedure was performed. ${ }^{24}$ This procedure allows the calculation of confidence bands around the model estimates by essentially simulating the process of drawing repeated random samples from the population. Appendix B contains a detailed discussion of this procedure and its implications.

\footnotetext{
${ }^{24}$ For a more detailed explanation of this procedure, see Eric W. Noreen, Computer-Intensive Methods for Testing Hypotheses, New York: Wiley, 1989, pp. 63-79.
} 
The results are presented separately for each utility. The results for Wisconsin Gas Company are presented in six sections: 1 ) a review of the overall trends in energy consumption and energy savings for program participants; 2) summary statistics of consumption and savings; 3) median polish and ANOVA results, including the model coefficients, and the estimates of gross (treated and untreated) and net energy savings derived from the median polish coefficients; 4) results of the subgroup analysis, which was conducted for various demographic and ECM categories; 5) discussion of the stability of the median polish model, with a comparison to net savings estimates based on the ANOVA coefficients; and 6) the results of the cost-effectiveness analysis.

The results for Madison Gas \& Electric Company are presented in five sections: 1) a review of the overall trends in energy consumption and energy savings for program participants; 2) summary statistics of consumption and savings; 3) overall median polish and ANOVA results, including the model coefficients, and the estimates of gross (treated and untreated) and net energy savings derived from the median polish coefficients; 4) results of the subgroup analysis, which was conducted for various demographic and ECM categories; and 5) the results of the cost-effectiveness analysis.

\section{WISCONSIN GAS COMPANY RESULTS}

\section{Overview of Gas Consumption and Savings Trends}

Figures 5 and 6 have four different representations of how gas consumption has changed over the years for the buildings in the study. The figures show both median NAC and 


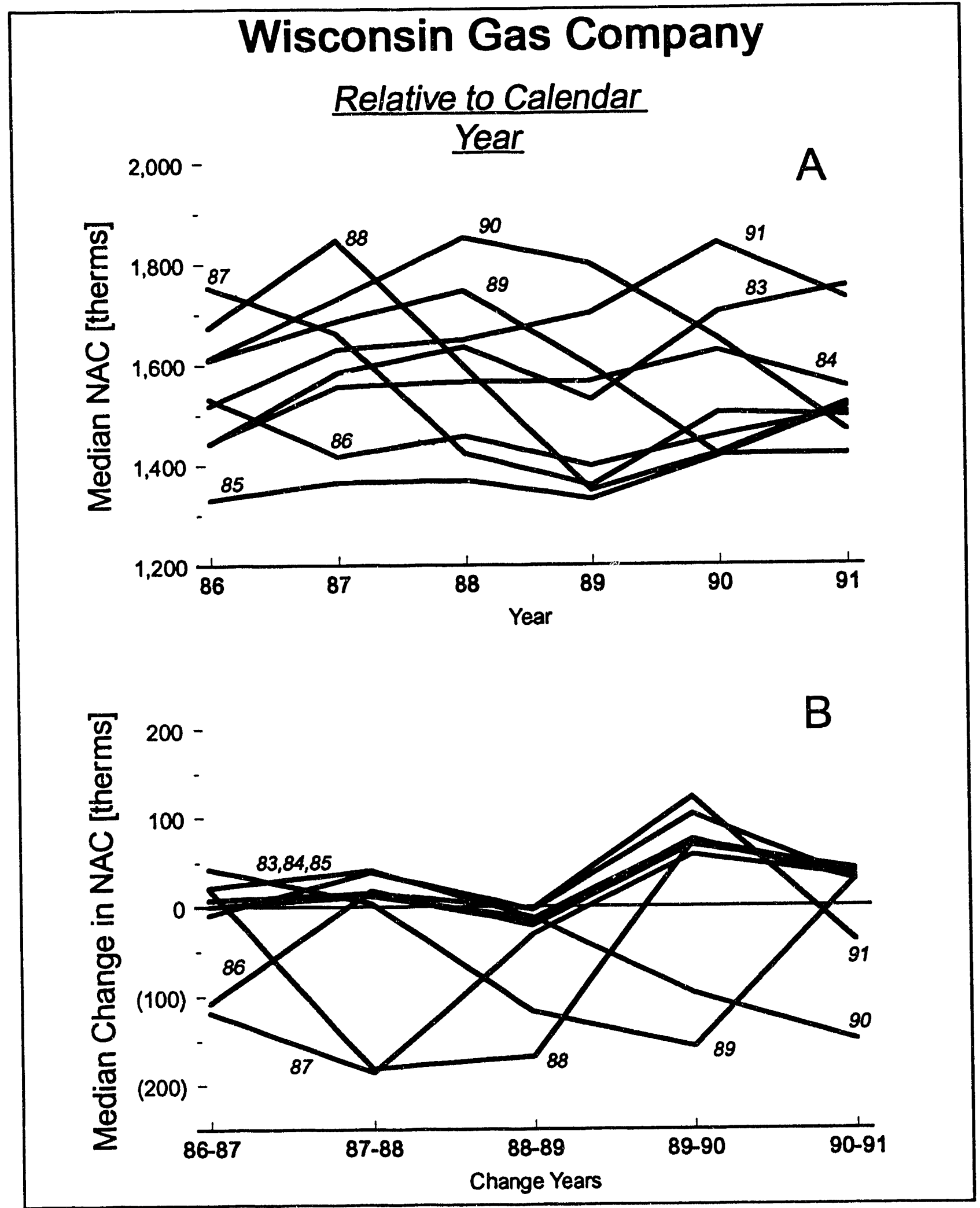

Figure 5

Wisconsin Energy Conservation Corporation 


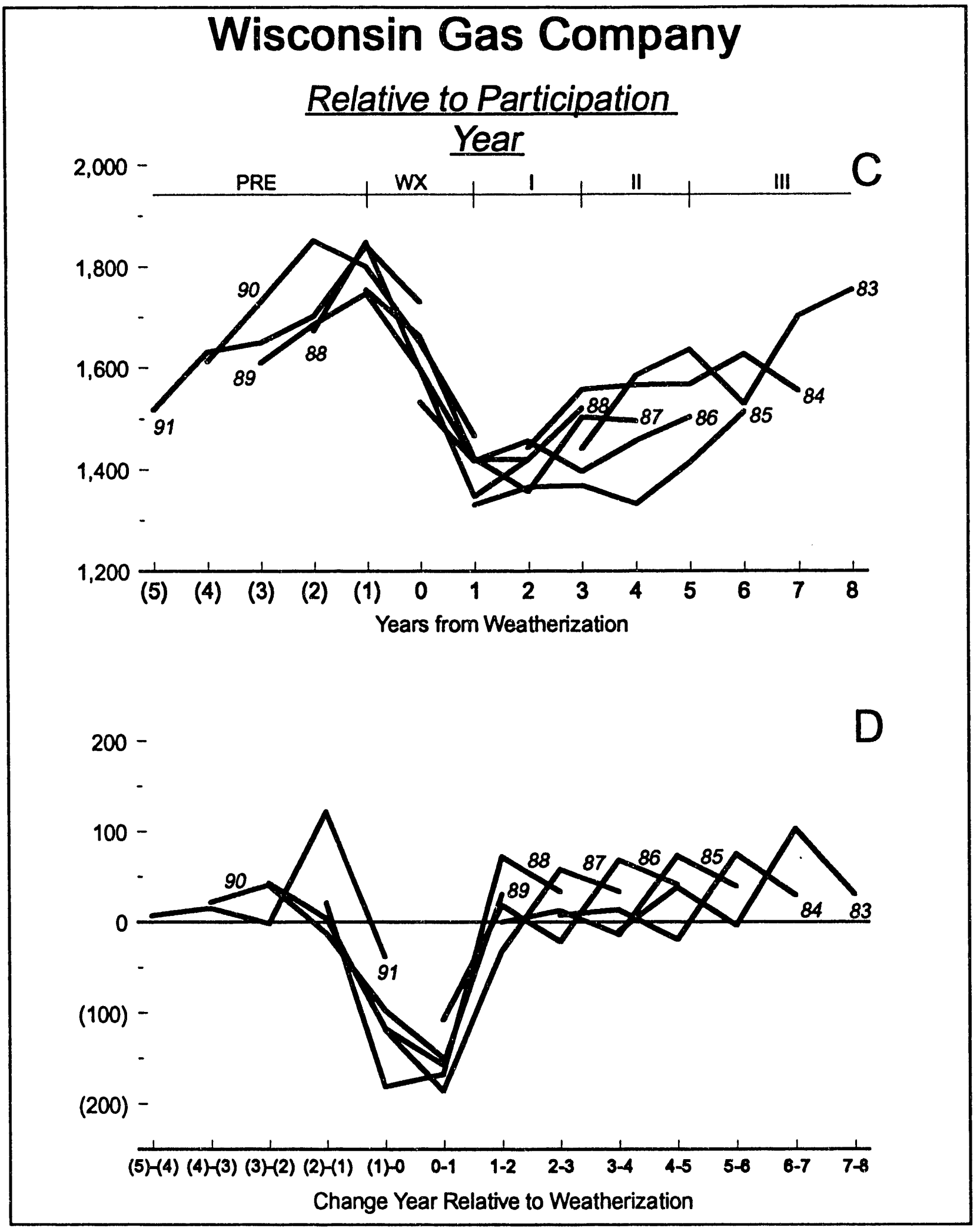

Figure 6 
the median change in NAC for each participation cohort across the years for which consumption data was available. In order to explore differences between year effects and weatherization effects, graphs A and B show NAC and change in NAC relative to calendar years, while graphs $C$ and $D$ show these quantities relative to the year of weatherization. Several observation can be made from the figures:

- Gas consumption drops considerably after weatherization. This immediate effect of weatherization on gas consumption is most clear when viewed relative to the year of weatherization, but can also be seen scattered across the calendar year graphs. As Table 8 shows, the median drop in gas consumption ranged from $16 \%$ to $23 \%$ for buildings that have NAC data for the years immediately before and after weatherization.

- Gas consumption increased in general over the six-year period of analysis for both weatherized and unweatherized buildings. The increase in gas consumption is manifested in the plots of median NAC as a slope in the trend in NAC over time. In the plots of the median change in NAC, the overall increase in NAC shows up in the fact that most of the data points lie above the horizontal line representing zero change.

- There are changes in gas consumption that occur across all participation cohorts in certain calendar years. Across the board changes in gas consumption can be seen in the plots of the change in NAC across calendar years. In particular, there is a significant increase in gas consumption between 1989 and 1990. This increase is evident in the lower lefthand graph of the change in NAC relative to calendar years, but it also shows up as a sawtooth pattern across the weatherization years in the lower righthand graph.

- Gas consumption for 1983 and 1984 participants is generally higher than that of other participation years. While the mean and median postweatherization NAC for most participation cohorts is in a rough range of 1,300 to 1,500 therms, the 1983 and 1984 cohorts fall between 1,400 and 1,850 therms. This suggests that something is different about either the buildings or the conservation measures that were implemented for these two early cohorts. 


\section{Summary Consumption and Savings Statistics}

To gain insight into the general pre- and post-weatherization energy use and energy savings characteristics of the Wisconsin Gas Company participant sample, summary statistics were compiled for a subgroup of program participants. Table 8 presents statistics for 1987-1990 participants that had both pre- and post-weatherization consumption information. In general, mean and median pre-weatherization (normalized) annual consumption ranged from 1700 to 1900 therms, and post-weatherization annual consumption ranged from 1330 to 1550 therms. First year mean and median therm savings ranged from 274 to 467 therms, and mean and median percentage savings ranged from 16 to 25 percent.

Table 8, Consumption and Savings Estimates, 1987-90 Wisconsin Gas Company Participants

\begin{tabular}{|c|c|c|c|c|c|c|c|c|c|}
\hline \multirow{3}{*}{$\begin{array}{c}\text { Participation } \\
\text { Year }\end{array}$} & \multicolumn{5}{|c|}{ CONSUMPTION } & \multicolumn{4}{|c|}{ SAVINGS } \\
\hline & \multirow[b]{2}{*}{$\mathbf{n}$} & \multicolumn{2}{|c|}{ Pre-WX } & \multicolumn{2}{|c|}{ Post-WX } & \multicolumn{2}{|c|}{ Mean } & \multicolumn{2}{|c|}{ Median } \\
\hline & & $\mathbf{M n}$ & Md & Mn & Md & Abs. & $\%$ & Abs. & $\%$ \\
\hline 1987 & 249 & 1796 & 1704 & 1415 & 1357 & 382 & 21.3 & 306 & 19.0 \\
\hline 1988 & 566 & 1875 & 1792 & 1408 & 1330 & 467 & 24.9 & 387 & 22.9 \\
\hline 1989 & 402 & 1813 & 1714 & 1449 & 1373 & 364 & 20.1 & 302 & 18.7 \\
\hline 1990 & 402 & 1892 & 1774 & 1551 & 1425 & 381 & 20.1 & 274 & 16.4 \\
\hline TOTAL & 1619 & 1852 & 1761 & 1445 & 1369 & 407 & 22.0 & 321 & 20.1 \\
\hline
\end{tabular}

Data are presented only for buildings with complete pre- and post-weatherization consumption information. The savings figures are not control-adjusted. $M n=$ mean, $M d=$ median. 


\section{Results of the Model Runs}

The results of the overall median polish and trimmed ANOVA ${ }^{25}$ runs for the Wisconsin Gas Company program are presented in Table 9. The period effects indicate a sharp decrease in consumption in the weatherization years. The effect should be interpreted as a two-year effect, because the weatherization effect represents buildings that are both entering and leaving their year of participation.

This means that the median polish estimate of weatherization-induced change in energy use is actually two times -155.6 , or -311.2 . The year effects indicate a declining usage in 1987-88 and 1988-89, and increasing usage in 1989-90
Table 9, Total Median Polish and Trimmed ANOVA Results, Wisconsin Gas Company

\begin{tabular}{||c|c|c|}
\hline $\begin{array}{c}\text { Weatherization } \\
\text { Effects }\end{array}$ & $\begin{array}{c}\text { Median } \\
\text { Polish }\end{array}$ & $\begin{array}{c}\text { Trimmed } \\
\text { ANOVA }\end{array}$ \\
\hline Pre & 15.9 & 38.8 \\
\hline Weatherization & -155.6 & -118.9 \\
\hline Post I & -4.6 & 23.1 \\
\hline Post II & 0.0 & 24.2 \\
\hline Post III & 6.9 & 0.0 \\
\hline \hline Year Effects & & \\
\hline $1986-87$ & 0.0 & -3.5 \\
\hline $1987-88$ & -8.8 & -25.4 \\
\hline $1988-89$ & -26.4 & -39.3 \\
\hline $1989-90$ & 57.1 & 47.0 \\
\hline $1990-91$ & 24.9 & 0.0 \\
\hline \hline Grand Effect & 13.3 & -11.5 \\
\hline
\end{tabular}
and 1990-91. The grand effect represents an increase in usage associated with all buildings, treated and untreated. (Appendix E contains the complete median polish results.)

A comparison of the year-to year rate of change in energy use for weatherized versus unweatherized buildings can be made by examining the pre- and post-weatherization effects. For both the median polish and ANOVA runs, the post-weatherization effects indicate a lower year-to-year increase in energy usage than the pre-weatherization effects. That is, buildings that are weatherized increase consumption more slowly than unweatherized buildings.

\footnotetext{
${ }^{2}$ The ANOVA group was trimmed of all year-to-year changes that exceeded 75 percent (negative or positive), thereby excluding extreme values.
} 
When the grand effect is considered, the median polish and trimmed ANOVA estimates of weatherization effects are quite comparable. The sum of the median polish preweatherization and grand effects is 29.2 therms, and the sum of the ANOVA preweatherization and grand effects is 27.3 therms. The sum of the median polish weatherization and grand effects is -142.3 therms, and the sum of the ANOVA weatherization and grand effects is -130.4 therms.

\section{Gross and Net Change in Energy Use}

The results of the median polish runs were used to create the following graphs of gross change in energy use following weatherization for treated and untreated buildings for the eight-year period following weatherization. Figures 7 and 8 show consumption increasing for both treated and untreated buildings, with the consumption in treated buildings rising at a slower rate.

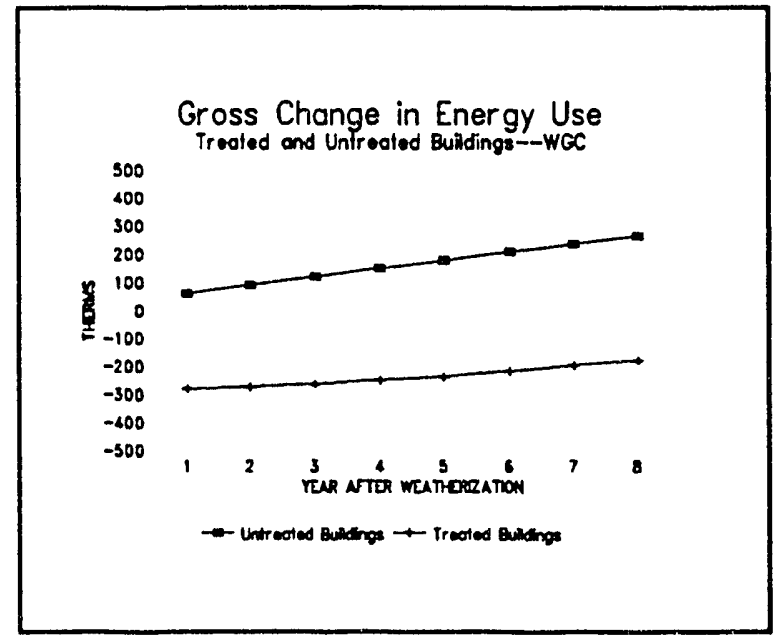

Figure 7

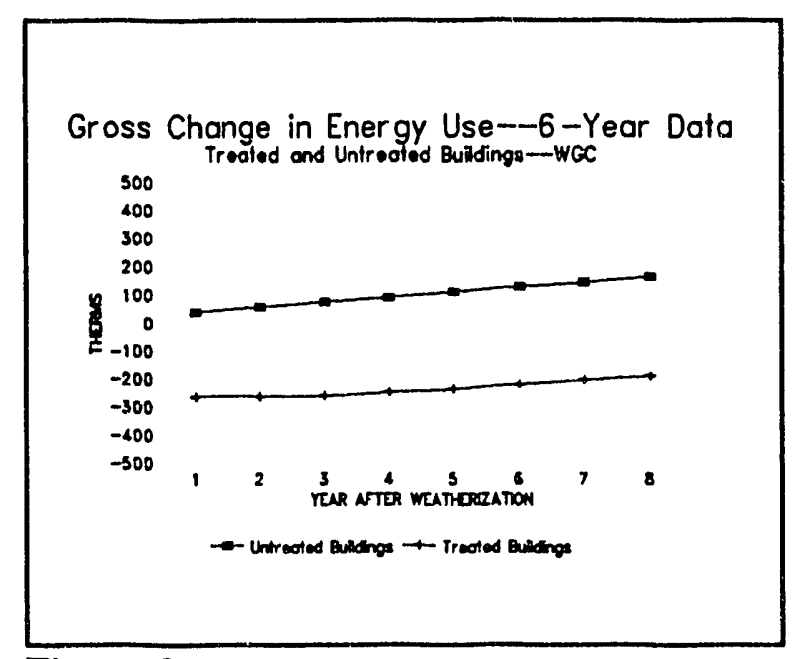

Figure 8

Figures 9 and 10 show net energy savings. The first-year median polish savings estimates of 343 therms are 19 percent of the median pre-weatherization NAC across all buildings, which is 1,803 therms for 2,617 buildings with first year pre-weatherization consumption information. The overall median polish results indicate that savings persist over time, increasing from Year 1 net savings of 343 therms to Year 8 net savings of 443 therms (a 


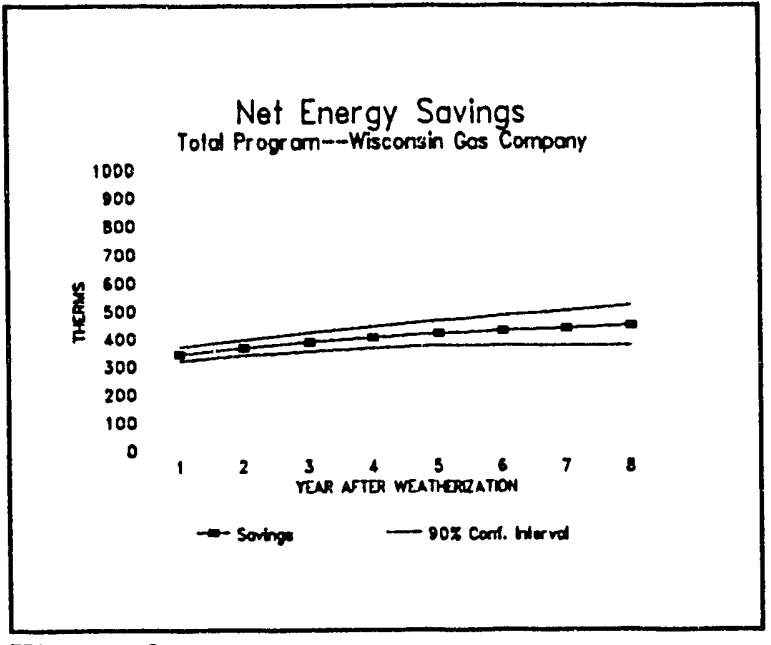

Figure 9

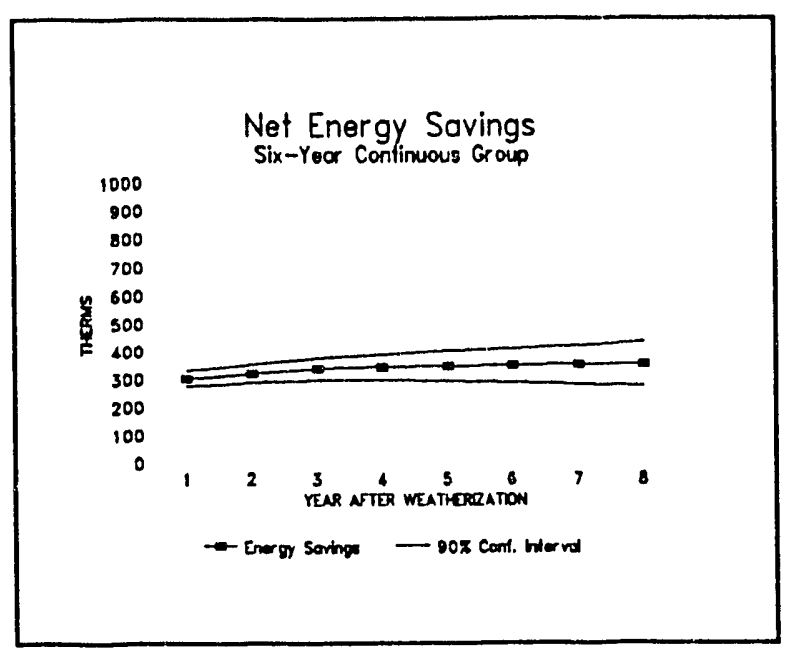

Figure 10

$29 \%$ increase). The 100 therm increase in net savings occurs because the consumption of untreated buildings increased by 204 therms from Year 1-8, where the consumption of weatherized buildings increased by 104 therms over the same period. It is important to keep in mind that these are composite results: 1) early participants have a greater proportion of shell measure installations than later participants, which have a greater proportion of "both" measure installations; 2) early participants have a greater proportion of 1-unit treatments, with the proportion of multi-unit treatments increasing in the later participant cohorts. Subgroup analysis (below) indicates that shell measures and heating measures differ more in the level of savings than in the trend of savings persistence or erosion, which suggests that the persistence trend (as opposed to level) over time will not be greatly affected. Table 10 shows the net savings results for the total and 6-year group median polish runs, and for the trimmed group ANOVA runs. 
Table 10, Net Savings, Total Group Median Polish, 6-Year Group Median Polish, and Trimmed Group ANOVA

\begin{tabular}{|c|c|c|c|c|c|c|c|c|}
\hline Year After & 1 & 2 & 3 & 4 & 5 & 6 & 7 & 8 \\
\hline $\begin{array}{l}\text { Total Group } \\
\text { Median Polish Net Savings } \\
\text { (therms) }\end{array}$ & 343 & 364 & 384 & 400 & 416 & 425 & 434 & 443 \\
\hline Upper Conf. (90\%) & 368 & 392 & 417 & 439 & 462 & 479 & 497 & 516 \\
\hline Lower Conf. (90\%) & 319 & 335 & 351 & 361 & 370 & 371 & 371 & 370 \\
\hline $\begin{array}{l}\text { 6-Year Group } \\
\text { Median Polish Net } \\
\text { Savings (therms) }\end{array}$ & 301 & 318 & 334 & 340 & 346 & 348 & 350 & 352 \\
\hline Upper Conf. (90\%) & 330 & 351 & 374 & 387 & 400 & 409 & 419 & 432 \\
\hline Lower Conf. (90\%) & 272 & 284 & 294 & 293 & 291 & 287 & 280 & 272 \\
\hline $\begin{array}{l}\text { Trimmed Group } \\
\text { ANOVA Net Savings }\end{array}$ & 316 & 332 & 348 & 363 & 378 & 417 & 456 & 495 \\
\hline
\end{tabular}

The statistics from the resampling procedure were used to estimate the probability that total program net savings in Years 5 and 8 were greater than zero, and greater than Year 1 savings (the procedure is explained in Appendix B):26

Table 11

\begin{tabular}{|c||c|c|}
\hline \multirow{2}{*}{$\begin{array}{c}\text { Probability That } \\
\text { Net Savings Are: }\end{array}$} & $\begin{array}{c}\text { Five Years After } \\
\text { Weatherization }\end{array}$ & $\begin{array}{c}\text { Eight Years After } \\
\text { Weatherization }\end{array}$ \\
\cline { 2 - 3 } & $>99.5$ & $>99.5$ \\
\hline Greater Than Zero & $>99.5$ & 99.5 \\
\hline $\begin{array}{c}\text { Greater Than Year 1 } \\
\text { Net Savings }\end{array}$ & \\
\hline
\end{tabular}

${ }^{26}$ For example, if 198 of the 200 resamples in Year 5 or 8 showed greater savings than zero, then $(198+1 / 200+1) / 2$, or $99 \%$, of the savings results were greater than zero. 


\section{Net Energy Savings by Measure Group}

Figures 11 and 12 present program savings (total and 6-year groups) for the major ECM groups (the data points without connecting lines represent results based on fewer than 50 NAC figures for those years). The shell measure subgroup contains buildings that received weatherstripping, caulking, and insulation measures but no heating measures. The heating measure subgroup contains buildings that received either a heating retrofit or replacement but no shell measures. The "both" measure subgroup contains those buildings that received both shell and heating measures. Table 12 shows the net savings results for measure subgroups.

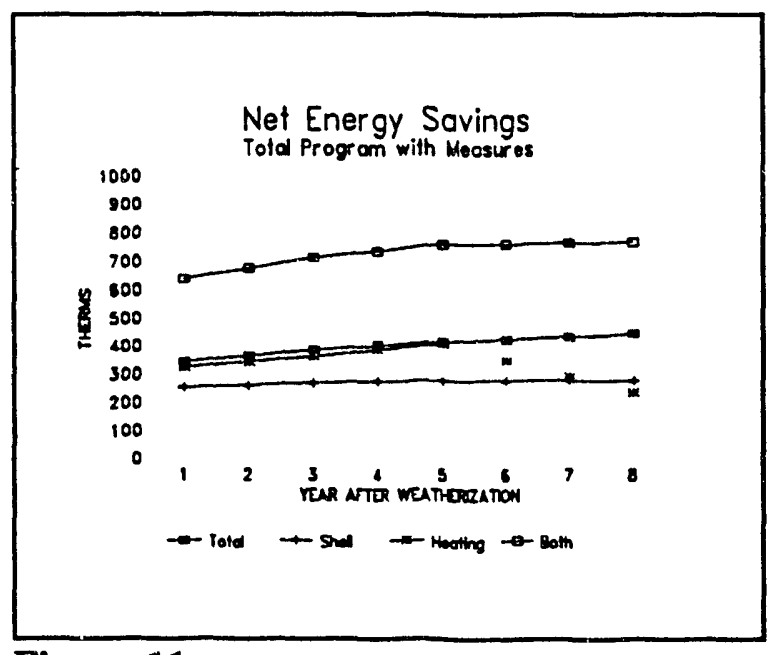

Figure 11

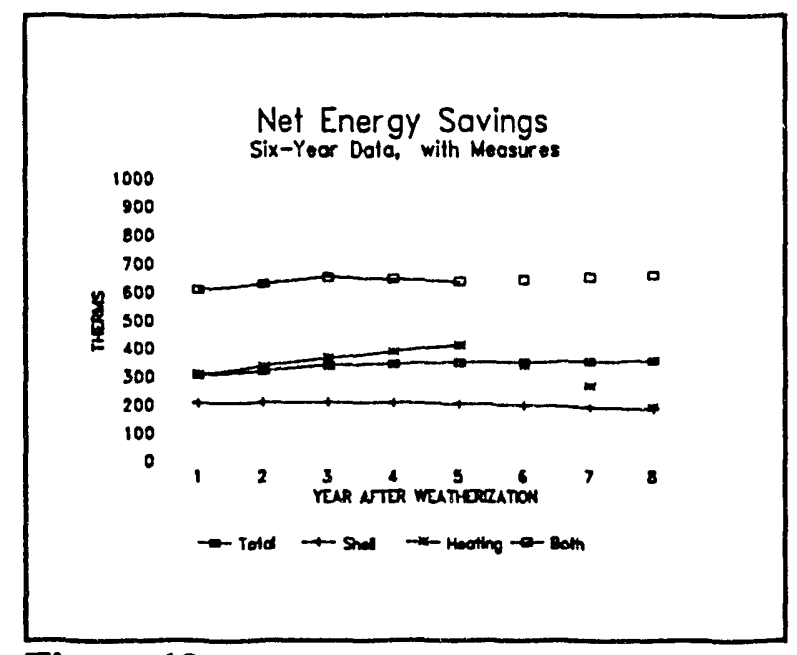

Figure 12

(Data points without connecting lines are estimates based on fewer than 50 NACs.)

For heating measures, the abrupt change in years 5-8 is an unreliable estimate of net energy savings because of the small sample sizes for heating installations for 1983-85 participants (a total of 23). Because of the larger sample sizes for the participant cohorts in Periods 1 and 2, an extrapolation of the 1-5 year trend may better represent the actual savings. If heating savings are viewed with this caveat, no measure (heating, shell, or both) indicates a marked erosion of energy savings. Shell measures have the lowest level net savings, which appears to erode slightly compared to the $1-5$ year heating 
Table 12, Net Energy Savings By Measure Type, Total Program and 6-Year Data Group

\begin{tabular}{|c||c|c|c|c|c|c|c|c|}
\hline Year After & 1 & 2 & 3 & 4 & 5 & 6 & 7 & 8 \\
\hline \hline Shell (Total) & 251 & 259 & 267 & 271 & 275 & 276 & 277 & 278 \\
\hline Heating (Total) & 323 & 341 & 360 & 383 & 406 & 349 & 292 & 235 \\
\hline Both (Total) & 636 & 674 & 711 & 735 & 758 & 762 & 765 & 769 \\
\hline \hline Shell (6-year) & 203 & 204 & 204 & 201 & 198 & 192 & 186 & 180 \\
\hline Heating (6-year) & 305 & 334 & 362 & 385 & 408 & 335 & 262 & 189 \\
\hline Both (6-year) & 603 & 626 & 648 & 640 & 632 & 640 & 648 & 656 \\
\hline
\end{tabular}

period and the total program and both measures periods. The both measure category shows greater savings than the sum of shell or heating categories, even though the savings should generally be less than the sum of shell and heating measures (because of measure interaction). This suggests that buildings receiving both measures had greater savings potential than those buildings receiving shell or heating measures alone.

\section{Stability of the Model Results}

The results of the Wisconsin Gas

company program were based primarily on median polish runs on the total group of buildings for which consumption was available $(5,129$ buildings) and on the group of buildings with six years of continuous information (1,214 buildings). To determine the stability of and corroborate these results, the same data were run in an ANOVA model. Two types of datasets were used: 1 ) the entire

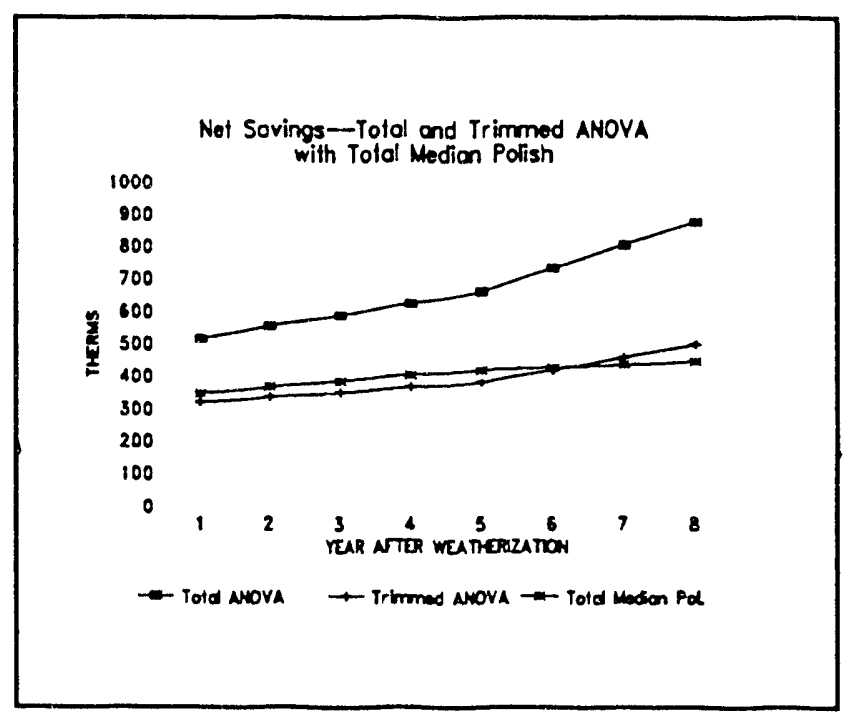

Figure 13 group of $(5,129)$ buildings; and 2 ) a trimmed group of buildings. For the trimmed 
dataset, all year-to-year changes that exceeded 75 percent (either positive or negative) of the preceding year's consumption were removed. The rationale for trimming the dataset is that ANOVA can be influenced by extreme values, and that changes of this magnitude are unlikely to be due to the program. As Figure 13 indicates, the net savings calculations for the total group ANOVA runs indicate a much higher year 1 savings estimate. $^{27}$ The ANOVA on the trimmed dataset, on the other hand, indicates net savings estimates that more closely mirror those of the median polish. Given the robustness of the median polish in its resistance to outliers, it can be expected that the forced removal of outliers in the trimmed ANOVA run will produce such similar results. Appendix $\mathrm{F}$ presents a comparison of model-derived estimates and raw data estimates for both NAC and change in NAC over the period 1986-91.

\section{Cost-Effectiveness Analysis}

A cost-effectiveness analysis was conducted for the total Wisconsin Gas Company program results, and for the shell, heating and both measure subgroups. Cumulative discounted savings (the sum of yearly discounted savings) and simple paybacks were calculated two ways: 1) based on first year savings; and 2) based on savings 1 to 8 years after weatherization. For the cumulative discounted savings, a discount rate of 5 percent, a constant therm cost of $\$ .57$ (the approximate average per therm cost of gas from 198691) were used. Eight-year simple payback and cost of conserved energy (CCE) estimates were calculated by taking the average of the savings over eight years (undiscounted). The CCE calculation assumed a 15-year measure life. Percent of cost recovered is the amount of the installation cost recovered after eight years. Table 13 shows the results of the cost-effectiveness analysis.

The results indicate that for all measures of cost-effectiveness, estimates based on firstyear savings only were lower than estimates using the full eight years of savings

\footnotetext{
${ }^{27}$ This is primarily because of the large pre-weatherization effect of the ANOVA (compared to the median polish) and the subsequent control-adjustment.
} 
Table 13, Cost-Effectiveness Analyses, First and First through Eighth Year Comparisons, Wisconsin Gas Company

\begin{tabular}{||c|c|c|c||}
\hline $\begin{array}{c}\text { Wisconsin Gas } \\
\text { Company, Installation } \\
\text { Cost }=\$ 1,591^{2}\end{array}$ & $\begin{array}{c}\text { Results Based on } \\
\text { First-Year Savings } \\
(90 \% \text { C })\end{array}$ & $\begin{array}{c}\text { Results Based on } \\
\text { First through Eighth } \\
\text { Year Savings } \\
(90 \% \text { CI })\end{array}$ & $\begin{array}{c}\text { Percentage } \\
\text { Difference } \\
\text { Between First } \\
\text { and Eighth Year }\end{array}$ \\
\hline $\begin{array}{c}8-\text { Year Cumulative } \\
\text { Discounted Savings (\$) }\end{array}$ & $1,266( \pm 90)$ & $1,466( \pm 160)$ & 15.8 \\
\hline Simple Payback (years) & $8.1( \pm .6)$ & $6.9^{c}( \pm .8)$ & -14.5 \\
\hline $\begin{array}{c}\text { Cost of Conserved } \\
\text { Energy (\$/MMBtu) }\end{array}$ & $4.5( \pm .3)$ & $3.9^{c}( \pm .4)$ & -13.7 \\
\hline $\begin{array}{c}\text { Percent of Cost } \\
\text { Recovered }\end{array}$ & 80 & 92 & 15 \\
\hline
\end{tabular}

This figure represents median per-building installation costs plus $\$ 300$ estimated for program administration costs, adjusted to a per-unit basis.

${ }^{b}$ Cumulative Discounted Savings are based on the discounted yearly dollar savings (5 percent discount rate, $5.57 /$ therm); for results based on first-year savings, net savings are assumed to stay the same over eight years.

'Eight-year estimates of Simple Payback and Cost of Conserved Energy are based on an average of first through eighth year savings. The CCE assumed a 15-year measure life.

$\mathrm{CI}=$ confidence interval.

estimates. The conclusion that eight-year savings provided better estimates of costeffectiveness also holds for the measure subgroups, which are presented in Table 14. As with the energy savings results, the cost-effectiveness measures for the ECM subgroups should be viewed with increasing caution as the sample size decreases (this is a concern primarily with the heating measures, which have a low $n$ in years 5-8). The cost of conserved energy (CCE) results are comparable to results of similar low-income weatherization programs. Eight programs reviewed by Schlegel and Pigg that offered comprehensive packages of measures had CCEs that ranged from $\$ 4.22$ to $\$ 7.46 / \mathrm{MMBtu}$. These figures compare to retail rates for natural gas of from $\$ 4.50$ to $\$ 6.00 / \mathrm{MMBtu} .{ }^{28}$

${ }^{28} \mathrm{Jeff}$ Schlegel and Scott Pigg, WECC, "The Potential for Energy Savings and Cost-Effectiveness of LowIncome Weatherization Programs: A Summary of Recent Evaluations," Proceedings of the ACEEE 1990 Summer Study on Energy Efficiency in Buildings, vol. 9, pp. 141-154. 
Table 14, Cost-Effectiveness Analyses, Total Program and Measure Comparisons

\begin{tabular}{||c||c|c|c|c|}
\hline $\begin{array}{c}\text { Measure } \\
\text { Median Installation Cost }\end{array}$ & $\begin{array}{c}\text { Total } \\
\$ 1,591\end{array}$ & $\begin{array}{c}\text { Shell } \\
\$ 1,232\end{array}$ & $\begin{array}{c}\text { Heating } \\
\$ 2,150\end{array}$ & $\begin{array}{c}\text { Both } \\
\$ 2,381\end{array}$ \\
\hline \hline Cumulative Savings--1YS (\$) & 1,266 & 925 & 1,191 & 2,347 \\
\hline Cumulative Savings--8YS (\$) & 1,466 & 990 & 1,249 & 2,662 \\
\hline Simple Payback--1YS (years) & 8.1 & 8.6 & 11.7 & 6.6 \\
\hline Simple Payback--8YS (years) & 6.9 & 8.0 & 11.2 & 5.7 \\
\hline CCE--1YS (\$/MMBtu) & 4.5 & 4.7 & 6.5 & 3.6 \\
\hline CCE--8YS (\$/MMBtu) & 3.9 & 4.4 & 6.1 & 3.2 \\
\hline $\begin{array}{c}\text { Percent of Cost Recovered } \\
\text { based on 8-Year Savings } \\
\text { Estimates (discounted) }\end{array}$ & 92 & 80 & 58 & 112 \\
\hline $\begin{array}{c}\text { Percent of Cost Recovered } \\
\text { based on 8-Year Savings } \\
\text { Estimates (undiscounted) }\end{array}$ & 115 & 100 & 71 & 139 \\
\hline
\end{tabular}

$1 Y S=$ results based on first-year savings

$8 Y S=$ results based on eight-year savings (average or cumulative discounted) 


\section{Subgroup Analysis--Wisconsin Gas Company, Net Energy Savings}

In addition to the total program and measure net energy savings analyses, net energy savings were also analyzed for various demographic and ECM subgroups, including: 1) single- and multi-unit buildings; 2) tenant and owner heatpayers; 3) high and low shell measure expenditures; 4) high and low heating measure expenditures; 5) low, high and medium cost heating measures that were installed with shell measures; 6) high and low usage; and 7) single- and multi-unit high and low usage. Figures 14 through 20 represent the results of the analyses.

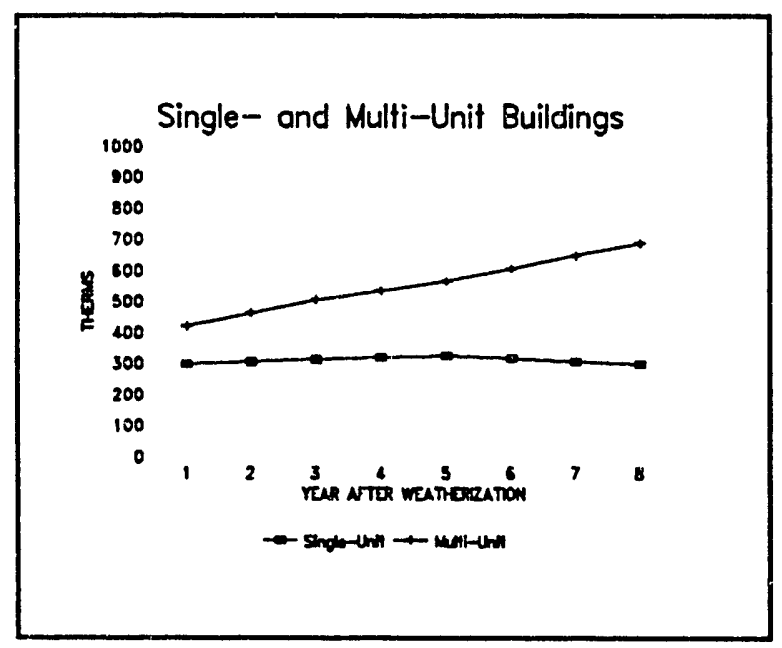

Figure 14, Net Energy Savings

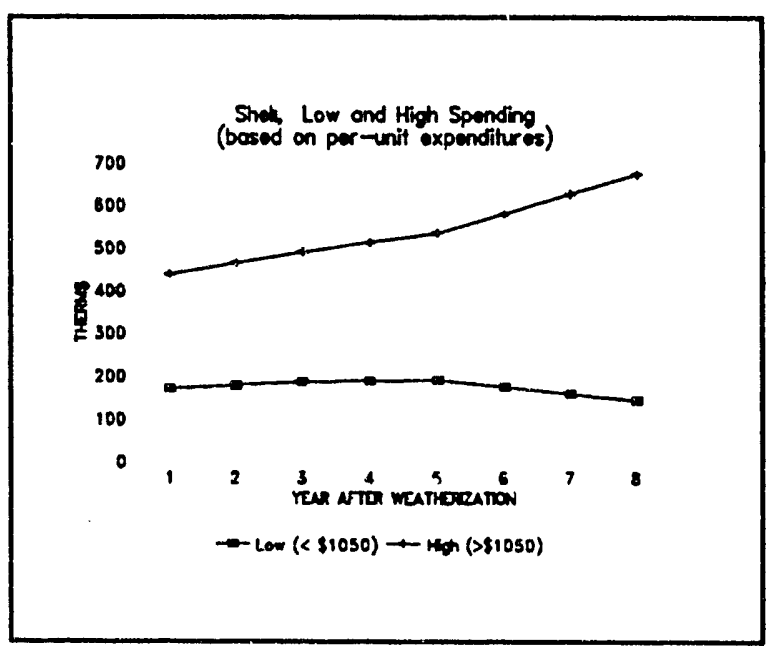

Fiơure 16, Net Energy Savings

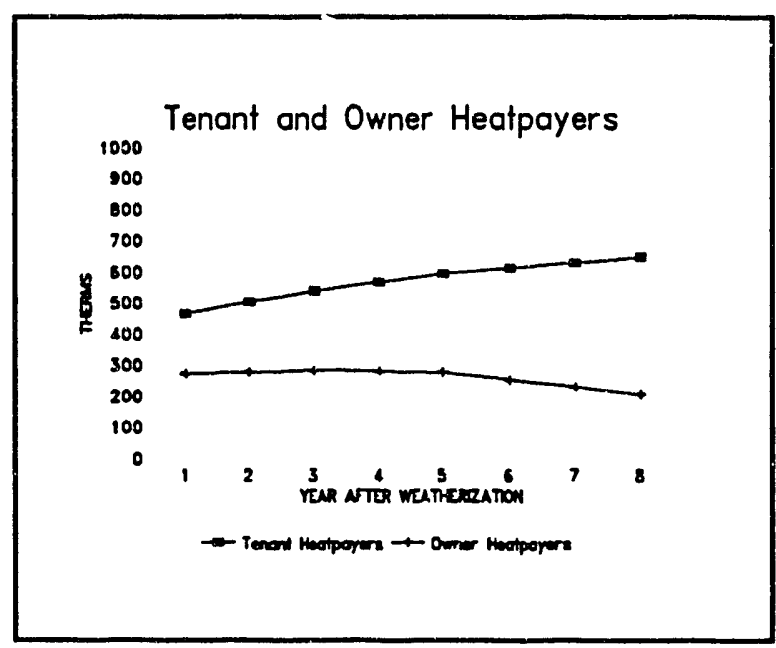

Figure 15, Net Energy Savings 
Subgroup Analysis, continued

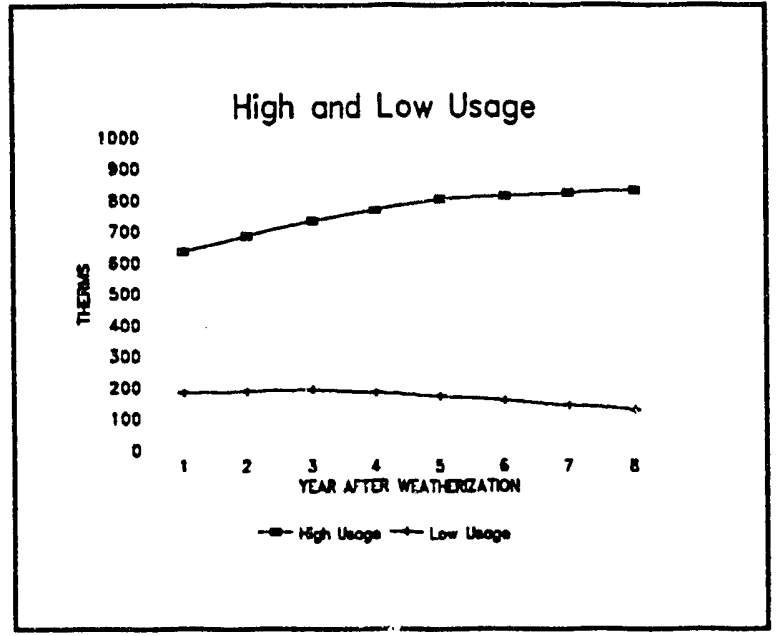

Figure 17, Net Energy Savings

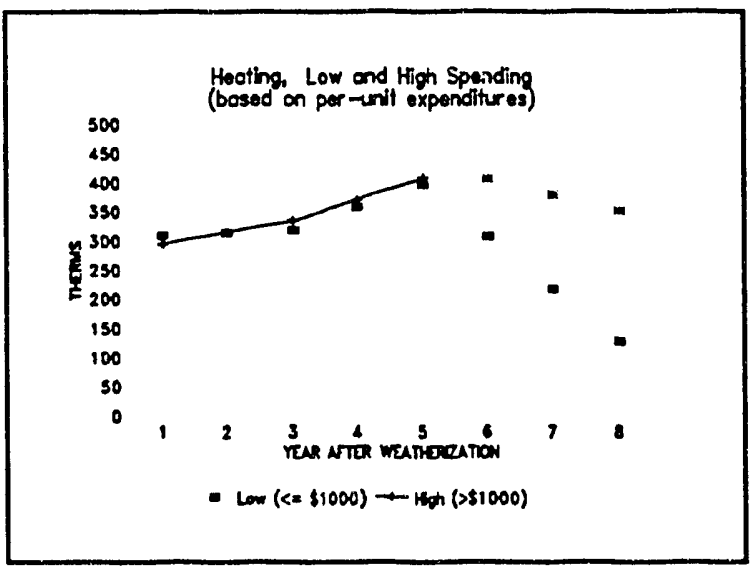

Figure 19, Net Energy Savings

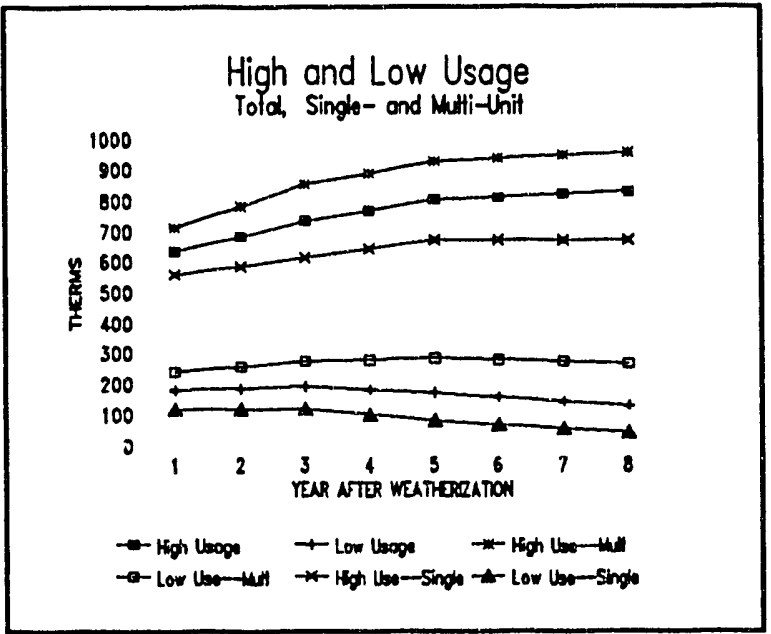

Figure 18, Net Energy Savings

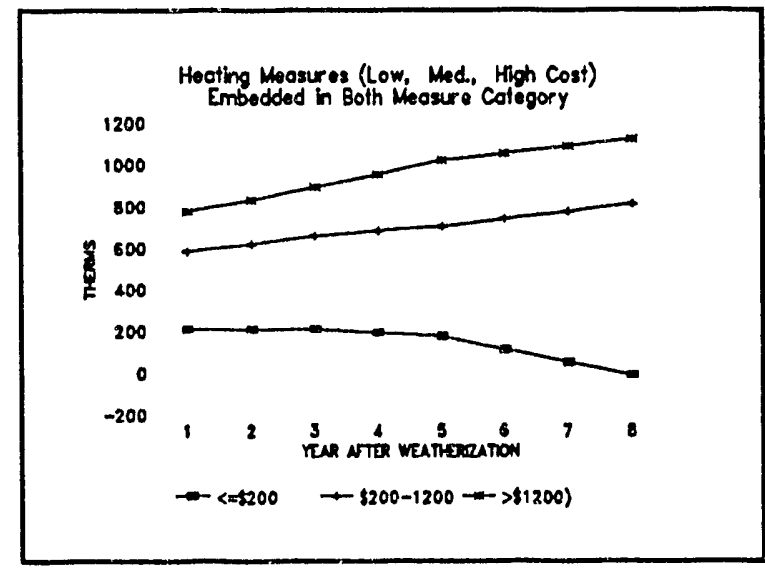

Figure 20, Net Energy Savings

(All graphs without connecting lines represent results based on fewer than 50 NAC figures.)

For the subgroups there are noticeable differences both in magnitude of savings and in the overall persistence trends. Multi-unit buildings show greater net savings and an increase in net savings over time compared to stable net energy savings for single-unit buildings. Tenant heatpayers had higher net savings and a more positive persistence trend than owner heatpayers. The result for heatpayers is similar to the results for the 
single- and multi-unit buildings, in large part because a greater percentage of renters in the Wisconsin Gas Company study sample are in multi-unit buildings:

$\begin{array}{lcc} & \text { Renter } & \text { Owner } \\ \text { Percentage in Single-Unit } & 43 \% & 57 \% \\ \text { Percentage in Multi-Unit } & 84 \% & 16 \%\end{array}$

This makes it difficult to distinguish between effects associated with building type as opposed to those associated with a particular occupant type.

For heating-only installations, there is little noticeable difference between high- and lowcost measures in years 1-5, although the results for low-cost heating measures in years 18 and the high-cost heating results for years 5-8 should be viewed with caution because of the small sample sizes. For heating measures installed with shell measures (the both measure category), higher expenditures indicate greater savings than lower expenditures, and savings from low-expenditure heating measures appear to erode over time.

The usage subgroups (high usage $=>1,800$ therms/year, low usage $=<1,800$ therms $/$ year $^{29}$ ) indicate an expected relationship between the level of energy use and the level of energy savings (high energy usage is associated with higher energy savings).

For all subgroups, the net savings results should be considered as exploratory rather than definitive because of the small sample sizes.

\footnotetext{
${ }^{2}$ Usage was estimated from base use and heat factor numbers contained in the weatherization database (this information was available for 73 percent of participants). The calculation was: usage $=365^{*}$ base use (per day) $+7,642 *$ heat factor. This procedure provided a consistent measure of usage at the time of participation.
} 


\section{MADISON GAS \& ELECTRIC COMPANY}

Figures 21 and 22 depict how gas consumption has changed over the years for the buildings in the Madison Gas \& Electric Company program. The figures show both median NAC and the median change in NAC for each participation cohort across the years for which consumption data was available. In order to explore differences between year effects and weatherization effects, graphs A and B show NAC and change in NAC relative to calendar years, while graphs $C$ and $D$ show these quantities relative to the year of weatherization. Several observation can be made from the figures:

- Gas consumption drops considerably after weatherization. This immediate effect of weatherization on gas consumption is most clear when viewed relative to the year of weatherization, but can also be seen scattered across the calendar year graphs. As Table 15 shows, the median drop in gas consumption was in the range of range of $14 \%$ to $17 \%$ for buildings that have NAC data for the years immediately before and after weatherization.

- Gas consumption increased in general over the five-year period of analysis for both weatherized and unweatherized buildings. The increase in gas consumption is manifested in the plots of median NAC as a slope in the trend in NAC over time. In the plots of the median change in NAC, the overall increase in NAC shows up in the fact that most of the data points lie above the horizontal line representing zero change.

- There are changes in gas consumption that occur across all participation cohorts in certain calendar years. Across the board changes in gas consumption can be seen in the plots of the change in NAC across calendar years. The effects are smaller than those for Wisconsin Gas Company, however.

The results below are presented in the following order: 1) summary consumption and savings statistics; 2) summary median polish and ANOVA statistics and overall gross and net energy savings; 3 ) measure and demographic subgroups analyse ${ }^{30}$; and 4) analysis of cost-effectiveness.

\footnotetext{
${ }^{30}$ Because of the more complete consumption information for Madison Gas \& Electric Company (92 percent of the possible NAC data points), it was not necessary to form two analysis groups.
} 


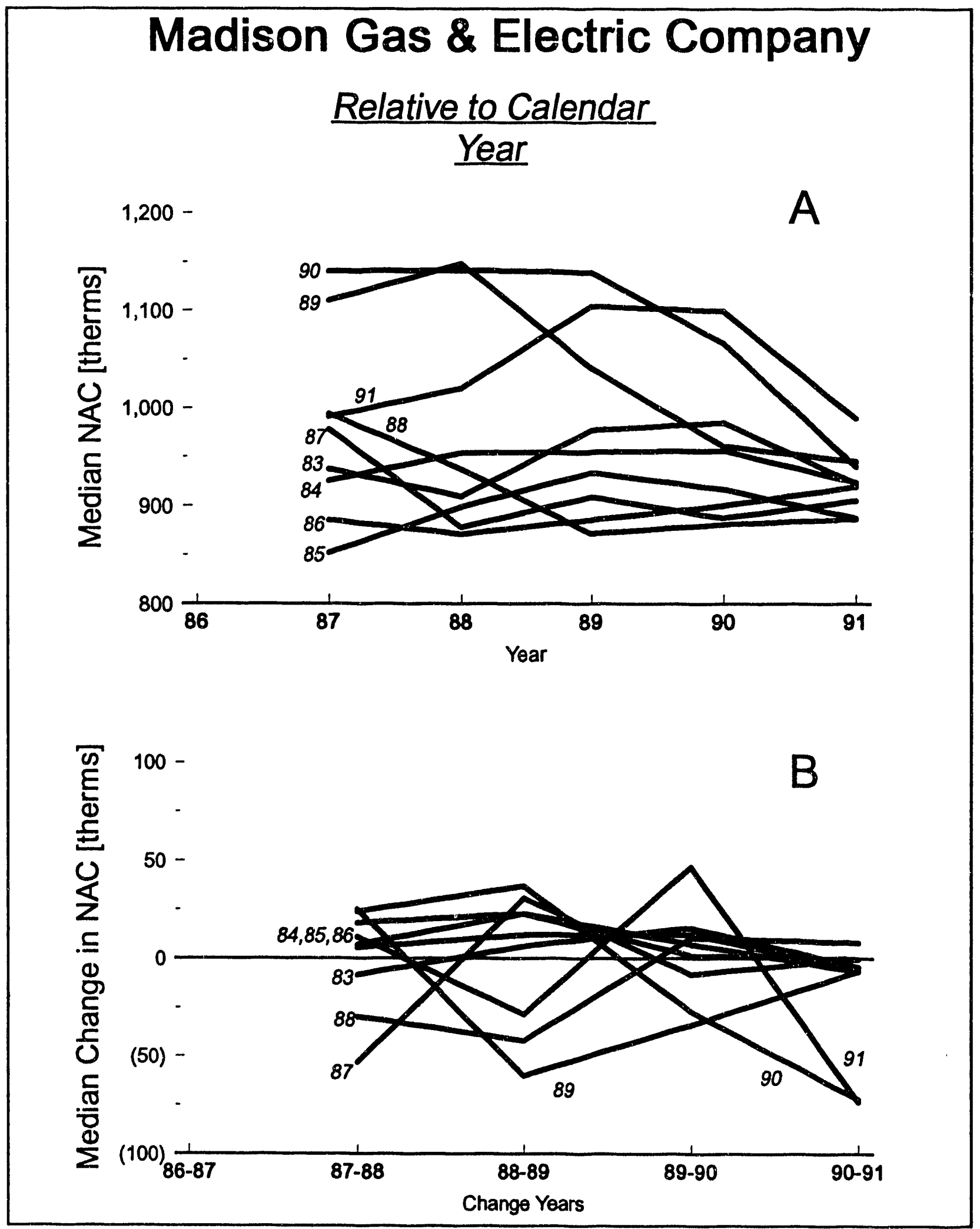

Figure 21 


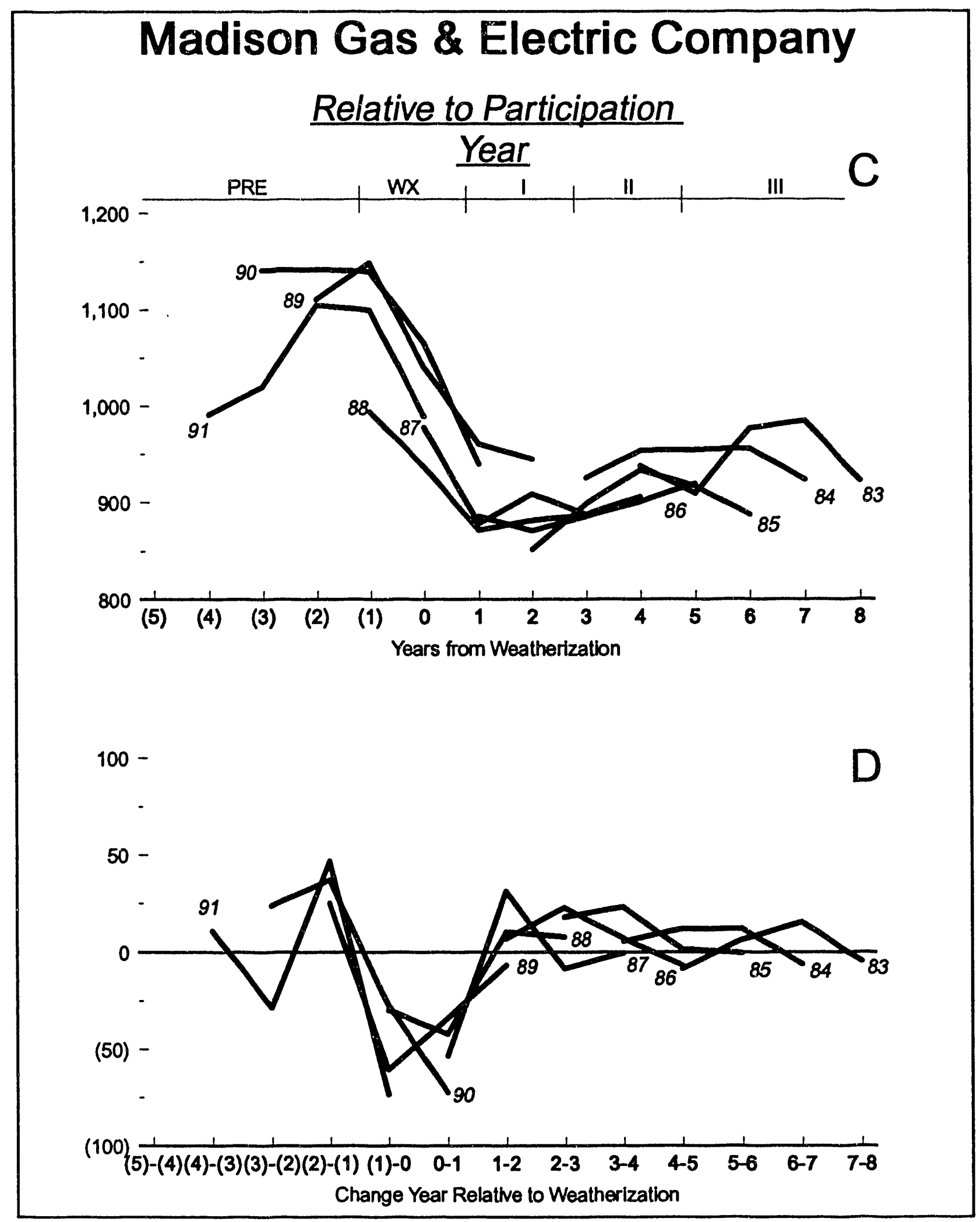

Figure 22 


\section{Summary Consumption and Savings Statistics}

To gain insight into the general pre- and post-weatherization energy use and energy savings characteristics of the Madison Gas \& Electric Company participant sample, summary statistics were compiled for a subgroup of program participants. Table 15 presents statistics for 1988-1990 participants that had both pre- and post-weatherization consumption information. In general, mean and median pre-weatherization (normalized) annual consumption ranged from 1000 to 1300 therms, and post-weatherization annual consumption ranged from 895 to 965 therms. First year mean and median therm savings ranged from 138 to 212 therms, and mean and median percentage savings ranged from 13 to 17 percent.

Table 15, Comparison of Consumption and Savings, 1988-90 Madison Gas \& Electric Company Participants

\begin{tabular}{||c||c|c|c|c|c||c|c|c|c||}
\hline \multicolumn{1}{|c||}{} & \multicolumn{4}{|c|}{ CONSUMPTION } & \multicolumn{4}{c||}{ SAVINGS } \\
\hline \hline \multirow{2}{*}{$\begin{array}{c}\text { Participation } \\
\text { Year }\end{array}$} & $\mathbf{n}$ & \multicolumn{2}{|c|}{ Pre-WX } & \multicolumn{2}{|c|}{ Post-WX } & \multicolumn{2}{|c|}{ Mean } & \multicolumn{2}{c|}{ Median } \\
\cline { 2 - 10 } & Mn & Md & Mn & Md & Abs. & $\%$ & Abs. & $\%$ \\
\hline 1988 & 126 & 1089 & 1009 & 951 & 895 & 138 & 12.7 & 144 & 15.4 \\
\hline 1989 & 159 & 1251 & 1184 & 1073 & 965 & 178 & 14.2 & 183 & 16.7 \\
\hline 1990 & 110 & 1304 & 1138 & 1093 & 956 & 212 & 16.3 & 175 & 14.4 \\
\hline TOTAL & 395 & 1214 & 1105 & 1040 & 946 & 174 & 14.3 & 176 & 15.7 \\
\hline \hline
\end{tabular}

Data are presented only for buildings with complete pre- and post-weatherization consumption information. The savings figures are not control-adjusted. $\mathrm{Mn}=$ mean, $\mathrm{Md}=$ median.

The total program results of the median polish and trimmed ANOVA runs for the Madison Gas \& Electric Company program are presented in Table 16. The median polish weatherization effects indicate a decrease in consumption in the weatherization years. The effect should be interpreted as a two-year effect, because the weatherization 
effect represents buildings that are both entering and leaving their year of participation. This means that weatherization-induced change in energy

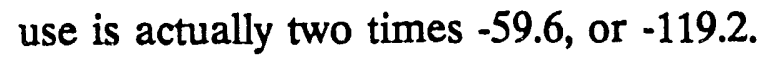
The year effects indicate relatively stable usage. The grand effect, 11.6 therms, represents an increase in usage associated with all buildings, untreated and treated. The small post-weatherization effects indicate that little change is occurring in the treated buildings following weatherization compared to the preweatherization effect.

The weatherization effect plus grand

effect for of the median polish and ANOVA are quite comparable: 23.1 therms for the median polish, and 27.5 therms for the ANOVA. The sum of the weatherization and grand effects for the median polish is 48 therms, a more conservative estimate than sum of the ANOVA weatherization and grand effects, which is -59.1 therms.
Table 16, Total Median Polish and Trimmed ANOVA Results, Madison Gas \& Electric Company

\begin{tabular}{|c||c|c||}
\hline $\begin{array}{c}\text { Weatherization } \\
\text { Effects }\end{array}$ & $\begin{array}{c}\text { Median } \\
\text { Polish }\end{array}$ & $\begin{array}{c}\text { Trimmed } \\
\text { ANOVA }\end{array}$ \\
\hline \hline Pre & 11.5 & 30.4 \\
\hline Weatherization & -59.6 & -56.2 \\
\hline Post I & 0.6 & 12.1 \\
\hline Post II & -4.5 & 6.5 \\
\hline Post III & 0.0 & 0 \\
\hline Year Effects & & \\
\hline $1987-88$ & -0.5 & 1.0 \\
\hline $1988-89$ & 8.1 & 10.5 \\
\hline $1989-90$ & 0.0 & 4.0 \\
\hline $1990-91$ & -13.5 & 0.0 \\
\hline \hline Grand Effect & 11.6 & -2.9 \\
\hline
\end{tabular}




\section{Gross and Net Energy Savings}

The results of the median polish runs were used to estimate composite changes in gross and net energy savings for the Madison Gas \& Electric Company participants. Figure 23 depicts the gross change energy savings for both treated and untreated buildings in the Madison Gas \& Electric Company program. The results are similar to the results for the Wisconsin Gas Company program, although the overall magnitude of savings is smaller.

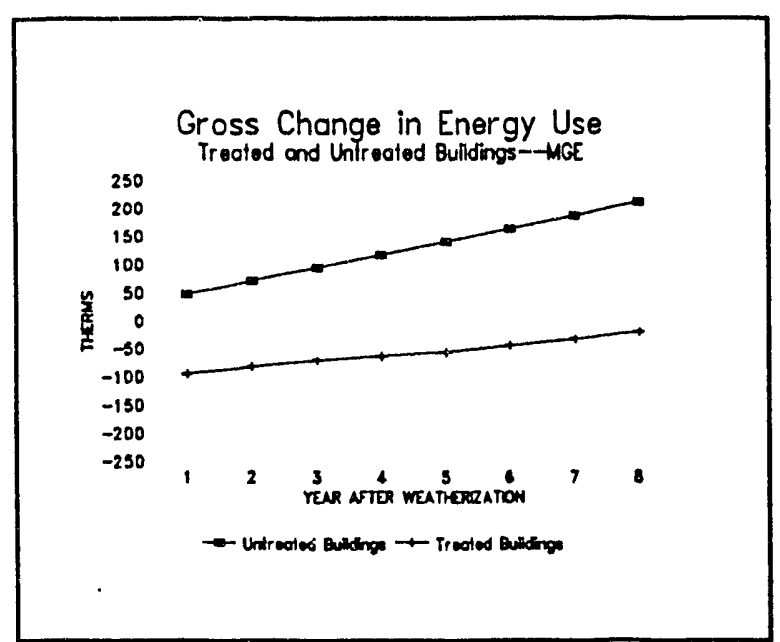

Figure 23

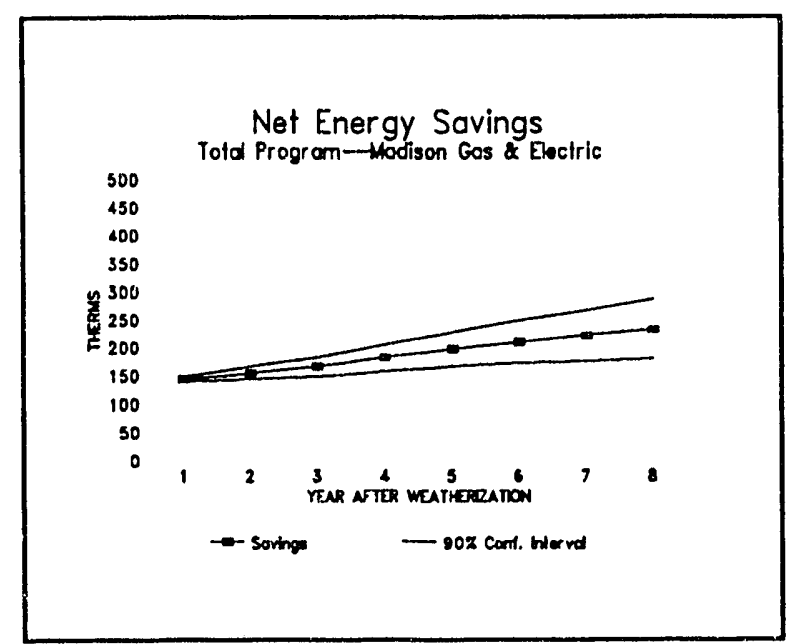

Figure 24

Figure 24 depicts the net change in energy savings for the total Madison Gas \& Electric Company program. As with the results for Wisconsin Gas Company, the net savings increase over time because of the greater increase in consumption for untreated buildings. First-year net savings of 142 therms represent 13 percent of median preretrofit NAC for all participants, which was 1,105 therms for 395 buildings from the 1988-90 participant cohorts; this figure is lower than first-year savings estimates calculated from buildings for which both first-year pre- and first-year post-weatherization consumption is available. As Table 17 indicates, Madison Gas \& Electric Company's overall program results indicate that net energy savings increase from Year 1 net savings of 142 therms to Year 8 net savings of 230 therms (a $62 \%$ increase). 
Table 17, Net Energy Savings, Median Polish and Trimmed ANOVA, Madison Gas \& Electric

\begin{tabular}{||c|c|c|c|c|c|c|c|c||}
\hline Year After & 1 & 2 & 3 & 4 & 5 & 6 & 7 & 8 \\
\hline Net Savings (therms) & 142 & 153 & 164 & 180 & 196 & 207 & 219 & 230 \\
\hline Upper Conf. (\%) & 147 & 164 & 181 & 204 & 227 & 245 & 264 & 283 \\
\hline Lower Conf. (90\%) & 138 & 142 & 146 & 156 & 165 & 169 & 174 & 178 \\
\hline Trimmed ANOVA & 173 & 192 & 210 & 234 & 258 & 288 & 319 & 349 \\
\hline
\end{tabular}

The resampling statistics were used to estimate the probability that net savings in Years 5 and 8 were greater than zero, and greater than Year 1 net savings:

\begin{tabular}{|c||c|c||}
\hline \multirow{2}{*}{$\begin{array}{c}\text { Probability That } \\
\text { Net Savings Are: }\end{array}$} & \multicolumn{2}{|c|}{ Probability (\%) } \\
\cline { 2 - 3 } & $\begin{array}{c}\text { Five Years After } \\
\text { Weatherization }\end{array}$ & $\begin{array}{c}\text { Eight Years After } \\
\text { Weatherization }\end{array}$ \\
\hline Greater Than Zero & $>99.5$ & $>99.5$ \\
\hline $\begin{array}{c}\text { Greater Than Year 1 } \\
\text { Net Savings }\end{array}$ & 98 & 99 \\
\hline \hline
\end{tabular}


Stability of Model Results

Figure 25 compares the total and trimmed group ANOVA runs with the total median polish results. As with the results for Wisconsin Gas Company, the higher preweatherization model coefficient from the ANOVA runs has produced greater first-year savings estimates, and also a greater increasing trend in net savings over time. As expected, the trimmed group ANOVA results

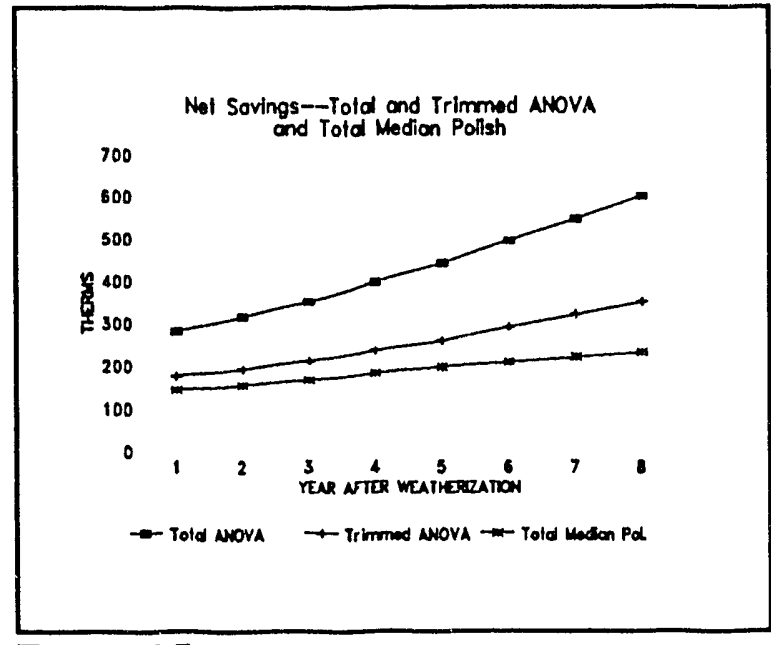

Figure 25 more closely mirror that of the total median polish group than does the total ANOVA. Appendix F presents comparisons of model-derived estimates and raw data estimates for both NAC and change in NAC from 1987 to 1991.

\section{Net Energy Savings by Measure Group}

Figure 26 represents the net energy savings for the total Madison Gas \& Electric Company program and for the shell, mechanical and both measure subgroups. The shell measure subgroup contains buildings that received both weatherization and insulation measures but no mechanical measures. The mechanical group contains buildings that received either a heating measure, water heater measure or clock

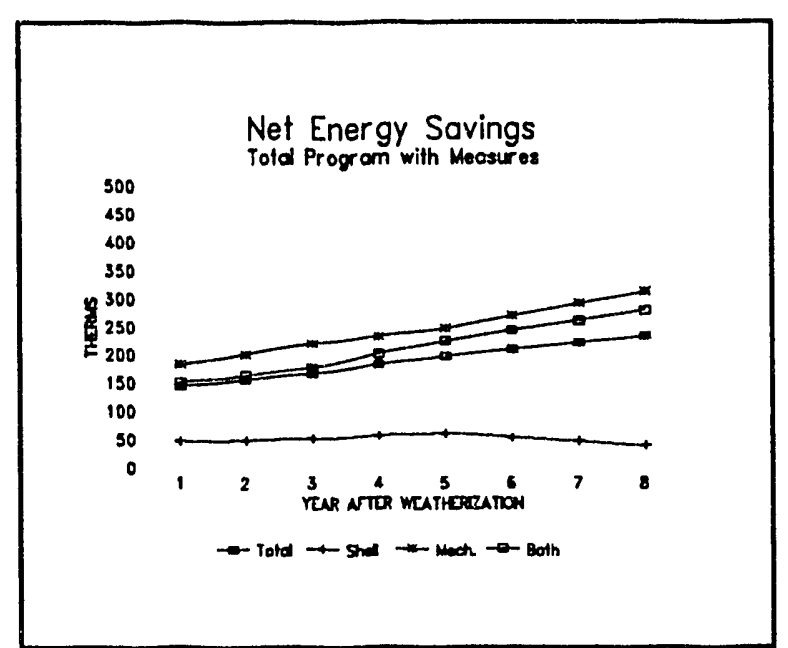

Figure 26 thermostat but no shell measures. The both measure category contains those buildings that received both shell and mechanical measures. 
Table 18, Net Energy Savings by Measure Group, Madison Gas \& Electric Company

\begin{tabular}{|c|c|c|c|c|c|c|c|c|}
\hline Year After & 1 & 2 & 3 & 4 & 5 & 6 & 7 & 8 \\
\hline \hline Shell & 44 & 46 & 48 & 53 & 58 & 51 & 44 & 37 \\
\hline Mechanical & 181 & 199 & 218 & 231 & 245 & 267 & 289 & 311 \\
\hline Both & 149 & 162 & 175 & 199 & 223 & 241 & 259 & 276 \\
\hline
\end{tabular}

No measure (shell, mechanical, or both) indicates a marked erosion of energy savings (see Table 18). Shell measures have the lowest level net savings, which appears to erode slightly in years 5-8. Mechanical measures indicate greater savings than the shell or both measure category. One factor that could influence the overall results is the greater proportion of "both" measure installations for 1983-85 participants; this may tend to influence Period III savings upward in comparison to Periods I and II insofar as the both measure category results show a greater increase over time in net savings than the other categories.

\section{Cost-Effectiveness Analysis}

A cost-effectiveness analysis was conducted for the total Madison Gas Company program results. Cumulative discounted savings (the sum of 8 years of discounted savings) and simple paybacks were calculated two ways: 1) based on first-year savings; and 2) based on savings 8 years after weatherization. For the cumulative discounted savings, a discount rate of 5 percent, a constant therm cost of $\$ .57$ were used. Eight-year simple payback and cost of conserved (CCE) energy estimates were calculated by taking the average of savings over eight years (undiscounted). The CCE calculation assumed a measure life of 15 years. As with the Wisconsin Gas Company cost-effectiveness analysis, measures of cost-effectiveness based solely on one year of savings estimates 
significantly undervalue the program when savings increase over time. ${ }^{31}$ Table 19 presents the results of this analysis.

Table 19, Cost-Effectiveness Analyses, First and First through Eighth Year Comparisons, Madison Gas \& Electric Company

\begin{tabular}{||c|c|c|c|}
\hline $\begin{array}{c}\text { Madison Gas \& Electric } \\
\text { Company, Installation } \\
\text { Cost }=\$ 1222^{\mathrm{a}}\end{array}$ & $\begin{array}{c}\text { Results Based on } \\
\text { First-Year } \\
\text { Savings } \\
(90 \% \mathrm{CI})\end{array}$ & $\begin{array}{c}\text { Results Based on } \\
\text { First through } \\
\text { Eighth Year } \\
\text { Savings }(90 \% \mathrm{CI})\end{array}$ & $\begin{array}{c}\text { Percentage } \\
\text { Difference Between } \\
\text { First and Eighth } \\
\text { Year Estimates }\end{array}$ \\
\hline $\begin{array}{c}\text { 8-Year Cumulative } \\
\text { Discounted Savings (\$) }\end{array}$ & $525( \pm 18)$ & $676( \pm 97)$ & 28.8 \\
\hline Simple Payback (years) & $15.1( \pm .5)$ & $11.5^{\mathrm{c}}( \pm 2.0)$ & -23.7 \\
\hline $\begin{array}{c}\text { Cost of Conserved Energy } \\
(\$ / M M B t u)\end{array}$ & $8.3( \pm .3)$ & $6.4^{\mathrm{c}}( \pm .9)$ & -22.4 \\
\hline
\end{tabular}

'This figure is based on a rough estimate (by Madison Gas \& Electric Company personnel) of average per-building installation costs plus $\$ 300$ estimated per-unit for program administration costs, adjusted to reflect per-unit installation costs. ${ }^{b}$ Cumulative Discounted Savings are based on the discounted yeariy dollar savings (5 percent discount rate, $\$ 57 /$ therm); for results based on first-year savings, net savings are assumed to stay the same over eight years.

Eight-year estimates of Simple Payback and Cost of Conserved Energy (CCE) are based on an average of first through eighth year savings. A measure life of 15 years is assumed for the CCE calculation.

$\mathrm{CI}=$ confidence interval.

${ }^{31}$ Cost-effectiveness estimates may be low owing to the underestimation of first-year energy savings calculation of the median polish model. 


\section{Subgroup Analysis--Madison Gas \& Electric}

In addition to the total program and measure net energy savings analyses, analyses were also conducted for two subgroups: 1) 1- and > 1-unit buildings; and 2) tenant and owner heatpayers. Figures 27 and 28 present the results of these analyses:

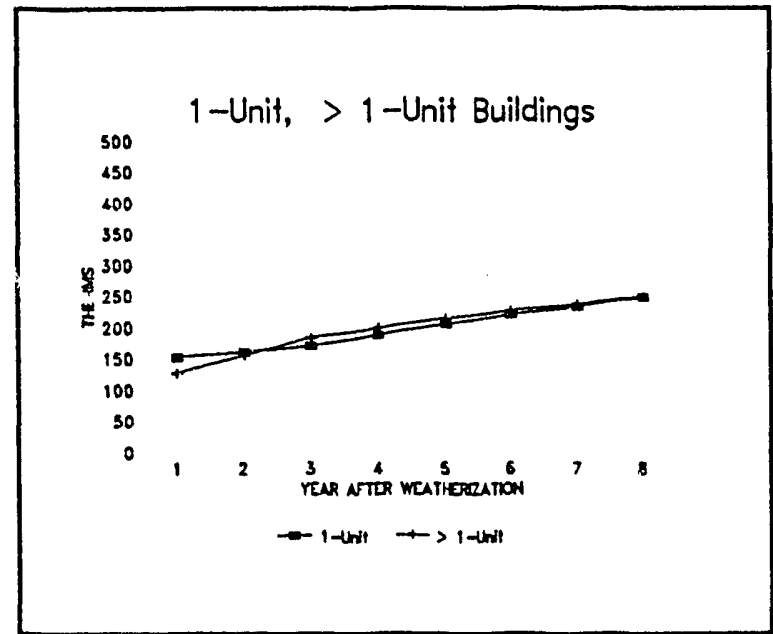

Figure 27, Net Energy Savings

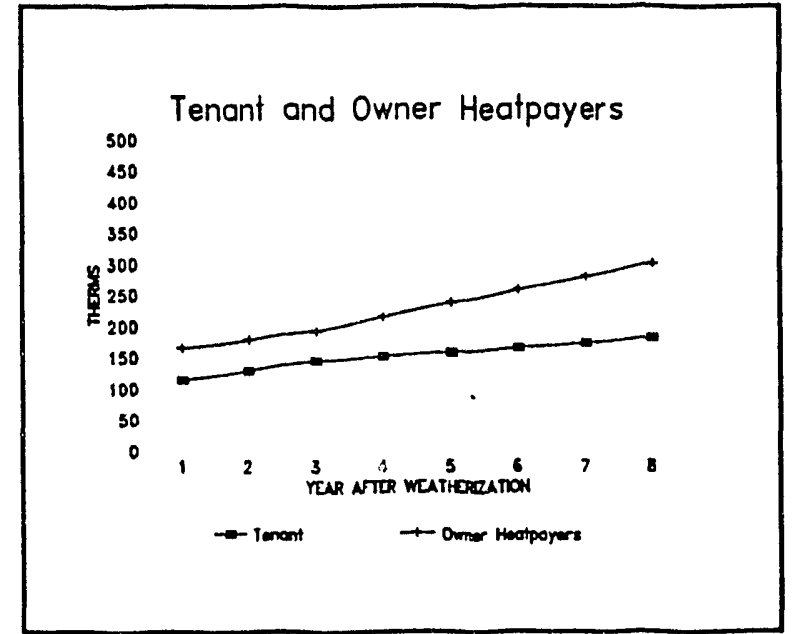

Figure 28, Net Energy Savings

The results of the subgroup analysis indicate little difference between 1-unit buildings and buildings with two or more units. The results for tenant and owner heatpayers indicate greater savings for owner heatpayers. The tenant/owner subgroup analysis is in contrast with the results for tenants and owners in the Wisconsin Gas Company program, which showed greater savings for tenant heatpayers. This difference is likely owing to the different nature of the housing stocks between the two utilities. 


\section{SNAPSHOT ANALYSIS}

In addition to the year-to-year persistence analysis, a "snapshot" analysis was conducted for two other Wisconsin utilities: Wisconsir Vatural Gas Company and Wisconsin Southern Gas Company. The data obtained from these utilities was the same data provided to the Public Service Commission of Wisconsin for the first evaluation of UWAP prog ams in Wisconsin in 1985. The utilities also provided recent consumption information for the buildings in the early evaluation sample.

A snapshot analysis essentially takes a picture of energy consumption at two different points in time, in this case 1984 and 1991. Consumption is weather-normalized for both years, and the average of the consumption figures for 1984 is compared to the average for 1991 (for the same group of buildings). The 1984 consumption figures are for the first year following weatherization; the 1991 consumption figures are for the eighth year after weatherization. No comparison group is used to help control for factors other than weatherization that might affect energy consumption.

Figures 29 and 30 depict the results of the snapshot analysis for the two utilities:

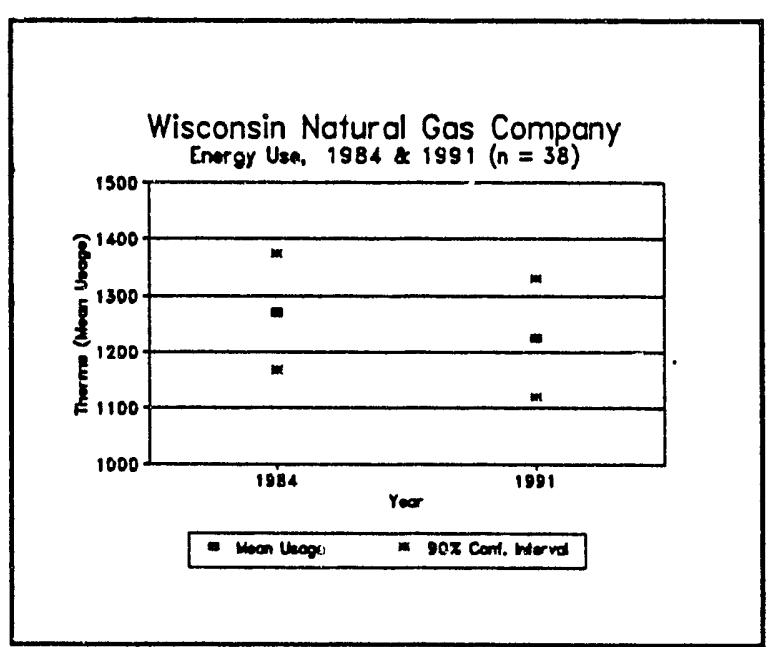

Figure 29

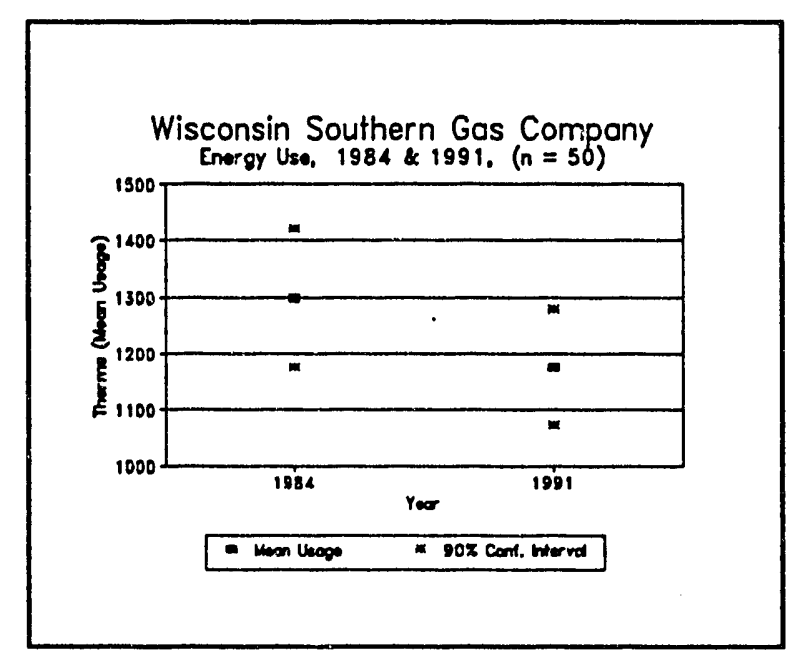

Figure 30 
Figure 31 depicts the change in energy consumption from 1984 to 1991 for the two utilities.

The results of the snapshot analysis for both utilities indicate a decrease in mean usage from 1984 to 1991 . These results are different from the results of for Wisconsin Gas Company and Madison Gas \& Electric Company, where gross energy consumption increased after weatherization (although the small sample sizes here make comparison difficult).

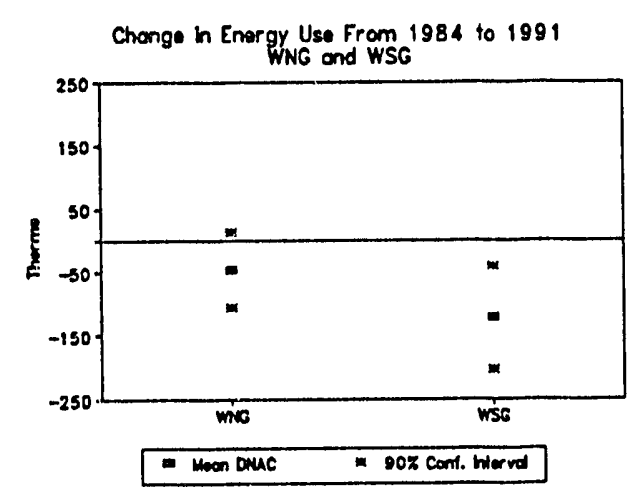

Figure 31 


\section{THE INCREASE IN CONSUMPTION}

The results indicate an increase in consumption over time for Wisconsin Gas Company and Madison Gas \& Electric Company in both treated and untreated buildings, though there is less of an increase in treated buildings. The increase affects treated and untreated buildings from both utilities.

The increase, while substantial for certain participant subgroups, is in line with increases in consumption for the average residential home in Wisconsin for various years in the period of analysis. On average, the largest absolute increase for a particular subgroup was with the Wisconsin Gas Company 1991 participants, who primarily serve as part of the comparison group in the analysis. Over a 5-year period (1986 to 1990), the median annual (weather-adjusted) consumption for these buildings went from 1519 therms to 1840 therms, an increase of 3.9 percent per year (approximately 64 therms per year). On the other hand, from 1987 to 1988, mean annual natural gas consumption for all Wisconsin residences increased from 992 therms to 1138 therms, a 14.7 percent increase. . $^{32}$

While the increase in consumption for particular program subgroups may be significant, an examination of the composite gross and net savings results may provide a more realistic picture of the actual trend in energy use for the buildings in the study. For Wisconsin Gas Company, the 8-year composite pictures for untreated and treated buildings showed increases of 204 therms and 104 therms, respectively. If we assume an average pre-weatherization NAC of 1600 therms for untreated buildings, then a 204 therm increase from Year 1 to Year 8 represents a 1.7 percent per year increase. Similarly, if we assume an average post-weatherization NAC of 1300 therms for treated buildings, then a 104 therm increase from Year 1 to Year 8 represents a 1.1 percent per year increase.

\footnotetext{
32"Wisconsin Energy Statistics--1991," Wisconsin Energy Bureau, 1991.
} 
There are a number of possible explanations for this rising trend in energy use, including: 1) decay in the quality of the housing stock (even for treated buildings); 2 ) the period of consumption may be an anomalous short-term trend in a different longterm trend of energy use; 3) changes in occupant characteristics; and 4) declining natural gas prices.

1. The generally poorer quality of low-income housing suggests that the energy efficiency of the buildings may decay over time, leading to increased energy usage. With the passage of time, all buildings (even those that have been treated) become less energy efficient. Mechanical systems become dirty and break down, insulation may settle or become damp, weatherstripping and caulking gradually lose their effectiveness, windows become broken, and so on. For low-income people, building maintenance may be financially burdensome or impractical, and rental tenants generally have little incentive to maintain or improve their dwelling. And while the decay in building energy efficiency is not eliminated through weatherization, any decay will affect consumption less because of the greater efficiency of energy use.

2. The time period of energy consumption we are viewing may be an anomalous short-term trend in a different long-term trend in energy use. Although the period of consumption that the study is considering indicates an increase in consumption over time for both treated and untreated buildings, this could be in part an artifact of the window through which we are viewing consumption. For example, a graph of 1970-90 residential natural gas consumption ${ }^{33}$ (see Figure 32 ) in Wisconsin shows generally declining per household consumption, but if one were studying the period $1987-89$, one could conclude that consumption was increasing.

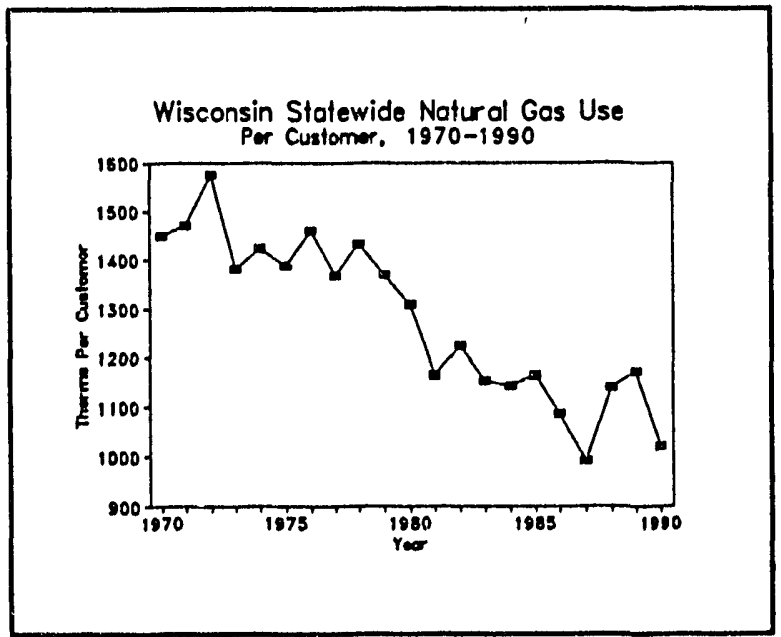

Figure 32 Without additional data on the longer-term trends in energy use for the buildings in the study, it is difficult to assess whether the period we are analyzing does represent such a short-term upward trend in energy use.

\footnotetext{
${ }^{33}$ Source: "Wisconsin Energy Statistics--1991," Wisconsin Energy Bureau, 1991. The buildings in the graph are not representative of the low-income populations in the siudy. The consumption figures are not normalized for yearly variations in weather.
} 
3. Changes in household characteristics and occupant behavior, such as changing economic status, a greater number of occupants, and/or different lifestyles can lead to increased energy usage. The study was not designed to discern the impact on the persistence of energy savings from changes in household characteristics and occupant behavior, yet these factors can significantly impact energy conservation over time. For example, data from the Wisconsin State Low Income Energy Assistance program (LIEAP) indicates an increase from 1989-91 in the median annual income of LIEAP participants. Higher incomes could be associated with increased energy usage. Given the limitations of the analysis, however, it is not possible to determine a correlation between household income and energy use. ${ }^{34}$ Another possibility is that average household size increased over the period of the analysis, leading to an increase in energy usage.

4. Declining energy prices over the period of analysis may have led to a price induced increase in energy consumption over time. Figure 33 represents the average price of natural gas for the residential sector in Wisconsin over the period 1970-90.35 As the figure shows, the real price of natural gas for Wisconsin residences has fallen 33 percent from 1983 to 1990 . This is a significant decrease, and could in part explain the increase in energy usage over the period of analysis.

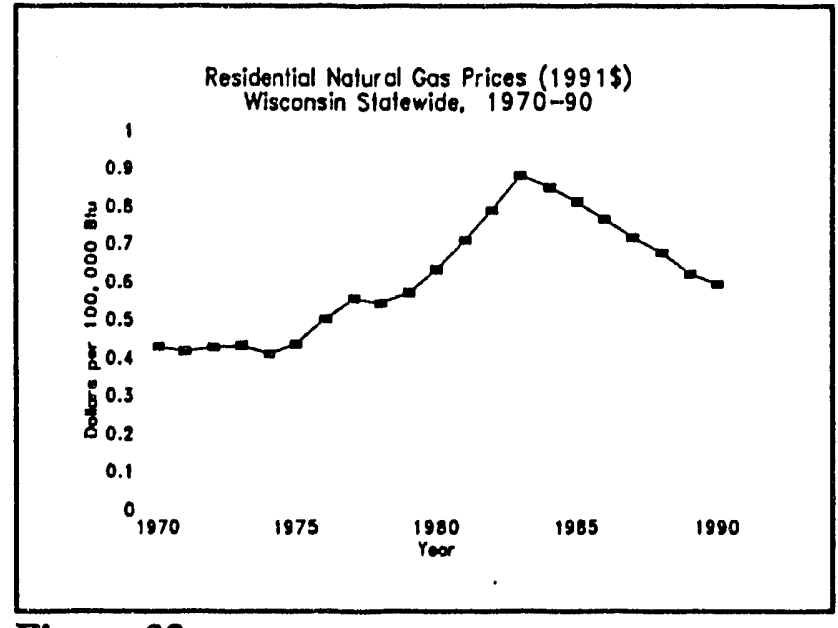

Figure 33

\footnotetext{
${ }^{34}$ LIEAP statistics were provided by Wisconsin Department of Health and Social Services personnel.

35Source: "Wisconsin Energy Statistics--1991," Wisconsin Energy Bureau, 1991.
} 


\section{CONCLUSIONS}

The following is a list of the major findings of the study:

1. First-year energy savings were 19 percent of pre-weatherization energy consumption for the Wisconsin Gas Company program, and 13 percent for the Madison Gas \& Electric Company program.

2. Overall, program savings did not erode over time. In fact, net savings increased over the time period studied.

3. There were differences in both the level and persistence of savings among subgroups within the programs.

4. Cost-effectiveness analyses based only on first-year savings underestimated costeffectiveness by about 15 percent.

These findings are discussed in greater detail below.

1. First-year energy savings were 19 percent of pre-weatherization energy consumption for the Wisconsin Gas Company program, and 13 percent for the Madison Gas \& Electric Company program. Weatherization resulted in a clear decrease in gas consumption between the years immediately before and after weatherization. For Wisconsin Gas Company participants, net first year energy savings were $343 \pm 25$ therms (at $90 \%$ confidence) per gas account, which represents a decrease in consumption of $19 \%$ when compared to the overall median gas consumption in the year before weatherization (1,801 therms). The Wisconsin Gas Company gas accounts studied largely represent single family homes and single dwelling units in 2-unit buildings.

For Madison Gas \& Electric Company participants, net first-year energy savings were $142 \pm 30$ therms (at $90 \%$ confidence) per gas account, or $13 \%$ of the median preweatherization gas consumption (1,088 therms). In comparison to first-year savings estimates derived from the consumption of participants for which we had both pre- and post-weatherization consumption information, the model appears to underestimate first- 
year savings by $15-20$ percent (though the trend in savings is unaffected). The Madison Gas \& Electric Company gas accounts mainly represented single family homes and individual dwelling units in 2- to 4-unit buildings.

These estimates provide insight into the level of savings for each utility compared to the median consumption of a group of buildings from each utility program. The higherusage buildings in the Wisconsin Gas Company program showed greater absolute savings than buildings in the Madison Gas \& Electric Company program. The higher level of percentage savings for Wisconsin Gas Company may be in part attributable to the nature of the low-income housing stock in each utility's service territory, with more savings potential existing for Wisconsin Gas Company's customers.

2. Overall, program savings did not erode over time. In fact, net savings increased over the time period studied. The overall results for the Wisconsin Gas Company indicate that net savings persist over time, increasing from Year 1 net savings of 343 therms to Year 8 net savings of 443 therms. Statistical analysis indicates a $99 \%$ probability that 5 th and 8th year savings are greater than savings in the year immediately following weatherization. On the other hand, analysis of subgroups within the Wisconsin Gas Company study group —and consideration of changes in the program over time- - suggest that there is more uncertainty in the magnitude of th? increase in net savirgs than the statistics indicate (see below). Regardless, it is clear that net program savius are not eroding over time. Almost all subgroups for the Wisconsin Gas Company program showed net energy savings that either remained stable or increased over the years.

The overall results for Madison Gas \& Electric Company's indicate that met energy savings persist over time, increasing from Year 1 net savings of 72 therns to Year 8 net savings of 230 therms. Statistical analysis indicates a $98 \%$ probasily that savings in the 5 th and 8 th year after weatherization are greater than first year scivings. As with the 
results for Wisconsin Gas Company, the statistical precision estimates do not account for biases caused by attrition or changes in the program over time.

In asking why net savings persisted, it may be useful to list some reasons why savings might not persist. The most obvious reason that savings might not persist is because the measure is removed or decays in some way: for example, disconnection of a setback thermostat, the settling of insulation, or a lack of mechanical system maintenance. Occupant characteristics and behavioral factors may also affect the persistence of energy savings: for example, changing occupancy patterns, a greater number of occupants, changing occupant work habits, or the "snapback" effect--all might result in a loss of weatherization effectiveness over time.

Although the study was not explicitly designed to examine any of the above threats to persistence, by showing that overall net energy savings persisted, it can be inferred that these threats did not lead to an erosion in net energy savings die to weatherization. While there may have been erosion in the effectiveness of weatherization for some of the study buildings or measures, the overall effect appears to have been minimal, and was negated by the increase in consumption for untreated buildings.

The question that arises is whether the control group of untreated buildings (later participants) is a good proxy for what would have happened in treated buildings had they not been weatherized. Later UWAP participants are likely to be a better comparison group than a random sample of residential buildings, primarily because they are similar customer types and have similar housing stocks. But if later participants differ from earlier participants, comparison-adjustment may misrepresent net savings. For Wisconsin Gas Company, a change in program focus in 1988 to focus on high arrearage customers could imply that later participants would use more energy than earlier customers (as high arrearage can be associated with high energy usage). An examination of preweatherization NAC and change in NAC for Wisconsin Gas Company 1987-91 
participants did not identify any statistcially significant differences. That the same trend is evident in the group of untreated buildings in the Madison Gas \& Electric Company sample tends to corroborate the reliability of the Wisconsin Gas Company comparison group.

Another question that could be asked is whether early participants (1983-5), which compose the savings trends in years 5-8, are similar to the later participants (1986-91). In 1983 and 1984, Wisconsin Gas Company participants had higher gas consumption than other post-weatherization cohorts. Though the level of gas consumption is higher for these early participants, changes in gas consumption over time appear to be in line with later participants. Nevertheless, these early participants who largely determine the savings trend 5-8 years after weatherization may be different from later participants in other unmeasured ways.

\section{Factors that Affect Net Savings}

The composite nature of the net energy savings results means that the estimates are affected by different ECM groups and participant cohorts at different periods of time. Heating system replacements became more common in the Wisconsin Gas Company program after 1986, and the frequency of shell-only jobs has decreased over the years. The Madison Gas \& Electric Company program has evolved to address both heating systems and shell measures more frequently than either measure alone in treated buildings. The net savings results should be viewed in light of these changes. Because of the lower level of net energy savings for shell measures, the effect on the Wisconsin Gas Company's results will be to understate net savings over time because of the overrepresentation of shell measures in years 5-8. Similarly, net savings will also likely be understated in years 5-8 for Madison Gas \& Electric Company because of the overrepresentation of shell measures in those years.

The study was based on gas accounts in single-family and 2-4 unit buildings. Most of the 
multi-unit gas accounts represent a single dwelling unit in a multi-unit building. This means that dwelling units in multi-unit buildings are under-represented in the study groups. This does not appear to affect the Madison Gas \& Electric Company program results, but probably causes the Wisconsin Gas Company program results to be understated somewhat.

3. There were differences in both the level and persistence of savings among subgroups within the programs. Analysis of subgroups of participants revealed some substantial differences in the level and persistence of energy savings. Subgroup analysis of Wisconsin Gas Company participants indicates that:

1) Buildings with higher pre-weatherization gas consumption had higher savings that tended to increase over time, while buildings with lower pre-weatherization gas consumption had lower savings that tended to erode over time. It can be expected that buildings that use more energy and have higher savings potential will be targeted with more ECMs, and buildings that consume less and have a lower potential for energy savings will be targeted with fewer ECMs.

2) Gas accounts from multi-unit buildings had higher savings than those from single family buildings. Tenants generally have less incentive to maintain building quality than owners. As a result, there may be greater savings in multiunit buildings because of their greater savings potential.

3) Combinations of shell and heating measures provided greater savings than either measure alone, and higher expenditures in buildings resulted in greater savings. None of the ECM subgroups indicated a significant erosion of energy savings over time. In fact, most showed an increase in net savings. Because buildings with greater savings potential (often the higher energy users) are targeted for more intensive weatherization, this result can be expected: more ECMs will (generally) provide more savings.

Subgroup analysis of Madison Gas \& Electric Company participants indicated tha:

1) Unlike the results for Wisconsin Gas Company, there were no differences between the savings and persistence of savings for gas accounts from multi-unit buildings versus those from single-family homes. The difference between the results for 
single- and multi-unit buildings for the two utilities is in part owing to a difference in the pre-weatherization energy use and energy efficiency of the rental housing stock in each utility's service territory. In general, the rental housing stock in Madison uses less energy and may have greater pre-weatherization energy efficiency.

2) Shell measures installed alone produced much lower savings than either mechanical measures alone or a combination of shell and mechanical measures. Because those buildings with less savings potential receive fewer ECMs (such as shell measures only), lower savings can be expected.

3) Buildings with owner heat payers tended to show greater energy savings than buildings with tenant heat payers. Again, this result is likely to be different from the results for Wisconsin Gas Company because of the different housing stocks in each utility.

These subgroup analyses represent exploratory results; in most cases the analyses did not attempt to analyze more than one variable at a time. For example, an analysis was conducted that compared tenants to owners, but not one that compared tenants who received shell measures to owners that received shell measures. A major problem with attempting to analyze too many variables is the possibility of attributing a certain level of energy savings to tenants, when in fact the savings are attributable more to the multi-unit building in which the tenants are living. In addition, too much disaggregation of the subgroups would have resulted in sample sizes too small to produce reliable savings estimates.

\section{Cost-effectiveness analyses based only on first-year savings underestimated cost-} effectiveness by about 15 percent. The effects of the persistence of savings results on a cost-effectiveness analysis of both utility programs indicates that analyses based solely on first-year post-weatherization savings estimates undervalue the program effects when net savings increase over time. Caution may thus be warranted in basing estimates of program cost-effectiveness on only one year of energy savings data or on engineering estimates of program savings. 
Summary

The results of the study indicate that energy savings from weatherization did not erode over time; in fact, net energy savings increased over the period of analysis for both Wisconsin Gas Company and Madison Gas \& Electric Company. Two points were especially important in reaching this conclusion:

- the small post-weatherization effects (no change or slight increase in consumption), relative to the weatherization effects (large decreases in consumption) for both utilities; and

- The similarity in energy savings trends between the two utilities.

The model produced weatherization effects for both utilities that showed a large decrease in consumption during weatherization, and very little change afterwards, indicating that weatherization-induced changes in energy consumption are largely stable after weatherization. The third post-weatherization period (5-8 years after weatherization) indicated a smaller year-to-year change in energy use for treeated buildings than for untreated buildings.

Secondly, the similarity between the results for the two utilities suggests that the increase in consumption in both treated and untreated buildings is not peculiar to a particular customer group or utility program, but rather is reflective of broader changes in customer behavior and building energy efficiency not associated with participation in a weatherization program. 


\section{List of Appendices:}

A: Representativeness Analysis

B: Bootstrap Resampling

C: Normalization Statistics

D: ECM and Demographic Data

E. Median Polish Statistics

F: Summary NAC and NAC Change Graphs 
APPENDIX A 


\section{APPENDIX A-- Representativeness Analysis}

\section{PURPOSE}

The purpose of this appendix is to assess how well study groups represent the total population of program participants. Because the final study groups for Wisconsin Gas Company and Madison Gas \& Electric Company were not chosen randomly from the program populations, but instead were the result of various attrition processess, it is important to assess whether the buildings that were used in the analyses adequately represent the populations from which they were drawn.

\section{METHOD}

The only way to make the above assessment is to compare quantities for which data are available for both the study groups and the populations from which they were obtained. This means that the analysis must be confined to information that is contained in the program databases; accordingly, an analysis was made of several key parameters from the Wisconsin Gas Company and Madison Gas \& Electric Company program databases. The purpose was to assess how the measured characteristics of each study group compare to its overall population, and whether the study groups can be considered to be a random sample of participants.

To assess whether the attrition that occured from the overall population of program participants can be considered to be random, simple Monte Carlo tests were performed on a number of parameters contained in the program databases. ${ }^{1}$ The best way to explain the purpose and method behind a Monte Carlo test is with an example.

Suppose that the average number of dwelling units is 1.6 for a hypothetical study group of 1,000 buildings, while the the program database indicates that the same statistic is 1.4 for the 10,000 buildings in the population. Thus the study group buildings tend to be larger than the general population of participants. The question that arises immediately is whether a deviation of $1.6-1.4=0.2$ is an unusual event for a sample of

\footnotetext{
${ }^{1}$ See Eric W. Noreen, Computer-Intensive Methods for Testing Hypotheses, New York: Wiley, 1989.
} 
1,000 buildings in a population of 10,000 . If random samples of 1,000 buildings often show at least as large a deviation as this, then the difference found for the study group is not a cause for concern. On the other hand, if a difference of this magnitude is a very rare occurence under random sampling, then some other non-random process is probably at work, and the study group may not be representative of the general population.

Monte Carlo tests address this question directly by simply drawing repeated random samples of the same size as the study group, and counting the frequency with which the sample statistic deviates from the population statistic by a given amount or more. To continue the example, suppose one draws 100 random samples of 1,000 buildings from the population of 10,000 buildings, and finds that in 40 of these samples, the average number of dwelling units is 1.6 or more. This means that there is a probability ${ }^{2}$ of about $40 / 100=0.4$ of obtaining a sample average dwelling units of 1.6 or more, and the study group average is therefore not unusual. On the other hand, suppose 100 random samples from the population yield only one sample with an average dwelling units of 1.6 or more. In this case, the probability of obtaining the result found for the study group is very small, and it is therefore much more likely that some non-random process eliminated smaller buildings from the group.

The Monte Carlo tests work by repeatedly drawing random samples (without replacement) of the same size as the study group from the program population, and assessing the probability, ${ }^{3} p$, that a difference at least as large as that of the study group would nccur randomly. The smaller the $p$ level, the less likely it is that any difference between the study group and the population is the result of random processes, and the more likely it is that some systematic process has biased the study group.

The Monte Carlo tests presented below were calculated based on 400 random samples from the program database for Wisconsin Gas Company and 200 random samples from Madison Gas \& Electric Company.

\footnotetext{
${ }^{2}$ Technically, the correct procedure (and the procedure followed for the analyses in this appendix) is to add 1 to the numerator and the denominator: hence, $(40+1) /(100+1)=0.406$.

${ }^{3}$ Note this is a one-sided probability. One is assessing the probability of obtaining a given magnitude of deviation, and in the same direction.
} 


\section{Wisconsin Gas Company}

A number of characteristics that represent the type of buildings and participants in the Wisconsin Gas Company program were available from the program database. Table A-I shows the population and study group mean values for these characteristics, along with the $p$ values from the Monte Carlo tests.

Overall, the results show that the study group differs only slightly from the general population in most respects. In particular, for the variables that are most likely to affect gas usage and weatherization savings, the analysis indicates that the study group:

- had slightly higher spending on weatherization;

- had slightly lower pre-participation gas usage;

- had fewer 1-unit buildings and more 2-unit buildings; and,

- had slightly more buildings with the owner on premise.

All of these differences are associated with very low $p$ values. This means it is extremely unlikely that the differences that exist between the the study group and the population are a random effect, and much more likely that some systematic attrition occurred.

\section{Madison Gas and Electric}

The population for the Madison Gas \& Electric Company program is defined here to be all participants in 1- to 4-unit buildings; these constitute $71 \%$ of the 2,987 total buildings in the program databases, or 2,124 buildings in all. (The Madison Gas \& Electric Company database contains a number of larger multifamily buildings that were not a part of this study.)

As with the Wisconsin Gas Company program, there are small but statistically significant differences between the study group and the program population for the characteristics available from the program database. Table A-II compares the distribution of dwelling units, building tenure, and building volume between the 2,124 total buildings in the program and the 1,553 buildings in the study group. The study group has a slightly higher proportion of 1-unit buildings, and a slightly lower proportion of 4-unit buildings than the overall population. The study group also contains slightly 
more renters and fewer owners than the overall population. Finally, the average volume for buildings in the study group is about $2 \%$ larger than that of the overall program population. Though the differences are small, they are all highly significant, given the high sampling fraction of the study group.

\section{CONCLUSIONS}

In general, the study groups reasonably approximate the populations from which they were taken. They cannot, however, be considered to be random samples of these populations. The attrition processes that eliminated buildings from the study groups apparently created small but statistically significant biases in the study groups.

The main ramification of these differences is to create uncertainty about the applicability of the results to the full program populations. The results of the subgroup analyses suggest that the basic conclusion that the savings from weatherization do persist is not threatened by the small biases that exist in the study groups.

Taking dwelling units for Wisconsin Gas Company participants as an example, the subgroup analysis shows that net savings for 1-unit buildings is 295 therms in the first year after weatherization. Two-unit buildings show first year savings of 444 therms. Since the study group comprises 43 percent 1-unit buildings and 52 percent 2-unit buildings, the overall results can be approximated as $295 *(47 / 95)+444 *(52 / 95)=$ 389 therms (which compares favorably with the actual overall result of 343 therms). ${ }^{4}$ How much difference does it make that in the overall program population the proportions of 1- and 2-unit buildings are slightly different: 47 percent and 48 percent, respectively? This can be estimated by simply reweighting the 1- and 2-unit subgroup results; $295^{*}(47 / 95)+444^{*}(48 / 95)=370$ therms. Thus, the population result is 389 $-370=19$ therms less than the study group results. A similar analysis using eighth year savings instead of first year savings gives comparable results. The difference in the results due to different proportions is about the same size as the confidence interval for first year savings, but is much smaller than the confidence band for savings in later years. This suggests that the differences between the study groups and their program

${ }^{4}$ Neglecting 3- and 4-unit buildings, which consitute less than $5 \%$ of the study group and the population. 
populations may invalidate the narrow confidence intervals for early post-weatherization savings, but are probably insignificant compared to the inherent uncertainty in results for later years. 
Table A-I, Population and study group characteristics from the WGC program database.

\begin{tabular}{|c|c|c|c|c|c|}
\hline & POPULATION & $\begin{array}{l}\text { STUDY } \\
\text { GROUP } \\
\end{array}$ & \multirow[t]{2}{*}{$\mathbf{p}^{n}$} & \multirow{2}{*}{$\begin{array}{c}\text { PERCENT OF } \\
\text { POPULATION } \\
\text { CONTAINING } \\
\text { DATA }\end{array}$} \\
\hline & & $\mathbf{n}=9956$ & $\mathbf{n}=5129$ & & \\
\hline \multicolumn{2}{|c|}{ Wx spending (mean \$) } & 2485 & 2595 & 0.002 & $89.0 \%$ \\
\hline \multicolumn{2}{|c|}{$\begin{array}{l}\text { base gas usage (mean } \\
\text { therms/day) }\end{array}$} & 1.25 & 1.22 & 0.007 & $60.5 \%$ \\
\hline \multicolumn{2}{|c|}{$\begin{array}{l}\text { heat factor (mean } \\
\text { therms/degree day) }\end{array}$} & 0.224 & 0.220 & 0.005 & $60.0 \%$ \\
\hline \multicolumn{2}{|c|}{ family size (mean) } & 3.46 & 3.40 & 0.025 & $35.5 \%$ \\
\hline \multicolumn{2}{|c|}{ monthly income (mean \$) } & 69: & 668 & 0.002 & $35.1 \%$ \\
\hline \multirow{6}{*}{$\begin{array}{l}\text { number of } \\
\text { dwelling } \\
\text { units (\%) }\end{array}$} & 1 & 47.0 & 43.4 & 0.002 & \multirow[t]{6}{*}{$99.9 \%$} \\
\hline & 2 & 48.4 & 51.7 & 0.002 & \\
\hline & 3 & 2.1 & 2.3 & 0.055 & \\
\hline & 4 & 2.5 & 2.6 & 0.372 & \\
\hline & unknown & 0.1 & 0.1 & 0.456 & \\
\hline & mean & 1.60 & 1.64 & 0.002 & \\
\hline \multirow{3}{*}{$\begin{array}{l}\text { who pays the } \\
\text { heat? }(\%)\end{array}$} & owner & 23.9 & 25.1 & 0.007 & \multirow[t]{3}{*}{$73.1 \%$} \\
\hline & tenant & 49.2 & 54.3 & 0.002 & \\
\hline & unknown & 26.9 & 20.7 & 0.002 & \\
\hline \multirow{3}{*}{$\begin{array}{l}\text { owner on } \\
\text { premise? } \\
\text { (\%) }\end{array}$} & no & 51.1 & 54.0 & 0.002 & \multirow[t]{3}{*}{$99.8 \%$} \\
\hline & yes & 48.7 & 45.8 & 0.002 & \\
\hline & unknown & 0.2 & 0.2 & 0.479 & \\
\hline
\end{tabular}

"Probability of obtaining a one-sided deviation from population that is at least as large as the study group (based on 400 Monte Carlo samples). 
Table A-II, Population and study group characteristics from MG\&E program database.

\begin{tabular}{|c|c|c|c|c|}
\hline & & POPULATION & STUDY GROUP & $\boldsymbol{p}^{\boldsymbol{e}}$ \\
\hline & & $\mathrm{n}=2124$ & $\mathrm{n}=1553$ & \\
\hline \multirow[t]{5}{*}{ Dwellieg Units (\%) } & 1 & 67.7 & 71.1 & 0.005 \\
\hline & 2 & 17.9 & 18.5 & 0.134 \\
\hline & 3 & 3.1 & 2.7 & 0.045 \\
\hline & 4 & 11.3 & 7.7 & 0.005 \\
\hline & average & 1.58 & 1.47 & 0.005 \\
\hline \multirow[t]{4}{*}{ Building Tenure (\%) } & renter & 49.9 & 46.0 & 0.005 \\
\hline & owner & 48.7 & 52.4 & 0.005 \\
\hline & $\begin{array}{l}\text { rentai, } \\
\text { owner } \\
\text { occupied }\end{array}$ & 1.1 & 1.2 & 0.194 \\
\hline & unknown & 0.3 & 0.3 & 0.587 \\
\hline $\begin{array}{l}\text { Building Volume } \\
\text { (mean } \mathrm{ft}^{3} \text { ) }\end{array}$ & & 9195 & 9413 & 0.005 \\
\hline
\end{tabular}

'Probability of obtaining a one-sided deviation from population that is at least as big as the study group (based on 200 Monte Cario samples). 
APPENDIX B 


\section{APPENDIX B--Bootstrap Resampling}

This appendix details the bootstrap resampling procedure used to estimate confidence bands for the median polish model. ${ }^{1}$ Confidence bands are intended to define sampling uncertainty. If one is interested in assessing a population characteristic from a sample, sampling uncertainty is always present; repeated samples from a population will yield somewhat different answers for whatever characteristic one is studying. If one could extract repeated samples, a pattern would emerge in which the sample results clustered around the true population result.

However, actually drawing repeated samples is seldom feasible. Instead, one normally relies on statistical theory to estimate the sampling distribution of the statistic of interest. The sampling uncertainty for a mean can be estimated from the sample standard deviation and the sample size, for example. The theory and practice of estimating sampling distribution is well-founded for more traditional statistics such as a mean or least squares regression, but less well established for procedures such as the median polish, which is more commonly used as an exploratory rather than confirmatory procedure.

To estimate the uncertainty in the median polish results, a method was chosen that substitutes brute computation for theoretical statistical elegance. The method is known as bootstrap resampling. Simply stated, bootstrap resampling simulates the process of drawing repeated samples from a population. By looking at the variability in results from sample to sample, one can estimate the sampling uncertainty.

To simulate drawing successive sample from a population, one needs a population. The "bootstrap" part of the procedure's name arises because the sample itself is used as a miniature version of the population. The assumption that the sample can be used in this way is a critical one, which will be discussed later in this appendix.

Before explaining how bootstrap resampling was used with the median polish model for this study, a demonstration of how it works in a simpler context is helpful. Suppose

\footnotetext{
'The bootstrap procedure used in this study was adapted froin Eric W. Noreen, Computer Intensive Methods for Testing Hypotheses, John Wiley \& Sons, 1989. A more detailed analysis and description of the bootstrap procedure can be found in B. Efron and R. Tibshirani, "Bootsirap Methods for Standard Errors, Confidence Intervals, and Other Measures of Statistical Accuracy," Statistical Science, 1984, No. 1, pp. 54-77.
} 
one has a sample of 100 buildings from a larger population, and that the sample has a median NAC of 1,000 therms. To find the confidence interval of this statistic using bootstrap resampling, one would use the following procedure:

1) Randomly draw 100 buildings with replacement from the pool of 100 buildings in the original sample. That is, each time a building is drawn, every building has an equal chance of being selected, and, over 100 draws, a building can be selected more than once.

2) Compute the median NAC of the 100 buildings selected in (1).

3) Repeat (1) and (2) a given number of times, say 200. Each repeat is a resample.

4) Assess the sampling variation in the statistic (median NAC) by computing the standard deviation of median NAC over all resamples. ${ }^{2}$

5) Use the appropriate $t$ - or $z$-statistic (based on degrees of freedom from the original sample size) to compute the confidence interval for median NAC.

A critical elemert of the procedure is the sampling with replacement that occurs in the first step. The reson sampling is done with replacement is that each data point in the original sample re resents a class of data points in the larger population. Moreover, if sampling were performed without replacement, each resample would merely recreate the original sample, and there would be no sampling variation.

To perform boostrap resampling for the model a similar procedure was used:

1) A random sample (with replacement) was drawn for each participation year. The size of the sample is equal to the total number of buildings available for that participation year.

2) Using the resample from (1) a median polish was performed, and the coefficients were used to calculate the composite 8-year gross and net savings estimate.

3) (1) and (2) were repeated 200 times.

4) The standard deviation was calculated for each of the median polish coefficients and for each year of the composite savings estimates.

5) The confidence interval for the coefficients and the composite savings estimates

${ }^{2}$ Note that this version of the procedure just uses bootstrap resampling to estimate the sampling standard deviation, and assumes that under the Central Limit theorem, the sampling distribution is Gaussian. Analysis of the median polish results indicates that this assumption is reasonable. 
was calculated at a $90 \%$ confidence interval by multiplying each coefficient by a $z$ statistic of 1.645 .

6) In addition, hypothesis tests were performed to test whether fifth and eighth year net composite savings were greater than zero or greater than first year savings. This was done by assessing the frequency with which fifth and eighth year net savings exceeded zero, and the frequency with which these quantities execeeded first year savings among the 200 resamples. For example if fifth year net savings exceeded first year net savings in $\mathbf{5 0}$ out of 200 resamples, the probability that fifth year savings exceeds first year savings in the population was calculated as $(50+1) /(200+1)=25.4 \%$ (one is added to both the numerator and the denominator to ensure that the test is valid at the stated probability level).

One of the major strengths of bootstrap resampling is that confidence intervals can be constructed for very complicated statistics without having to make assumptions about distributions, error structures, correlation, or other worrisome quantities. This is evident in the ability to construct confidence intervals for the composite savings estimates, which are secondary calculations based on combining coeficients from the median polish model. The resampling procedure also makes the simultaneous hypothesis tests of whether fifth and eighth year savings exceed first year savings easy to compute. In practice, one can assess any statistic, no matter how complicated, with bootstrap resampling, simply by computing the statistic for each resample, and analysing its varition from resample to resample.

However, bootstrapping does not work magic, nor does it create information where there is none. Noreen ${ }^{3}$ tested bootstrap resampling against the conventional $t$-test for estimating the confidence interval of sample means, and found that at best the bootstrap achieved about the same performance as a $t$-test. For small samples from non-normal populations, the bootstrap procedure faired much worse than the $t$-test, which is fairly robust in practice. In general, it appears that the procedure is most appropriate when sample sizes are large, and when a conventional method of assessing statistical confidence intervals does not exist. Both of these conditions are true for the data and methods used in this study.

In part because this procedure was novel to us, we tested the procedure using a

\footnotetext{
${ }^{3}$ Op. cit. Note 2.
} 
hypothetical population of buildings that closely mimic those of the WGC participant population. We specified an infinite population of buildings with Normally distributed NAC levels in $1982,{ }^{4}$ and then allowed the NAC levels to randomly "walk" through the years 1983 through 1991. The rule for the random walk was that NAC in Year $i+1$ was equal to NAC in Year $i$ plus some (Normally distributed) random variation with a mean of zero and a standard deviation equal to $10 \%$ of $\mathrm{NAC}_{\mathrm{i}}$. In other words, between one year and the next, about two-thirds of the buildings can be expected to be within $\pm 10 \%$ of their consumption in the previous year, and about $95 \%$ can be expected to be within $\pm 20 \%$. The main assumption behind this rule is that the absolute variability in consumption is proportional to the NAC level, a result that we have found to be generally true among residential buildings. Figure B-I shows six of these hypothetical consumption histories.

The important thing to remember abous ihis hypothetical population is that the data represent pure noise from the standpoint of assessing year and weatherization effects: houses go up and down in consumption from year to year, but there is no overall weatherization effect, nor is there any calendar year effect across buildings. Thus, the true population resuli for all of the median polish coefficients and net savings estimates is zero, though individual samples of buildings can be expected to vary from this overall result. If the $(90 \%)$ confidence intervals calculated from the bootstrap resampling procedure are correct, then under repeated sampling of the population, 9 out of 10 confidence

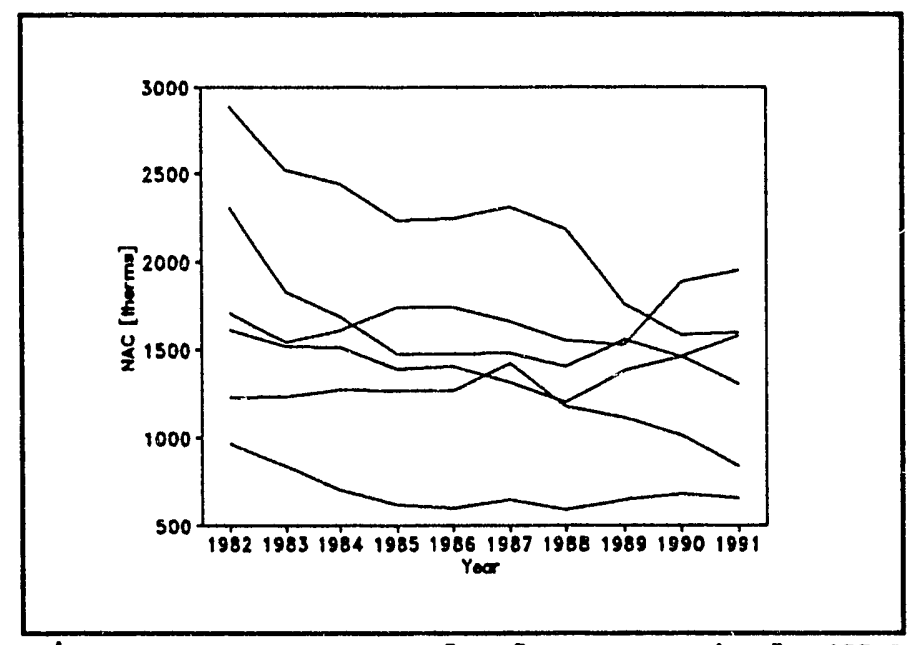
Figure B-I, Randomly created NAC histories over the period from 1982 through 1991 for six buildings. intervals should contain the true population result (zero). Note that this is just another

${ }^{4}$ The distribution was actually a truncated Normal distribution, with a mean of 1800 therms, a standard deviation of 500 therms, and absolute limits of 500 therms and 5000 therms. 
way of stating the fact that for any one sample there is a $90 \%$ chance that the confidence bands span the true result.

To test whether the confidence interva' are in fact correct for this population, 50 samples were drawn from the hypothetical infinite population. Each sample had 100 buildings in each of the nine participation years (1983 through 1991), for a total of 900 buildings in each sampie. The median polish and composite savings analysis was performed on each sample, and the bootstrap resampling procedure was used to estimate the confidence interval for the sample median polish coefficients, and the composite savings estimates. As with the bootstrap procedure used in the study itself, 200 resamples were periormed for each sample.

Figure B-II shows the composite net savings for the 50 random samples. As expected, the results for individual samples do cluster around the population characteristic of zero savings for all years. Also, as expected, there is more scatter in the results in later years compared to early years. First year savings estimates have a range of only about \pm 40 therms, but eighth year savings have a range that is about \pm 125 therms. This is a result of adding median polish coefficients to get later postweatherization savings estimates; estimates that are the sum of other estimates each with its own uncertainty are subject to more variability.

The key question, however, is whether the bootstrap confidence intervals correctly assess the sampling uncertainty. Table B-I shows the percent of the 50 samples for which the bootstrap confidence interval includes the true median polish coeffcicient or net savings estimate of zero. The percentages for the variables are around $90 \%$, which

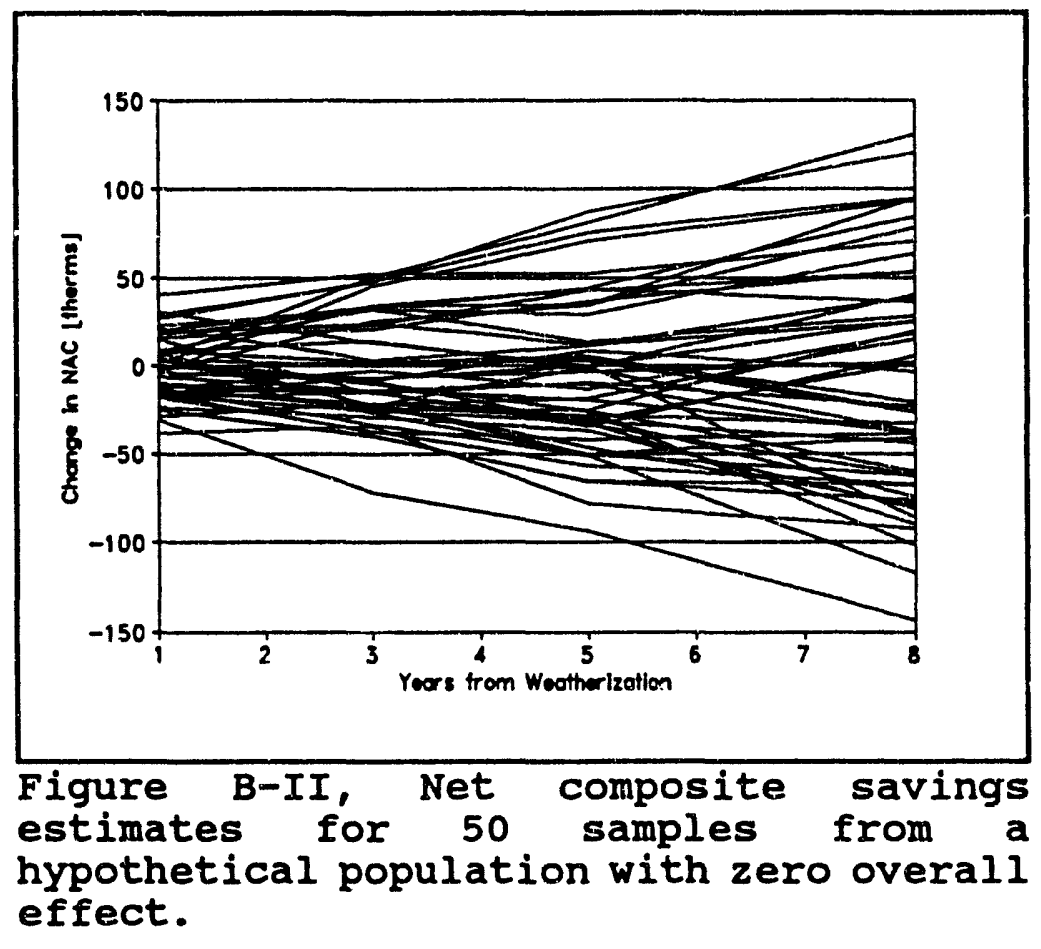


indicates that

bootstrap resampling does provide reliable confidence intervals in this case.

One might argue about whether a random walk is the proper error structure to apply to a population of buildings (an alternative might be random variation about a fixed mean). Nevertheless, it appears that the boostrap procedure is doing its job reasonably well for hypothetical buildings that are similar to the ones encountered in the study.

One point remains to be discussed about the validity of confidence intervals from the bootstrap procedure. As with all confidence interval estimation procedures, the bootstrap estimates are predicated on the assumption that the sample in hand was
Table B-I, Percent of 50 samples in which the bootstrap confidence intervals enclose the true population effect (zero). If the procedure is correct, the percentage should be about $90 \%$.

\begin{tabular}{|c|c|c|c|}
\hline \multicolumn{3}{|c|}{$\begin{array}{c}\text { Median Polish Coefincient or Net Composite } \\
\text { Savings Estimate }\end{array}$} & $\begin{array}{l}\text { Percent of } \\
\text { Confidence } \\
\text { Intervals that }\end{array}$ \\
\hline \multirow{11}{*}{$\begin{array}{l}\text { Median Polish } \\
\text { Coefficients }\end{array}$} & \multicolumn{2}{|l|}{ pre Wx effects } & $95 \%$ \\
\hline & \multicolumn{2}{|l|}{ Wx effects } & $93 \%$ \\
\hline & \multirow{3}{*}{$\begin{array}{l}\text { post Wx } \\
\text { effects }\end{array}$} & 1 & $90 \%$ \\
\hline & & 2 & $98 \%$ \\
\hline & & 3 & $90 \%$ \\
\hline & \multirow[t]{5}{*}{ year effects } & 1 & $95 \%$ \\
\hline & & 2 & $93 \%$ \\
\hline & & 3 & $95 \%$ \\
\hline & & 4 & $98 \%$ \\
\hline & & 5 & $85 \%$ \\
\hline & \multicolumn{2}{|l|}{ grand effect } & $95 \%$ \\
\hline \multirow{8}{*}{$\begin{array}{l}\text { Net } \\
\text { Composite } \\
\text { Savings } \\
\text { Estimates }\end{array}$} & \multirow[t]{8}{*}{ years from $W x$} & 1 & $93 \%$ \\
\hline & & 2 & $95 \%$ \\
\hline & & 3 & $93 \%$ \\
\hline & & 4 & $93 \%$ \\
\hline & & 5 & $93 \%$ \\
\hline & & 6 & $93 \%$ \\
\hline & & 7 & $93 \%$ \\
\hline & & 8 & $93 \%$ \\
\hline
\end{tabular}

Based on 50 samples with confidence intervals calculated for 200 resamples for each sample. 
randomly drawn from the population. Confidence intervals only deal with sampling uncertainty; they do not account for any systematic differences (bias) that might exist between a sample and the population from which it was taken.

Buildings used for this study were not selected by random sampling of the population, however. Instead, an attempt was made to study all buildings in the program populations, but various sources of attrition resulted in final study groups that included less than the full population.

Can the study groups be considered to be samples of the program populations? In Appendix A, an analysis was conducted of how well the study groups represent the populations from which they were drawn. The analysis shows that while the study groups differ only slightly from the program populations for the characteristics that could be measured, the differences are unlikely to occur randomly. This means that the study groups are biased in these characteristics (and perhaps other unmeasured ways) relative to the population. This bias does not seem to be large, but it is not accounted for by the bootstrap (or any other) confidence estimation procedure.

Bias only becomes a problem if it is large relative to the sampling confidence intervals calculated. So far as can be determined from the available data, this does not appear to be the case for this study, except for the net savings results for the first few years after weatherization. The confidence band for the early post-weatherization savings is very tight, in part because it is based on thousands of buildings for which early post-weatherization data are available during the six-year period for which consumption histories were available. In this case, the bootstrap confidence interval probably underestimates the size of the interval in which the true (program-wide) results lie. The net savings estimates for later years have much wider confidence bands, because they are based on fewer data and because they are calculated as sums of median polish coefficients. The degree of bias in the study groups is likely to be insignificant for these results.

Moreover, it is unlikely that eliminating the small degree of bias that exists in the study groups would negate the primary conclusions of the study; that significant savings occur in these programs, and that these savings are relatively stable over time. Overall, it appears that the boostrap procedure is a reasonable one to employ in this situation. 


\section{APPENDIX C}




\begin{tabular}{|c|c|c|c|c|c|c|c|c|c|c|}
\hline SUMOMAR & WEATHER-N & NORMALIZATI & STATISTI & SS-WISC & ISN G & $S C O M$ & & & & \\
\hline Part.Yr. & Cons.Yr. & Statistic & n Reads & Days & NAC & NAHC & Baseload & Slope & Ref.Temp & R-Sqrd. \\
\hline 1983 & 1986 & $\mathrm{n}$ & 73.0 & & & & & & & \\
\hline 1983 & 1986 & median & 8.0 & 448 & 1442 & 1047 & 397 & 0.20 & 58.5 & 0.99 \\
\hline 1983 & 1986 & mean & 8.0 & 427 & 1548 & 1088 & 460 & 0.21 & 57.4 & 0.96 \\
\hline 1983 & 1986 & trimmed mean & 7.8 & 433 & 1516 & 1072 & 444 & 0.20 & 58.0 & 0.99 \\
\hline 1983 & 1986 & stand. dev. & 1.9 & 57 & 606 & 454 & 275 & 0.09 & 6.5 & 0.10 \\
\hline 1983 & 1986 & upper hinge & 8.0 & 459 & 1757 & 1266 & 552 & 0.24 & 60.8 & 1.00 \\
\hline 1983 & 1986 & lower hinge & 6.0 & 426 & 1154 & 766 & 263 & 0.15 & 55.0 & 0.98 \\
\hline 1983 & 1986 & $\min$ & 6.0 & 241 & 115 & 16 & 44 & 0.00 & 29.2 & 0.44 \\
\hline 1983 & 1986 & $\max$ & 14.0 & 491 & 3279 & 2202 & 1221 & 0.54 & 67.1 & 1.00 \\
\hline 1983 & 1987 & $\mathrm{n}$ & 109.0 & & & & & & & \\
\hline 1983 & 1987 & median & 8.0 & 363 & 1584 & 1111 & 423 & 0.21 & 58.8 & 0.99 \\
\hline 1983 & 1987 & mean & 8.2 & 331 & 1718 & 1237 & 481 & 0.23 & 58.6 & 0.98 \\
\hline 1983 & 1987 & trimmed mean & 8.2 & 333 & 1685 & 1215 & 468 & 0.22 & 58.7 & 0.98 \\
\hline 1983 & 1987 & stand. dev. & 1.3 & 45 & 691 & 565 & 268 & 0.11 & 5.6 & 0.04 \\
\hline 1983 & 1987 & upper hinge & 9.0 & 365 & 2156 & 1511 & 629 & 0.25 & 62.0 & 1.00 \\
\hline 1983 & 1987 & lower hinge & 7.0 & 274 & 1136 & 844 & 276 & 0.15 & 55.3 & 0.98 \\
\hline 1983 & 1987 & $\min$ & 6.0 & 214 & 584 & 223 & 45 & 0.05 & 42.0 & 0.75 \\
\hline 1983 & 1987 & $\max$ & 11.0 & 399 & 3584 & 3008 & 1243 & 0.87 & 72.5 & 1.00 \\
\hline 1983 & 1988 & $\mathrm{n}$ & 109.0 & & & & & & & \\
\hline 1983 & 1988 & median & 9.0 & 336 & 1635 & 1114 & 453 & 0.20 & 59.6 & 0.99 \\
\hline 1983 & 1988 & mean & 8.6 & 334 & 1720 & 1209 & 510 & 0.21 & 59.0 & 0.97 \\
\hline 1983 & 1988 & trimmed mean & 8.7 & 337 & 1677 & 1176 & 484 & 0.21 & 59.0 & 0.98 \\
\hline 1983 & 1988 & stand. dev. & 1.3 & 42 & 717 & 545 & 335 & 0.08 & 5.9 & 0.05 \\
\hline 1983 & 1988 & upper hirge & 9.0 & 349 & 2022 & 1410 & 663 & 0.25 & 62.1 & 1.00 \\
\hline 1983 & 1988 & lower hinge & 8.0 & 334 & 1213 & 901 & 267 & 0.16 & 55.4 & 0.98 \\
\hline 1983 & 1988 & $\min$ & 6.0 & 171 & 463 & 153 & 11 & 0.04 & 41.2 & 0.71 \\
\hline 1983 & 1988 & $\max$ & $: 1.0$ & 398 & 4064 & 3080 & 2172 & 0.47 & 75.7 & 1.00 \\
\hline 1983 & 1989 & $\mathbf{n}$ & in 7 & & & & & & & \\
\hline 1983 & 1989 & median & 9.6 & 351 & 1530 & 1119 & 405 & 0.20 & 61.0 & 0.98 \\
\hline 1983 & 1989 & mean & 8.6 & 335 & 1676 & 1192 & 484 & 0.20 & 60.3 & 0.95 \\
\hline 1983 & 1989 & trimmed mean & 8.5 & 338 & 1631 & 1170 & 446 & 0.20 & 60.4 & 0.97 \\
\hline 1983 & 1989 & stand. dev. & 1.4 & 37 & 671 & 547 & 382 & 0.09 & 7.0 & 0.11 \\
\hline 1983 & 1989 & upper hinge & 9.0 & 366 & 2031 & 1466 & 562 & 0.24 & 64.2 & 0.99 \\
\hline 1983 & 1989 & lower hinge & 8.0 & 306 & 1164 & 810 & 269 & 0.14 & 56.6 & 0.95 \\
\hline 1983 & 1989 & $\min$ & 6.0 & 208 & 592 & -377 & 9 & -0.05 & 37.0 & 0.02 \\
\hline 1983 & 1989 & $\max$ & 14.0 & 398 & 4377 & 2818 & 2829 & 0.52 & 81.0 & 1.00 \\
\hline 1983 & 1990 & $\mathrm{n}$ & 117.0 & & & & & & & \\
\hline 1983 & 1990 & median & 9.0 & 333 & 1702 & 1235 & 428 & 0.21 & 60.2 & 0.99 \\
\hline 1983 & 1990 & mean & 8.7 & 331 & 1806 & 1312 & 495 & 0.24 & 59.9 & 0.96 \\
\hline 1983 & 1990 & trimmed mean & 8.7 & 333 & 1769 & 1291 & 456 & 0.22 & 60.4 & 0.98 \\
\hline 1983 & 1990 & stand. dev. & 1.2 & 38 & 737 & 587 & 371 & 0.18 & 7.7 & 0.10 \\
\hline 1983 & 1990 & upper hinge & 9.0 & 365 & 2216 & 1619 & 581 & 0.27 & 63.7 & 0.99 \\
\hline 1983 & 1990 & lower hinge & 8.0 & 305 & 1249 & 860 & 287 & 0.16 & 56.9 & 0.98 \\
\hline 1983 & 1990 & $\min$ & 6.0 & 200 & 154 & 31 & 10 & 0.01 & 29.0 & 0.38 \\
\hline 1983 & 1990 & $\max$ & 12.0 & 394 & 4512 & 3028 & 2805 & 1.80 & 78.0 & 1.00 \\
\hline 1983 & 1991 & $\mathrm{n}$ & 94.0 & & & & & & & \\
\hline 1983 & 1991 & median & 8.0 & 244 & 1753 & 1226 & 513 & 0.20 & 60.4 & 0.99 \\
\hline 1983 & 1991 & mean & 7.5 & 261 & 1904 & 1289 & 615 & 0.22 & 60.1 & 0.96 \\
\hline 1983 & 1991 & trimmed mean & 7.5 & 261 & 1858 & 1259 & 575 & 0.21 & 60.2 & 0.98 \\
\hline 1983 & 1991 & stand. dev. & 0.8 & 30 & 789 & 546 & 420 & 0.10 & 5.1 & 0.10 \\
\hline 1983 & 1991 & upper hinge & 8.0 & 302 & 2302 & 1531 & 725 & 0.26 & 63.3 & 1.00 \\
\hline 1983 & 1991 & lower hinge & 7.0 & 243 & 1398 & 969 & 359 & 0.15 & 56.9 & 0.97 \\
\hline 1983 & 1991 & $\min$ & 6.0 & 211 & 283 & 43 & 38 & 0.01 & 44.0 & 0.27 \\
\hline 1983 & 1991 & & 10.0 & 305 & 4722 & 3428 & 2767 & 0.59 & 72.3 & 1.00 \\
\hline
\end{tabular}




\section{SUMMARY WEATHER-NORMALIZATION STATISTICS-WISCONSIN GAS COMPANY}

\begin{tabular}{|c|c|c|c|c|c|c|c|c|c|c|}
\hline $\begin{array}{r}\text { Part.Yr. } \\
1984\end{array}$ & $\begin{array}{l}\text { Cons.Yr. } \\
1986\end{array}$ & Statistic & $\begin{array}{r}\text { n Reads } \\
130.0\end{array}$ & Days & NAC & NAHC & Baseload & Slope & Ref.Temp & R-Sqrd. \\
\hline 1984 & 1986 & median & 7.0 & 457 & 1444 & 1006 & 420 & 0.18 & 59.1 & 0.99 \\
\hline 1984 & 1986 & mean & 7.8 & 433 & 1540 & 1042 & 499 & 0.19 & 58.5 & 0.95 \\
\hline 1984 & 1986 & trimmed mean & 7.6 & 438 & 1509 & 1011 & 471 & 0.19 & 58.8 & 0.97 \\
\hline 1984 & 1986 & stand. dev. & 2.0 & 53 & 592 & 456 & 325 & 0.08 & 6.4 & 0.11 \\
\hline 1984 & 1986 & upper hinge & 8.0 & 459 & 1860 & 1235 & 601 & 0.23 & 61.4 & 0.99 \\
\hline 1984 & 1986 & lower hinge & 7.0 & 425 & 1111 & 714 & 295 & 0.14 & 55.3 & 0.97 \\
\hline 1984 & 1986 & $\min$ & 6.0 & 244 & 165 & 57 & 13 & 0.03 & 30.7 & 0.13 \\
\hline 1984 & 1986 & $\max$ & 15.0 & 509 & 3574 & 2769 & 1695 & 0.45 & 84.0 & 1.00 \\
\hline 1984 & 1987 & $\mathbf{n}$ & 183.0 & & & & & & & \\
\hline 1984 & 1987 & median & 8.0 & 335 & 1556 & 1055 & 427 & 0.19 & 59.6 & 0.99 \\
\hline 1984 & 1987 & mean & 8.1 & 322 & 1663 & 1168 & 496 & 0.21 & 59.4 & 0.96 \\
\hline 1984 & 1987 & trimmed mean & 8.1 & 326 & 1619 & 1119 & 476 & 0.20 & 59.5 & 0.97 \\
\hline 1984 & 1987 & stand. dev. & 1.3 & 49 & 667 & 570 & 303 & 0.12 & 6.9 & 0.07 \\
\hline 1984 & 1987 & upper hinge & 9.0 & 365 & 1997 & 1367 & 650 & 0.25 & 63.5 & 0.99 \\
\hline 1984 & 1987 & lower binge & 7.0 & 274 & 1222 & 796 & 276 & 0.14 & 56.0 & 0.96 \\
\hline 1984 & 1987 & $\min$ & 6.0 & 181 & 245 & 219 & 16 & 0.04 & 32.0 & 0.47 \\
\hline 1984 & 1987 & $\max$ & 11.0 & 399 & 5259 & 4826 & 1799 & 1.29 & 76.9 & 1.00 \\
\hline 1984 & 1988 & $\mathbf{n}$ & 204.0 & & & & & & & \\
\hline 1984 & 1988 & median & 9.0 & 336 & 1566 & 1035 & 429 & 0.19 & 59.9 & 0.99 \\
\hline 1984 & 1988 & mean & 8.6 & 336 & 1659 & 1171 & 488 & 0.21 & 59.3 & 0.97 \\
\hline 1984 & 1988 & trimmed mean & 8.6 & 338 & 1620 & 1125 & 471 & 0.20 & 59.3 & 0.97 \\
\hline 1984 & 1988 & stand. dev. & 1.4 & 41 & 650 & 556 & 291 & 0.09 & 6.1 & 0.06 \\
\hline 1984 & 1988 & upper hinge & 10.0 & 342 & 2006 & 1370 & 643 & 0.25 & 62.0 & 0.99 \\
\hline 1984 & 1988 & lower hinge & 8.0 & 333 & 1187 & 786 & 293 & 0.14 & 56.0 & 0.97 \\
\hline 1984 & 1988 & $\min$ & 6.0 & 206 & 254 & 226 & 0 & 0.04 & 38.0 & 0.61 \\
\hline 1984 & 1988 & $\max$ & 12.0 & 398 & 3790 & 3693 & 2174 & 0.61 & 77.1 & 1.00 \\
\hline 1984 & 1989 & n & 171.0 & & & & & & & \\
\hline 1984 & 1989 & median & 9.0 & 364 & 1567 & 1039 & 423 & 0.17 & 60.8 & 0.98 \\
\hline 1984 & 1989 & mean & 8.5 & 333 & 1611 & 1133 & 478 & 0.19 & 60.3 & 0.95 \\
\hline 1984 & 1989 & trimmed mean & 8.5 & 337 & 1579 & 1100 & 454 & 0.18 & 60.3 & 0.97 \\
\hline 1984 & 1989 & stand. dev. & 1.3 & 41 & 632 & 516 & 277 & 0.08 & 6.1 & 0.10 \\
\hline 1984 & 1989 & upper hinge & 9.0 & 366 & 1927 & 1365 & 575 & 0.22 & 63.8 & 0.99 \\
\hline 1984 & 1989 & lower hinge & 8.0 & 306 & 1148 & 772 & 295 & 0.14 & 57.0 & 0.96 \\
\hline 1984 & 1989 & $\min$ & 6.0 & 182 & 58 & 1 & 23 & 0.00 & 44.3 & 0.02 \\
\hline 1984 & 1989 & $\max$ & 12.0 & 396 & 4643 & 3143 & 1601 & 0.50 & 77.9 & 1.00 \\
\hline 1984 & 1990 & $\mathbf{n}$ & 200.0 & & & & & & & \\
\hline 1984 & 1990 & median & 9.0 & 364 & 1626 & 1096 & 433 & 0.19 & 60.0 & 0.99 \\
\hline 1984 & 1990 & mean & 8.6 & 334 & 1713 & 1192 & 521 & 0.22 & 59.2 & 0.96 \\
\hline 1984 & 1990 & trimmed mean & 8.5 & 337 & 1683 & 1155 & 497 & 0.21 & 59.6 & 0.97 \\
\hline 1984 & 1990 & stand. dev. & 1.4 & 41 & 653 & 544 & 320 & 0.11 & 7.1 & 0.09 \\
\hline 1984 & 1990 & upper hinge & 9.0 & 365 & 2045 & 1407 & 655 & 0.25 & 63.1 & 0.99 \\
\hline 1984 & 1990 & lower hinge & 8.0 & 304 & 1210 & 791 & 316 & 0.15 & 56.0 & 0.97 \\
\hline 1984 & 1990 & $\min$ & 6.0 & 168 & 60 & 4 & 6 & 0.00 & 33.2 & 0.16 \\
\hline 1984 & 1990 & $\max$ & 12.0 & 397 & 3595 & 3299 & 2138 & 0.94 & 77.0 & 1.00 \\
\hline 1984 & 1991 & $\mathbf{n}$ & 153.0 & & & & & & & \\
\hline 1984 & 1991 & median & 8.0 & 244 & 1554 & 1067 & 489 & 0.17 & 60.1 & 0.99 \\
\hline 1984 & 1991 & mean & 7.5 & 261 & 1706 & 1156 & 550 & 0.24 & 60.1 & 0.96 \\
\hline 1984 & 1991 & trimmed mean & 7.5 & 262 & 1674 & 1126 & 515 & 0.19 & 60.5 & 0.98 \\
\hline 1984 & 1991 & stand. dev. & 0.8 & 33 & 667 & 505 & 370 & 0.48 & 7.3 & 0.08 \\
\hline 1984 & 1991 & upper hinge & 8.0 & 302 & 2077 & 1448 & 688 & 0.24 & 64.0 & 0.99 \\
\hline 1984 & 1991 & lower hinge & 7.0 & 242 & 1151 & 780 & 315 & 0.14 & 56.9 & 0.97 \\
\hline 1984 & 1991 & $\min$ & 6.0 & 143 & 244 & 207 & 37 & 0.04 & 12.7 & 0.40 \\
\hline 1984 & 1991 & $\max$ & 10.0 & 321 & 3648 & 2700 & 2495 & 6.02 & 82.0 & 1.00 \\
\hline
\end{tabular}


SUMMARY WEATHER-NORMALIZATION STATISTICS-WISCONSIN GAS COMPANY

\begin{tabular}{|c|c|c|c|c|c|c|c|c|c|c|}
\hline $\begin{array}{r}\text { Part.Yr. } \\
1985\end{array}$ & $\begin{array}{l}\text { Cons.Yr. } \\
1986 \text { n }\end{array}$ & Statistic & $\begin{array}{r}\text { n Reads } \\
230.0\end{array}$ & $\begin{array}{l}\text { Days } \\
230\end{array}$ & $\begin{array}{l}\text { NAC } \\
230\end{array}$ & $\begin{array}{r}\text { NAHC } \\
230\end{array}$ & $\begin{array}{r}\text { Baseload } \\
230\end{array}$ & $\begin{array}{l}\text { Slope } \\
230.00\end{array}$ & $\begin{array}{c}\text { Ref.Temp } \\
230.0\end{array}$ & $\begin{array}{r}\text { R-Sqrd. } \\
230.00\end{array}$ \\
\hline 1985 & $1986 \mathrm{n}$ & median & 8.0 & 457 & 1330 & 956 & 365 & 0.17 & 58.8 & 0.99 \\
\hline 1985 & $1986 n$ & mean & 7.9 & 434 & 1437 & 1015 & 421 & 0.22 & 58.2 & 0.96 \\
\hline 1985 & $1986 t$ & trimmed mean & 7.7 & 438 & 1405 & 988 & 403 & 0.18 & 58.5 & 0.97 \\
\hline 1985 & $1986 \mathrm{~s}$ & stand. dev. & 1.9 & 49 & 545 & 438 & 257 & 0.37 & 7.6 & 0.09 \\
\hline 1985 & 1986 & upper hinge & 8.0 & 459 & 1711 & 1220 & 563 & 0.22 & 61.7 & 1.00 \\
\hline 1985 & $1986 \mathrm{k}$ & lower hinge & 7.0 & 426 & 1069 & 744 & 248 & 0.14 & 55.1 & 0.97 \\
\hline 1985 & $1986 \mathrm{n}$ & $\min$ & 6.0 & 254 & 217 & 21 & 18 & 0.01 & 9.0 & 0.26 \\
\hline 1985 & 1986 & $\max$ & 15.0 & 500 & 4543 & 4250 & 1569 & 5.64 & 85.0 & 1.00 \\
\hline 1985 & 1987 & $\mathrm{n}$ & 274.0 & & & & & & & \\
\hline 1985 & 1987 & median & 8.0 & 364 & 1364 & 976 & 370 & 0.17 & 59.3 & 0.99 \\
\hline 1985 & 1987 & mean & 8.2 & 336 & 1496 & 1055 & 441 & 0.19 & 59.1 & 0.96 \\
\hline 1985 & $1987 \mathrm{t}$ & trimmed mean & 8.2 & 339 & 1462 & 1026 & 410 & 0.18 & 59.2 & 0.97 \\
\hline 1985 & $1987 \mathrm{~s}$ & stand. dev. & 1.4 & 45 & 618 & 465 & 313 & 0.12 & 6.5 & 0.10 \\
\hline 1985 & 1987 & upper hinge & 9.0 & 365 & 1788 & 1271 & 567 & 0.22 & 62.7 & 1.00 \\
\hline 1985 & 1987 I & lower hinge & 7.0 & 304 & 1100 & 754 & 240 & 0.14 & 55.8 & 0.97 \\
\hline 1985 & 1987 & $\min$ & 6.0 & 210 & 83 & 13 & 3 & 0.00 & 34.6 & 0.37 \\
\hline 1985 & 1987 & $\max$ & 12.0 & 398 & 4699 & 3066 & 2561 & 1.64 & 84.0 & 1.00 \\
\hline 1985 & 1988 & $\mathrm{n}$ & 292.0 & & & & & & & \\
\hline 1985 & 1988 & median & 9.0 & 336 & 1369 & 960 & 366 & 0.18 & 58.5 & 0.99 \\
\hline 1985 & 1988 & mean & 8.7 & 345 & 1521 & 1045 & 475 & 0.19 & 57.8 & 0.96 \\
\hline 1985 & $1988 t$ & trimmed mean & 8.7 & 348 & 1485 & 1019 & 437 & 0.19 & 58.0 & 0.98 \\
\hline 1985 & $1988 s$ & stand. dev. & 1.3 & 41 & 641 & 492 & 374 & 0.08 & 6.8 & 0.09 \\
\hline 1985 & 1988 & upper hinge & 9.0 & 368 & 1831 & 1256 & 596 & 0.24 & 61.4 & 1.00 \\
\hline 1985 & 19881 & lower hinge & 8.0 & 335 & 1071 & 754 & 265 & 0.14 & 54.8 & 0.97 \\
\hline 1985 & 1988 & $\min$ & 6.0 & 155 & 106 & -379 & 20 & -0.15 & 20.2 & 0.04 \\
\hline 1985 & 1988 & $\max$ & 12.0 & 401 & 3671 & 2768 & 3534 & 0.45 & 87.0 & 1.00 \\
\hline 1985 & 1989 & $\mathbf{n}$ & 273.0 & & & & & & & \\
\hline 1985 & 1989 & median & 9.0 & 365 & 1331 & 955 & 335 & 0.17 & 60.3 & 0.98 \\
\hline 1985 & 1989 & mean & 8.5 & 341 & 1477 & 1068 & 409 & 0.18 & 60.0 & 0.95 \\
\hline 1985 & 1989 & trimmed mean & 8.5 & 345 & 1441 & 1031 & 386 & 0.18 & 60.0 & 0.97 \\
\hline 1985 & 1989 & stand. dev. & 1.4 & 38 & 614 & 517 & 280 & 0.07 & 6.8 & 0.11 \\
\hline 1985 & 1989 & upper hinge & 10.0 & 366 & 1809 & 1261 & 536 & 0.22 & 64.0 & 0.99 \\
\hline 1985 & 1989 & lower hinge & 8.0 & 307 & 1067 & 740 & 221 & 0.13 & 56.6 & 0.96 \\
\hline 1985 & 1989 & $\min$ & 6.0 & 204 & 123 & 14 & 8 & 0.00 & 34.0 & 0.22 \\
\hline 1985 & 1989 & $\max$ & 12.0 & 410 & 3581 & 3003 & 1504 & 0.56 & 81.0 & 1.00 \\
\hline 1985 & 1990 & & 276.0 & & & & & & & \\
\hline 1985 & 1990 & median & 9.0 & 364 & 1416 & 1009 & 383 & 0.18 & 59.6 & 0.99 \\
\hline 1985 & 1990 & mean & 8.7 & 339 & 1550 & 1107 & 443 & 0.20 & 59.4 & 0.97 \\
\hline 1985 & $\cdot 1990$ & trimmed mean & 8.7 & 343 & 1500 & 1060 & 417 & 0.19 & 59.7 & 0.98 \\
\hline 1985 & 1990 & stand. dev. & 1.3 & 39 & 668 & 559 & 287 & 0.09 & 6.4 & 0.08 \\
\hline 1985 & 1990 & upper hinge & 10.0 & 365 & 1797 & 1293 & 563 & 0.23 & 63.0 & 1.00 \\
\hline 1985 & 1990 & lower hinge & 8.0 & 306 & 1125 & 762 & 246 & 0.14 & 57.0 & 0.97 \\
\hline 1985 & 1990 & $\min$ & 6.0 & 181 & 113 & 17 & 5 & 0.00 & 29.1 & 0.18 \\
\hline 1985 & 1990 & $\max$ & 12.0 & 396 & 4778 & 4733 & 2373 & 0.56 & 79.0 & 1.00 \\
\hline 1985 & 1991 & $\mathbf{n}$ & 242.0 & & & & & & & \\
\hline 1985 & 1991 & median & 8.0 & 244 & 1514 & 1055 & 402 & 0.19 & 60.0 & 0.99 \\
\hline 1985 & 1991 & mean & 7.5 & 265 & 1636 & 1152 & 484 & 0.21 & 59.7 & 0.95 \\
\hline 1985 & 1991 & trimmed mean & 7.5 & 267 & 1586 & 1112 & 454 & 0.19 & 60.2 & 0.98 \\
\hline 1985 & 1991 & stand. dev. & 0.8 & 33 & 703 & 569 & 342 & 0.14 & 7.6 & 0.12 \\
\hline 1985 & 1991 & upper hinge & 8.0 & 302 & 1911 & 1348 & 658 & 0.23 & 65.1 & 0.99 \\
\hline 1985 & 1991 & lower hinge & 7.0 & 242 & 1190 & 837 & 247 & 0.14 & 56.7 & 0.97 \\
\hline 1985 & 1991 & $\min$ & 6.0 & 158 & 84 & 5 & 20 & 0.00 & 19.0 & 0.05 \\
\hline 1985 & 1991 & $\max$ & 9.0 & 321 & 4842 & 4269 & 2128 & 1.91 & 82.0 & 1.00 \\
\hline
\end{tabular}


SUMMARY WEATHER-NORMALIZATION STATISTICS-WISCONSIN GAS COMPANY

\begin{tabular}{|c|c|c|c|c|c|c|c|c|c|c|}
\hline $\begin{array}{r}\text { Part.Yr. } \\
1986\end{array}$ & $\begin{array}{l}\text { Cons. Yr. } \\
1986\end{array}$ & Statistic & $\begin{array}{r}\text { n Reads } \\
318.0\end{array}$ & Days & NAC & NAHC & Baseload & Slope & Ref.Temp & R-Sqrd. \\
\hline 1986 & 1986 & median & 7.0 & 456 & 1533 & 1078 & 452 & 0.20 & 59.1 & 0.98 \\
\hline 1986 & 1986 & mean & 7.8 & 421 & 1650 & 1152 & 498 & 0.37 & 57.4 & 0.95 \\
\hline 1986 & 1986 & trimmed mean & 7.6 & 427 & 1608 & 1118 & 472 & 0.22 & 58.2 & 0.97 \\
\hline 1986 & 1986 & stand. dev. & 1.8 & 63 & 672 & 566 & 293 & 1.43 & 10.1 & 0.11 \\
\hline 1986 & 1986 & upper hinge & 8.0 & 459 & 2015 & 1447 & 618 & 0.27 & 62.0 & 0.99 \\
\hline 1986 & 1986 & lower hinge & 7.0 & 395 & 1189 & 753 & 308 & 0.15 & 55.2 & 0.96 \\
\hline 1986 & 1986 & $\min$ & 6.0 & 234 & 343 & 74 & 18 & 0.01 & 2.7 & 0.10 \\
\hline 1986 & 1986 & $\max$ & 15.0 & 511 & 6374 & 4862 & 2605 & 19.37 & 84.0 & 1.00 \\
\hline 1986 & 1987 & n & 369.0 & & & & & & & \\
\hline 1986 & 1987 & median & 8.0 & 363 & 1417 & 940 & 417 & 0.17 & 59.0 & 0.98 \\
\hline 1986 & 1987 & mean & 8.3 & 332 & 1485 & 1015 & 470 & 0.22 & 58.5 & 0.94 \\
\hline 1986 & 1987 & trimmed mean & 8.3 & 335 & 1446 & 980 & 451 & 0.18 & 58.8 & 0.96 \\
\hline 1986 & 1987 & stand. dev. & 1.2 & 46 & 602 & 499 & 261 & 0.45 & 8.4 & 0.10 \\
\hline 1986 & 1987 & upper hinge & 9.0 & 365 & 1784 & 1264 & 557 & 0.23 & 62.8 & 0.99 \\
\hline 1986 & 1987 & lower hinge & 8.0 & 303 & 1082 & 678 & 314 & 0.13 & 55.2 & 0.94 \\
\hline 1986 & 1987 & $\min$ & 6.0 & 162 & 336 & 58 & 34 & 0.01 & 10.5 & 0.17 \\
\hline 1986 & 1987 & $\max$ & 12.0 & 400 & 6174 & 4324 & 1850 & 8.35 & 85.0 & 1.00 \\
\hline 1986 & 1988 & n & 414.0 & & & & & & & \\
\hline 1986 & 1988 & median & 9.0 & 336 & 1457 & 964 & 435 & 0.18 & 58.7 & 0.98 \\
\hline 1986 & 1988 & mean & 8.8 & 338 & 1556 & 1058 & 499 & 0.20 & 58.2 & 0.96 \\
\hline 1986 & 1988 & trimmed mean & 8.8 & 341 & 1513 & 1019 & 471 & 0.19 & 58.5 & 0.97 \\
\hline 1986 & 1988 & stand. dev. & 1.4 & 42 & 681 & 551 & 305 & 0.11 & 7.7 & 0.09 \\
\hline 1986 & 1988 & upper hinge & 10.0 & 365 & 1907 & 1336 & 624 & 0.24 & 62.4 & 0.99 \\
\hline 1986 & 1988 & lower hinge & 8.0 & 334 & 1058 & 674 & 310 & 0.13 & 54.9 & 0.96 \\
\hline 1986 & 1988 & $\min$ & 6.0 & 176 & 281 & 8 & 2 & 0.01 & 20.0 & 0.03 \\
\hline 1986 & 1988 & $\max$ & 12.0 & 406 & 6152 & 4161 & 2553 & 1.51 & 86.0 & 1.00 \\
\hline 1986 & 1989 & $\mathbf{n}$ & 379.0 & & & & & & & \\
\hline 1986 & 1989 & median & 9.0 & 364 & 1397 & 920 & 398 & 0.16 & 60.1 & 0.97 \\
\hline 1986 & 1989 & mean & 8.6 & 338 & 1486 & 1034 & 452 & 0.25 & 59.2 & 0.94 \\
\hline 1986 & 1989 & trimmed mean & 8.6 & 341 & 1451 & 999 & 429 & 0.17 & 60.0 & 0.95 \\
\hline 1986 & 1989 & stand. dev. & 1.4 & 39 & 622 & 536 & 283 & 0.90 & 9.3 & 0.10 \\
\hline 1986 & 1989 & upper hinge & 10.0 & 366 & 1813 & 1289 & 557 & 0.22 & 64.3 & 0.98 \\
\hline 1986 & 1989 & lower hinge & 8.0 & 307 & 1033 & 671 & 280 & 0.12 & 55.8 & 0.94 \\
\hline 1986 & 1989 & $\min$ & 6.0 & 196 & 245 & 11 & 6 & 0.00 & 9.1 & 0.17 \\
\hline 1986 & 1989 & $\max$ & 12.0 & 423 & 3744 & 3260 & 2202 & 15.42 & 82.7 & 1.00 \\
\hline 1986 & 1990 & $\mathbf{n}$ & 402.0 & & & & & & & \\
\hline 1986 & 1990 & median & 9.0 & 364 & 1456 & 977 & 411 & 0.18 & 60.0 & 0.99 \\
\hline 1986 & 1990 & mean & 8.7 & 335 & 1612 & 1124 & 487 & 0.20 & 58.9 & 0.95 \\
\hline 1986 & 1990 & trimmed mean & 8.7 & 339 & 1554 & 1076 & 455 & 0.19 & 59.2 & 0.97 \\
\hline 1986 & 1990 & stand. dev. & 1.3 & 43 & 746 & 639 & 327 & 0.11 & 7.9 & 0.12 \\
\hline 1986 & 1990 & upper hinge & 9.0 & 365 & 2001 & 1368 & 608 & 0.25 & 63.7 & 0.99 \\
\hline 1986 & 1990 & lower hinge & 8.0 & 304 & 1107 & 720 & 288 & 0.13 & 55.4 & 0.96 \\
\hline 1986 & 1990 & $\min$ & 6.0 & 151 & 255 & 8 & 3 & 0.00 & 28.0 & 0.08 \\
\hline 1986 & 1990 & $\max$ & 12.0 & 396 & 6014 & 5303 & 2999 & 0.90 & 85.0 & 1.00 \\
\hline 1986 & 1991 & $\mathbf{n}$ & 332.0 & & & & & & & \\
\hline 1986 & 1991 & median & 8.0 & 244 & 1503 & 989 & 443 & 0.18 & 59.9 & 0.98 \\
\hline 1986 & 1991 & mean & 7.6 & 263 & 1656 & 1129 & 527 & 0.21 & 59.2 & 0.94 \\
\hline 1986 & 1991 & trimmed inean & 7.5 & 264 & 1597 & 1071 & 496 & 0.19 & 59.5 & 0.96 \\
\hline 1986 & 1991 & stand. dev. & 0.8 & 33 & 766 & 663 & 356 & 0.17 & 8.9 & 0.14 \\
\hline 1986 & 1991 & upper hinge & 8.0 & 302 & 2011 & 1362 & 664 & 0.24 & 64.7 & 0.99 \\
\hline 1986 & 1991 & lower hinge & 7.0 & 242 & 1163 & 735 & 294 & 0.14 & 54.6 & 0.96 \\
\hline 1986 & 1991 & $\min$ & 6.0 & 176 & 337 & 44 & 17 & 0.01 & 13.5 & 0.07 \\
\hline 1986 & 1991 & $\max$ & 10.0 & 325 & 6788 & 6655 & 2276 & 1.82 & 83.0 & 1.00 \\
\hline
\end{tabular}




\begin{tabular}{|c|c|c|c|c|c|c|c|c|c|c|}
\hline & & & & & & & & & & \\
\hline $\begin{array}{r}\text { Part.Yr. } \\
1987\end{array}$ & $\begin{array}{r}\text { Cons.Yr. } \\
1986\end{array}$ & Statistic & $\begin{array}{r}\text { n Reads } \\
312.0\end{array}$ & Days & NAC & NAHC & Baseload & Slope & Ref.Temp & R-Sqrd. \\
\hline 1987 & 1986 & median & 7.0 & 455 & 1753 & 1241 & 414 & 0.22 & 59.5 & 0.99 \\
\hline 1987 & 1986 & mean & 7.8 & 426 & 1816 & 1353 & 463 & 0.27 & 59.1 & 0.96 \\
\hline 1987 & 1986 & trimmed mean & 7.6 & 430 & 1770 & 1305 & 430 & 0.24 & 59.5 & 0.98 \\
\hline 1987 & 1986 & stand. dev. & 1.8 & 59 & 729 & 653 & 328 & 0.28 & 8.6 & 0.08 \\
\hline 1987 & 1986 & upper hinge & 8.0 & 459 & 2186 & 1657 & 565 & 0.28 & 63.0 & 1.00 \\
\hline 1987 & 1986 & lower hinge & 7.0 & 401 & 1327 & 896 & 254 & 0.17 & 56.1 & 0.97 \\
\hline 1987 & 1986 & $\min$ & 6.0 & 231 & 418 & 316 & 1 & 0.04 & 14.4 & 0.46 \\
\hline 1987 & 1986 & $\max$ & 15.0 & 510 & 5415 & 4741 & 2612 & 3.18 & 84.0 & 1.00 \\
\hline 1987 & 1987 & $\mathrm{n}$ & 411.0 & & & & & & & \\
\hline 1987 & 1987 & median & 8.0 & 363 & 1662 & 1171 & 405 & 0.22 & 59.5 & 0.98 \\
\hline 1987 & 1987 & mean & 8.2 & 331 & 1772 & 1285 & 487 & 0.24 & 58.8 & 0.94 \\
\hline 1987 & 1987 & trimmed mean & 8.2 & 335 & 1728 & 1240 & 456 & 0.23 & 59.1 & 0.96 \\
\hline 1987 & 1987 & stand. dev. & 1.2 & 47 & 740 & 648 & 328 & 0.16 & 7.6 & 0.11 \\
\hline 1987 & 1987 & upper hinge & 9.0 & 365 & 2164 & 1635 & 617 & 0.29 & 63.6 & 0.99 \\
\hline 1987 & 1987 & lower hinge & 7.0 & 301 & 1250 & 806 & 266 & 0.15 & 54.6 & 0.95 \\
\hline 1987 & 1987 & $\min$ & 6.0 & 164 & 422 & 152 & 6 & 0.04 & 28.0 & 0.04 \\
\hline 1987 & 1987 & $\max$ & 12.0 & 421 & 5136 & 3888 & 2212 & 1.76 & 84.0 & 1.00 \\
\hline 1987 & 1988 & n & 426.0 & & & & & & & \\
\hline 1987 & 1988 & median & 9.0 & 336 & 1423 & 903 & 419 & 0.17 & 58.6 & 0.98 \\
\hline 1987 & 1988 & mean & 8.7 & 334 & 1512 & 998 & 515 & 0.23 & 58.1 & 0.94 \\
\hline 1987 & 1988 & trimmed mean & 8.7 & 337 & 1474 & 965 & 473 & 0.18 & 58.5 & 0.96 \\
\hline 1987 & 1988 & stand. dev. & 1.3 & 49 & 629 & 486 & 382 & 0.91 & 8.3 & 0.11 \\
\hline 1987 & 1988 & upper hinge & 10.0 & 365 & 1847 & 1246 & 645 & 0.22 & 62.7 & 0.99 \\
\hline 1987 & 1988 & lower hinge & 8.0 & 324 & 1063 & 651 & 274 & 0.13 & 54.7 & 0.95 \\
\hline 1987 & 1988 & $\min$ & 6.0 & 168 & 345 & 188 & 13 & 0.05 & -2.0 & 0.23 \\
\hline 1987 & 1988 & $\max$ & 12.0 & 424 & 4392 & 3680 & 2372 & 18.84 & 87.0 & 1.00 \\
\hline 1987 & 1989 & $\mathrm{n}$ & 385.0 & & & & & & & \\
\hline 1987 & 1989 & median & 9.0 & 365 & 1357 & 931 & 377 & 0.15 & 60.9 & 0.97 \\
\hline 1987 & 1989 & mean & 8.6 & 336 & 1479 & 1023 & 457 & 0.19 & 59.9 & 0.94 \\
\hline 1987 & 1989 & trimmed mean & 8.6 & 340 & 1439 & 986 & 423 & 0.17 & 60.3 & 0.95 \\
\hline 1987 & 1989 & stand. dev. & 1.3 & 41 & 635 & 516 & 318 & 0.16 & 8.1 & 0.09 \\
\hline 1987 & 1989 & upper hinge & 10.0 & 366 & 1829 & 1280 & 589 & 0.21 & 64.2 & 0.98 \\
\hline 1987 & 1989 & lower hinge & 8.0 & 306 & 1033 & 676 & 251 & 0.12 & 56.0 & 0.94 \\
\hline 1987 & 1989 & $\min$ & 6.0 & 182 & 489 & 165 & 0 & 0.04 & 19.3 & 0.27 \\
\hline 1987 & 1989 & $\max$ & 13.0 & 412 & 5154 & 4513 & 2110 & 2.43 & 84.0 & 1.00 \\
\hline 1987 & 1990 & $\mathbf{n}$ & 422.0 & & & & & & & \\
\hline 1987 & 1990 & median & 9.0 & 364 & 1503 & 974 & 445 & 0.17 & 59.9 & 0.98 \\
\hline 1987 & 1990 & mean & 8.7 & 334 & 1595 & 1074 & 521 & 0.24 & 58.6 & 0.95 \\
\hline 1987 & 1990 & trimmed mean & 8.7 & 338 & 1553 & 1041 & 488 & 0.19 & 59.2 & 0.96 \\
\hline 1987 & 1990 & stand. dev. & 1.2 & 42 & 688 & 538 & 349 & 0.63 & 8.3 & 0.10 \\
\hline 1987 & 1990 & upper hinge & 10.0 & 365 & 1961 & 1374 & 650 & 0.24 & 63.2 & 0.99 \\
\hline 1987 & 1990 & lower hinge & 8.0 & 304 & 1106 & 675 & 285 & 0.13 & 55.0 & 0.95 \\
\hline 1987 & 1990 & $\min$ & 6.0 & 170 & 304 & 77 & 1 & 0.01 & 7.0 & 0.02 \\
\hline 1987 & 1990 & $\max$ & 12.0 & 403 & 5146 & 4220 & 2335 & 12.73 & 85.0 & 1.00 \\
\hline 1987 & 1991 & $\mathbf{n}$ & 366.0 & & & & & & & \\
\hline 1987 & 1991 & median & 8.0 & 244 & 1495 & 976 & 448 & 0.17 & 60.0 & 0.98 \\
\hline 1987 & 1991 & mean & 7.6 & 260 & 1595 & 1056 & 539 & 0.21 & 59.6 & 0.95 \\
\hline 1987 & 1991 & trimmed mean & 7.6 & 262 & 1555 & 1029 & 497 & 0.18 & 60.0 & 0.97 \\
\hline 1987 & 1991 & stand. dev. & 0.8 & 33 & 661 & 494 & 410 & 0.31 & 8.8 & 0.11 \\
\hline 1987 & 1991 & upper hinge & 8.0 & 302 & 1936 & 1324 & 683 & 0.22 & 64.7 & 0.99 \\
\hline 1987 & 1991 & lower hinge & 7.0 & 242 & 1139 & 726 & 256 & 0.13 & 55.5 & 0.96 \\
\hline 1987 & 1991 & $\min$ & 6.0 & 161 & 300 & 148 & 1 & 0.04 & 12.5 & 0.05 \\
\hline 1987 & 1991 & $\max$ & 10.0 & 314 & 5053 & 3533 & 2319 & 5.70 & 83.0 & 1.00 \\
\hline
\end{tabular}




\begin{tabular}{|c|c|c|c|c|c|c|c|c|c|c|}
\hline $\begin{array}{r}\text { Part.Yr. } \\
1988\end{array}$ & $\begin{array}{r}\text { Cons. Yr. } \\
1986\end{array}$ & Statistic & $\begin{array}{r}\text { a Reads } \\
527.0\end{array}$ & Days & NAC & NAHC & Baseload & Slope & Ref.Temp & R-Sqrd. \\
\hline 1988 & 1986 & median & 7.0 & 446 & 1673 & 1189 & 439 & 0.22 & 59.8 & 0.99 \\
\hline 1988 & 1986 & mean & 7.6 & 423 & 1753 & 1289 & 464 & 0.26 & 58.4 & 0.96 \\
\hline 1988 & 1986 & trimmed mean & 7.5 & 427 & 1726 & 1260 & 452 & 0.23 & 59.1 & 0.97 \\
\hline 1988 & 1986 & stand. dev. & 1.6 & 60 & 680 & 628 & 240 & 0.29 & 9.5 & 0.09 \\
\hline 1988 & 1986 & upper hinge & 8.0 & 460 & 2179 & 1635 & 578 & 0.28 & 63.1 & 1.00 \\
\hline 1988 & 1986 & lower hinge & 7.0 & 389 & 1248 & 850 & 311 & 0.17 & 55.3 & 0.97 \\
\hline 1988 & 1986 & $\min$ & 6.0 & 141 & 261 & 30 & 4 & 0.02 & 10.0 & 0.09 \\
\hline 1988 & 1986 & $\max$ & 15.0 & 511 & 4197 & 3755 & 1970 & 4.31 & 84.0 & 1.00 \\
\hline 1988 & 1987 & $\mathbf{n}$ & 741.0 & 741 & 741 & 741 & 741 & 741.00 & 741.0 & 741.00 \\
\hline 1988 & 1987 & median & 8.0 & 363 & 1847 & 1307 & 459 & 0.22 & 60.5 & 0.98 \\
\hline 1988 & 1987 & mean & 8.2 & 333 & 1909 & 1390 & 518 & 0.25 & 60.0 & 0.94 \\
\hline 1988 & 1987 & trimmed mean & 8.2 & 337 & 1878 & 1363 & 488 & 0.23 & 60.3 & 0.96 \\
\hline 1988 & 1987 & stand. dev. & 1.2 & 45 & 749 & 631 & 327 & 0.21 & 7.7 & 0.10 \\
\hline 1988 & 1987 & upper hinge & 9.0 & 365 & 2366 & 1786 & 650 & 0.30 & 64.3 & 0.99 \\
\hline 1988 & 1987 & lower hinge & 7.0 & 304 & 1347 & 951 & 315 & 0.17 & 56.3 & 0.95 \\
\hline 1988 & 1987 & $\min$ & 6.0 & 170 & 247 & 16 & 6 & 0.00 & 21.0 & 0.18 \\
\hline 1988 & 1987 & $\max$ & 13.0 & 421 & 5047 & .1314 & 2345 & 3.11 & 83.0 & 1.00 \\
\hline 1988 & 1988 & $\mathbf{n}$ & 804.0 & & & & & & & \\
\hline 1988 & 1988 & median & 9.0 & 336 & 1597 & 1096 & 442 & 0.19 & 59.6 & 0.97 \\
\hline 1988 & 1988 & mean & 8.6 & 331 & 1675 & 1163 & 513 & 0.22 & 59.4 & 0.93 \\
\hline 1988 & 1988 & trimmed mean & 8.6 & 334 & 1643 & 1143 & 465 & 0.20 & 59.9 & 0.95 \\
\hline 1988 & 1988 & stand. dev. & 1.3 & 48 & 679 & 552 & 446 & 0.19 & 9.0 & 0.11 \\
\hline 1988 & 1988 & upper hinge & 9.0 & 364 & 2051 & 1492 & 619 & 0.25 & 64.7 & 0.99 \\
\hline 1988 & 1988 & lower hinge & 8.0 & 307 & 1213 & 776 & 289 & 0.14 & 55.3 & 0.92 \\
\hline 1988 & 1988 & $\min$ & 6.0 & 188 & 272 & -760 & 9 & -0.40 & 15.3 & 0.03 \\
\hline 1988 & 1988 & $\max$ & 12.0 & 424 & 7111 & 3566 & 7871 & 3.06 & 87.6 & 1.00 \\
\hline 1988 & 1989 & $\mathbf{n}$ & 752.0 & & & & & & & \\
\hline 1988 & 1989 & median & 9.0 & 364 & 1348 & 874 & 428 & 0.15 & 61.0 & 0.97 \\
\hline 1988 & 1989 & mean & 8.6 & 335 & 1429 & 945 & 484 & 0.24 & 59.6 & 0.93 \\
\hline 1988 & 1989 & trimmed mean & 8.7 & 339 & 1396 & 917 & 450 & 0.16 & 60.2 & 0.95 \\
\hline 1988 & 1989 & stand. dev. & 1.3 & 43 & 580 & 470 & 331 & 1.30 & 9.2 & 0.12 \\
\hline 1988 & 1989 & upper hinge & 10.0 & 366 & 1751 & 1205 & 593 & 0.20 & 65.0 & 0.98 \\
\hline 1988 & 1989 & lower hinge & 8.0 & 306 & 1042 & 619 & 281 & 0.11 & 55.6 & 0.93 \\
\hline 1988 & 1989 & $\min$ & 6.0 & 169 & 387 & -224 & 3 & -2.03 & 8.0 & 0.02 \\
\hline 1988 & 1989 & $\max$ & 12.0 & 412 & 4820 & 3345 & 2611 & 32.30 & 81.0 & 1.00 \\
\hline 1988 & 1990 & $\mathbf{n}$ & 792.0 & & & & & & & \\
\hline 1988 & 1990 & median & 9.0 & 364 & 1421 & 943 & 436 & 0.17 & 60.0 & 0.98 \\
\hline 1988 & 1990 & mean & 8.6 & 333 & 1503 & 1012 & 491 & 0.21 & 59.1 & 0.94 \\
\hline 1988 & 1990 & trimmed mean & 8.6 & 337 & 1477 & 984 & 464 & 0.18 & 59.7 & 0.96 \\
\hline 1988 & 1990 & stand. dev. & 1.3 & 43 & 588 & 479 & 317 & 0.51 & 8.6 & 0.10 \\
\hline 1988 & 1990 & upper hinge & 9.0 & 365 & 1852 & 1282 & 624 & 0.22 & 64.4 & 0.99 \\
\hline 1988 & 1990 & lower hinge & 8.0 & 304 & 1094 & 664 & 275 & 0.13 & 55.4 & 0.94 \\
\hline 1988 & 1990 & $\min$ & 6.0 & 153 & 315 & 90 & 5 & 0.03 & 7.0 & 0.05 \\
\hline 1988 & 1990 & $\max$ & 15.0 & 416 & 4204 & 3245 & 2283 & 13.78 & 85.0 & 1.00 \\
\hline 1988 & 1991 & $\mathbf{n}$ & 673.0 & & & & & & & \\
\hline 1988 & 1991 & median & 8.0 & 245 & 1521 & 930 & 509 & 0.17 & 59.0 & 0.98 \\
\hline 1988 & 1991 & mean & 7.6 & 261 & 1590 & 994 & 596 & 0.31 & 57.7 & 0.94 \\
\hline 1988 & 1991 & trimmed mean & 7.6 & 262 & 1557 & 968 & 557 & 0.18 & 58.3 & 0.96 \\
\hline 1988 & 1991 & stand. dev. & 0.9 & 35 & 652 & 490 & 413 & 1.74 & 10.4 & 0.12 \\
\hline 1988 & 1991 & upper hinge & 8.0 & 302 & 1948 & 1251 & 774 & 0.23 & 64.0 & 0.99 \\
\hline 1988 & 1991 & lower hinge & 7.0 & 241 & 1134 & 660 & 313 & 0.13 & 53.0 & 0.94 \\
\hline 1988 & 1991 & $\min$ & 6.0 & 165 & 350 & -549 & 2 & -7.75 & 8.0 & 0.08 \\
\hline 1988 & 1991 & $\max$ & 11.0 & 329 & 5696 & 3420 & 3041 & 30.56 & 83.0 & 1.00 \\
\hline
\end{tabular}




\begin{tabular}{|c|c|c|c|c|c|c|c|c|c|c|}
\hline $\begin{array}{r}\text { Part.Yr. } \\
1989\end{array}$ & $\begin{array}{l}\text { Cons.Yr. } \\
1986\end{array}$ & Statistic & $\begin{array}{r}\text { n Reads } \\
346.0\end{array}$ & Days & NAC & NAHC & Baseload & Slope & Ref.Temp & R-Sqrd. \\
\hline 1989 & 1986 & median & 8.0 & 450 & 1609 & 1145 & 397 & 0.22 & 59.6 & 0.99 \\
\hline 1989 & 1986 & mean & 8.0 & 424 & 1710 & 1257 & 453 & 0.25 & 58.5 & 0.96 \\
\hline 1989 & 1986 & trimmed mean & 7.8 & 429 & 1672 & 1227 & 430 & 0.22 & 59.1 & 0.97 \\
\hline 1989 & 1986 & stand. dev. & 1.9 & 65 & 628 & 555 & 272 & 0.25 & 8.2 & 0.10 \\
\hline 1989 & 1986 & upper hinge & 8.0 & 462 & 2056 & 1592 & 574 & 0.28 & 63.0 & 1.00 \\
\hline 1989 & 1986 & lower hinge & 7.0 & 381 & 1244 & 862 & 279 & 0.16 & 55.4 & 0.97 \\
\hline 1989 & 1986 & $\min$ & 6.0 & 178 & 448 & 87 & 10 & 0.07 & 15.9 & 0.22 \\
\hline 1989 & 1986 & $\max$ & 15.0 & 506 & 4199 & 3323 & 2408 & 3.55 & 84.0 & 1.00 \\
\hline 1989 & 1987 & n & 405.0 & & & & & & & \\
\hline 1989 & 1987 & median & 8.0 & 356 & 1686 & 1247 & 410 & 0.21 & 59.9 & 0.98 \\
\hline 1989 & 1987 & mean & 8.3 & 332 & 1802 & 1323 & 479 & 0.27 & 59.6 & 0.94 \\
\hline 1989 & 1987 & trimmed mean & 8.3 & 335 & 1747 & 1282 & 444 & 0.22 & 60.0 & 0.96 \\
\hline 1989 & 1987 & stand. dev. & 1.3 & 45 & 716 & 590 & 363 & 0.55 & 7.2 & 0.11 \\
\hline 1989 & 1987 & upper hinge & 9.0 & 365 & 2136 & 1601 & 585 & 0.28 & 64.0 & 0.99 \\
\hline 1989 & 1987 & lower hinge & 8.0 & 304 & 1303 & 900 & 273 & 0.16 & 56.5 & 0.94 \\
\hline 1989 & 1987 & $\min$ & 6.0 & 149 & 330 & 72 & 1 & 0.01 & 14.5 & 0.22 \\
\hline 1989 & 1987 & $\max$ & 12.0 & 411 & 5792 & 4131 & 3914 & 8.98 & 79.9 & 1.00 \\
\hline 1989 & 1988 & $\mathbf{n}$ & 493.0 & & & & & & & \\
\hline 1989 & 1988 & median & 9.0 & 336 & 1746 & 1284 & 446 & 0.22 & 60.0 & 0.99 \\
\hline 1989 & 1988 & mean & 8.6 & 334 & 1835 & 1338 & 497 & 0.23 & 59.8 & 0.96 \\
\hline 1989 & 1988 & trimmed mean & 8.6 & 337 & 1798 & 1308 & 473 & 0.23 & 60.1 & 0.97 \\
\hline 1989 & 1988 & stand. dev. & 1.3 & 45 & 647 & 552 & 302 & 0.09 & 7.1 & 0.07 \\
\hline 1989 & 1988 & upper hinge & 9.0 & 365 & 2199 & 1639 & 631 & 0.27 & 63.4 & 0.99 \\
\hline 1989 & 1988 & lower hinge & 8.0 & 309 & 1386 & 934 & 282 & 0.18 & 56.7 & 0.96 \\
\hline 1989 & 1988 & $\min$ & 6.0 & 170 & 240 & 19 & 4 & 0.05 & 2.0 & 0.09 \\
\hline 1989 & 1988 & $\max$ & 13.0 & 418 & 4526 & 3490 & 2271 & 0.74 & 82.0 & 1.00 \\
\hline 1989 & 1989 & $\mathbf{n}$ & 437.0 & & & & & & & \\
\hline 1989 & 1989 & median & 9.0 & 365 & 1597 & 1145 & 411 & 0.19 & 61.1 & 0.97 \\
\hline 1989 & 1989 & mean & 8.6 & 337 & 1720 & 1269 & 451 & 0.22 & 60.8 & 0.93 \\
\hline 1989 & 1989 & trimmed mean & 8.6 & 341 & 1671 & 1230 & 429 & 0.20 & 61.0 & 0.95 \\
\hline 1989 & 1989 & stand. dev. & 1.3 & 37 & 686 & 600 & 261 & 0.21 & 6.7 & 0.09 \\
\hline 1989 & 1989 & upper hinge & 9.0 & 366 & 2020 & 1582 & 562 & 0.26 & 64.7 & 0.98 \\
\hline 1989 & 1989 & lower hinge & 8.0 & 306 & 1260 & 887 & 276 & 0.15 & 57.3 & 0.93 \\
\hline 1989 & 1989 & $\min$ & 6.0 & 188 & 359 & 107 & 23 & 0.03 & 16.7 & 0.46 \\
\hline 1989 & 1989 & $\max$ & 12.0 & 403 & 6376 & 5906 & 2014 & 4.11 & 82.0 & 1.00 \\
\hline 1989 & 1990 & n & 497.0 & & & & & & & \\
\hline 1989 & 1990 & median & 9.0 & 364 & 1419 & 968 & 445 & 0.17 & 60.6 & 0.98 \\
\hline 1989 & 1990 & mean & 8.7 & 339 & 1539 & 1028 & 511 & 0.19 & 59.6 & 0.95 \\
\hline 1989 & 1990 & trimmed mean & 8.7 & 342 & 1475 & 993 & 466 & 0.17 & 60.0 & 0.96 \\
\hline 1989 & 1990 & stand. dev. & 1.3 & 39 & 831 & 528 & 474 & 0.11 & 8.2 & 0.11 \\
\hline 1989 & 1990 & upper hinge & 9.0 & 365 & 1759 & 1239 & 620 & 0.21 & 64.1 & 0.99 \\
\hline 1989 & 1990 & lower hinge & 8.0 & 305 & 1145 & 715 & 279 & 0.13 & 56.0 & 0.96 \\
\hline 1989 & 1990 & $\min$ & 6.0 & 168 & 146 & 5 & 14 & 0.00 & 25.0 & 0.14 \\
\hline 1989 & 1990 & $\max$ & 12.0 & 417 & 14188 & 6080 & 8108 & 1.33 & 83.2 & 1.00 \\
\hline 1989 & 1991 & n & 418.0 & & & & & & & \\
\hline 1989 & 1991 & median & 8.0 & 247 & 1421 & 945 & 458 & 0.16 & 60.9 & 0.98 \\
\hline 1989 & 1991 & mean & 7.7 & 265 & 1569 & 1008 & 561 & 0.20 & 59.7 & 0.93 \\
\hline 1989 & 1991 & trimmed mean & 7.7 & 267 & 1489 & 968 & 498 & 0.17 & 60.3 & 0.96 \\
\hline 1989 & 1991 & stand. dev. & 0.8 & 33 & 993 & 595 & 597 & 1.26 & 9.8 & 0.14 \\
\hline 1989 & 1991 & upper hinge & 8.0 & 302 & 1819 & 1223 & 669 & 0.21 & 64.9 & 0.99 \\
\hline 1989 & 1991 & lower hinge & 7.0 & 242 & 1119 & 694 & 279 & 0.12 & 56.0 & 0.94 \\
\hline 1989 & 1991 & $\min$ & 6.0 & 146 & 202 & .952 & 11 & -11.99 & 8.0 & 0.06 \\
\hline 1989 & 1991 & $\max$ & 11.0 & 319 & 16914 & 7374 & 9540 & 20.56 & 83.0 & 1.00 \\
\hline
\end{tabular}




\begin{tabular}{|c|c|c|c|c|c|c|c|c|c|c|}
\hline & NEATHER-N & & & & & & & & & \\
\hline $\begin{array}{r}\text { Part.Yr. } \\
1990\end{array}$ & $\begin{array}{r}\text { Cons.Yr. } \\
1986\end{array}$ & Statistic & $\begin{array}{r}\mathrm{a} \text { Reads } \\
439.0\end{array}$ & Days & NAC & NAHC & Baseload & Slope & Ref.Temp & R-Sqrd. \\
\hline 1990 & 1986 & median & 7.0 & 447 & 1612 & 1190 & 413 & 0.22 & 59.5 & 0.99 \\
\hline 1990 & 1986 & mean & 7.7 & 420 & 1720 & 1267 & 453 & 0.28 & 58.2 & 0.96 \\
\hline 1990 & 1986 & trimmed mean & 7.5 & 425 & 1689 & 1234 & 426 & 0.23 & 59.0 & 0.98 \\
\hline 1990 & 1986 & stand. dev. & 1.6 & 64 & 680 & 587 & 284 & 0.49 & 9.0 & 0.09 \\
\hline 1990 & 1986 & upper hinge & 8.0 & 460 & 2122 & 1553 & 546 & 0.29 & 62.4 & 1.00 \\
\hline 1990 & 1986 & lower hinge & 7.0 & 380 & 1243 & 857 & 272 & 0.17 & 55.5 & 0.97 \\
\hline 1990 & 1986 & $\min$ & 6.0 & 218 & 34 & 18 & 14 & 0.00 & 2.9 & 0.09 \\
\hline 1990 & 1986 & $\max$ & 15.0 & 508 & 4088 & 3431 & 1822 & 7.03 & 84.0 & 1.00 \\
\hline 1990 & 1987 & n & 546.0 & & & & & & & \\
\hline 1990 & 1987 & median & 8.0 & 352 & 1729 & 1271 & 444 & 0.23 & 59.9 & 0.98 \\
\hline 1990 & 1987 & mean & 8.2 & 328 & 1853 & 1329 & 525 & 0.26 & 58.8 & 0.94 \\
\hline 1990 & 1987 & trimmed mean & 8.2 & 332 & 1812 & 1298 & 477 & 0.24 & 59.2 & 0.96 \\
\hline 1990 & 1987 & stand. dev. & 1.2 & 49 & 756 & 596 & 418 & 0.21 & 8.5 & 0.12 \\
\hline 1990 & 1987 & upper hinge & 9.0 & 366 & 2231 & 1635 & 630 & 0.29 & 63.9 & 0.99 \\
\hline 1990 & 1987 & lower hinge & 7.0 & 295 & 1323 & 901 & 278 & 0.17 & 55.3 & 0.95 \\
\hline 1990 & 1987 & $\min$ & 6.0 & 164 & 41 & 4 & 3 & 0.00 & 18.0 & 0.06 \\
\hline 1990 & 1987 & $\max$ & 12.0 & 421 & 6075 & 4882 & 4596 & 2.91 & 83.0 & 1.00 \\
\hline 1990 & 1988 & n & 612.0 & & & & & & & \\
\hline 1990 & 1988 & median & 9.0 & 336 & 1851 & 1315 & 469 & 0.24 & 59.5 & 0.99 \\
\hline 1990 & 1988 & mean & 8.6 & 325 & 1972 & 1410 & 561 & 0.28 & 59.2 & 0.95 \\
\hline 1990 & 1988 & trimmed mean & 8.6 & 328 & 1911 & 1359 & 505 & 0.24 & 59.5 & 0.97 \\
\hline 1990 & 1988 & stand. dev. & 1.3 & 50 & 840 & 702 & 470 & 0.62 & 8.3 & 0.10 \\
\hline 1990 & 1988 & upper hinge & 9.0 & 347 & 2353 & 1730 & 653 & 0.30 & 63.5 & 0.99 \\
\hline 1990 & 1988 & lower hinge & 8.0 & 290 & 1398 & 923 & 309 & 0.18 & 55.6 & 0.95 \\
\hline 1990 & 1988 & $\min$ & 6.0 & 171 & 17 & 2 & 4 & 0.00 & 2.0 & 0.23 \\
\hline 1990 & 1988 & $\max$ & 13.0 & 421 & 7352 & 7242 & 5105 & 15.36 & 82.7 & 1.00 \\
\hline 1990 & 1989 & $\mathbf{n}$ & 579.0 & & & & & & & \\
\hline 1990 & 1989 & median & 9.0 & 348 & 1800 & 1281 & 446 & 0.22 & 61.0 & 0.98 \\
\hline 1990 & 1989 & mean & 8.5 & 332 & 1934 & 1399 & 535 & 0.52 & 59.9 & 0.94 \\
\hline 1990 & 1989 & trimmed mean & 8.5 & 335 & 1876 & 1354 & 478 & 0.23 & 60.5 & 0.96 \\
\hline 1990 & 1989 & stand. dev. & 1.3 & 44 & 858 & 680 & 444 & 6.04 & 8.2 & 0.10 \\
\hline 1990 & 1989 & upper hinge & 9.0 & 366 & 2318 & 1738 & 614 & 0.29 & 64.6 & 0.99 \\
\hline 1990 & 1989 & lower hinge & 8.0 & 306 & 1363 & 923 & 312 & 0.17 & 56.7 & 0.94 \\
\hline 1990 & 1989 & $\min$ & 6.0 & 154 & 22 & 2 & 5 & 0.00 & 5.0 & 0.27 \\
\hline 1990 & 1989 & $\max$ & 13.0 & 420 & 10608 & 6368 & 4460 & 144.96 & 81.0 & 1.00 \\
\hline 1990 & 1990 & n & 632.0 & & & & & & & \\
\hline 1990 & 1990 & median & 9.0 & 363 & 1651 & 1140 & 448 & 0.22 & 59.1 & 0.97 \\
\hline 1990 & 1990 & mean & 8.7 & 335 & 1809 & 1283 & 526 & 0.27 & 58.1 & 0.94 \\
\hline 1990 & 1990 & trimmed mean & 8.7 & 338 & 1756 & 1234 & 496 & 0.24 & 58.6 & 0.95 \\
\hline 1990 & 1990 & stand. dev. & 1.3 & 41 & 770 & 658 & 352 & 0.40 & 9.2 & 0.09 \\
\hline 1990 & 1990 & upper hinge & 10.0 & 365 & 2207 & 1572 & 672 & 0.30 & 63.6 & 0.99 \\
\hline 1990 & 1990 & lower hinge & 8.0 & 304 & 1273 & 840 & 295 & 0.16 & 53.7 & 0.93 \\
\hline 1990 & 1990 & $\min$ & 6.0 & 181 & 364 & 189 & 2 & 0.04 & 0.5 & 0.17 \\
\hline 1990 & 1990 & $\max$ & 12.0 & 411 & 7179 & 5528 & 3528 & 9.51 & 79.0 & 1.00 \\
\hline 1990 & 1991 & $\mathrm{n}$ & 577.0 & & & & & & & \\
\hline 1990 & 1991 & median & 8.0 & 244 & 1467 & 920 & 449 & 0.17 & 60.0 & 0.98 \\
\hline 1990 & 1991 & mean & 7.6 & 262 & 1581 & 1013 & 568 & 0.26 & 58.6 & 0.94 \\
\hline 1990 & 1991 & trimmed mean & 7.6 & 263 & 1519 & 986 & 512 & 0.18 & 59.4 & 0.96 \\
\hline 1990 & 1991 & stand. dev. & 0.8 & 33 & 729 & 546 & 522 & 0.74 & 10.1 & 0.12 \\
\hline 1990 & 1991 & upper hinge & 8.0 & 302 & 1833 & 1251 & 674 & 0.22 & 64.0 & 0.99 \\
\hline 1990 & 1991 & lower hinge & 7.0 & 242 & 1109 & 696 & 287 & 0.13 & 55.4 & 0.94 \\
\hline 1990 & 1991 & $\min$ & 6.0 & 134 & 360 & -3018 & 0 & -0.50 & 8.0 & 0.04 \\
\hline 1990 & 1991 & $\max$ & 10.0 & 321 & 8678 & 4419 & 7225 & 10.84 & 83.0 & 1.00 \\
\hline
\end{tabular}




\begin{tabular}{|c|c|c|c|c|c|c|c|c|c|c|c|}
\hline & & & . & & & & & & & & \\
\hline $\begin{array}{r}\text { Part.Yr. } \\
1991\end{array}$ & Cor & $\begin{array}{l}\text { Yr. } \\
1986\end{array}$ & Statistic & $\begin{array}{r}\text { n Reads } \\
358.0\end{array}$ & Days & NAC & NAHC & Baseload & Slope & Ref.Temp & R-Sqrd. \\
\hline 1991 & & 1986 & median & 8.0 & 447 & 1519 & 1094 & 392 & 0.20 & 58.5 & 0.99 \\
\hline 1991 & & 1986 & mean & 7.9 & 426 & 1605 & 1179 & 426 & 0.35 & 57.8 & 0.95 \\
\hline 1991 & & 1986 & trimmed mean & 7.7 & 430 & 1573 & 1142 & 409 & 0.21 & 58.4 & 0.97 \\
\hline 1991 & & 1986 & stand. dev. & 1.9 & 57 & 640 & 573 & 255 & 2.10 & 8.8 & 0.10 \\
\hline 1991 & & 1986 & upper hinge & 8.0 & 459 & 1939 & 1413 & 544 & 0.27 & 62.9 & 1.00 \\
\hline 1991 & & 1986 & lower hinge & 7.0 & 395 & 1135 & 790 & 255 & 0.15 & 54.6 & 0.97 \\
\hline 1991 & & 1986 & $\min$ & 6.0 & 244 & 295 & 25 & 9 & 0.02 & 4.0 & 0.41 \\
\hline 1991 & & 1986 & $\max$ & 14.0 & 515 & 4328 & 3533 & 1678 & 39.64 & 79.0 & 1.00 \\
\hline 1991 & & 1987 & $\mathrm{n}$ & 451.0 & & & & & & & \\
\hline 1991 & & 1987 & median & 8.0 & 358 & 1630 & 1158 & 402 & 0.21 & 59.1 & 0.98 \\
\hline 1991 & & 1987 & mean & 8.2 & 330 & 1727 & 1249 & 477 & 0.24 & 58.3 & 0.93 \\
\hline 1991 & & 1987 & trimmed mean & 8.2 & 334 & 1690 & 1216 & 441 & 0.22 & 58.9 & 0.95 \\
\hline 1991 & & 1987 & stand. dev. & 1.2 & 50 & 710 & 607 & 352 & 0.16 & 7.7 & 0.14 \\
\hline 1991 & & 1987 & upper hinge & 9.0 & 365 & 2103 & 1575 & 584 & 0.28 & 62.7 & 0.99 \\
\hline 1991 & & 1987 & lower hinge & 7.0 & 304 & 1238 & 828 & 266 & 0.16 & 55.4 & 0.94 \\
\hline 1991 & & 1987 & $\min$ & 6.0 & 138 & 115 & -341 & 8 & -0.46 & 13.0 & 0.02 \\
\hline 1991 & & 1987 & $\max$ & 12.0 & 421 & 5202 & 4123 & 3526 & 1.70 & 77.0 & 1.00 \\
\hline 1991 & & 1988 & $\mathbf{n}$ & 464.0 & & & & & & & \\
\hline 1991 & & 1988 & median & 9.0 & 336 & 1649 & 1206 & 412 & 0.21 & 58.7 & 0.98 \\
\hline 1991 & & 1988 & mean & 8.6 & 329 & 1768 & 1291 & 476 & 0.26 & 58.3 & 0.95 \\
\hline 1991 & & 1988 & trimmed mean & 8.6 & 332 & 1723 & 1255 & 441 & 0.23 & 58.8 & 0.97 \\
\hline 1991 & & 1988 & stand. dev. & 1.3 & 48 & 760 & 628 & 343 & 0.27 & 8.6 & 0.09 \\
\hline 1991 & & 1988 & upper hinge & 9.0 & 364 & 2157 & 1597 & 604 & 0.28 & 63.2 & 0.99 \\
\hline 1991 & & 1988 & lower hinge & 8.0 & 300 & 1224 & 834 & 256 & 0.17 & 54.5 & 0.96 \\
\hline 1991 & & 1988 & $\min$ & 6.0 & 169 & 304 & 12 & 2 & 0.01 & 9.0 & 0.21 \\
\hline 1991 & & 1988 & $\max$ & 13.0 & 412 & 5423 & 4676 & 2818 & 3.75 & 82.0 & 1.00 \\
\hline 1991 & & 1989 & $\mathbf{n}$ & 426.0 & & & & & & & \\
\hline 1991 & & 1989 & median & 9.0 & 357 & 1702 & 1211 & 434 & 0.21 & 59.7 & 0.97 \\
\hline 1991 & & 1989 & mean & 8.6 & 331 & 1840 & 1314 & 526 & 0.25 & 59.1 & 0.93 \\
\hline 1991 & & 1989 & trimmed mean & 8.6 & 336 & 1770 & 1261 & 473 & 0.22 & 59.6 & 0.95 \\
\hline 1991 & & 1989 & stand. dev. & 1.3 & 45 & 914 & 744 & 464 & 0.31 & 8.2 & 0.11 \\
\hline 1991 & & 1989 & upper hinge & 9.0 & 366 & 2228 & 1589 & 626 & 0.27 & 63.7 & 0.99 \\
\hline 1991 & & 1989 & lower hinge & 8.0 & 305 & 1227 & 847 & 305 & 0.15 & 55.2 & 0.93 \\
\hline 1991 & & 1989 & $\min$ & 6.0 & 161 & 197 & 38 & 3 & 0.01 & 14.0 & 0.03 \\
\hline 1991 & & 1989 & $\max$ & 12.0 & 398 & 9771 & 8864 & 4843 & 5.24 & 81.0 & 1.00 \\
\hline 1991 & & 1990 & $\mathbf{n}$ & 492.0 & & & & & & & \\
\hline 1991 & & 1990 & median & 9.0 & 364 & 1840 & 1313 & 461 & 0.23 & 60.5 & 0.98 \\
\hline 1991 & & 1990 & mean & 8.7 & 335 & 1954 & 1432 & 522 & 0.29 & 59.4 & 0.95 \\
\hline 1991 & & 1990 & trimmed mean & 8.7 & 339 & 1902 & 1380 & 486 & 0.24 & 59.9 & 0.96 \\
\hline 1991 & & 1990 & stand. dev. & 1.3 & 42 & 797 & 724 & 362 & 0.61 & 8.3 & 0.09 \\
\hline 1991 & & 1990 & upper hinge & 9.0 & 365 & 2380 & 1755 & 650 & 0.30 & 64.4 & 0.99 \\
\hline 1991 & & 1990 & lower hinge & 8.0 & 305 & 1370 & 924 & 297 & 0.17 & 56.0 & 0.95 \\
\hline 1991 & & 1990 & $\min$ & 6.0 & 145 & 341 & 16 & 1 & 0.00 & 7.0 & 0.18 \\
\hline 1991 & $-\cdots$ & 1990 & $\max$ & 12.0 & 418 & 5813 & 5197 & 3465 & 11.87 & 79.0 & 1.00 \\
\hline 1991 & & 1991 & $\mathrm{n}$ & 420.0 & & & & & & & \\
\hline 1991 & & 1991 & median & 8.0 & 244 & 1730 & 1108 & 522 & 0.21 & 58.1 & 0.96 \\
\hline 1991 & & 1991 & mean & 7.6 & 264 & 1887 & 1227 & 660 & 0.32 & 57.9 & 0.92 \\
\hline 1991 & & 1991 & trimmed mean & 7.6 & 265 & 1816 & 1178 & 601 & 0.22 & 58.3 & 0.94 \\
\hline 1991 & & 1991 & stand. dev. & 0.8 & 34 & 909 & 660 & 554 & 0.94 & 10.4 & 0.11 \\
\hline 1991 & & 1991 & upper hinge & 8.0 & 302 & 2289 & 1509 & 801 & 0.29 & 63.8 & 0.99 \\
\hline 1991 & & 1991 & lower hinge & 7.0 & 241 & 1243 & 750 & 312 & 0.15 & 53.6 & 0.90 \\
\hline 1991 & & 1991 & $\min$ & 6.0 & 160 & 167 & 29 & 7 & 0.01 & 12.2 & 0.12 \\
\hline 1991 & & 1991 & $\max$ & 10.0 & 330 & 8603 & 4694 & 4403 & 16.97 & 82.0 & 1.00 \\
\hline
\end{tabular}

(A "hinge" is analogous to a quartile.) 


\begin{tabular}{|c|c|c|c|c|c|c|c|c|c|c|}
\hline \multicolumn{11}{|c|}{ UUMMARY WEATHER-NORMALIZATION STATISTICS-MADISON GAS \& ELECTRIC COMPANY } \\
\hline Part.Yr. & Cons. Yr. & Statistic & n reads & Days & NAC & NAHC & Baseload & Slope & Ref. Te & R-Sqrd. \\
\hline 1983 & 1987 & $\mathbf{n}$ & 31.0 & & & & & & & \\
\hline 1983 & 1987 & median & 9.0 & 354 & 977 & 740 & 239 & 0.14 & 59.0 & 0.98 \\
\hline 1983 & 1987 & mean & 9.2 & 351 & 1073 & 808 & 265 & 0.15 & 58.1 & 0.91 \\
\hline 1983 & 1987 & trimmed mean & 9.3 & 352 & 1054 & 791 & 240 & 0.14 & 58.6 & 0.95 \\
\hline 1983 & 1987 & stand. dev. & 0.9 & 17 & 373 & 286 & 233 & 0.07 & 6.7 & 0.17 \\
\hline 1983 & 1987 & upper hinge & 10.0 & 365 & 1234 & 909 & 327 & 0.15 & 60.9 & 0.98 \\
\hline 1983 & 1987 & lower hinge & 9.0 & 336 & 768 & 600 & 156 & 0.11 & 55.0 & 0.96 \\
\hline 1983 & 1987 & $\min$ & 7.0 & 306 & 401 & 344 & -69 & 0.06 & 35.2 & 0.24 \\
\hline 1983 & 1987 & $\max$ & 10.0 & 370 & 2018 & 1455 & 1325 & 0.41 & 73.0 & 1.00 \\
\hline 1983 & 1988 & $\mathbf{n}$ & 31.0 & & & & & & & \\
\hline 1983 & 1988 & median & 11.0 & 365 & 948 & 672 & 257 & 0.14 & 57.4 & 0.99 \\
\hline 1983 & 1988 & mean & 11.0 & 350 & 1014 & 751 & 263 & 0.17 & 55.8 & 0.93 \\
\hline 1983 & 1988 & trimmed mean & 11.1 & 352 & 1012 & 740 & 256 & 0.14 & 56.4 & 0.96 \\
\hline 1983 & 1988 & stand. dev. & 1.1 & 24 & 324 & 292 & 167 & 0.14 & 10.3 & 0.14 \\
\hline 1983 & 1988 & upper hinge & 12.0 & 366 & 1223 & 831 & 300 & 0.16 & 59.5 & 0.99 \\
\hline 1983 & 1988 & lower hinge & 11.0 & 337 & 755 & 546 & 147 & 0.10 & 53.8 & 0.96 \\
\hline 1983 & 1988 & $\min$ & 8.0 & 247 & 367 & 311 & -60 & 0.05 & 21.0 & 0.48 \\
\hline 1983 & 1988 & $\max$ & 12.0 & 369 & 1643 & 1364 & 784 & 0.86 & 77.3 & 0.99 \\
\hline 1983 & 1989 & $\mathbf{n}$ & 31.0 & & & & & & & \\
\hline 1983 & 1989 & median & 12.0 & 364 & 1056 & 703 & 208 & 0.13 & 56.3 & 0.98 \\
\hline 1983 & 1989 & mean & 11.5 & 360 & 1040 & 792 & 248 & 0.15 & 56.2 & 0.97 \\
\hline 1983 & 1989 & trimmed mean & 11.7 & 362 & 1033 & 771 & 251 & 0.15 & 56.2 & 0.97 \\
\hline 1983 & 1989 & stand. dev. & 1.4 & 15 & 336 & 308 & 163 & 0.07 & 7.6 & 0.04 \\
\hline 1983 & 1989 & upper hinge & 12.0 & 364 & 1201 & 920 & 298 & 0.18 & 57.8 & 0.99 \\
\hline 1983 & 1989 & lower hinge & 12.0 & 362 & 777 & 582 & 163 & 0.11 & 53.9 & 0.96 \\
\hline 1983 & 1989 & $\min$ & 6.0 & 307 & 373 & 306 & -196 & 0.06 & 36.0 & 0.77 \\
\hline 1983 & 1989 & $\max$ & 13.0 & 392 & 1752 & 1561 & 594 & 0.40 & 79.0 & 1.00 \\
\hline 1983 & 1990 & $\mathbf{n}$ & 33.0 & & & & & & & \\
\hline 1983 & 1990 & median & 12.0 & 364 & 1000 & 732 & 277 & 0.14 & 57.9 & 0.99 \\
\hline 1983 & 1990 & mean & 11.4 & 362 & 1064 & 801 & 263 & 0.17 & 56.1 & 0.97 \\
\hline 1983 & 1990 & trimmed mean & 11.7 & 364 & 1053 & 780 & 254 & 0.15 & 57.2 & 0.98 \\
\hline 1983 & 1990 & stand. dev. & 1.6 & 16 & 325 & 286 & 174 & 0.12 & 7.0 & 0.07 \\
\hline 1983 & 1990 & upper hinge & 12.0 & 364 & 1257 & 902 & 359 & 0.17 & 59.4 & 0.99 \\
\hline 1983 & 1990 & lower hinge & 12.0 & 364 & 878 & 626 & 145 & 0.11 & 55.5 & 0.98 \\
\hline 1983 & 1990 & $\min$ & 6.0 & 273 & 430 & 305 & -6 & 0.07 & 31.0 & 0.67 \\
\hline 1983 & 1990 & $\max$ & 12.0 & 367 & 1837 & 1687 & 769 & 0.71 & 63.0 & 1.00 \\
\hline 1983 & 1991 & $\mathbf{n}$ & 33.0 & & & & & & & \\
\hline 1983 & 1991 & median & 10.0 & 306 & 998 & 735 & 278 & 0.12 & 58.7 & 0.99 \\
\hline 1983 & 1991 & mean & 9.8 & 317 & 1079 & 797 & 282 & 0.13 & 59.2 & 0.91 \\
\hline 1983 & 1991 & trimmed mean & 10.0 & 318 & 1062 & 770 & 267 & 0.13 & 58.7 & 0.93 \\
\hline 1983 & 1991 & stand. dev. & 1.6 & 16 & 344 & 319 & 223 & 0.06 & 6.2 & 0.17 \\
\hline 1983 & 1991 & upper hinge & 11.0 & 335 & 1216 & 894 & 381 & 0.16 & 61.8 & 0.99 \\
\hline 1983 & 1991 & lower hinge & 10.0 & 306 & 861 & 578 & 124 & 0.10 & 54.4 & 0.94 \\
\hline 1983 & 1991 & $\min$ & 5.0 & 274 & 496 & 381 & -160 & 0.06 & 49.5 & 0.47 \\
\hline 1983 & 1991 & $\max$ & 11.0 & 338 & 1976 & 1732 & 889 & 0.34 & 82.0 & 1.00 \\
\hline
\end{tabular}


SUMMARY WEATHER-NORMALIZATION STATISTICS-MADISON GAS \& ELECTRIC COMPANY

\begin{tabular}{|c|c|c|c|c|c|c|c|c|c|c|}
\hline Part.Yr. & Cons.Yr. & Statistic & a reads & Dayd & NAC & NAIHC & Bancload & Slope & Ref. Te & R-Sqrd. \\
\hline 1984 & 1987 & n & 312.0 & & & & & & & \\
\hline 1984 & 1987 & median & 9.0 & 336 & 939 & 739 & 215 & 0.12 & 58.6 & 0.97 \\
\hline 1984 & 1987 & $\operatorname{mean}$ & 9.1 & 345 & 1008 & 794 & 214 & 0.15 & 57.5 & 0.91 \\
\hline 1984 & 1987 & trimmed mean & 9.2 & 348 & 970 & 759 & 213 & 0.14 & 57.9 & 0.93 \\
\hline 1984 & 1987 & stand. dev. & 1.0 & 22 & 442 & 417 & 140 & 0.14 & 9.0 & 0.16 \\
\hline 1984 & 1987 & upper hinge & 10.0 & 365 & 1161 & 930 & 288 & 0.17 & 61.2 & 0.99 \\
\hline 1984 & 1987 & lower hinge & 9.0 & 336 & 715 & 510 & 127 & 0.10 & 55.3 & 0.93 \\
\hline 1984 & 1987 & $\min$ & 4.0 & 244 & 153 & 29 & -272 & 0.01 & 15.0 & 0.12 \\
\hline 1984 & 1987 & $\max$ & 10.0 & 378 & $3 i 93$ & 2777 & 702 & 1.32 & 84.0 & 1.00 \\
\hline 1984 & 1988 & $\mathbf{n}$ & 351.0 & & & & & & & \\
\hline 1984 & 1988 & median & 11.0 & 365 & 946 & 668 & 254 & 0.12 & 57.0 & 0.98 \\
\hline 1984 & 1988 & mean & 11.0 & 352 & 1006 & 740 & 266 & 0.16 & 56.3 & 0.93 \\
\hline 1984 & 1988 & trimmed mean & 12.1 & 354 & 964 & 704 & 255 & 0.13 & 56.7 & 0.95 \\
\hline 1984 & 1988 & stand. dev. & 1.3 & 21 & 480 & 410 & 177 & 0.32 & 8.9 & 0.13 \\
\hline 1984 & 1988 & upper hinge & 12.0 & 368 & 1157 & 894 & 331 & 0.16 & 60.6 & 0.99 \\
\hline 1984 & 1988 & lower hinge & 11.0 & 337 & 718 & 478 & 166 & 0.09 & 52.9 & 0.95 \\
\hline 1984 & 1988 & $\min$ & 4.0 & 243 & 46 & 13 & -142 & 0.00 & 4.0 & 0.12 \\
\hline 1984 & 1988 & $\max$ & 12.0 & 378 & 4759 & 2953 & 1806 & 5.73 & 86.0 & 1.00 \\
\hline 1984 & 1989 & $\mathbf{n}$ & 354.0 & 354 & 334 & 354 & 354 & 354.00 & 354.0 & 354.00 \\
\hline 1984 & 1989 & median & 120 & 364 & 966 & 687 & 256 & 0.12 & 57.7 & 0.98 \\
\hline 1984 & 1989 & $\operatorname{mean}$ & 11.3 & 361 & 1012 & 746 & 266 & 0.15 & 57.0 & 0.92 \\
\hline 1984 & 1989 & trimmed mean & 11.5 & 363 & 972 & 711 & 256 & 0.13 & 57.5 & 0.95 \\
\hline 1984 & 1989 & stand. dev. & 1.5 & 15 & 490 & 424 & 165 & 0.14 & 8.4 & 0.15 \\
\hline 1984 & 1989 & upper hinge & 120 & 364 & 1163 & 891 & 343 & 0.17 & 61.0 & 0.99 \\
\hline 1984 & 1989 & lower hinge & 11.0 & 364 & 728 & 485 & 167 & 0.09 & 54.4 & 0.94 \\
\hline 1984 & 1989 & $\min$ & 4.0 & 240 & 43 & 6 & -71 & 0.00 & 8.0 & 0.03 \\
\hline 1984 & 1989 & $\max$ & 13.0 & 407 & 4831 & 3633 & 1198 & 1.37 & 82.6 & 1.00 \\
\hline 1984 & 1990 & $\mathbf{n}$ & 353.0 & & & & & & & \\
\hline 1984 & 1990 & median & 12.0 & 364 & 956 & 672 & 261 & 0.12 & 58.0 & 0.98 \\
\hline 1984 & 1990 & mean & 113 & 363 & 1013 & 735 & 278 & 0.16 & 56.3 & 0.94 \\
\hline 1984 & 1990 & trimmed mean & 11.6 & 364 & 971 & 697 & 270 & 0.14 & 57.1 & 0.96 \\
\hline 1984 & 1990 & stand. dev. & 1.5 & 11 & 470 & 399 & 183 & 0.16 & 9.8 & 0.12 \\
\hline 1984 & 1990 & upper hinge & 120 & 364 & 1172 & 901 & 364 & 0.16 & 61.3 & 0.99 \\
\hline 1984 & 1990 & lower hinge & 12.0 & 364 & 734 & 492 & 174 & 0.09 & 53.5 & 0.95 \\
\hline 1984 & 1990 & $\min$ & 4.0 & 274 & 40 & 8 & -262 & 0.00 & 13.0 & 0.19 \\
\hline 1984 & 1990 & $\operatorname{man} x$ & 13.0 & 395 & 4517 & 3279 & 1239 & 1.88 & 81.2 & 1.00 \\
\hline 1984 & 1991 & $\mathbf{n}$ & 357.0 & 357 & 357 & 357 & 357 & 357.00 & 357.0 & 357.00 \\
\hline 1984 & 1991 & median & 10.0 & 306 & 924 & $\operatorname{set}$ & 241 & 0.11 & 59.1 & 0.98 \\
\hline 1984 & 1991 & mean & 9.8 & 315 & 993 & 746 & 248 & 0.13 & 59.2 & 0.90 \\
\hline 1984 & 1991 & trimmed mean & 9.9 & 316 & 951 & 703 & 242 & 0.12 & $\$ 9.1$ & 0.93 \\
\hline 2984 & 1991 & stand. dey. & 13 & 16 & 496 & 452 & 175 & 0.08 & 9.1 & 0.18 \\
\hline 1984 & 1991 & upper hinge & 11.0 & 334 & 1143 & 910 & 347 & 0.15 & 62.6 & 0.99 \\
\hline 1984 & 1991 & lower hinge & 10.0 & 304 & 701 & 478 & 142 & 0.09 & 55.2 & 0.92 \\
\hline 1984 & 1991 & $\min$ & 4.0 & 243 & 7 & 2 & -307 & 0.00 & -2.0 & 0.01 \\
\hline 1984 & 1991 & $\max$ & 11.0 & 343 & 5238 & 4376 & 1131 & 0.93 & 82.0 & 1.00 \\
\hline
\end{tabular}


SUMMARY WEATHER-NORMALIZATION STATISTICS-MADISON GAS \& ELECTRIC COMPANY

\begin{tabular}{|c|c|c|c|c|c|c|c|c|c|c|}
\hline $\begin{array}{r}\text { Part.Yr. } \\
1985\end{array}$ & $\begin{array}{r}\text { Cons.Yr. } \\
1987\end{array}$ & Statistic & $\begin{array}{r}\text { a reads } \\
295.0\end{array}$ & Days & NAC & NAHC & Baseload & Slope & Ref. Te & R-Sqrd. \\
\hline 1985 & 1987 & median & 9.0 & 337 & 851 & 679 & 177 & 0.12 & 58.9 & 0.98 \\
\hline 1985 & 1987 & mean & 9.1 & 345 & 951 & 752 & 199 & 0.15 & 57.7 & 0.92 \\
\hline 1985 & 1987 & trimmed mean & 9.2 & 349 & 920 & 721 & 192 & 0.13 & 58.3 & 0.95 \\
\hline 1985 & 1987 & stand. dev. & 1.0 & 24 & 438 & 409 & 155 & 0.21 & 8.3 & 0.16 \\
\hline 1985 & 1987 & upper hinge & 10.0 & 365 & 1121 & 895 & 272 & 0.15 & 61.5 & 0.99 \\
\hline 1985 & 1987 & lower hinge & 9.0 & 336 & 671 & 496 & 98 & 0.09 & 55.5 & 0.93 \\
\hline 1985 & 1987 & $\min$ & 5.0 & 243 & 38 & 5 & -444 & 0.00 & 18.1 & 0.08 \\
\hline 1985 & 1987 & $\max$ & 10.0 & 378 & 2798 & 2905 & 832 & 2.90 & 84.0 & 1.00 \\
\hline 1985 & 1988 & $\mathbf{n}$ & 312.0 & 312 & 312 & 312 & 312 & 312.00 & 312.0 & 312.00 \\
\hline 1985 & 1988 & median & 11.0 & 365 & 897 & 669 & 235 & 0.12 & 58.2 & 0.99 \\
\hline 1985 & 1988 & mean & 10.9 & 350 & 967 & 728 & 240 & 0.13 & 57.7 & 0.93 \\
\hline 1985 & 1988 & trimmed mean & 11.1 & 352 & 938 & 703 & 231 & 0.12 & 57.8 & 0.96 \\
\hline 1985 & 1988 & stand. dev. & 1.4 & 21 & 420 & 383 & 161 & 0.09 & 7.8 & 0.16 \\
\hline 1985 & 1988 & upper hinge & 12.0 & 366 & 1172 & 894 & 307 & 0.15 & 61.7 & 0.99 \\
\hline 1985 & 1988 & lower hinge & 11.0 & 337 & 706 & 481 & 129 & 0.09 & 53.9 & 0.95 \\
\hline 1985 & 1988 & $\min$ & 5.0 & 257 & 25 & 7 & -243 & 0.00 & 24.0 & 0.01 \\
\hline 1985 & 1988 & $\max$ & 12.0 & 379 & 2738 & 2394 & 1087 & 1.06 & 86.0 & 1.00 \\
\hline 1985 & 1989 & $\mathbf{n}$ & 315.0 & & & & & & & \\
\hline 1985 & 1989 & median & 12.0 & 364 & 931 & 684 & 224 & 0.12 & 59.0 & 0.98 \\
\hline 1985 & 1989 & $\operatorname{mean}$ & 11.3 & 362 & 996 & 762 & 234 & 0.14 & 58.4 & 0.93 \\
\hline 1985 & 1989 & trimmed mean & 11.6 & 363 & 959 & 726 & 227 & 0.13 & 58.9 & 0.95 \\
\hline 1985 & 1989 & stand. dev. & 1.5 & 15 & 436 & 408 & 162 & 0.13 & 8.7 & 0.15 \\
\hline 1985 & 1989 & upper hinge & 12.0 & 364 & 1186 & 913 & 329 & 0.15 & 62.4 & 0.99 \\
\hline 1985 & 1989 & lower hinge & 11.0 & 364 & 703 & 506 & 120 & 0.09 & 55.0 & 0.95 \\
\hline 1985 & 1989 & $\min$ & 4.0 & 241 & 60 & 6 & -260 & 0.00 & 14.6 & 0.03 \\
\hline 1985 & 1989 & $\max$ & 13.0 & 397 & 3133 & 3393 & 960 & 1.54 & 83.0 & 1.00 \\
\hline 1985 & 1990 & $\mathbf{n}$ & 319.0 & & & & & & & \\
\hline 1985 & 1990 & median & 12.0 & 364 & 903 & 659 & 222 & 0.12 & 58.0 & 0.99 \\
\hline 1985 & 1990 & $\operatorname{mean}$ & 11.4 & 361 & 989 & 734 & 255 & 0.14 & 57.2 & 0.94 \\
\hline 1985 & 1990 & trimmed mean & 11.6 & 363 & 950 & 703 & 241 & 0.13 & 57.7 & 0.97 \\
\hline 1985 & 1990 & stand. dev. & 1.5 & 15 & 449 & 385 & 200 & 0.11 & 8.4 & 0.12 \\
\hline 1985 & 1990 & upper hinge & 12.0 & 364 & 1147 & 879 & 327 & 0.15 & 61.2 & 0.99 \\
\hline 1985 & 1990 & lower hinge & 12.0 & 364 & 696 & 491 & 131 & 0.09 & 54.7 & 0.96 \\
\hline 1985 & 1990 & $\min$ & 4.0 & 265 & 55 & 6 & -264 & 0.00 & 15.0 & 0.10 \\
\hline 1985 & 1990 & $\max$ & 12.0 & 394 & 3645 & 2946 & 2065 & 1.36 & 80.0 & 1.00 \\
\hline 1985 & 1991 & $\mathbf{n}$ & 317.0 & & & & & & & \\
\hline 1985 & 1991 & median & 10.0 & 306 & 887 & 682 & 215 & 0.11 & 59.9 & 0.98 \\
\hline 1985 & 1991 & mean & 9.9 & 315 & 987 & 755 & 231 & 0.33 & 59.8 & 0.92 \\
\hline 1985 & 1991 & trimmed mean & 10.1 & 316 & 949 & 721 & 222 & 0.12 & 60.0 & 0.94 \\
\hline 1985 & 1991 & stand. dev. & 1.1 & 18 & 457 & 421 & 169 & 2.66 & 10.3 & 0.16 \\
\hline 1985 & 1991 & upper hinge & 11.0 & 335 & 1146 & 889 & 308 & 0.14 & 64.2 & 0.99 \\
\hline 1985 & 1991 & lower hinge & 10.0 & 304 & 714 & 499 & 122. & 0.09 & 55.0 & 0.93 \\
\hline 1985 & 1991 & $\min$ & 4.0 & 243 & 56 & 4 & -215 & 0.00 & -2.0 & 0.01 \\
\hline 1985 & 1991 & $\max$ & 11.0 & 349 & 2948 & 2877 & 1270 & 44.99 & 82.0 & 1.00 \\
\hline
\end{tabular}


SUMMARY WEATHER-NORMALIZATION STATISTICS-MADISON GAS \& ELECTRIC COMPANY

\begin{tabular}{|c|c|c|c|c|c|c|c|c|c|c|}
\hline Part.Yr. & Cons. Yr. & Statistic & $n$ reads & Days & NAC & NAHC & Baseload & Slope & Ref. Te & R-Sqrd. \\
\hline 1986 & 1987 & $\mathbf{n}$ & 177.0 & & & & & & & \\
\hline 1986 & 1987 & median & 9.0 & 336 & 868 & 683 & 187 & 0.12 & 59.2 & 0.97 \\
\hline 86 & 1987 & mean & 9.2 & 344 & 949 & 749 & 201 & 0.13 & 58.1 & 0.93 \\
\hline 1986 & 1987 & trimmed mean & 9.3 & 346 & 904 & 698 & 190 & 0.12 & 58.4 & 0.95 \\
\hline 1986 & 1987 & stand. dev. & 0.7 & 22 & 499 & 465 & 174 & 0.08 & 8.1 & 0.13 \\
\hline 1986 & 1987 & upper hinge & 10.0 & 365 & 1114 & 855 & 262 & 0.15 & 62.2 & 0.99 \\
\hline 1986 & 1987 & lower hinge & 9.0 & 336 & 638 & 482 & 117 & 0.09 & 55.4 & 0.94 \\
\hline 1986 & 1987 & $\min$ & 6.0 & 244 & 25 & 8 & -317 & 0.00 & 23.0 & 0.13 \\
\hline 1986 & 1987 & $\max$ & 10.0 & 375 & 4215 & 3964 & 1554 & 0.68 & 81.0 & 1.00 \\
\hline 1986 & 1988 & $\mathbf{n}$ & 199.0 & & & & & & & \\
\hline 1986 & 1988 & median & 11.0 & 365 & 877 & 610 & 212 & 0.12 & 57.4 & 0.98 \\
\hline 1986 & 1988 & mean & 11.1 & 353 & 932 & 689 & 243 & 0.15 & 55.9 & 0.93 \\
\hline 1986 & 1988 & trimmed mean & 11.3 & 355 & 892 & 642 & 230 & 0.12 & 56.5 & 0.96 \\
\hline 1986 & 1988 & stand. dev. & 1.3 & 20 & 480 & 460 & 188 & 0.23 & 10.2 & 0.16 \\
\hline 1986 & 1988 & upper hinge & 12.0 & 366 & 1107 & 819 & 325 & 0.15 & 60.6 & 0.99 \\
\hline 1986 & 1988 & lower hinge & 11.0 & 337 & 645 & 432 & 130 & 0.09 & 52.1 & 0.94 \\
\hline 1986 & 1988 & $\min$ & 5.0 & 248 & 21 & 1 & -285 & 0.00 & 3.4 & 0.01 \\
\hline 1986 & 1988 & $\max$ & 12.0 & 382 & 4097 & 4044 & 1222 & 3.06 & 87.0 & 1.00 \\
\hline 1986 & 1989 & $\mathbf{n}$ & 200.0 & & & & & & & \\
\hline 1986 & 1989 & median & 12.0 & 364 & 878 & 677 & 220 & 0.12 & 57.7 & 0.98 \\
\hline 1986 & 1989 & mean & 11.3 & 362 & 974 & 743 & 230 & 0.14 & 57.4 & 0.92 \\
\hline 1986 & 1989 & trimmed mean & 11.6 & 363 & 927 & 697 & 224 & 0.13 & 57.7 & 0.94 \\
\hline 1986 & 1989 & stand. dev. & 1.7 & 9 & 480 & 459 & 166 & 0.12 & 8.8 & 0.15 \\
\hline 1986 & 1989 & upper hinge & 12.0 & 364 & 1105 & 857 & 322 & 0.16 & 61.2 & 0.99 \\
\hline 1986 & 1989 & lower hinge & 12.0 & 364 & 665 & 475 & 127 & 0.09 & 53.6 & 0.94 \\
\hline 1986 & 1989 & $\min$ & 4.0 & 305 & 19 & 4 & -422 & 0.00 & 27.0 & 0.05 \\
\hline 1986 & 1989 & $\max$ & 13.0 & 393 & 3849 & 3730 & 1143 & 1.34 & 83.0 & 1.00 \\
\hline 1986 & 1990 & n & 201.0 & & & & & & & \\
\hline 1986 & 1990 & median & 12.0 & 364 & 900 & 667 & 232. & 0.11 & 58.2 & 0.98 \\
\hline 1986 & 1990 & mean & 11.5 & 363 & 976 & 725 & 251 & 0.16 & 56.8 & 0.93 \\
\hline 1986 & 1990 & trimmed mean & 11.7 & 364 & 930 & 681 & 237 & 0.13 & 57.7 & 0.96 \\
\hline 1986 & 1990 & stand. dev. & 1.4 & 13 & 520 & 478 & 186 & 0.18 & 9.5 & 0.13 \\
\hline 1986 & 1990 & upper hinge & 12.0 & 364 & 1122 & 816 & 330 & 0.16 & 61.4 & 0.99 \\
\hline 1986 & 1990 & lower hinge & 12.0 & 364 & 649 & 458 & 145 & 0.08 & 54.9 & 0.94 \\
\hline 1986 & 1990 & $\min$ & 5.0 & 256 & 18 & 3 & -169 & 0.00 & 10.9 & 0.05 \\
\hline 1986 & 1990 & $\max$ & 13.0 & 395 & 4200 & 4370 & 1364 & 1.73 & 80.0 & 1.00 \\
\hline 1986 & 1991 & $\mathbf{n}$ & 202.0 & & & & & & & \\
\hline 1986 & 1991 & median & 10.0 & 306 & 907 & 652 & 232 & 0.11 & 59.8 & 0.98 \\
\hline 1986 & 1991 & mean & 9.9 & 313 & 936 & 704 & 232 & 0.11 & 60.3 & 0.94 \\
\hline 1986 & 1991 & trimmed mean & 10.0 & 313 & 910 & 678 & 225 & 0.11 & 60.2 & 0.96 \\
\hline 1986 & 1991 & stand. dev. & 1.0 & 14 & 431 & 383 & 174 & 0.06 & 8.4 & 0.12 \\
\hline 1986 & 1991 & upper hinge & 10.0 & 332 & 1124 & 866 & 315 & 0.14 & 64.5 & 0.99 \\
\hline 1986 & 1991 & lower hinge & 10.0 & 304 & 652 & 476 & 129 & 0.08 & 55.7 & 0.95 \\
\hline 1986 & 1991 & $\min$ & 6.0 & 244 & 15 & 4 & -428 & 0.00 & 33.8 & 0.33 \\
\hline 1986 & 1991 & $\max$ & 11.0 & 336 & 2936 & 2507 & 1281 & 0.45 & 82.0 & 1.00 \\
\hline
\end{tabular}




\begin{tabular}{|c|c|c|c|c|c|c|c|c|c|c|}
\hline Part.Yr. & Cons.Yr. & Statistic & n reads & Days & NAC & NAHC & Baseload & Slope & Ref. Te & R-Sqrd. \\
\hline 1987 & 1987 & $\mathbf{n}$ & 204.0 & & & & & & & \\
\hline 1987 & 1987 & median & 9.0 & 336 & 984 & 787 & 197 & 0.13 & 59.0 & 0.97 \\
\hline 1987 & 1987 & mean & 9.0 & 340 & 1099 & 888 & 211 & 0.17 & 58.5 & 0.93 \\
\hline 1987 & 1987 & trimmed mean & 9.1 & 343 & 1041 & 840 & 198 & 0.15 & 58.8 & 0.95 \\
\hline 1987 & 1987 & stand. dev. & 1.0 & 26 & 603 & 526 & 190 & 0.17 & 8.2 & 0.11 \\
\hline 1987 & 1987 & upper hinge & 10.0 & 365 & 1301 & 1053 & 274 & 0.18 & 62.7 & 0.99 \\
\hline 1987 & 1987 & lower hinge & 9.0 & 336 & 768 & 570 & 109 & 0.09 & 56.0 & 0.94 \\
\hline 1987 & 1987 & $\min$ & 5.0 & 241 & 13 & 5 & -357 & 0.00 & 23.0 & 0.38 \\
\hline 1987 & 1987 & $\max$ & 10.0 & 376 & 5215 & 3947 & 1417 & 1.59 & 84.0 & 1.00 \\
\hline 1987 & 1988 & $\mathbf{n}$ & 226.0 & & & & & & & \\
\hline 1987 & 1988 & median & 11.0 & 366 & 878 & 646 & 217 & 0.12 & 58.6 & 0.98 \\
\hline 1987 & 1988 & mean & 11.0 & 351 & 986 & 749 & 237 & 0.14 & 57.1 & 0.92 \\
\hline 1987 & 1988 & trimmed mean & 11.2 & 354 & 933 & 704 & 220 & 0.13 & 57.5 & 0.95 \\
\hline 1987 & 1988 & stand. dev. & 1.3 & 24 & 564 & 508 & 211 & 0.10 & 9.8 & 0.17 \\
\hline 1987 & 1988 & upper hinge & 12.0 & 368 & 1134 & 897 & 288 & 0.16 & 62.1 & 0.99 \\
\hline 1987 & 1988 & lower hinge & 11.0 & 337 & 679 & 479 & 113 & 0.09 & 53.4 & 0.95 \\
\hline 1987 & 1988 & $\min$ & 4.0 & 250 & 26 & 0 & -208 & 0.00 & 18.6 & 0.00 \\
\hline 1987 & 1988 & $\max$ & 12.0 & 369 & 4825 & 5032 & 1739 & 0.91 & 86.0 & 1.00 \\
\hline 1987 & 1989 & $\mathbf{n}$ & 221.0 & & & & & & & \\
\hline 1987 & 1989 & median & 12.0 & 364 & 891 & 652 & 215 & 0.12 & 58.4 & 0.98 \\
\hline 1987 & 1989 & mean & 11.5 & 361 & 1020 & 776 & 243 & 0.15 & 57.0 & 0.94 \\
\hline 1987 & 1989 & trimmed mean & 11.6 & 362 & 961 & 732 & 227 & 0.14 & 57.4 & 0.96 \\
\hline 1987 & 1989 & stand. dev. & 1.2 & 12 & 555 & 482 & 212 & 0.13 & 8.6 & 0.11 \\
\hline 1987 & 1989 & upper hinge & 12.0 & 364 & 1180 & 954 & 321 & 0.17 & 61.8 & 0.99 \\
\hline 1987 & 1989 & lower hinge & 12.0 & 363 & 674 & 511 & 128 & 0.09 & 54.3 & 0.94 \\
\hline 1987 & 1989 & $\min$ & 4.0 & 287 & 20 & 3 & -118 & 0.00 & 22.5 & 0.19 \\
\hline 1987 & 1989 & $\max$ & 13.0 & 393 & 4743 & 4711 & 2074 & 1.28 & 81.3 & 1.00 \\
\hline 1987 & 1990 & $\mathbf{n}$ & 228.0 & & & & & & & \\
\hline 1987 & 1990 & median & 12.0 & 364 & 894 & 638 & 235 & 0.12 & 58.2 & 0.98 \\
\hline 1987 & 1990 & mean & 11.4 & 362 & 1008 & 738 & 271 & 0.17 & 56.1 & 0.93 \\
\hline 1987 & 1990 & trimmed mean & 11.5 & 364 & 949 & 701 & 244 & 0.13 & 56.6 & 0.96 \\
\hline 1987 & 1990 & stand. dev. & 1.3 & 11 & 605 & 449 & 298 & 0.25 & 10.5 & 0.15 \\
\hline 1987 & 1990 & upper hinge & 12.0 & 364 & 1165 & 895 & 362 & 0.16 & 61.9 & 0.99 \\
\hline 1987 & 1990 & lower hinge & 11.0 & 364 & 675 & 461 & 121 & 0.09 & 52.5 & 0.95 \\
\hline 1987 & 1990 & $\min$ & 6.0 & 272 & 16 & 4 & .641 & 0.00 & 11.6 & 0.04 \\
\hline 1987 & 1990 & $\max$ & 13.0 & 394 & 5945 & 3343 & 2603 & 2.64 & 80.0 & 1.00 \\
\hline 1987 & 1991 & $\mathbf{n}$ & 233.0 & & & & & & & \\
\hline 1987 & 1991 & median & 10.0 & 306 & 917 & 691 & 199 & 0.11 & 60.0 & 0.98 \\
\hline 1987 & 1991 & mean & 9.7 & 313 & 1007 & 764 & 244 & 0.13 & 58.9 & 0.89 \\
\hline 1987 & 1991 & trimmed mean & 9.9 & 313 & 959 & 729 & 219 & 0.12 & 59.3 & 0.91 \\
\hline 1987 & 1991 & stand. dev. & 1.3 & 15 & 566 & 473 & 242 & 0.09 & 9.0 & 0.20 \\
\hline 1987 & 1991 & upper hinge & 10.0 & 333 & 1205 & 964 & 319 & 0.15 & 63.4 & 0.99 \\
\hline 1987 & 1991 & lower hinge & 9.0 & 304 & 692 & 503 & 110 & 0.08 & 54.5 & 0.90 \\
\hline 1987 & 1991 & $\min$ & 4.0 & 246 & 14 & 2 & -204 & 0.00 & 3.0 & 0.06 \\
\hline 1987 & 1991 & $\max$ & 11.0 & 347 & 4536 & 4314 & 2429 & 0.81 & 82.0 & 1.00 \\
\hline
\end{tabular}




\section{SUMMARY WEATHER-NORMALIZATION STATISTICS-MADISON GAS \& ELECTRIC COMPANY}

\begin{tabular}{|c|c|c|c|c|c|c|c|c|c|c|}
\hline $\begin{array}{r}\text { Part.Yr. } \\
1988\end{array}$ & $\begin{array}{r}\text { Cons.Yr. } \\
1987\end{array}$ & Statistic & $\begin{array}{r}\text { n reads } \\
164.0\end{array}$ & Dayn & NAC & NAHC & Bascload & Slope & Ref. Te & R-Sqrd. \\
\hline 1988 & 1987 & median & 9.0 & 336 & 997 & 753 & 206 & 0.13 & 58.4 & 0.27 \\
\hline 1988 & 1987 & mean & 8.9 & 342 & 1070 & 836 & 234 & 0.21 & 56.2 & 0.91 \\
\hline 1988 & 1987 & trimmed mean & 9.0 & 345 & 1034 & 806 & 227 & 0.15 & 56.7 & 0.94 \\
\hline 1988 & 1987 & stand. dev. & 1.0 & 24 & 527 & 458 & 186 & 0.62 & 9.4 & 0.15 \\
\hline 1988 & 1987 & upper hinge & 9.0 & 365 & 1273 & 1050 & 328 & 0.18 & 61.0 & 0.99 \\
\hline 1988 & 1987 & lower hinge & 9.0 & 336 & 747 & 595 & 110 & 0.10 & 54.2 & 0.91 \\
\hline 1988 & 1987 & $\min$ & 5.0 & 243 & 18 & 7 & -524 & 0.00 & 14.2 & 0.08 \\
\hline 1988 & 1987 & $\max$ & 10.0 & 384 & 3410 & 2928 & 1057 & 7.83 & 84.0 & 1.00 \\
\hline 1988 & 1988 & $\mathbf{n}$ & 201.0 & & & & & & & \\
\hline 1988 & 1988 & median & 11.0 & 365 & 936 & 715 & 225 & 0.12 & 58.7 & 0.98 \\
\hline 1988 & 1988 & mean & 10.7 & 347 & 1031 & 788 & 243 & 0.15 & 57.8 & 0.93 \\
\hline 1988 & 1988 & trimmed mean & 10.9 & 349 & 993 & 751 & 230 & 0.14 & 58.1 & 0.95 \\
\hline 1988 & 1988 & stand. dev. & 1.6 & 25 & 484 & 432 & 194 & 0.15 & 9.5 & 0.12 \\
\hline 1988 & 1988 & upper hinge & 12.0 & 367 & 1218 & 963 & 324 & 0.18 & 62.7 & 0.99 \\
\hline 1988 & 1988 & lower hinge & 10.0 & 337 & 743 & 515 & 108 & 0.09 & 53.7 & 0.92 \\
\hline 1988 & 1988 & $\min$ & 5.0 & 270 & 53 & 25 & -206 & 0.00 & 10.0 & 0.31 \\
\hline $1988^{\circ}$ & 1988 & $\max$ & 12.0 & 369 & 3507 & 3188 & 1094 & 1.94 & 84.0 & 1.00 \\
\hline 1988 & 1989 & $\mathbf{n}$ & 207.0 & & & & & & & \\
\hline 1988 & 1989. & modian & 12.0 & 364 & 884 & 658 & 212 & 0.11 & 58.4 & 0.97 \\
\hline 1988 & 1989 & mean & 11.2 & 358 & 940 & 703 & 237 & 0.14 & 57.0 & 0.91 \\
\hline 1988 & 1989 & trimmed mean & 11.4 & 360 & 909 & 671 & 226 & 0.13 & 57.5 & 0.93 \\
\hline 1988 & 1989 & stand. dev. & 1.4 & 20 & 442 & 396 & 177 & 0.10 & 10.3 & 0.16 \\
\hline 1988 & 1989 & upper hinge & 12.0 & 364 & 1094 & 804 & 333 & 0.15 & 62.7 & 0.99 \\
\hline 1988 & 1989 & lower hinge & 11.0 & 364 & 692 & 468 & 109 & 0.08 & 53.0 & 0.91 \\
\hline 1988 & 1989 & $\min$ & 4.0 & 243 & 53 & 11 & -215 & 0.00 & 16.9 & 0.12 \\
\hline 1988 & 1989 & $\max$ & 13.0 & 393 & 2743 & 2338 & 865 & 0.69 & 84.0 & 1.00 \\
\hline 1988 & 1990 & $\mathbf{n}$ & 201.0 & & & & & & & \\
\hline 1988 & 1990 & median & 12.0 & 364 & 892 & 677 & 213 & 0.11 & 59.5 & 0.98 \\
\hline 1988 & 1990 & mean & 11.6 & 362 & 925 & 688 & 238 & 0.13 & 58.0 & 0.92 \\
\hline 1988 & 1990 & trimmed mean & 11.8 & 364 & 897 & 664 & 225 & 0.11 & 58.9 & 0.95 \\
\hline 1988 & 1990 & stand. dev. & 1.0 & 11 & 442 & 382 & 194 & 0.13 & 10.5 & 0.17 \\
\hline 1988 & 1990 & upper hinge & 12.0 & 364 & 1096 & 830 & 323 & 0.14 & 63.0 & 0.99 \\
\hline 1988 & 1990 & lower hinge & 12.0 & 364 & 680 & 440 & 119 & 0.08 & 55.8 & 0.94 \\
\hline 1988 & 1990 & $\min$ & 6.0 & 275 & 20 & 2 & -372 & 0.00 & 2.0 & 0.02 \\
\hline 1988 & 1990 & $\max$ & 13.0 & 393 & 3002 & 2369 & 1048 & 1.30 & 80.0 & 1.00 \\
\hline 1988 & 1991 & $\mathbf{n}$ & 211.0 & & & & & & & \\
\hline 1988 & 1991 & median & 10.0 & 306 & 887 & 668 & 189 & 0.10 & 60.1 & 0.98 \\
\hline 1988 & 1991 & mean & 9.7 & 312 & 930 & 717 & 213 & 0.14 & 60.9 & 0.91 \\
\hline 1988 & 1991 & trimmed mean & 9.8 & 314 & 893 & 684 & 204 & 0.11 & 61.3 & 0.93 \\
\hline 1988 & 1991 & stand. dev. & 1.2 & 19 & 461 & 414 & 190 & 0.43 & 10.9 & 0.17 \\
\hline 1988 & 1991 & upper hinge & 10.0 & 333 & 1060 & 857 & 302 & 0.13 & 65.8 & 0.99 \\
\hline 1988 & 1991 & lower hinge & 9.0 & 304 & 672 & 482 & 79 & 0.08 & 56.1 & 0.92 \\
\hline 1988 & 1991 & $\min$ & 4.0 & 242 & 38 & 9 & -384 & 0.00 & 3.0 & 0.08 \\
\hline 1988 & 1991 & $\max$ & 11.0 & 353 & 3100 & 2590 & 1127 & 6.29 & 82.0 & 1.00 \\
\hline
\end{tabular}




\begin{tabular}{|c|c|c|c|c|c|c|c|c|c|c|}
\hline Part.Yr. & Cons.Yr. & Statistic & n reads & Days & NAC & NAHC & Baseload & Slope & Ref. Te & R-Sqrd. \\
\hline 1989 & 1987 & $\mathbf{n}$ & 177.0 & & & & & & & \\
\hline 1989 & 1987 & modian & 9.0 & 337 & 1035 & 855 & 212 & 0.14 & 59.0 & 0.98 \\
\hline 1989 & 1987 & mean & 9.1 & 346 & 1083 & 863 & 220 & 0.18 & 58.0 & 0.91 \\
\hline 1989 & 1987 & trimmed mean & 9.3 & 349 & 1053 & 834 & 213 & 0.14 & 58.7 & 0.94 \\
\hline 1989 & 1987 & stand. dev. & 1.1 & 23 & 530 & 494 & 146 & 0.39 & 8.3 & 0.18 \\
\hline 1989 & 1987 & upper hinge & 10.0 & 365 & 1340 & 1078 & 288 & 0.18 & 61.8 & 0.99 \\
\hline 1989 & 1987 & lower hinge & 9.0 & 336 & 759 & 563 & 115 & 0.10 & 56.0 & 0.92 \\
\hline 1989 & 1987 & $\min$ & 4.0 & 241 & 53 & 9 & -219 & 0.00 & 10.8 & 0.06 \\
\hline 1989 & 1987 & $\max$ & 10.0 & 374 & 3264 & 3192 & 1010 & 4.97 & 81.0 & 1.00 \\
\hline 1989 & 1988 & $\mathbf{n}$ & 194.0 & & & & & & & \\
\hline 1989 & 1988 & median & 11.0 & 365 & 1093 & 787 & 267 & 0.14 & 59.2 & 0.98 \\
\hline 1989 & 1988 & mean & 10.9 & 351 & 1185 & 905 & 280 & 0.19 & 57.4 & 0.92 \\
\hline 1989 & 1988 & trimmed mean & 11.1 & 354 & 1133 & 850 & 274 & 0.15 & 58.2 & 0.94 \\
\hline 1989 & 1988 & stand. dev. & 1.6 & 22 & 610 & 608 & 198 & 0.30 & 11.3 & 0.16 \\
\hline 1989 & 1988 & upper hinge & 12.0 & 367 & 1434 & 1123 & 386 & 0.20 & 62.5 & 0.99 \\
\hline 1989 & 1988 & lower hinge & 11.0 & 337 & 826 & 558 & 170 & 0.10 & 53.4 & 0.92 \\
\hline 1989 & 1988 & $\min$ & 4.0 & 244 & 35 & 3 & -604 & 0.00 & 3.3 & 0.02 \\
\hline 1989 & 1988 & $\max$ & 12.0 & 381 & 4344 & 4454 & 1063 & 3.83 & 86.0 & 1.00 \\
\hline 1989 & 1989 & $\mathbf{n}$ & 222.0 & & & & & & & \\
\hline 1989 & 1989 & median & 12.0 & 364 & 1012 & 779 & 213 & 0.13 & 58.8 & 0.96 \\
\hline 1989 & 1989 & mean & 11.0 & 358 & 1065 & 817 & 248 & 0.20 & 56.6 & 0.89 \\
\hline 1989 & 1989 & trimmed mean & 11.2 & 361 & 1049 & 796 & 236 & 0.15 & 57.7 & 0.92 \\
\hline 1989 & 1989 & stand. dev. & 1.8 & 21 & 495 & 457 & 208 & 0.33 & 12.3 & 0.18 \\
\hline 1989 & 1989 & upper hinge & 12.0 & 364 & 1315 & 1073 & 335 & 0.19 & 63.0 & 0.99 \\
\hline 1989 & 1989 & lower hinge & 11.0 & 363 & 763 & 526 & 120 & 0.10 & 54.6 & 0.88 \\
\hline 1989 & 1989 & $\min$ & 4.0 & 243 & 41 & 4 & -576 & 0.00 & 10.5 & 0.03 \\
\hline 1989 & 1989 & $\max$ & 12.0 & 399 & 3273 & 3132 & 1612 & 2.73 & 83.0 & 1.00 \\
\hline 1989 & 1990 & $\mathbf{n}$ & 213.0 & & & & & & & \\
\hline 1989 & 1990 & median & 12.0 & 364 & 939 & 680 & 242 & 0.12 & 58.9 & 0.98 \\
\hline 1989 & 1990 & mean & 11.4 & 363 & 1021 & 763 & 258 & 0.15 & 57.2 & 0.93 \\
\hline 1989 & 1990 & trimmed mean & 11.6 & 364 & 990 & 728 & 250 & 0.13 & 57.7 & 0.95 \\
\hline 1989 & 1990 & stand. dev. & 1.4 & 10 & 485 & 453 & 214 & 0.14 & 9.2 & 0.15 \\
\hline 1989 & 1990 & upper hinge & 12.0 & 364 & 1235 & 936 & 352 & 0.17 & 61.7 & 0.99 \\
\hline 1989 & 1990 & lower hinge & 11.0 & 364 & 720 & 506 & 129 & 0.09 & 54.1 & 0.94 \\
\hline 1989 & 1990 & $\min$ & 6.0 & 305 & 43 & 1 & -833 & 0.00 & 12.4 & 0.04 \\
\hline 1989 & 1990 & $\max$ & 13.0 & 396 & 3735 & 3444 & 1472 & 1.79 & 81.0 & 1.00 \\
\hline 1989 & 1991 & $\mathbf{n}$ & 226.0 & & & & & & & \\
\hline 1989 & 1991 & median & 10.0 & 306 & 921 & 673 & 219 & 0.11 & 59.7 & 0.98 \\
\hline 1989 & 1991 & mean & 9.8 & 316 & 982 & 743 & 239 & 0.12 & 59.9 & 0.89 \\
\hline 1989 & 1991 & trimmed mean & 9.9 & 317 & 944 & 707 & 227 & 0.12 & 59.9 & 0.92 \\
\hline 1989 & 1991 & stand. dev. & 1.2 & 17 & 524 & 465 & 188 & 0.08 & 9.1 & 0.19 \\
\hline 1989 & 1991 & upper hinge & 10.0 & 335 & 1207 & 941 & 322 & 0.15 & 64.3 & 0.99 \\
\hline 1989 & 1991 & lower hinge & 10.0 & 304 & 676 & 452 & 112 & 0.08 & 54.7 & 0.92 \\
\hline 1989 & 1991 & $\min$ & 4.0 & 241 & 45 & 2 & -244 & 0.00 & 32.0 & 0.02 \\
\hline 1989 & 1991 & $\max$ & 11.0 & 338 & 3799 & 3083 & 1294 & 0.57 & 82.0 & 1.00 \\
\hline
\end{tabular}


SUMMARY WEATHER-NORMALIZATION STATISTICS--MADISON GAS \& ELECTRIC COMPANY

\begin{tabular}{|c|c|c|c|c|c|c|c|c|c|c|}
\hline Part.Yr. & Cons.Yr. & Statistic & n reads & Days & NAC & NAHC & Baseload & Slope & Ref. Te & R-Sqrd. \\
\hline 1990 & 1987 & $\mathbf{n}$ & 109.0 & & & & & & & \\
\hline 1990 & 1987 & median & 9.0 & 337 & 1141 & 906 & 229 & 0.16 & 58.8 & 0.98 \\
\hline 1990 & 1987 & mean & 8.8 & 341 & 1261 & 1031 & 231 & 0.19 & 57.5 & 0.92 \\
\hline 1990 & 1987 & trimmed mean & 8.9 & 343 & 1215 & 985 & 229 & 0.18 & 58.1 & 0.94 \\
\hline 1990 & 1987 & stand. dev. & 1.3 & 23 & 626 & 599 & 146 & 0.14 & 8.3 & 0.14 \\
\hline 1990 & 1987 & upper hinge & 9.0 & 365 & 1494 & 1278 & 311 & 0.23 & 62.5 & 0.99 \\
\hline 1990 & 1987 & lower hinge & 9.0 & 336 & 870 & 685 & 145 & 0.12 & 54.8 & 0.94 \\
\hline 1990 & 1987 & $\min$ & 4.0 & 248 & 74 & 33 & -171 & 0.01 & 29.0 & 0.07 \\
\hline 1990 & 1987 & $\max$ & 10.0 & 373 & 4324 & 3916 & 714 & 1.09 & 73.0 & 1.00 \\
\hline 1990 & 1988 & $\mathbf{n}$ & 129.0 & & & & & & & \\
\hline 1990 & 1988 & median & 12.0 & 366 & 1134 & 842 & 251 & 0.14 & 59.0 & 0.98 \\
\hline 1990 & 1988 & mean & 11.0 & 349 & 1230 & 962 & 268 & 0.28 & 57.4 & 0.94 \\
\hline 1990 & 1988 & trimmed mean & 11.2 & 353 & 1173 & 911 & 258 & 0.17 & 58.2 & 0.96 \\
\hline 1990 & 1988 & stand. dev. & 1.7 & 29 & 669 & 597 & 194 & 1.17 & 11.3 & 0.12 \\
\hline 1990 & 1988 & upper hinge & 12.0 & 367 & 1448 & 1195 & 352 & 0.21 & 62.5 & 0.99 \\
\hline 1990 & 1988 & lower hinge & 11.0 & 337 & 765 & 555 & 150 & 0.10 & 54.5 & 0.94 \\
\hline 1990 & 1988 & $\min$ & 5.0 & 244 & 56 & 4 & -89 & 0.00 & -5.5 & 0.35 \\
\hline 1990 & 1988 & $\max$ & 12.0 & 377 & 4383 & 3573 & 906 & 13.31 & 84.4 & 1.00 \\
\hline 1990 & 1989 & $\mathbf{n}$ & 132.0 & & & & & & & \\
\hline 1990 & 1989 & median & 12.0 & 364 & 1145 & 861 & 243 & 0.16 & 59.5 & 0.98 \\
\hline 1990 & 1989 & mean & 11.2 & 358 & 1300 & 1026 & 274 & 0.21 & 57.7 & 0.91 \\
\hline 1990 & 1989 & trimmed mean & 11.4 & 361 & 1238 & 968 & 262 & 0.17 & 58.5 & 0.93 \\
\hline 1990 & 1989 & stand. dev. & 1.6 & 22 & 688 & 630 & 198 & 0.23 & 9.7 & 0.17 \\
\hline 1990 & 1989 & upper hinge & 12.0 & 364 & 1524 & 1265 & 345 & 0.22 & 62.7 & 0.99 \\
\hline 1990 & 1989 & lower hinge & 11.0 & 364 & 859 & 658 & 157 & 0.11 & 53.9 & 0.93 \\
\hline 1990 & 1989 & $\min$ & 4.0 & 241 & 194 & 8 & -117 & 0.00 & 12.3 & 0.20 \\
\hline 1990 & 1989 & $\max$ & 12.0 & 395 & 5162 & 4546 & 1111 & 2.17 & 84.0 & 1.00 \\
\hline 1990 & 1990 & $\mathbf{n}$ & 141.0 & & & & & & & \\
\hline 1990 & 1990 & median & 12.0 & 364 & 1086 & 845 & 219 & 0.14 & 59.2 & 0.98 \\
\hline 1990 & 1990 & mean & 11.4 & 362 & 1231 & 970 & 261 & 0.19 & 58.2 & 0.94 \\
\hline 1990 & 1990 & trimmed mean & 11.7 & 363 & 1178 & 914 & 248 & 0.16 & 58.9 & 0.96 \\
\hline 1990 & 1990 & stand. dev. & 1.5 & 16 & 640 & 587 & 209 & 0.19 & 9.7 & 0.12 \\
\hline 1990 & 1990 & upper hinge & 12.0 & 364 & 1431 & 1124 & 344 & 0.20 & 63.0 & 0.99 \\
\hline 1990 & 1990 & lower hinge & 12.0 & 364 & 842 & 645 & 133 & 0.11 & 56.1 & 0.95 \\
\hline 1990 & 1990 & $\min$ & 4.0 & 241 & 57 & 2 & -165 & 0.01 & 10.7 & 0.08 \\
\hline 1990 & 1990 & $\max$ & 13.0 & 395 & 5333 & 4751 & 1473 & 1.93 & 81.0 & 1.00 \\
\hline 1990 & 1991 & $\mathbf{n}$ & 143.0 & & & & & & & \\
\hline 1990 & 1991 & median & 10.0 & 306 & 942 & 721 & 221 & 0.11 & 60.6 & 0.99 \\
\hline 1990 & 1991 & mean & 9.8 & 313 & 1047 & 816 & 231 & 0.13 & 61.0 & 0.91 \\
\hline 1990 & 1991 & trimmed mean & 9.9 & 313 & 998 & 765 & 225 & 0.12 & 60.9 & 0.94 \\
\hline 1990 & 1991 & stand. dev. & 0.9 & 15 & 588 & 535 & 212 & 0.07 & 8.5 & 0.16 \\
\hline 1990 & 1991 & upper hinge & 10.0 & 333 & 1170 & 929 & 322 & 0.15 & 64.3 & 0.99 \\
\hline 1990 & 1991 & lower hinge & 10.0 & 304 & 746 & 548 & 125 & 0.09 & 56.4 & 0.93 \\
\hline 1990 & 1991 & $\min$ & 5.0 & 243 & 50 & 11 & -686 & 0.00 & 33.0 & 0.04 \\
\hline 1990 & 1991 & $\max$ & 11.0 & 336 & 4976 & 4281 & 1304 & 0.51 & 82.0 & 1.00 \\
\hline
\end{tabular}


SUMMARY WEATHER-NORMALIZATION STATISTICS-MADISON GAS \& ELECTRIC COMPANY

\begin{tabular}{|c|c|c|c|c|c|c|c|c|c|c|}
\hline Part.Yr. & Cons. Yr. & Statistic & n reads & Days & NAC & NAHC & Baseload & Slope & Ref. Te & R-Sqrd. \\
\hline 1991 & 1987 & n & 36.0 & & & & & & & \\
\hline 1991 & 1987 & median & 9.0 & 336 & 947 & 718 & 213 & 0.12 & 60.5 & 0.97 \\
\hline 1991 & 1987 & mean & 9.2 & 346 & 1049 & 827 & 222 & 0.13 & 58.5 & 0.89 \\
\hline 1991 & 1987 & trimmed mean & 9.3 & 346 & 1019 & 798 & 219 & 0.13 & 59.0 & 0.93 \\
\hline 1991 & 1987 & stand. dev. & 0.8 & 17 & 580 & 569 & 116 & 0.09 & 5.9 & 0.23 \\
\hline 1991 & 1987 & upper hinge & 10.0 & 365 & 1257 & 957 & 274 & 0.16 & 62.0 & 0.98 \\
\hline 1991 & 1987 & lower hinge & 9.0 & 336 & 645 & 455 & 165 & 0.08 & 56.0 & 0.95 \\
\hline 1991 & 1987 & $\min$ & 6.0 & 299 & 126 & 12 & 1 & 0.00 & 41.0 & 0.09 \\
\hline 1991 & 1987 & $\max$ & 10.0 & 384 & 2477 & 2277 & 497 & 0.37 & 65.8 & 1.00 \\
\hline 1991 & 1988 & $\mathbf{n}$ & 38.0 & & & & & & & \\
\hline 1991 & 1988 & median & 11.5 & 366 & 1020 & 728 & 245 & 0.13 & 59.4 & 0.98 \\
\hline 1991 & 1988 & mean & 11.1 & 357 & 1134 & 837 & 297 & 0.16 & 56.5 & 0.92 \\
\hline 1991 & 1988 & trimmed mean & 11.3 & 359 & 1085 & 804 & 281 & 0.15 & 57.4 & 0.94 \\
\hline 1991 & 1988 & stand. dev. & 1.6 & 16 & 647 & 579 & 198 & 0.12 & 11.0 & 0.16 \\
\hline 1991 & 1988 & upper hinge & 12.0 & 368 & 1376 & 1003 & 406 & 0.19 & 61.4 & 0.99 \\
\hline 1991 & 1988 & lower hinge & 11.0 & 339 & 730 & 399 & 210 & 0.09 & 54.5 & 0.93 \\
\hline 1991 & 1988 & $\min$ & 4.0 & 309 & 168 & 20 & -17 & 0.00 & 19.0 & 0.27 \\
\hline 1991 & 1988 & $\max$ & 12.0 & 370 & 3081 & 2517 & 1036 & 0.70 & 74.0 & 1.00 \\
\hline 1991 & 1989 & $\mathbf{n}$ & 39.0 & & & & & & & \\
\hline 1991 & 1989 & median & 12.0 & 364 & 1080 & 790 & 244 & 0.12 & 59.5 & 0.98 \\
\hline 1991 & 1989 & mean & 11.3 & 358 & 1200 & 910 & 290 & 0.17 & 58.9 & 0.93 \\
\hline 1991 & 1989 & trimmed mean & 11.4 & 360 & 1162 & 882 & 266 & 0.15 & 59.1 & 0.95 \\
\hline 1991 & 1989 & stand. dev. & 1.3 & 17 & 698 & 611 & 229 & 0.18 & 7.1 & 0.13 \\
\hline 1991 & 1989 & upper hinge & 12.0 & 364 & 1332 & 1092 & 346 & 0.17 & 61.5 & 0.99 \\
\hline 1991 & 1989 & lower hinge & 11.0 & 363 & 738 & 517 & 160 & 0.09 & 55.2 & 0.94 \\
\hline 1991 & 1989 & $\min$ & 7.0 & 302 & 195 & 37 & -3 & 0.00 & 36.8 & 0.27 \\
\hline 1991 & 1989 & $\max$ & 12.0 & 378 & 2907 & 2425 & 1056 & 1.04 & 73.0 & 1.00 \\
\hline 1991 & 1990 & n & 39.0 & & & & & & & \\
\hline 1991 & 1990 & median & 12.0 & 364 & 1118 & 799 & 249 & 0.14 & 57.9 & 0.98 \\
\hline 1991 & 1990 & mean & 11.5 & 362 & 1301 & 940 & 361 & 0.16 & 57.9 & 0.92 \\
\hline 1991 & 1990 & trimmed mean & 11.7 & 364 & 1244 & 916 & 309 & 0.16 & 58.1 & 0.95 \\
\hline 1991 & 1990 & stand. dev. & 1.2 & 15 & 786 & 615 & 363 & 0.09 & 6.1 & 0.17 \\
\hline 1991 & 1990 & upper hinge & 12.0 & 364 & 1494 & 1059 & 347 & 0.21 & 61.5 & 0.99 \\
\hline 1991 & 1990 & lower hinge & 11.5 & 364 & 729 & 486 & 197 & 0.09 & 56.0 & 0.93 \\
\hline 1991 & 1990 & $\min$ & 6.0 & 283. & 178 & 25 & -39 & 0.00 & 40.1 & 0.09 \\
\hline 1991 & 1990 & $\max$ & 12.0 & 393 & 3802 & 2414 & 1759 & 0.35 & 73.0 & 1.00 \\
\hline 1991 & 1991 & $\mathbf{n}$ & 41.0 & & & & & & & \\
\hline 1991 & 1991 & median & 10.0 & 306 & 911 & 668 & 229 & 0.10 & 62.5 & 0.95 \\
\hline 1991 & 1991 & mean & 9.6 & 311 & 1120 & 882 & 238 & 0.12 & 63.2 & 0.84 \\
\hline 1991 & 1991 & trimmed mean & 9.7 & 312 & 1051 & 813 & 214 & 0.12 & 63.5 & 0.87 \\
\hline 1991 & 1991 & stand. dev. & 1.3 & 19 & 748 & 716 & 216 & 0.09 & 10.2 & 0.24 \\
\hline 1991 & 1991 & upper hinge & 10.0 & 332 & 1259 & 1058 & 310 & 0.13 & 66.4 & 0.99 \\
\hline 1991 & 1991 & lower hinge & 9.0 & 304 & 677 & 452 & 107 & 0.07 & 58.4 & 0.87 \\
\hline 1991 & 1991 & $\min$ & 6.0 & 243 & 136 & 17 & -31 & 0.00 & 34.0 & 0.09 \\
\hline 1991 & 1991 & $\max$ & 11.0 & 336 & 3684 & 3687 & 1188 & 0.37 & 82.0 & 1.00 \\
\hline
\end{tabular}

(A "hinge" is roughly analogous to a quartile.) 
APPENDIX D 
Summary of ECM and Demographic Information

Wisconsin Gas Company Participant Sample

\begin{tabular}{|c|c|c|c|c|c|c|c|}
\hline \multirow{2}{*}{$\begin{array}{l}\text { Part. } \\
\text { Year }\end{array}$} & \multicolumn{4}{|c|}{ ECM Installation Type--Absolute } & \multicolumn{3}{|l|}{ Percentage } \\
\hline & Shell & Heating & Both & Total & Shell & Heating & Both \\
\hline 1983 & 134 & 1 & 12 & 147 & $91 \%$ & $1 \%$ & $8 \%$ \\
\hline 1984 & 202 & 2 & 57 & 261 & $77 \%$ & $1 \%$ & $22 \%$ \\
\hline 1985 & 298 & 20 & 46 & 364 & $82 \%$ & $5 \%$ & $13 \%$ \\
\hline 1986 & 338 & 51 & 143 & 532 & $64 \%$ & $10 \%$ & $27 \%$ \\
\hline 1987 & 250 & 73 & 243 & 566 & $44 \%$ & $13 \%$ & $43 \%$ \\
\hline 1988 & 550 & 81 & 451 & 1082 & $51 \%$ & $7 \%$ & $42 \%$ \\
\hline 1989 & 361 & 77 & 200 & 638 & $57 \%$ & $12 \%$ & $31 \%$ \\
\hline 1990 & 388 & 82 & 408 & 878 & $44 \%$ & $9 \%$ & $46 \%$ \\
\hline 1991 & 289 & 77 & 186 & 552 & $52 \%$ & $14 \%$ & $34 \%$ \\
\hline Total & 2810 & 464 & 1746 & 5020 & $56 \%$ & $9 \%$ & $35 \%$ \\
\hline Part. & \multicolumn{4}{|c|}{ Average ECM Expenditures (\$) } & \multicolumn{3}{|l|}{1991 dollars } \\
\hline Year & Shell & Heating & Both & Total & Shell & Heating & Both \\
\hline 1983 & 1694 & 2520 & 2857 & 1795 & 2278 & 3388 & 3842 \\
\hline 1984 & 2182 & 2048 & 3383 & 2444 & 2827 & 2653 & 4383 \\
\hline 1985 & 1693 & 2098 & 2485 & 1810 & 2123 & 2631 & 3116 \\
\hline 1986 & 1889 & 2401 & 2728 & 2160 & 2313 & 2940 & 3340 \\
\hline 1987 & 1766 & 2313 & 3149 & 2430 & 2067 & 2707 & 3686 \\
\hline 1988 & 1644 & 2670 & 4029 & 2715 & 1853 & 3009 & 4540 \\
\hline 1989 & 1563 & 3023 & 4061 & 2522 & 1685 & 3259 & 4378 \\
\hline 1990 & 1713 & 2572 & 4265 & 2979 & 1764 & 2649 & 4392 \\
\hline 1991 & 1653 & 2166 & 4114 & 2482 & 1653 & 2166 & 4114 \\
\hline Part. & \multicolumn{4}{|c|}{ Number of Units--Absolute } & \multicolumn{3}{|l|}{ Percentage } \\
\hline Year & 1 & 2 & $>2$ & Total & 1 & 2 & $>2$ \\
\hline 1983 & 90 & 53 & 4 & 147 & $61 \%$ & $36 \%$ & $3 \%$ \\
\hline 1984 & 146 & 109 & 6 & 261 & $56 \%$ & $42 \%$ & $2 \%$ \\
\hline 1985 & 236 & 125 & 4 & 365 & $65 \%$ & $34 \%$ & $1 \%$ \\
\hline 1986 & 225 & 278 & 30 & 533 & $42 \%$ & $52 \%$ & $6 \%$ \\
\hline 1987 & 236 & 306 & 24 & 566 & $42 \%$ & $54 \%$ & $4 \%$ \\
\hline 1988 & 410 & 612 & 59 & 1081 & $38 \%$ & $57 \%$ & $5 \%$ \\
\hline 1989 & 255 & 351 & 31 & 637 & $40 \%$ & $55 \%$ & $5 \%$ \\
\hline 1990 & 371 & 450 & 54 & 875 & $42 \%$ & $51 \%$ & $6 \%$ \\
\hline 1991 & 253 & 367 & 39 & 659 & $38 \%$ & $56 \%$ & $6 \%$ \\
\hline Total & 2222 & 2651 & 251 & 5124 & $43 \%$ & $52 \%$ & $5 \%$ \\
\hline Part. & \multicolumn{3}{|c|}{ Occupant Type--Absolute } & \multicolumn{4}{|l|}{ Percentage } \\
\hline Year & Renter & Owner & Total & Renter & Owner & & \\
\hline 1985 & 6 & 54 & 60 & $10 \%$ & $90 \%$ & & \\
\hline 1986 & 221 & 144 & 365 & $61 \%$ & $39 \%$ & & \\
\hline 1987 & 240 & 131 & 371 & $65 \%$ & $35 \%$ & & \\
\hline 1988 & 644 & 280 & 924 & $70 \%$ & $30 \%$ & & \\
\hline 1989 & 362 & 206 & 568 & $64 \%$ & $36 \%$ & & \\
\hline 1990 & 563 & 231 & 794 & $71 \%$ & $29 \%$ & & \\
\hline 1991 & 418 & 180 & 598 & $70 \%$ & $30 \%$ & & \\
\hline Total & 2454 & 1226 & 3680 & $67 \%$ & $33 \%$ & & \\
\hline
\end{tabular}


Summary of ECM and Demographic Information Madison Gas \& Electric Company Participant Sample

\begin{tabular}{|c|c|c|c|c|c|c|c|}
\hline \multirow{2}{*}{$\begin{array}{l}\text { Part. } \\
\text { Year }\end{array}$} & \multicolumn{4}{|c|}{ ECM Type--Absolute } & \multicolumn{3}{|c|}{ Percentage } \\
\hline & Shell & Mech. & Both & Total & Shell & Mech. & Both \\
\hline 1983 & 1 & 5 & 23 & 29 & $3 \%$ & $17 \%$ & $79 \%$ \\
\hline 1984 & 62 & 23 & 227 & 312 & $20 \%$ & $7 \%$ & $73 \%$ \\
\hline 1985 & 79 & 42 & 170 & 291 & $27 \%$ & $14 \%$ & $58 \%$ \\
\hline 1986 & 42 & 58 & 87 & 187 & $22 \%$ & $31 \%$ & $47 \%$ \\
\hline 1987 & 47 & 67 & 90 & 204 & $23 \%$ & $33 \%$ & $44 \%$ \\
\hline 1988 & 40 & 66 & 67 & 173 & $23 \%$ & $38 \%$ & $39 \%$ \\
\hline 1989 & 44 & 92 & 56 & 192 & $23 \%$ & $48 \%$ & $29 \%$ \\
\hline 1990 & 39 & 52 & 36 & 127 & $31 \%$ & $41 \%$ & $28 \%$ \\
\hline 1991 & 13 & 11 & 14 & 38 & $34 \%$ & $29 \%$ & $37 \%$ \\
\hline Total & 367 & 416 & 770 & 1553 & $24 \%$ & $27 \%$ & $50 \%$ \\
\hline Part. & \multicolumn{4}{|c|}{ Building Type (Units)--Absolute } & \multicolumn{3}{|c|}{ Percentage } \\
\hline Year & 1 & 2 & 2 & Total & 1 & 2 & $>2$ \\
\hline 1983 & 25 & 3 & 1 & 29 & $86 \%$ & $10 \%$ & $3 \%$ \\
\hline 1984 & 215 & 63 & 34 & 312 & $69 \%$ & $20 \%$ & $11 \%$ \\
\hline 1985 & 223 & 44 & 24 & 291 & $77 \%$ & $15 \%$ & $8 \%$ \\
\hline 1986 & 133 & 33 & 21 & 187 & $71 \%$ & $18 \%$ & $11 \%$ \\
\hline 1987 & 149 & 33 & 22 & 204 & $73 \%$ & $16 \%$ & $11 \%$ \\
\hline 1988 & 117 & 32 & 24 & 173 & $68 \%$ & $18 \%$ & $14 \%$ \\
\hline 1989 & 130 & 39 & 23 & 192 & $68 \%$ & $20 \%$ & $12 \%$ \\
\hline 1990 & 86 & 31 & 10 & 127 & $68 \%$ & $24 \%$ & $8 \%$ \\
\hline 1991 & 25 & 9 & 4 & 38 & $66 \%$ & $24 \%$ & $11 \%$ \\
\hline Total & 1103 & 287 & 163 & 1553 & $71 \%$ & $18 \%$ & $10 \%$ \\
\hline Part. & \multicolumn{3}{|c|}{ Occupant Type--Absolute } & \multicolumn{4}{|l|}{ Percentage } \\
\hline Year & \begin{tabular}{|l|} 
Renter \\
\end{tabular} & Owner & Total & Renter & Owner & & \\
\hline 1983 & 6 & 17 & 23 & $26 \%$ & $74 \%$ & & \\
\hline 1984 & 161 & 143 & 304 & $53 \%$ & $47 \%$ & & \\
\hline 1985 & 117 & 170 & 287 & $41 \%$ & $59 \%$ & & \\
\hline 1986 & 80 & 103 & 183 & $44 \%$ & $56 \%$ & & \\
\hline 1987 & 90 & 113 & 203 & $44 \%$ & $56 \%$ & & \\
\hline 1588 & 82 & 91 & 173 & $47 \%$ & $53 \%$ & & \\
\hline 1989 & 99 & 93 & 192 & $52 \%$ & $48 \%$ & & \\
\hline 1990 & 65 & 61 & 126 & $52 \%$ & $48 \%$ & & \\
\hline 1991 & 16 & 22 & 38 & $42 \%$ & $58 \%$ & & \\
\hline Total & 716 & 813 & 1529 & $47 \%$ & $53 \%$ & & \\
\hline
\end{tabular}


APPENDIX E 


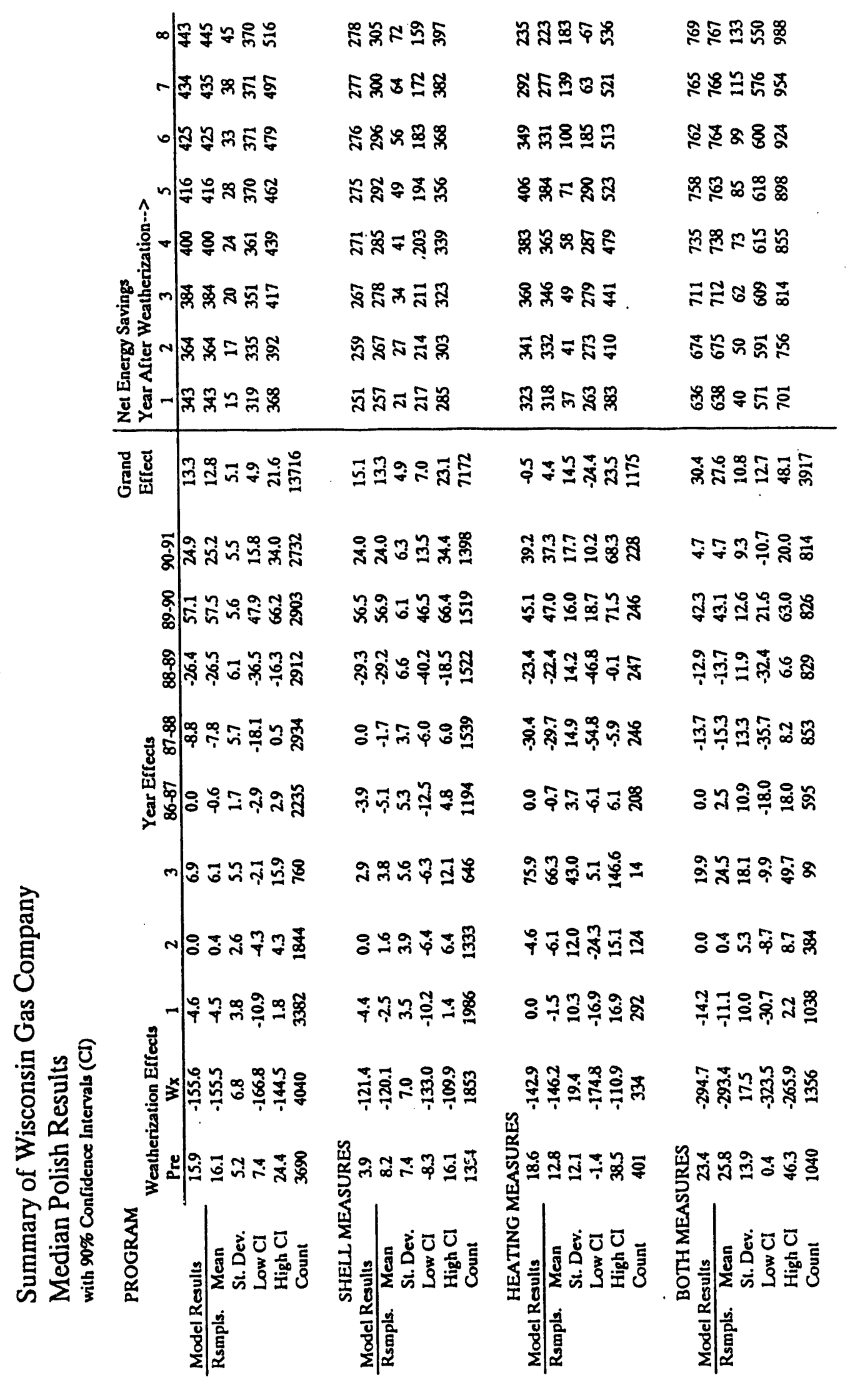




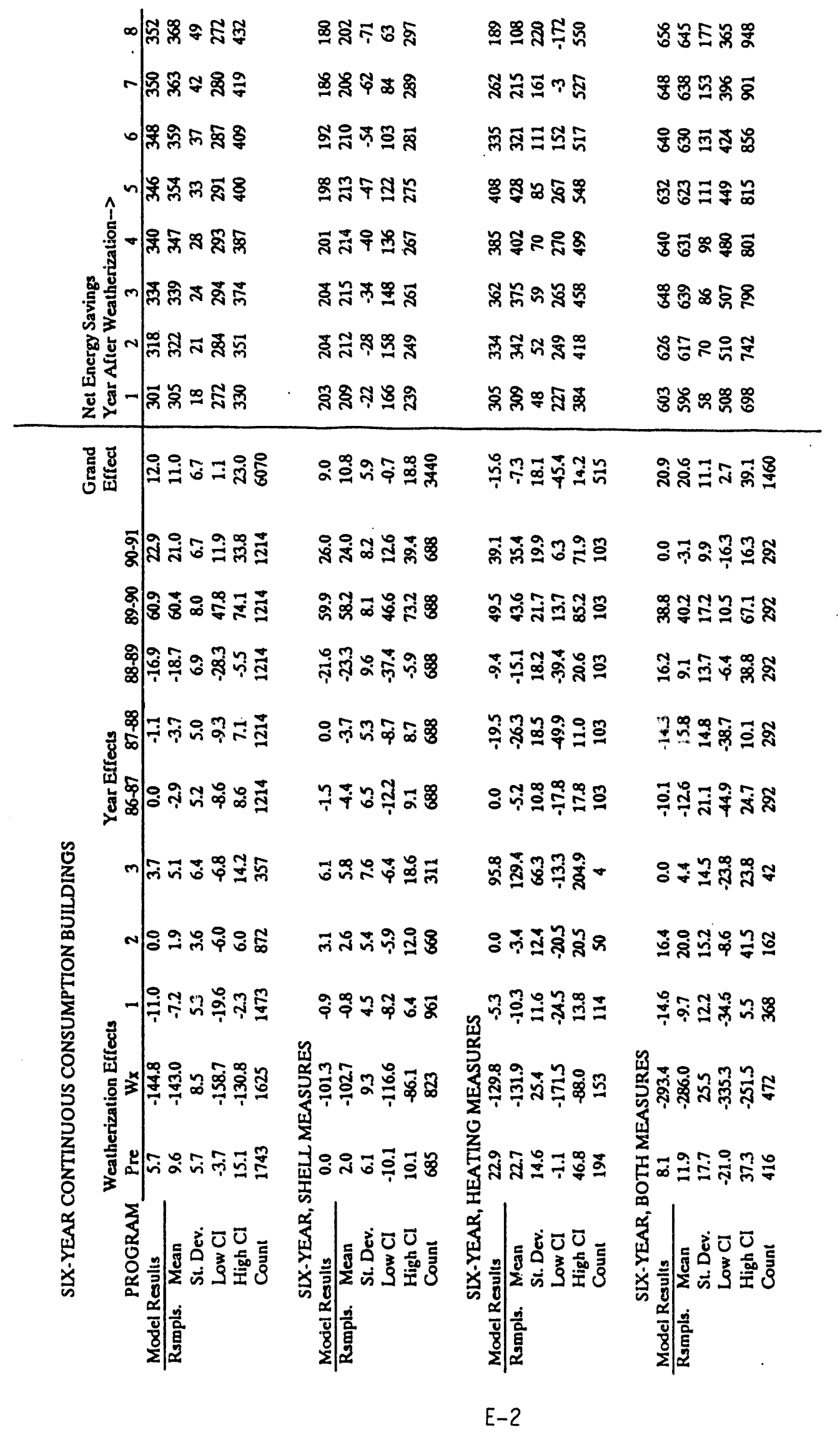




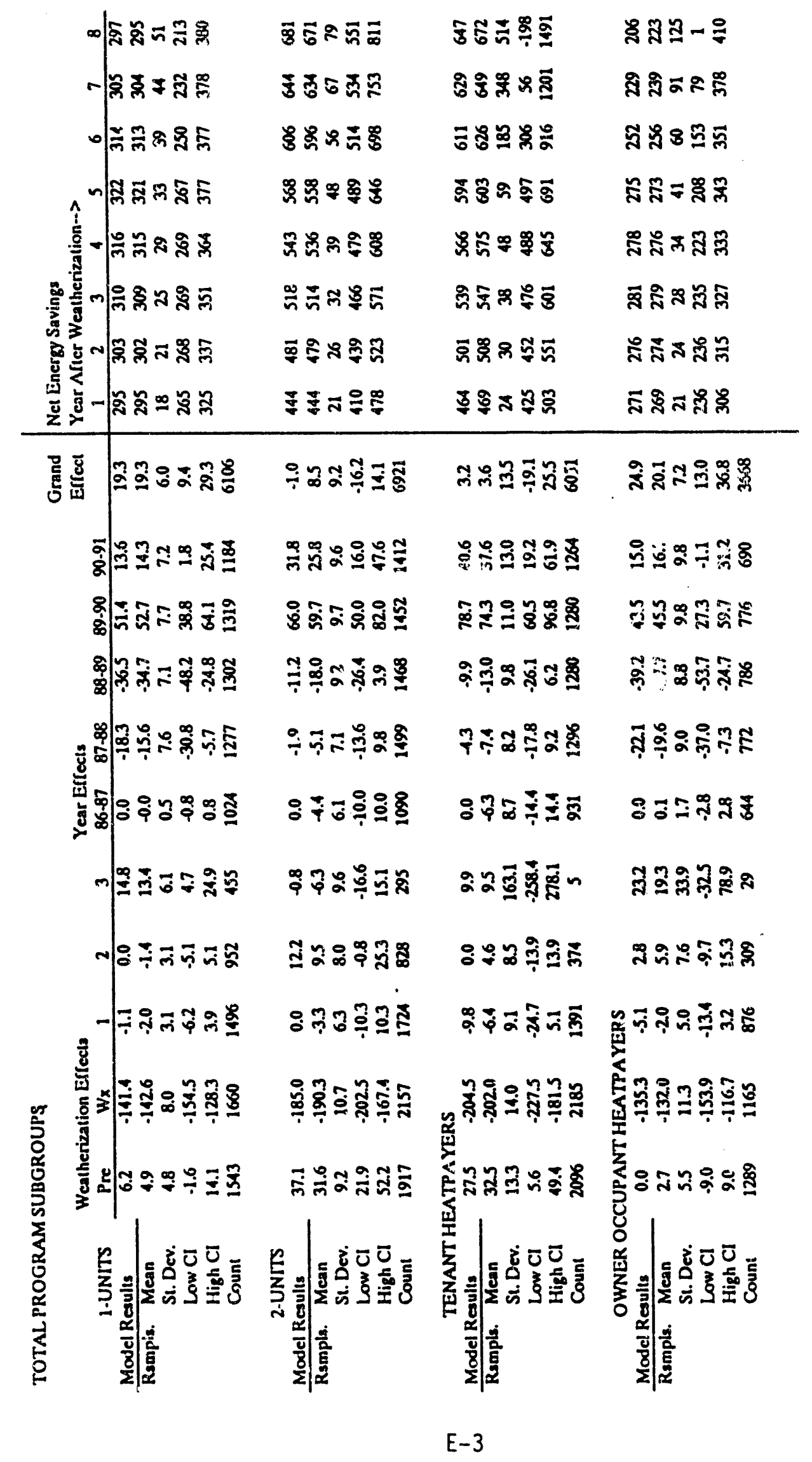




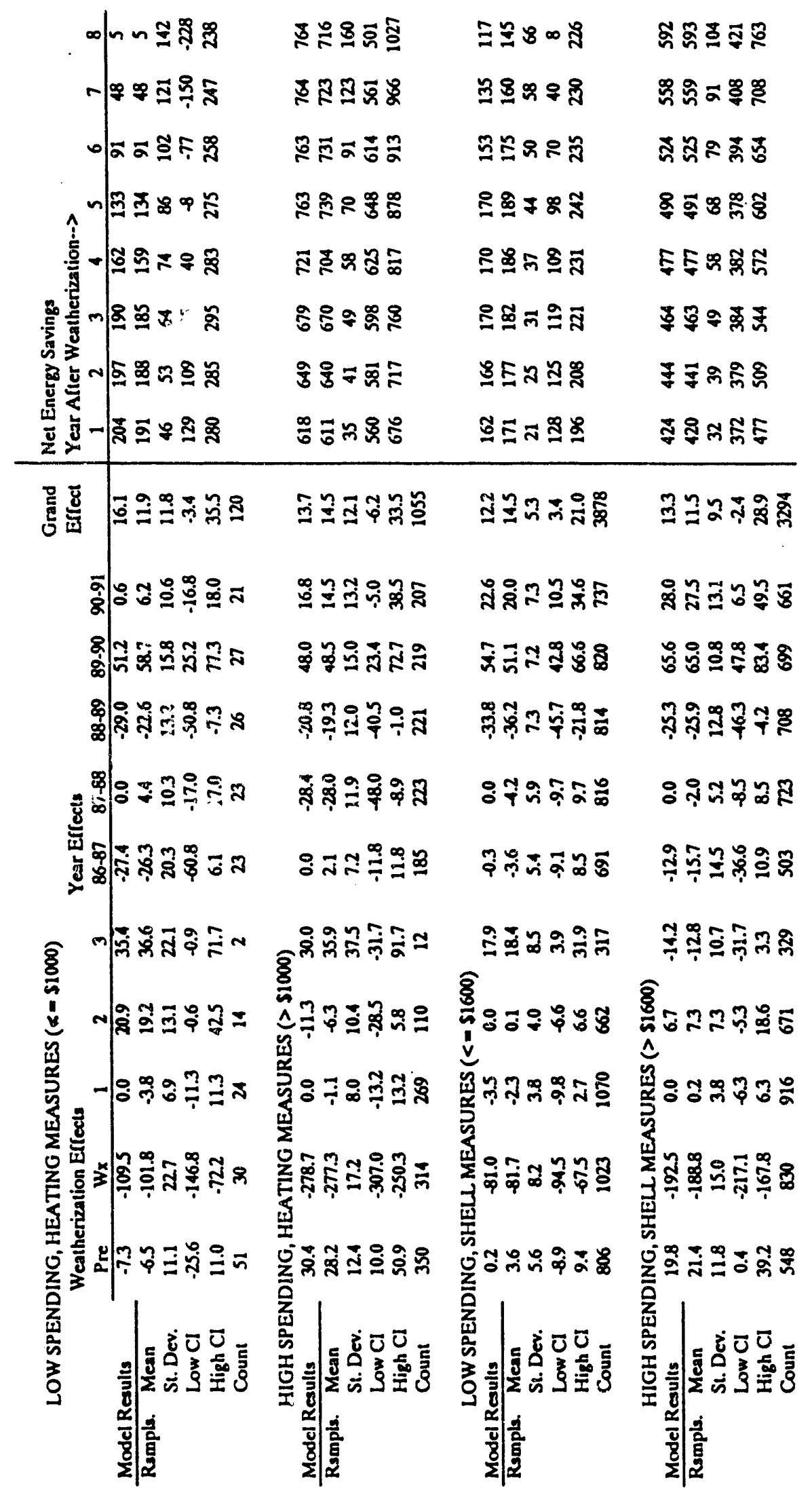




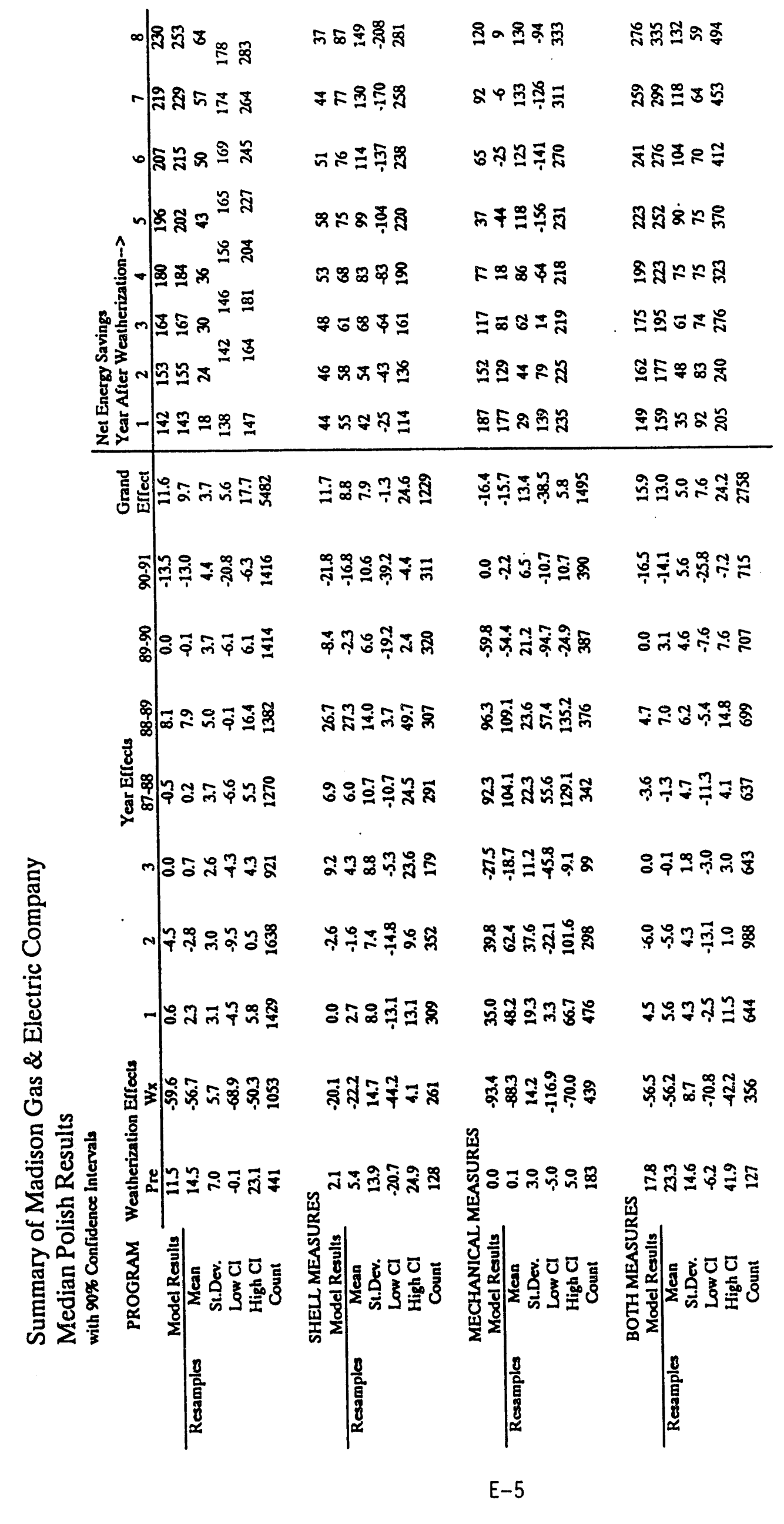




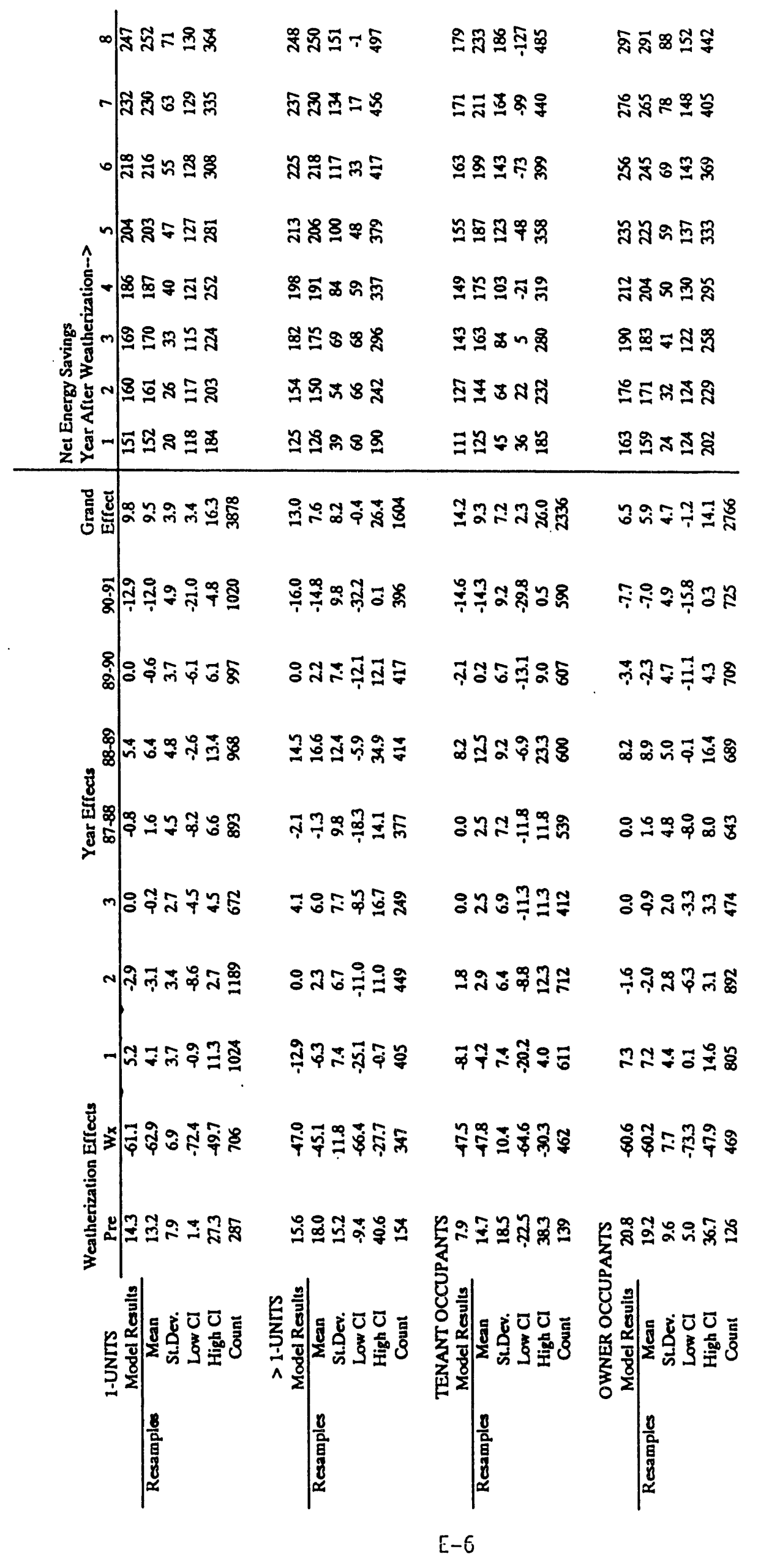




\section{APPENDIX F}

The graphs in this appendix are summaries of the NAC and change in NAC trends for both Wisconsin Gas Company and Madison Gas \& Electric Company. The graphs are based on: 1) data from the total participant samples; 2) data from participants with continuous consumption histories over the period of analysis; and 3) median polish model-derived estimates. Because the median polish model is based on change in NAC, the first year of consumption in the NAC trend graphs is assumed to be the same as that of the total participant population. 

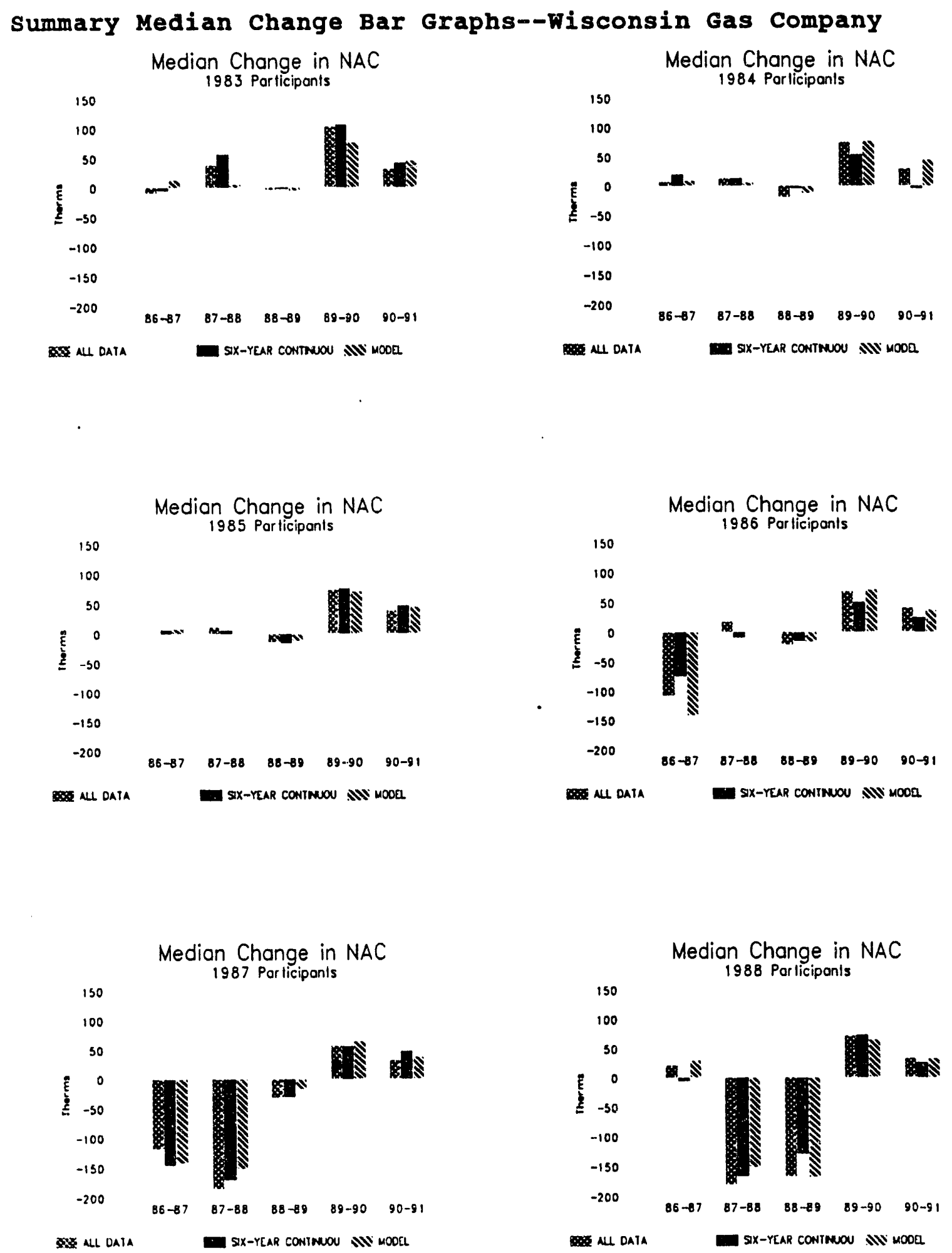

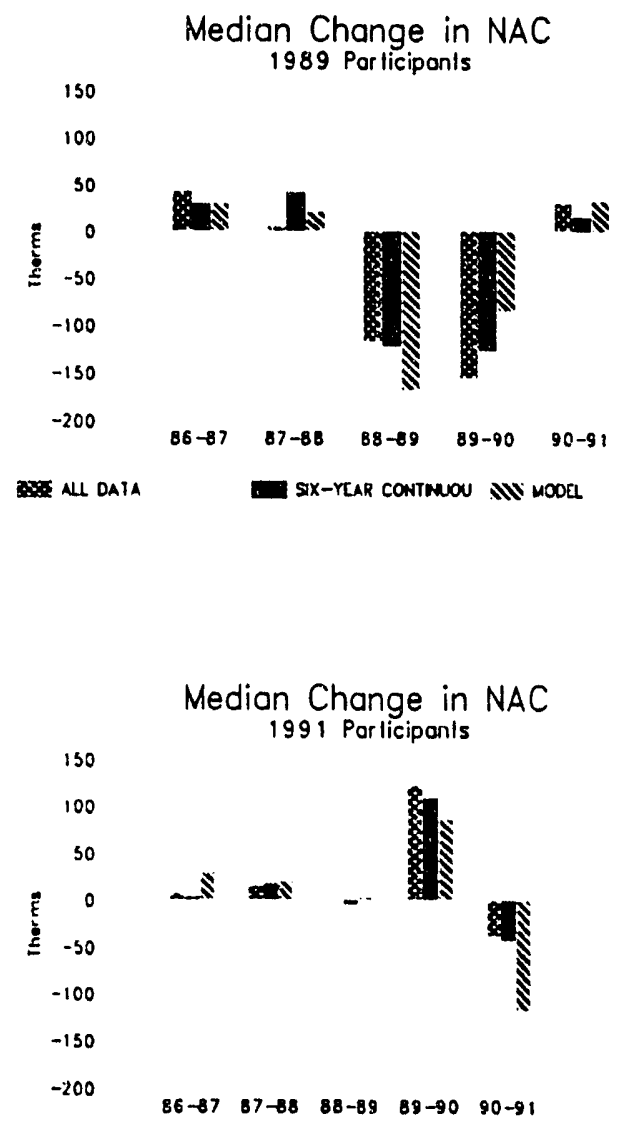

\% all data

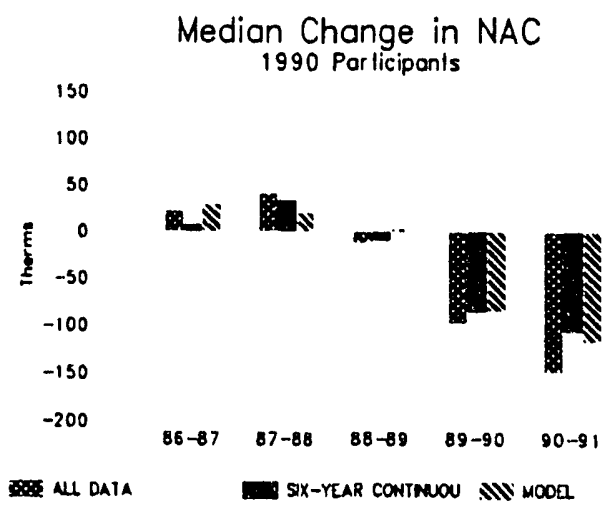

Median Change in NAC
1990 Parlicipants

aid-rear contmou NN moor 


\section{Summary Median NAC Graphs--Wisconsin Gas Company}
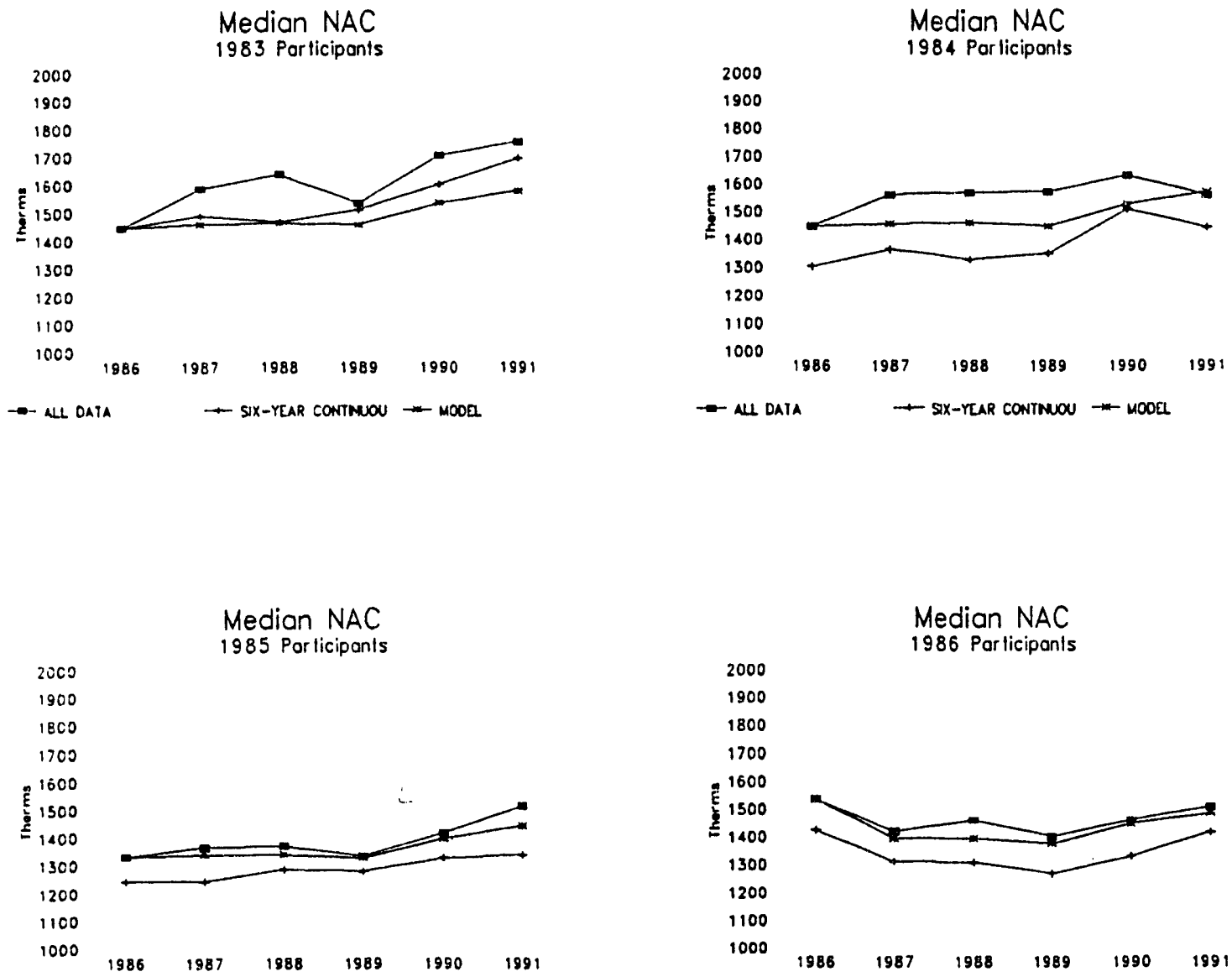

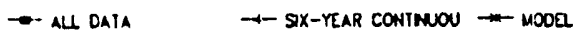

- All DATA $\rightarrow$ SX-YEAR CONTMUOU $\rightarrow$ MOOSL
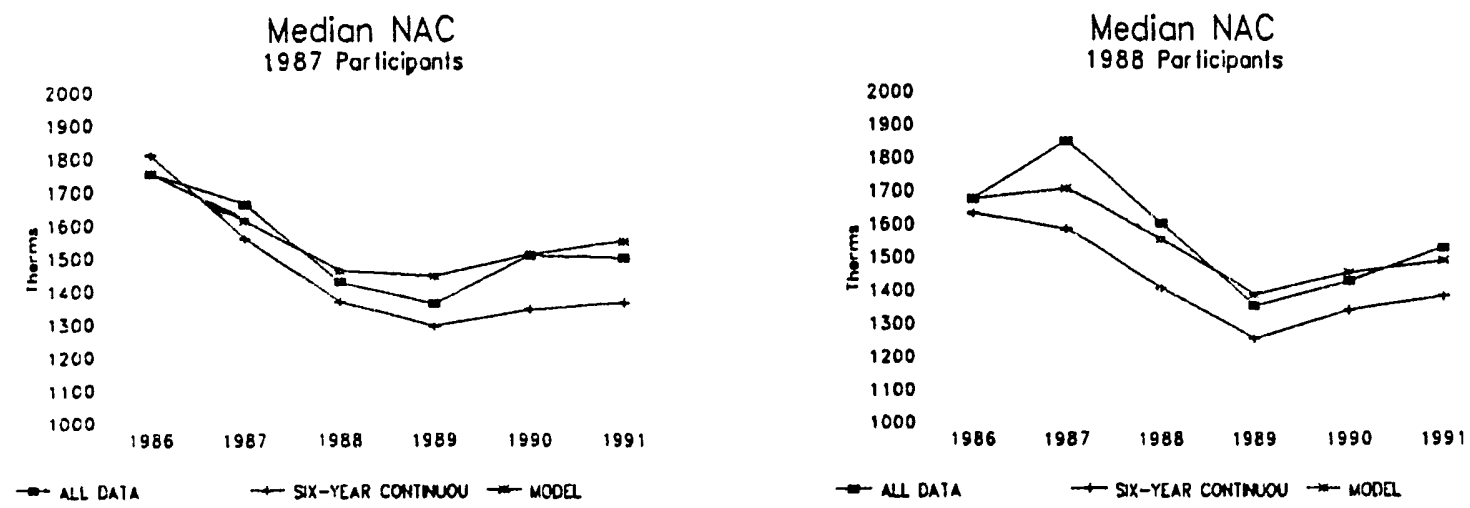

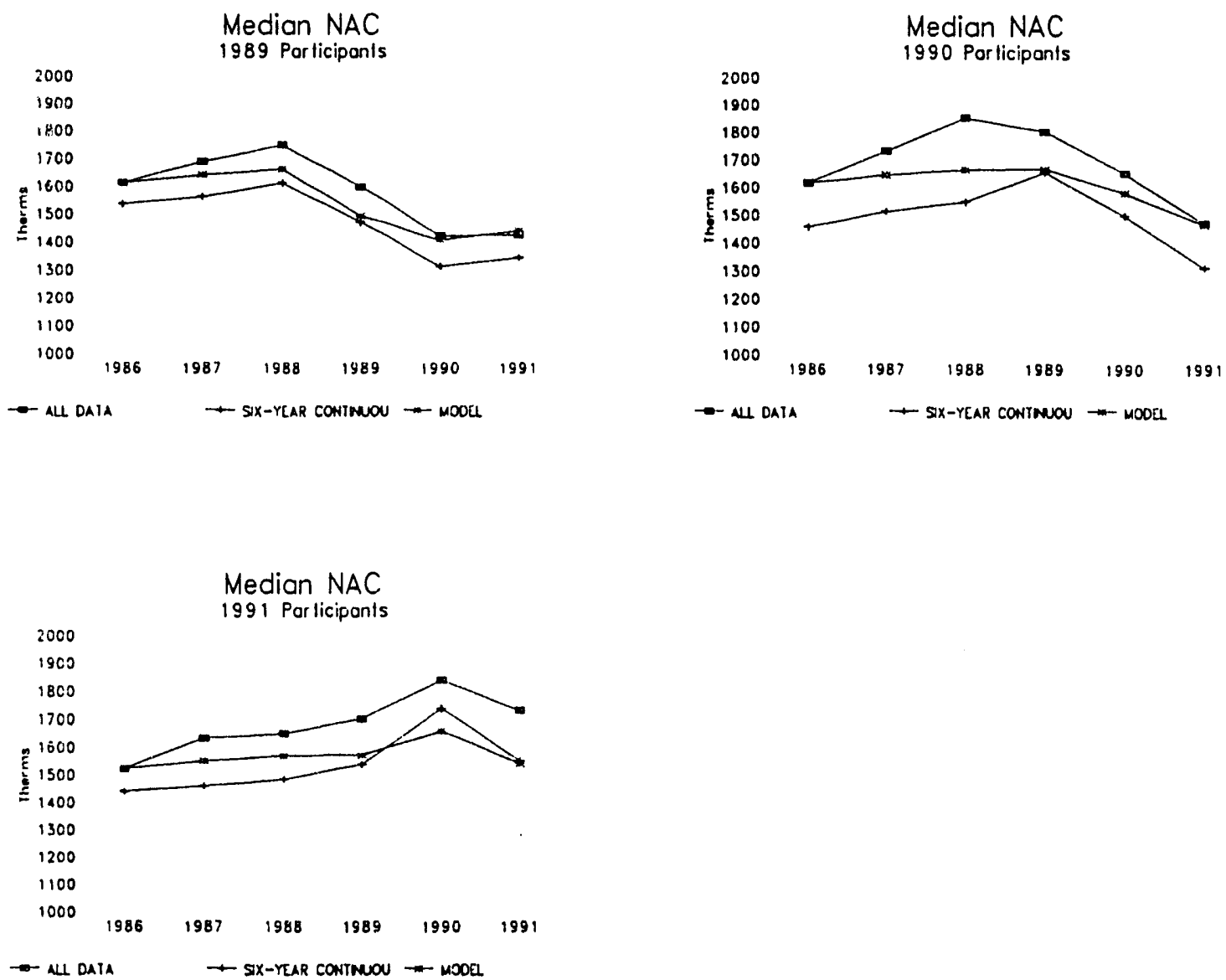


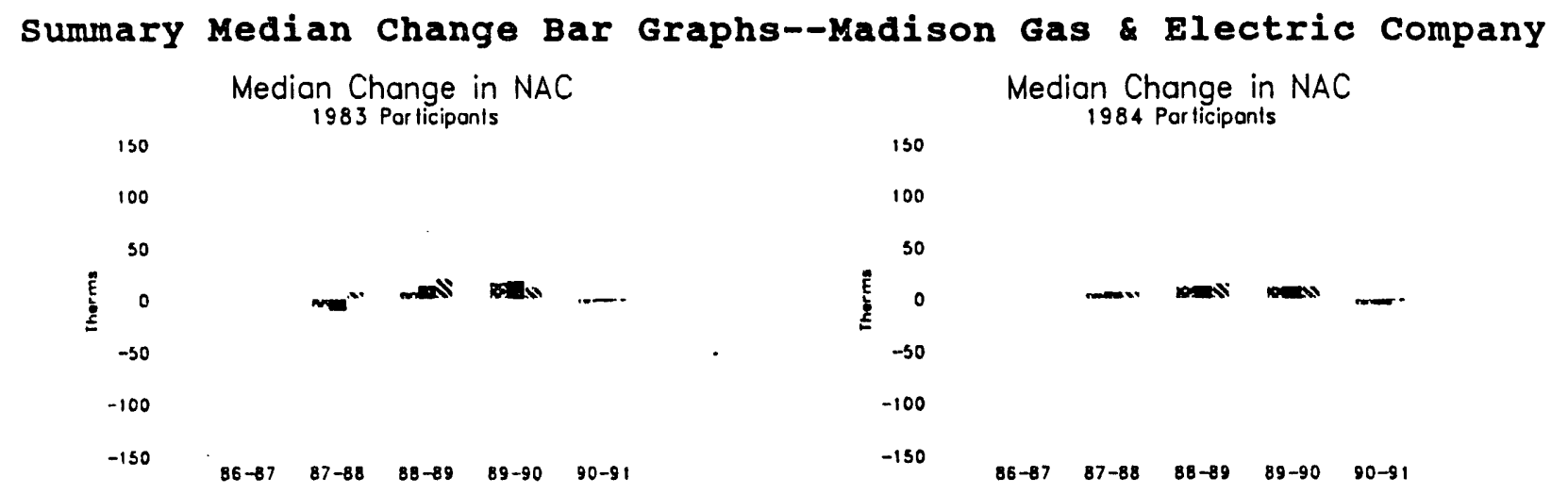

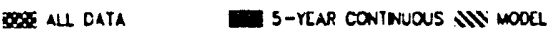
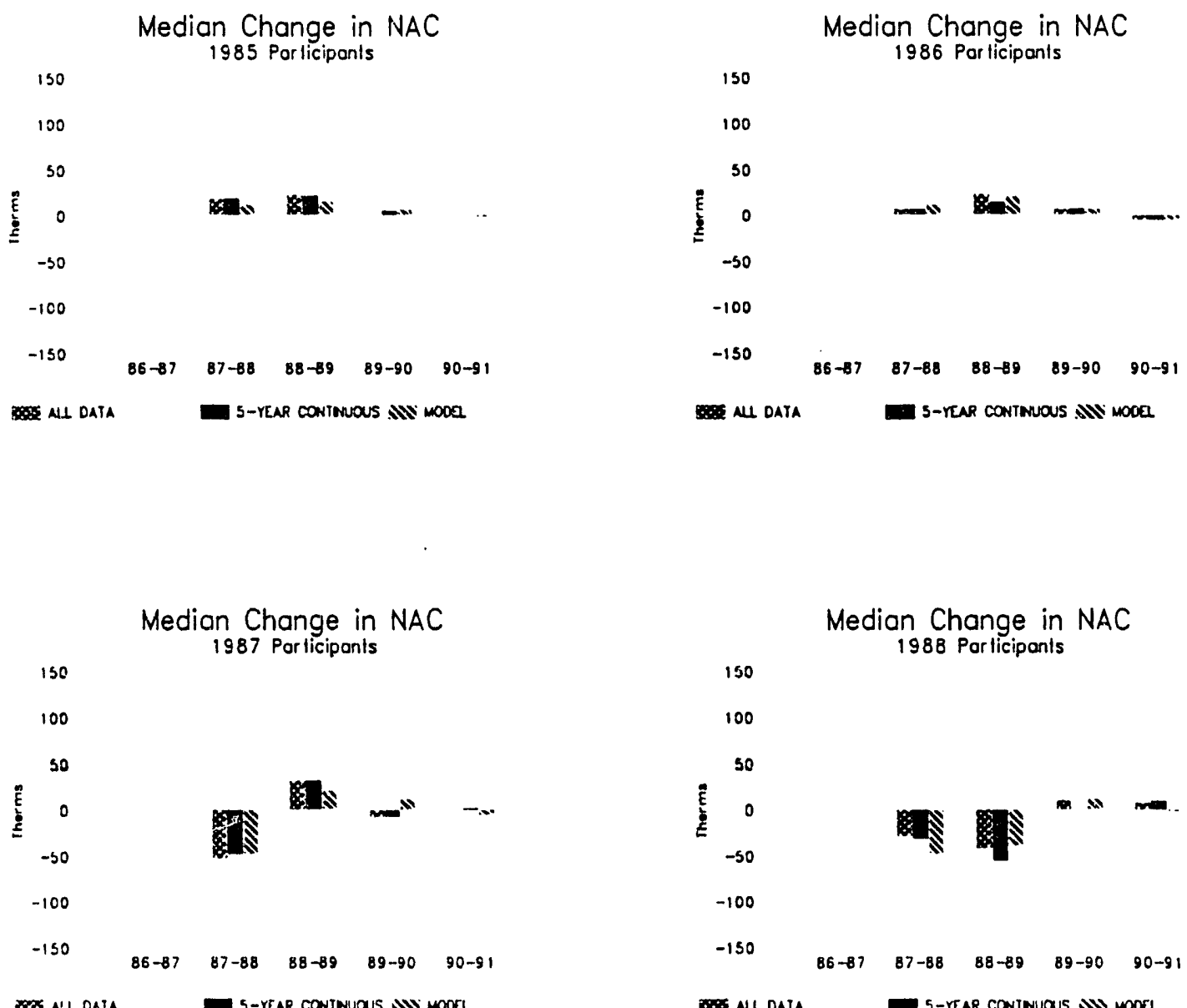

all DATA 5 -rear contwuOUs ill moorl 

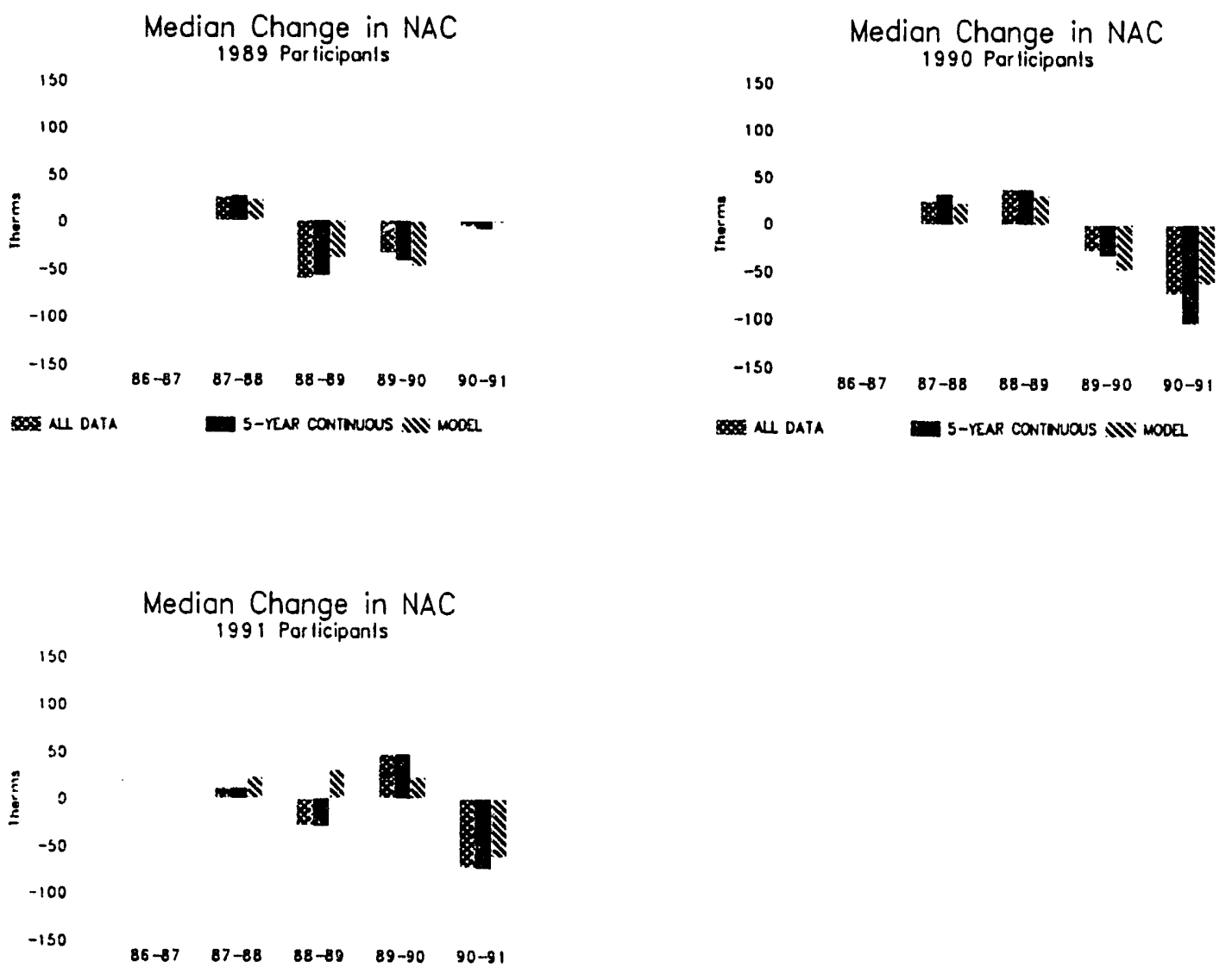

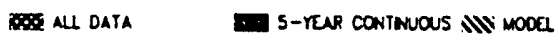



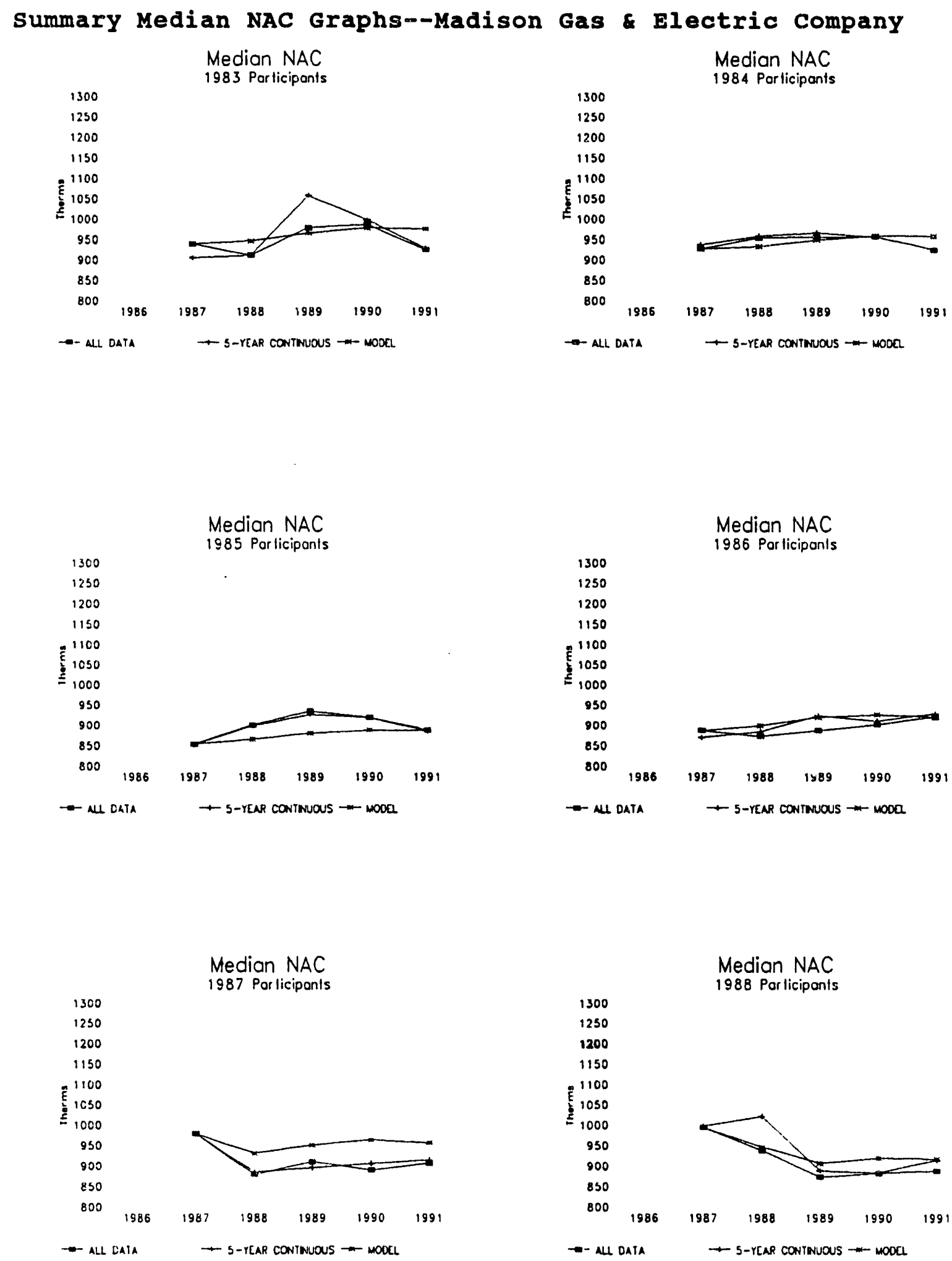

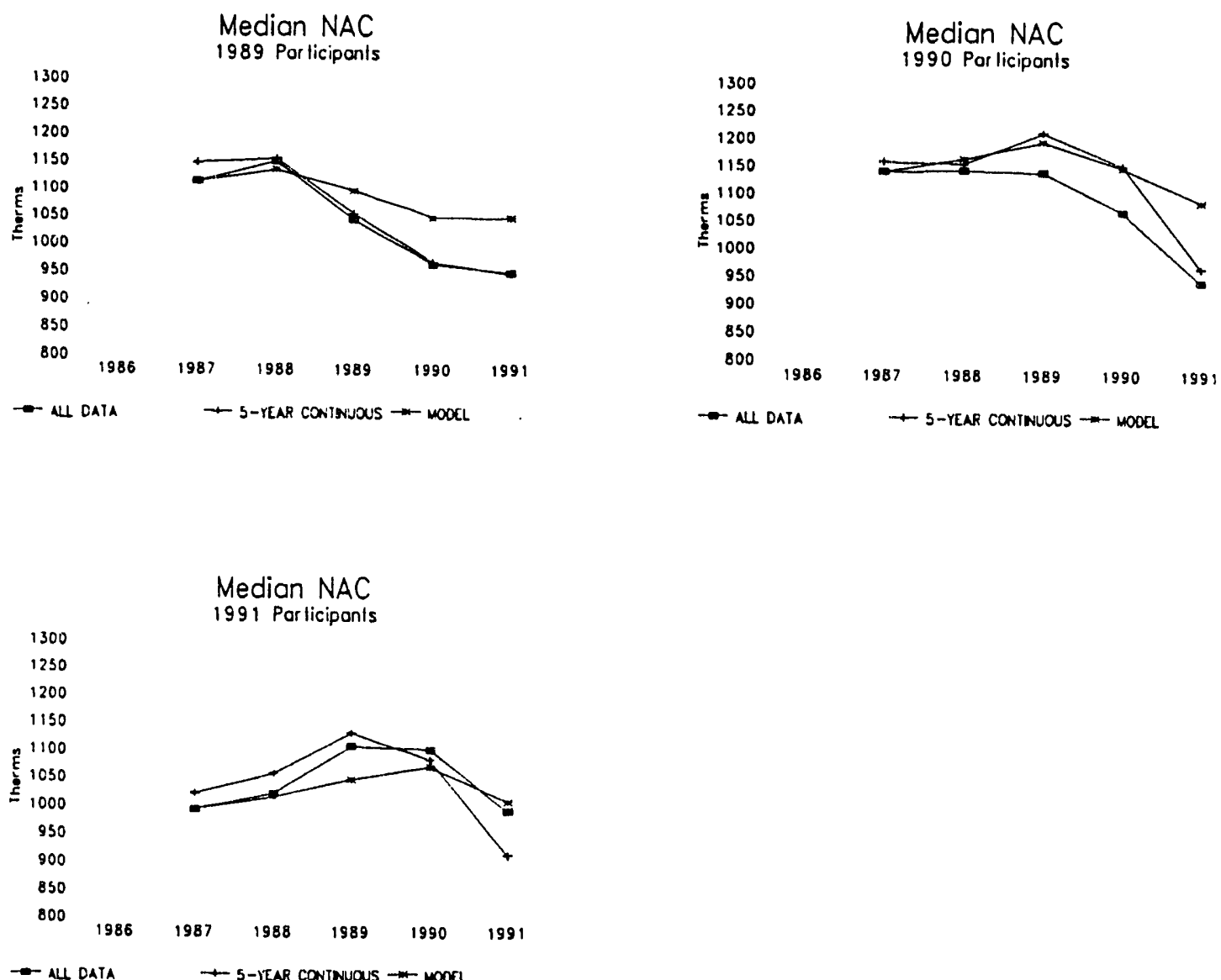

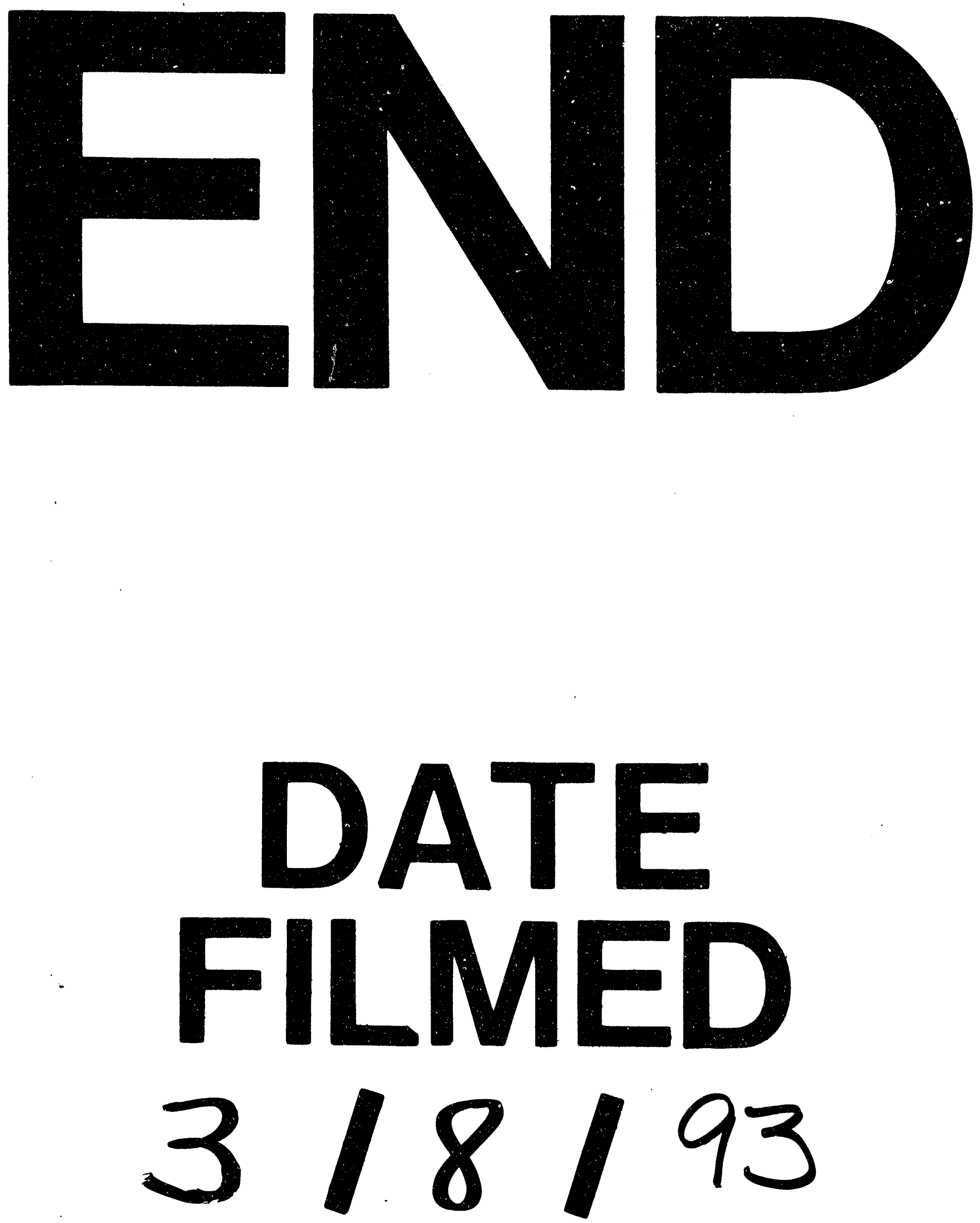